
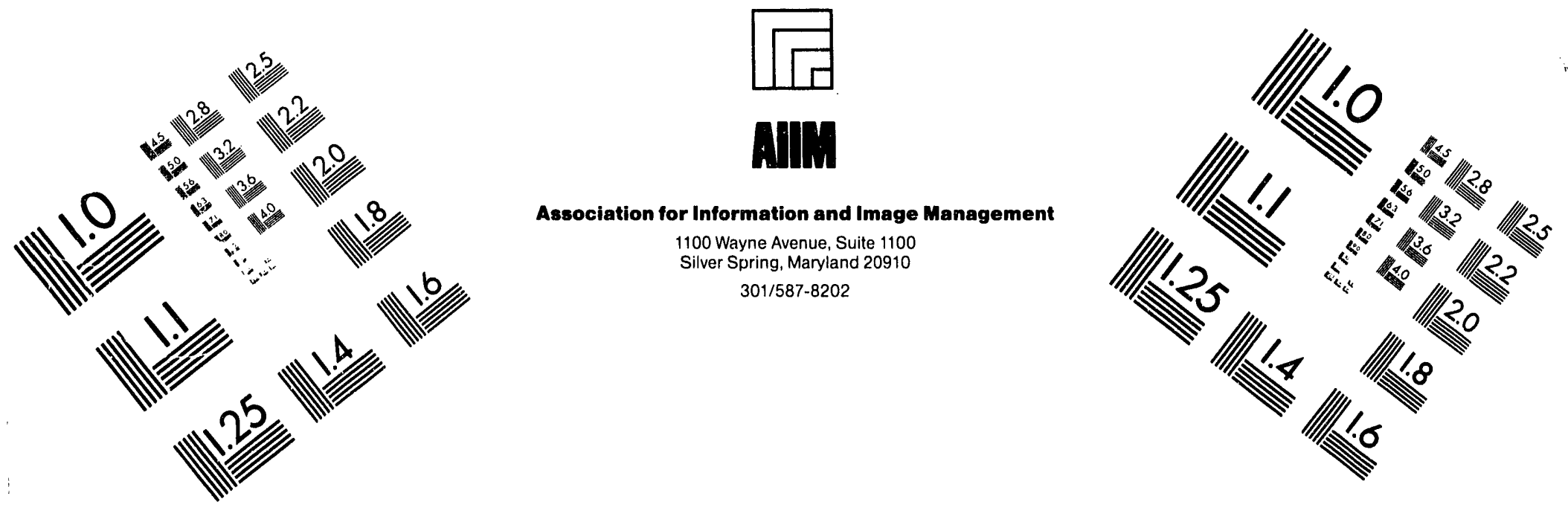

Centimeter

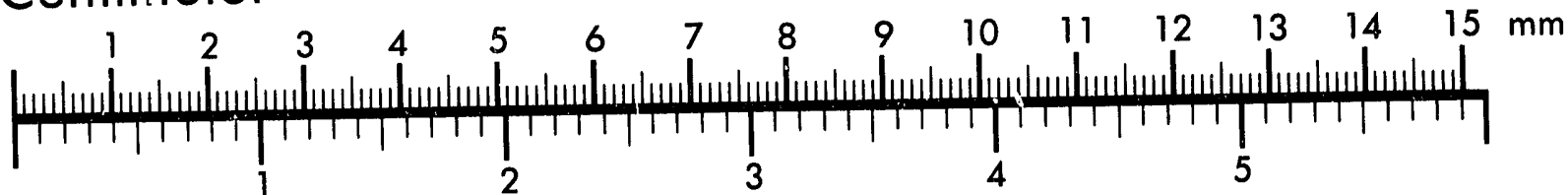
Inches
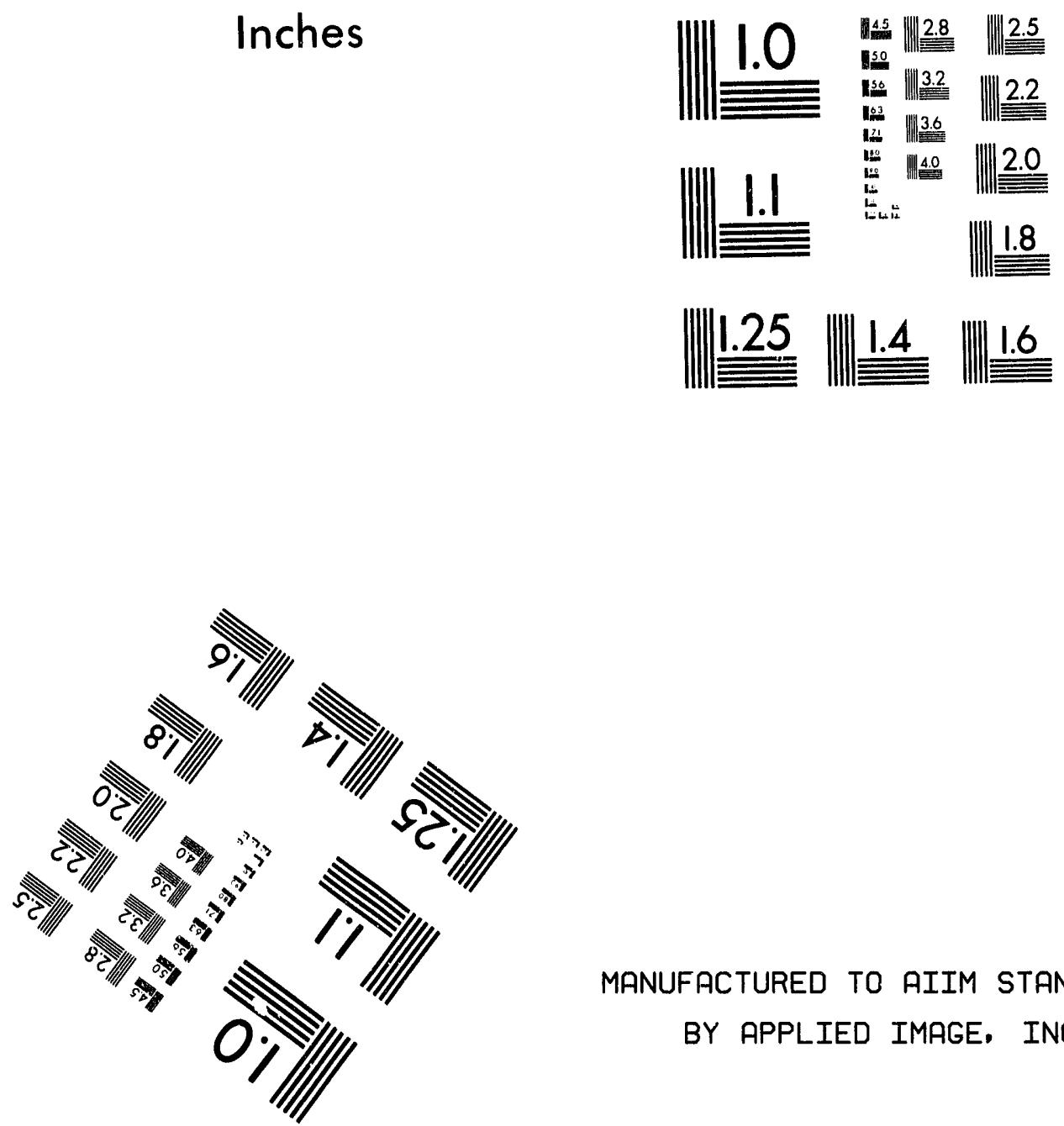

MANUFACTURED TO AIIM STANDARDS

BY APPLIED IMAGE, INC.

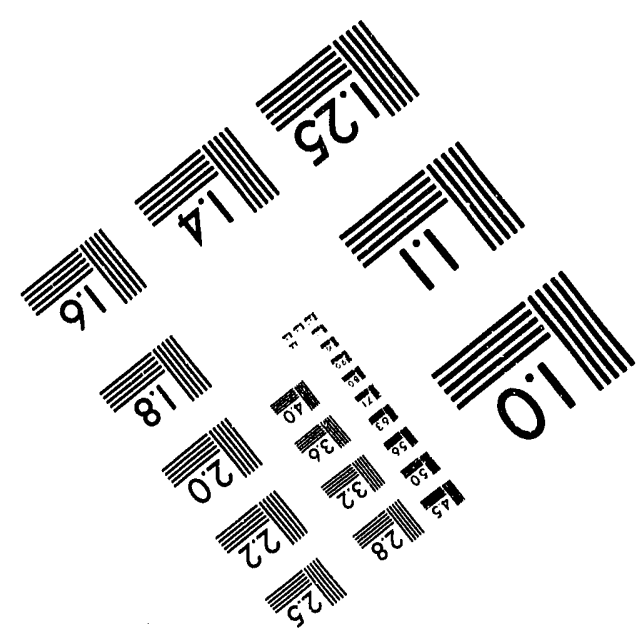



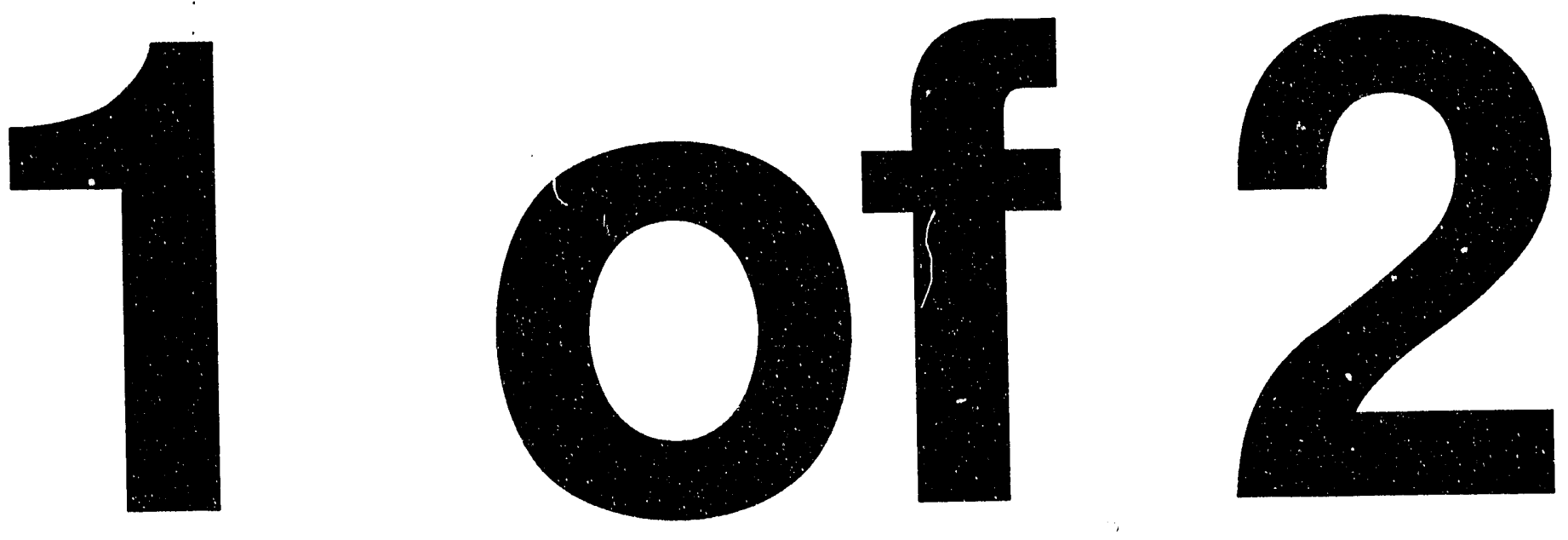
Contracts for field projects and supporting research on ...

\section{Enhanced Oil Recovery}

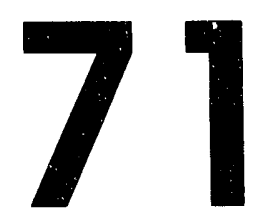

DOE/BC--92/3

(DE93000116)

PROGRESS REVIEW Quarter Ending June 30, 1992

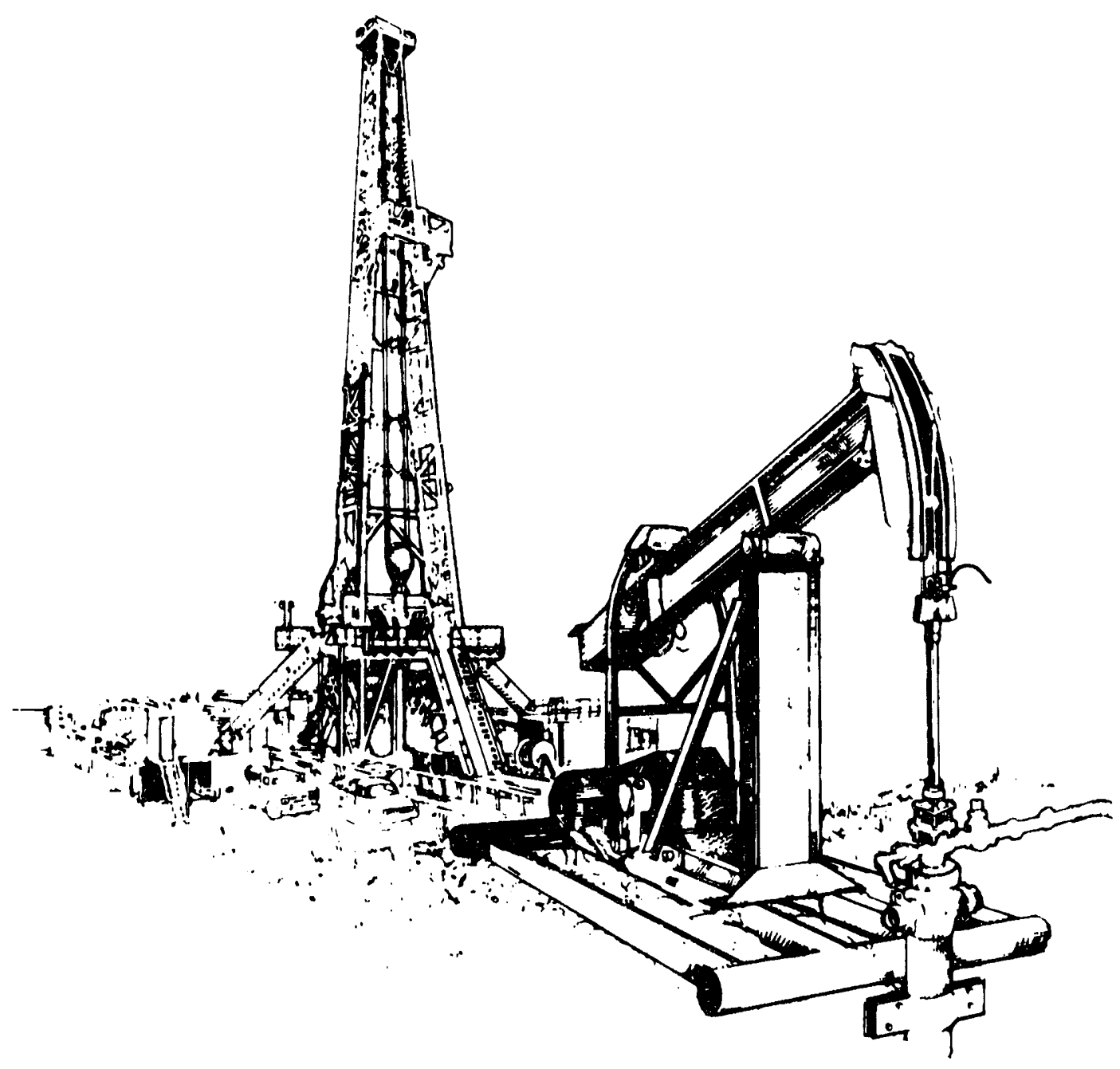

United States Department of Energy

Office of Gas and Petroleum Technology and Bartlesville Project Office 


\section{DISCLAIMFR}

This report was prepared as an account of work sponsored by an agency of the United States Government. Neither the United States Governmen', nor any agency thereof, nor any of their employees, makes any warranty, express or implied, or assume is any legal liablity or responsibility for the accuracy, completeness, or usefulness of any information, apparatus, product, or process disclosed, or represents that its use would not infringe privately owned rights. Reference herein to any specific commerclal product, process, or service by trade name, trademark, manutacturer, or otherwise does not necessarily constitute or imply its endorsement, recommendation, or favoring by the United Stctes Government or any agency thereof. The views and opinions of authors expressed herein do not necessarily state or reflect those of the United States Government or any agency thereof.

Available to DOE and DOE contractors from the Office of Scientific and Technical Information, P.O. Box 62, Oak Ridge, Tennessee 37831; prices available from (615) 576-8401.

Available to the public from the National Technical Infoi mation Service, U.S. Department of Commerce, 5285 Port Royal Rd., Springfield, Virginia 22161; prices available from (703) 487-4650. 
U.S. Department of Energy

Washington, D.C. 20545

JACK SIEGEL

Acting Assistant Secretary for Fossil Energy

Room 4G-084 Forrestal Building

Telephone Number 202-586-4695

(Vacant)

Deputy Assistant Secretary for Gas and Petroleum Technology

DONALD JUCKETT

Director for Oil and Gas Exploration and Production

Bartlesville Project Office P.O. Box 1398

Bartlesville, Oklahoma 74005

Telephone No. 918-337-4401

THOMAS C. WESSON

Director

R. M. RAY

Deputy Director

EDITH ALLISON

Acting Program Coordinator, Enhanced Oil Recovery

HERBERT A. TIEDEMANN

Project Manager for

Technology Transfer
DOE/BC--92/3

(DE93000116)

Distribution Category UC-122

\section{CONTRACTS FOR FIELD PROJECTS AND SUPPORTING RESEARCH ON ENHANCED OIL RECOVERY}




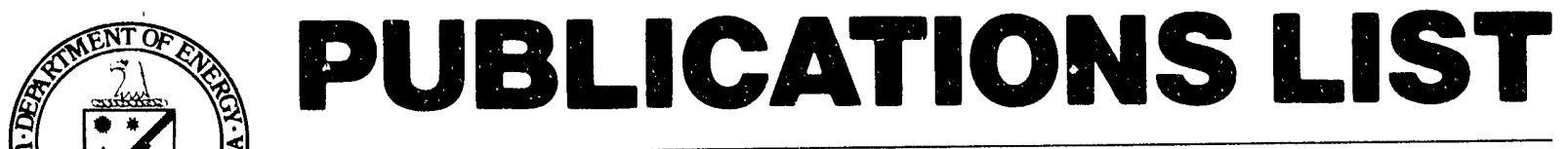

Bartlesville Project Office

Thomas C. Wesson. Director

\section{AVAILABILITY OF PUBLICATIONS}

The Department of Energy makes the results of all DOE-funded research and development efforts available to DOE and DOE contractors from the Office of Scientific and Technical Information, P.O. Box 62, Oak Ridge. TN 37831 ; prices available from (615) 576-8401, FTS 626-8401.

Available to the public from the National Technical Information Service, U.S. Department of Commerce, 5285 Port Royal Road, Springfield, VA 22161: prices available from (703) 487-4650.

Give the full title of the report and the report number.

Sometimes there are slight delaus between the time reports are shipped to NTIS and the time it takes for NTIS to process the reports and make them available. Accordingly, we will provide one copy of any individual report as long as our limited supply lasts. Please help us in our effort to eliminate wasteful spending on govemment publications by requesting only those publications needed. Order by the report number listed at the beginning of each citation and enclose a self-addressed mailing label. Available from DOE Bartlesville Project Office, ATTN: Herbert A. Thedemann, P.O. Box 1398, Bartlesville, OK 74005; (918) 337-4293.

\section{Quarterly Reports}

\section{DOE/BC-91/3}

Contracts for Field Projects and Supporting Research on Enhanced Oil Recovery. Progress Review No. 67. Quarter ending June 30, 1991. May 1992. 206 pp. Order No. DE92001008. Status reports are given for various enhanced cil recovery and gas recovery projects sponsored by the Department of Energy. The field tests and supporting research on enhanced oil recovery include chemical flooding, gas displacement, thermal/ heavy oil, resource assessment, geoscience technology, microbial tech. nology, novel technology, and environmental technology.

\section{Chemical Flooding}

\section{DOE/BC/14447-15}

Fluid Diversion and Sweep Improvement with Chemical Gels in Oil Recovery Processes. Final Report. New Mexico Institute of Mining and Technology. September 1992. $184 \mathrm{pp}$. Order No. DE92001061. The report describes progress made during the third and final year of the project. Four gels were the focus of experimental work: (1) resorcinol-formaldehyde. (2) colloidal silica. (3) $\mathrm{Cr}^{3+}$ (chloride)-xanthan, and (4) $\mathrm{Cr}^{3}$ lacetate)-polyacrylamide. All experiments were performed at $41{ }^{\circ} \mathrm{C}$. During injection of gelants that contained $\mathrm{Cr}^{3}{ }^{4}$, chromium propagation was significantly more rapid when the counterion was acetate rather than chloride. For a given counterion. chromium propagation was much more rapid in Berea sandstone cores than in Indiana limestone cores. It is doubtful that unbuffered chromium-chloride gelants can propagate through carbonate reservoirs. During core experiments. the strongest gels reduced the permeability of all cores to ab'sut the same value (in iow microdarcy range). For weaker gels (i.e., those leaving a significant permeability), residual resistance factors decreased with increased rock permeability in Berea sandstone. Tracer studies indicated that strong gels occupled most of the pore space. while weaker gels occupied a smail fraction of pore space. Experiments revealed that gelation in the porous rock was often far less complete than that in a bottle. For unbuffered gelants in porous rocks, the $\mathrm{pH}$ at which gelation occurs may be determined by rock mineralogy than by the $\mathrm{pH}$ at which gelation occurs may be determined more by rock mineralogy than by the $\mathrm{pH}$ of the injected gelant. Thus, the buffering action of reservor rocks must be considered when evaluating gel performance in the laboratory

\section{Gas Displacement}

DOE/BC/92001027

Predicted Optimal Well Geometries for a Carbon Dioxide Flood in A West Texas Fỉeld Unit. Morgantown Energy Technology Center. July 1992. 44 pp. Order No. DE92001027. Tertiary production due to carbon dioxide flooding in a waterflooded. 240 -acre $\left(1 \mathrm{~km}^{2}\right)$ pattem in a west Texas tield unit was modeled with a black-oil. pseudo-miscible simulator. This pattern was a small portion of a stratified sandstone formation with an average thickness and permeability of $25 \mathrm{ft}(7.6 \mathrm{~m})$ and $32 \mathrm{md}\left(10^{-3} \mathrm{um}^{2}\right)$. respectively. It consisted of two sands that were separated by a shale barier. This barier did not completely prevent flow in the vertical direction. but it did reduce the vertical transmissibility between the two sands. The vertical permeability was equal to approximately $90 \%$ of the horizontal permeability throughout the formation. After simulating primary recovery and secondary recovery using an inverted five-spot pattern, many different tertiary well geometries, consisting of vertical and/or horizontal injectors and producers. were considered.

\section{DOE/BC/92001066}

The Validation of Horizontal Well Models Using A Physical Model of Heat Flow In An Anisotropic Conductor. Morgantown Energy Technology Center. August 1992. 32 pp. Order No. DE92001066. Two recently proposed models of fluid flow in an anisotropic media yield different expressions for horizontal well productivity because of their representation of the wellbore. The model developed by Babu and Odeh used a point source/sink for the wellbore, while Peaceman's model implemented an isobaric boundary along the surface of the wellbore. Babu and Odeh's model predicted elliptical isobars, even in the immediate vicinity of the wellbore. Peaceman's model predicted a rapid transition from circular to elliptical isobars as the distance from the wellbore increased. Both models were mathematically correct and seemed plausible, but only one could have been accurate with respect to the actual system. Therefore, the more appropriate model to use in reservoir simulation was determined experimentally. The temperature induced flow of heat from an anisotropic conductor into a circular heat sink is analogous to the pressure-induced flow of fluids from an anisotropic porous medium into a circular wellbore, since the governing differential equations for both processes are identical in form. Heat transfer experiments were, therefore, used to model this fluid flow problem. Three types of experiments were conducted: unsteady-state heat transfer from a high-conductivity source into an anisotropic medium. steady-state heat transfer from an isothermal elliptical boundary to a high-conductivity circular heat sink, and steady-state heat transfer from a circular high conductivity heat source to an isothermal elliptical boundary. These boundary conditions were in agreement with both mathematical models. Since the anisotropic conductor, a thermoplastic copolymer, was coated with a thin layer of wax which melted at $308 \mathrm{~K}$. the $308 \mathrm{~K}$ isotherm was easily detected as the boundary between the wet and the dry portions of the wax. The position and shape of this isotherm corresponded to the position and shape of an isobar in a porous medium. The results clearly indicated that a transition from circular to elliptical isopotentials occurred, in agreement with Peaceman's model. It is. therefore. more appropriate to model a wellbore as an isopotential when studying near-wellbore problems. such as the calculation of well productivity.

\section{Thermal Recovery}

NIPER-584

Feasibility Study of Heavy OIl Recovery in the Appalachian, Black Warrior, Illi. nois, and Michigan Basins. National Institute for Petroleum and Energy Research. July 1992. 52 pp. Order No. DE92001055. This report is one of a series of publications assessing the feasibility of increasing domestic heavy oil production. Each report covers select areas of the United 
States. The Appalachian. Black Wamor. Illinois, and Mictuyan basins cover most of the depositional basins in the Midwest and Eastern United States These basins produce sweet. paraffinic light oil and are considered minor heavy oil $\left(10^{\circ}\right.$ to $20^{\circ} \mathrm{API}$ gravity or 100 to 10.000$) \mathrm{cP}$ viscosity) producers Heavy oil occurs in both carbonate and sandstone reservoirs of Paleozolic Age along the perimeters of the basins in the same sediments where light oil occurs. The oil is heavy because escape of light ends, water washing of the oil. and biodegradation of the oil have occurred over millions of years. The Appalachian, Black Warrior. Illinois, and Michigan basins' heavy oil fields have prodcued some 450.000 bbl of heavy oll of an estimated 14,000,000 bbl originally in place. The basins have been long-term. major light-oilproducing areas and are served by an extensive pipeline network connected to refineries designed to process light sweet. and with few exceptions. limited volumes of sour or heavy crude oils. Since the light oil is principally paraffinic, it commands a higher price than the asphaltic heavy crude oils of California. The heavy oil that is refined in the Midwest and Eastern United States is imported and refined at select refineries. Imports of crude of all grades accounts for 37 to $>95 \%$ of the oil refined in these areas. Because of the nature of the resource, the Appalachian. Black Warrior. Illinois and Michigan basins are not expected to become major heavy oil producing areas. The crude oil collection system will continue to degrade as light oil production declines. Smaller refineries will close because of lack of local, sweet light oil, economies of scale and environmental constraints on operations and product quality. Major refineries will refine increasing volumes of imported higher-sulfur, low'or-gravity crude oil from Canada and Venezuela. Select East Coast refineries will process increasing volumes of light Mideast crude. The demand for crude oil will increase pipeline and tanker transport of crude to select large refineries to meet the areas liquid fuels needs.

\section{NIPER-587}

Trends in Heavy OII Production and Refining in California. National Institute for Petroleum and Energy Research. July 1992. 28 pp. Order No. DE92001056. This report is one of a series of publications assessing the feasibility of increasing domestic heavy oil production and summarizing trends in oil production and refining in Califormia. Heavy oil $\left(10^{\circ}\right.$ to $20^{\circ} \mathrm{API}$ gravity) production in California has increased from $20 \%$ of the state's total oil production in the early 1940 s to $70 \%$ in the late 1980 s. In each of the three principal petroleum producing districts (Los Angeles Basin. Coastal Region, and San Joaquin Valley) oil production has peaked and then declined at different times throughout the past 30 years. Thermal production of heavy oil has contributed to making California the largest producer of oil by enhanced oil recovery processes in spite of low oil prices for heavy oil and stringent environmental regulation. Opening of Naval Petroleum Reserve No. 1. Elk Hills (CA) field in 1976, brought about a major new source of light oil at a time when light oil production had greatly declined. Although Califomia is a major petroleum-consuming state, in 1989 the state used 13.3 billion gallons of gasoline or $11.5 \%$ of U.S. demand but it contributed substantially to the Nation's energy production and refining capability. Califomia is the recipient and refines most of Alaska's 1.7 million barrel per day oil production. With Califomia production, Alaskan oil, and imports brought into Califomia for refining, California has an excess of oil and refined products and is a net exporter to other states. The local surplus of oil inhibits exploitation of Califomia heavy oil resources even though the heavy oil resources exist. Transportation, refining, and competition in the market limit full development of Califomia heavy oil resources.

\section{DOE/BC/14600-29 In Situ Combustion With Metallic Ad-} ditives - SUPRI TR 87. Stanford Univer-

sity. July 1992. 68 pp. Order No. DE92001057. In situ combustion is the most energy efficient of the thermal oil recovery methods. In this process. a portion of a reservoir's oil is bumed in situ as fuel to drive the recovery process. In light oil reservoirs. too little fuel may be deposited leading to high air injection requirements and unfavorable economics. This study has been designed to attack these problems. Water soluble metallic additives are investigated as agents to modify fuel deposition and combustion per formance. In previous papers by Shallcross (1989) and De los Rios et al (1988). results were reported from kinetic experiments run on Huntington Beach (CA) and Hamaca (Venezuela) crude oils. In these experiments. mixtures of sand. crude oil. and aqueous metallic salts were oxidized. While the presence of copper. nickel and cadmium had little or no effect. iron and tin increased oxidation rates and oxygen consumption. This report describes seven combustion tube runs using two crude oils and two metallic additives. The oils are $12^{\circ}$ and $34^{\circ} \mathrm{API}$, both from Cymric (CA). The metallic additives tested are iron nitrate $\left(\mathrm{Fe}\left(\mathrm{NO}_{3}\right)_{3} 9 \mathrm{H}_{2} \mathrm{O}\right)$ and zinc nitrate $\left(\mathrm{Zn}\left(\mathrm{NO}_{3}\right)_{2} 6 \mathrm{H}_{2} \mathrm{O}\right)$. Iron and tin additives improved the combustion efficiency in all cases.
Fluctuations in the produced gas compositions were observed in all control runs. but nearly disappeared with the iron and tin additives. The combustion front velocities were also increased by iron and tin. Changes were also observed in the apparent hydrogen to carbon $(\mathrm{H} / \mathrm{C})$ ratio of the fuel. heat of combustion, air requirements, and amount of fuel deprsited. Iron and tin caused increases in fuel concentration while causing a decrease in air requirement. The increase in fuel concentration while causing a decrease in air requirement. The increase in fuel concentration varied between the oils. however: tin and iron were consistently more effective than zinc. A particularly interesting result occurred with the Cymric light oil. In the control runs, a sustained combustion front was not achieved. while in the iron additive runs, stable, sustained combustion was achieved. Iron and tin salts are suitable additives to increase fuel deposition when that is needed. Additives suitable for use as a fuel recycling agent have not yet been found

$\mathrm{DOE} / \mathrm{BC} / 14600-32$ Visualization of Foam/Oil In A New, High-Resolution, Sandstone Replica Micromodel - SUPRI TR 86. Stanford University. August 1992. 36 pp. Order No. DE92001067. A new micromodel construction procedure has been developed as a tool to better understand and model pore-level events in porous media. The construction procedure allows for the almost exact two-dimensional replication of any porous medium of interest. For the case presented here, a Berea sandstone was chosen. Starting with a thin section of the porous medium of interest, a two-dimensional replica of the flow path is etched into a silicon wafer to a prescribed depth. Bonding the etched pattem to a flat glass plate isolates the flow path and allows the pore level flow events to be studied. The high resolution micromodels constructed with the new procedure were used to study wettability. A crude oil was injected into the micromodel, partially filling it. The oil was then produced under two different displacement schemes. First, a slug of surfactant was used. Second, foam generated in situ, far from the oil bank, was used to displace the oil. Qualitative observations indicate significant differences at the interface between the oil and the displacing phase. When slug surfactant injection is used, the oil appears to wet the surface. The oil displacement process is efficient due to a large fractional production of oil from the large pores before the surfactant breaks through. When in situ foam is the displacing phase, the foam is observed to break near the oil interface. The liquid phase in the foam becomes the wetting phase. It is observed to reside in the small pores and to coat most of the grain surfaces. Displacement of oil under this injection scheme is inefficient due to transfer of the surfactant along grain edges and subsequent early breakthrough of the surfactant.

DOE/BC/14600_33 A Three-Dimensional Laboratory Steam Injection Model Allowing In Situ Saturation Measurements - SUPRI TR 83. Stanford University. August 1992. 92 pp. Order No. DE92001059. The CT imaging technique together with temperature and pressure measurements were used to follow the steam propagation during steam and steam foam injection experiments in a three-dimensional (3.D) laboratory steam injection mold. During the design period. the advantages and disadvantages of different geometries were examined to find out which could best represent radial and gravity override flows and also fit the dimensions of the scanning field of the $\mathrm{CT}$ scanner. As a result of this analysis a 3-D rectangular box with dimensions $20 \times 20 \times 7.5 \mathrm{~cm}$ was constructed. This box simulates one quarter of a five-spot pattern. Aluminum, Teflon'" and Fiberfax' were chosen as sup. porting and insulating materials. Teflon' "was placed between the porous medium and the aluminum shell so that the rate of heat transfer in the porous medium would be much faster than that in the aluminum during a steam injection run. During experiments, steam was injected continuously at a constant rate into the water-saturated model and CT scans were taken at six different cross sections of the model. Pressure and temperature data were collected with time at three different levels in the model. CT pictures and 3-D temperature distributions were compared and analyzed in terms of observed steam zone at each section. To do that, CT numbers within the scan section were used to determine the steam and water zones, and with the aid of $x$-ray pictures the position and propagation of the steam zone was determined. In addition. using the 3.D temperature distribution measurements at the same times. steam displacement fronts could be drawn at the scan section locations. These pictures and drawings were used to compare the results obtained from classical temperature-pressure monitoring and from CT scans.

DOE/BC/92001058 Report on Variation of Electrical Conductivity During Steam Injection in Unconsolidated Sand Saturated With A Salt Solution. Lawrence Livermore National Laboratory. July 1992. 52 pp. Order No. 
DE92001058. The spatial and temporal variation of electrical conductivity in saturated sands during steam injection has been measured and modeled Experiments consisted of introducing steam into one end of a tube filled with a sand saturated with a slightly saline solution. Measurements of electrical conductivity were then made every 10 seconds at 10 locations along the tube using a four-electrode technique. After injection. a steam condensation tront forms ahead of the steam front that separates the mixed-phase steam zone from the liquid zone. Conductivity measurements at a specilic position in the tube throughout time show that the electrical conductivity starts at a constant value, decreases before the steain front arrives and then. immediately prior to the steam front arrival, goes through a maximum before dropping by a factor of about 25 . These variations can be explained by (1) a dilution of the interstitial solution ahead of the steam front thereby causing the initial drop in conductivity, (2) an increase in tempera. ture of the solution immediately prior to the arrival of the steam front causing the cunductivity maximum, and (3) a drop in conductivity due to the combined effects of a decrease in saturation and dilution of the residual liquid in the two-phase zone. Mathematical solutions of a set of differential equations that take into consideration all of these effects are presented. These solutions reproduce the significant features of the conductivity data, and help to explain the physical phenomenon. The study suggests that the measurements of changes in the subsurface conductivity field during steam injection operations may indicate the Incation of ionic concentration, temperature. and steam-saturation fields.

\section{DOE/BC/92001062 A Pore-Level Scenario for the Develop.} ment of Mixed.Wettability in OIl Reser. voirs. Lawrence Berkeley Laboratory. University of California. September 1992. 60 pp. Order No. DE92001062. Understanding the role of thin films in porous media is vital if wettability is to be elucidated at the pore level. The type and thickness of films coating pore walls determines reservoir wettability and whether or not reservoir rock can be altered from its initial state of wettability. Pore shape, especially pore wall curvature, is an important factor in determining wetting-film thicknesses. Yet, pore shape and the physics of thin wetting films are generally neglected in models of flow in porous rocks. This paper incorporates thin-film forces into a collection of star-shaped capillary tubes model to describe the geological development of mixed-wettability in reservoir rock. Here, mixed-wetiability refers to continuous and distinct oil and water-wetting surfaces coexisting in the porous medium. The proposed model emphasizes the remarkable role of thin films. New pore-level fluid configurations arise that are quite unexpected. For example, efficient water displacement of oil (i.e., low residual oil saturation) characteristic of mixed-wettability porous media is ascribed to interconnected oil lenses or rivulets which bridge the walls adjacent to a pore comer. Predicted residual oil saturations are approximately $35 \%$ less in mixed-wet rock compared to completely water-wet rock. Calculated capillary pressure curves mimic those of mixed-wet porous media in the primary drainage of water. imbibition of water, and secondary drainage modes. Amott-Harvey indices range from -0.18 to 0.36 , also in good agreement with experimental values.

\section{Geoscience Technology}

\section{DOE/BC/92001051 Kinetic Modeling of Petroleum Forma-} tion in the Maracaibo Basin: Final Re. port. Lawrence Livermore National Laboratory and INTEVEP. July 1992. $136 \mathrm{pp}$. Order No. DE92001051. The purpose of this project is to develop and test improved kinetic models of petroleum generation and cracking, pore pressure buildup, and fluid expulsion. The work was per. formed jointly and laboratory experiments were conducted at both Law. rence Livermore National Laboratory (LLNL) and INTEVEP to obtain the reaction rate and product composition information needed to develop chemical kinetic models. Experiments at INTEVEP included hydrous pyroly. sis and characterization of oils by gas and liquid chromatography. Experiments at LLNL included programmed pyrolysis in open and self-purging reactors, sometime including on-line gas analysis by tandem mass spec. trometry, and characterization of oils by gas chromatography and nuclear magnetic resonance. Global hydrocarbon generation kinetics were derived using an activation energy distribution model. These were combined with thermal histories of 80 wells to calculate global maturation across the Maracaibo basin. The thermal histories were intially derived at INTEVEP and were modified slightly at LLNL based on comparison of observed vitrinite reflectance profiles and those calculated from the LLNL EASY\%Ro vitrinite reflectance model. Calculated $\mathrm{T}_{\max }$ and $\mathrm{H} / \mathrm{C}$ ratios of the residual kerogen agreed well with observed values, and the calculated fraction of kerogen converted agreed well with the API gravity and sulfur content of oil in Cretaceous reservoirs. In parallel, a formalism was developed for calculating pore pressures and fluid expulsion. This formalism was first incorporated into PYROL the detailed LLNL pyrolysis parameters model. The pore pressurefluid expulsion formalism was tested initially using kinetic parameters for the Green River formation and preliminary kinetic parameters for a generic marine source rock. Although the approach appeared promising, the PYROL code was difficult to modify and use. so a more easily used and flexible code. PMOD was developed. PMOD enables the user to develop interactively a pyrolysis mechanism that satisfies elemental balance and to automatically calculate many geochemical indicators.

\section{DOE/BC/14443-12 A Field Laboratory for Improved Oll Re.} covery. Final Report. University of Houston. $108 \mathrm{pp}$. Order No. DE92001063. The purpose of this project was to develop a field laboratory for research in improved oil recovery using a Gulf Coast reservoir in Texas. The participants (1) made a field site selection and conducted a high-resolution seismic survey in the demonstration field, (2) obtained characteristics of the reservoir, (3) developed an evaluation of local flood efficiency in different parts of the demonstration reservoir. (4) used diverse methodology to evaluate the potential recovery of the remaining oil in the test reservoir, (5) developed crosswell seismic tomography, and (6) urill transfer the learned technologies to oil operators through publications and workshops. The report describes each of the tasks performed.

DOE/BC/14657-7 Measuring and Predicting Reservolr Heterogeneity in Complex Deposystems. Annual Report for the Period September 20, 1990-September 20, 1991. West Virginia University, Appalachian Oil and Natural Gas Research Consortium. August 1992. 160 pp. Order No. DE92001068. The Lower Mississippian Big Injun sandstone, a major oil producer in the westem half of West Virginia, consists of several sandstones that overstep each other from east to west. In Granny Creek field. Roane and Clay counties, the Big Injun can be subdivided into three informal units. designated $A, B$, and $C$ from top to bottom, based on the bulk density log Furthermore, the lower $C$ unit can be divided into ascending $C 1, C 2$ and $C 3$ subunits that overstep each other to the west. An uncontormity between the $A$ unit and the overlying Greenbrier Limestone represents an erosional episode that has progressively eliminated the $A, B$ and $C 2$ units eastward across Granny Creek field. The distribution of Big injun oil fieids in south central West Virginia is influenced by geologic structure. Oil tields have been developed on the flanks of anticlines and synclines in the area. and can be observed to wrap around the nose of the Parkersburg Syncline and the northeastward plunging nose of the Wartield Anticline. Seismic data collected across Granny Creek field have good resolution in the Greenbrier-Big Injun interval and strengthen stratigraphic and structural interpretations based on geophysical logs and drillers' data. Examination of cores and thin sections has led to preliminary interpretations of depositional environments for the Big Injun. These include distributary-mouth bars with associated distal, bar crest and back bar environments in a marine-deltaic system. and channel. point bar and chute environments in a fluvial system. Overall. the Big Injun is a medium-grained sublitharenite in which initially high porosity has been modified by compaction and diagenesis. Chlorite grain coatings helped to preserve original porosity. whereas illite promoted pressure so. lution during compaction, resulting in a loss of porosity. Diagenetic effects within specific environments are being evaluated to determine if environ. mental interpretations can be used to predict porosity preservations.

DOE/BC/14471-11 Analysis of Reservoir Heterogeneities Due to Shallowing. Upward Cycles in Carbonate Rocks of the Pennsyluanian Wahoo Limestone of Northeastem Alaska. University of Alaska. Annual Report for the Period September 1989-September 1990. September $1992.76 \mathrm{pp}$. Order No. DE92001064. The primary objective of this project was to develop an integrated database to characterize reservoir heterogeneities resulting from numerous small-scale shallowing-upward cycles (parasequences) comprising the Pennsylvanian Wahoo Limestone. The Wahoo Limestone is the upper part of an extensive carbonate platform sequence of the Carboniferous Lisbume Group that is widely exposed in the Brooks Range and is a widespread hydrocarbon reservoir unit in the subsurface of the North Slope of the Alaska. A major goal is to determine lateral and vertical variations in the complex mosaic of carbonate facies comprising the Wahoo Limestone. This report presents the preliminary results of research in carbonate petrology, biostratigraphy, and diagenesis during the year. It includes a summary of some petrographic data which has been entered into 
a computerized database; a discussion of biostratgraphic data, particularly conodont biofacies analyses; an overview of diagenetic studies; and a section of the regional geological framework studies. The database allows tests of which parameters, such as ooids, can be used to recognize and understand the carbonate petrology of the shallowing-upward cycles. The cycles have been interpreted in terms of depositional environments and sea-level fluctu. ations and used to develop detailed facies models. Conodont biostratigraphy is providing an independent means of correlation and age dating. Conodont biofacies analyses are being related to paleoenvironments as determined by carbonate facies analysis. Analyses of diagenesis have allowed recognition of a number of subaerial exposure surfaces that are another important means of correlation and will figure importantly in developing seal level curves. Regional studies provide an understanding of lateral facies relationships and how position on a southward-facing carbonate ramp affects the nature of carbonate shallowing-upward cycles.

\section{DOE/BC/14471-12 Analysis of Reservolr Heterogeneities} Due to Shallowing-Upward Cycles In Carbonate Rocks of the Pennsylvanian Wahoo Limeatone of Northeastern Alaska. Univeralty of Alaska. Annual Report for the Period October 1990.September 1991. September 1992. 76 pp. Order No. DE92001065. This is the second annual report of the project to develop an integrated database to characterize reservoir heterogeneities resulting from numerous small-scale shallowing-upward cycles (parasequences) comprising the carboniferous Pennsylvanian Wahoo Limestone. The Wahoo Lmestone is the upper formation of an extensive carbonate platform sequence of the Carboniferous Lisbum Group which is widely exposed in the Brooks Range and is a widespread hydrocarbon reservoir unit in the subsurface of the North Slope of Alaska. A principal goal is to determine lateral and vertical variations in the complex mosaic of carbonate facies comprising the Wahoo Limestone. The report presents preliminary results of research in carbonate petrology, biostratigraphy, and diagensis during the year. It includes a summary of regional geological framework studies, a discussion of conodont analyses, an overview of diagenetic studies, a brief description of progress in computerized database development, and appendices containing some of the new data on petrographic analyses, conodont analyses, and locality and sample information. Regional studies provide an understanding of lateral facies relationships and describe how position on a southward-facing carbonate ramp affect the nature of carbonate parasequences (shallowing-upward cycles). In order to understand the overall basin history and its relationship to the stratigraphic and structural framework, the research considers the rock units adjacent to the Wahoo Limestone, the undertying Alapah Limestone and overlying Echooka Formation. Conodont biostratigraphy is providing an independent means of correlation and age dating. Conodont biofacies analyses are being related to palecenvironments as determined by carbonate facies analysis. Analyses of diagenesis have allowed recognition of a number of subaerial exposure surfaces which are another important means of correlation and will figure importantly in developing sea-level curves. The computerized database allows tests of which parameters, such as ooids, can be used to recognize and understand the carbonate petrology of the parasequences/shallowingupward cycles. The cycles have been interpreted in terms of depositional environments and sea-level fluctuations and have been used to develop detailed facies models.

\section{Resource Assessment}

DOE/BC/14476-10 Characterization of Reservoir Rocks and Fluids By Surface Electromagnetic Transent Methods. Blackhawk Geosclences Inc. Annual Report for 1990-1991. September 1992. 76 pp. Order No. DE92001060. The objectives of this research were to improve the interpretations of transient electromagnetic (TEM) measurements over two-dimensional subsurface structures. TEM is a surface electromagnetic method employed in fossil energy reservoir exploration and characterization. Electrical measurements find application in (1) assisting in fossil energy exploration, mainly in areas where seismic methods yield inadequate data quality, such as volcaniccovered terrain, permafrost areas, and the Rocky Mountain Overthrust; (2) mapping contacts between hydrocarbon and brines in shallow producing horizons; and (3) monitoring enhanced oil recovery processes which cause zones of lower resistivity. The work under this contract consisted of three tasks: (1) Selection of a test site and acquisition of a high-density, 3-component data set over the test site; (2) Development of finite element modeling algorithms for computing 3.D EM fields over 2-D subsurface structures; and (3) Development of TEM 2-D subsurface imaging method. 
Brookhaven National Laboratory

Effects of Selected Thermophilic Microorganisms on Crude Oils at Elevated Temperatures and Pressures

Idaho National Engineering Laboratory

Microbial Enhanced Oil Recovery and Wettability Research Program

Ikwuakolam Energy Company Inc.

Use of Rock-Typing To Characterize Carbonate Reservoir Heterogeneity

Illinois Department of Energy and

Natural Resources

Research on Improved and Enhanced Oil Recovery in Illinois Through Reservoir Characterization

K\&A Energy Consultants, Inc.

Simulation Studies To Evaluate the Effect of Fracture Closure on the Performance of Naturally Fractured Reservoirs

Lawrence Berkeley Laboratory

Electrical and Electromagnetic Methods for Reservoir Description and Process Monitoring

Lawrence Livermore National Laboratory

Enhanced Oil Recovery Sensing

Louisiana State University Cyclic $\mathrm{CO}_{2}$ Injection for Light Oil Recovery: Performance of a Cost-Shared Field Test in Louisiana

Morgantown Energy Technology Center Quantification of Mobility Control in Enhanced Recovery of Light Oil by Carbon Dioxide

National Institute for Petroleum and Energy Research

Development of Improved Alkaline Flooding Methods

Development of Improved Microbial Flooding Methods

Development of Methods for Mapping Distribution of Clays in Petroleum Reservoirs Feasibility Study of Heavy Oil Recovery in the Midcontinent Region: Oklahoma, Kansas, and Missouri
Gas Flood Performance Prediction Improvement

Imaging Techniques Applied to the Study of Fluids in Porous Media

Microbial Enhanced Waterflooding Field Project

Mobility Control and Sweep Improvement in Chemical Flooding

Mobility Control, Profile Modifications, and Sweep Improvement in Gas Flooding

Reservoir Assessment and Characterization Simulation Analysis of Steam-Foam Projects

Surfactant-Enhanced Alkaline Flooding Field Project

Surfactant Flooding Methods

Thermal Processes for Heavy Oil Recovery

Thermal Processes for Light Oil Recovery

Third International Reservoir Characterization Technical Conference

Three-Phase Relative Permeability Research

TORIS Research Support

New Mexico Institute of Mining and Technology

Field Verification of $\mathrm{CO}_{2}$-Foam

Fluid Diversion and Sweep Improvement with Chemical Gels in Oil Recovery Processes

Oklahoma Geological Survey

Natural Resources Information System for the State of Oklahoma

Sandia National Laboratories

Geodiagnostics for Reservoir Heterogeneities and Process Mapping

Stanford University

Research on Oil Recovery Mechanisms in Heavy Oil Reservoirs

Scaleup of Miscible Flood Processes

Texas A\&M University

Oil Recovery Enhancement from Fractured, Low-Permeability Reservoirs

University of Alaska

Analysis of Reservoir Heterogeneities Due to Shallowing-Upward Cycles in Carbonate Rocks of the Pennsylvanian Wahoo Limestone of Northeastern Alaska

University of California, Berkeley

Geophysical and Transport Properties of Reservoir Rocks 


\section{University of Michigan}

Characterization and Modification of Fluid Conductivity in Heterogeneous Reservoirs To Improve Sweep Efficiency

91

Polysaccharides and Bacterial Plugging

\section{University of Oklahoma}

Dispersion Measurement as a Method of Quantifying Geologic Characterization and Defining Reservoir Heterogeneity

\section{University of Southern California}

Modification of Reservoir Chemical and Physical Factors in Steamfloods To Increase Heavy Oil Recovery

University of Texas at Austin

A Novel Approach To Modeling Unstable Enhanced Oil Recovery Displacements Microbial Enhanced Oil Recovery Research

\section{University of Tulsa}

Reservoir Characterization of Punnsylvanian Sandstone Reservoirs

59

\section{West Virginia University}

Measuring and Predicting Reservoir Heterogeneity in Complex Deposystems

\section{Western Research Institute}

Characterization of the Gravity Drainage

Phenomena Through Numerical and

Physical Simulation

\section{CONTENTS BY EOR PROCESS}

Chemical Flooding-Supporting Research

Gas Displacement-Supporting Research

Thermal Recovery-Supporting Research

Geoscience Technology

Resource Assessment Technology

Microbial Technology

52 
DOE Technical Project Officers for

Enhanced Oil Recovery

DIRECTORY

\begin{tabular}{|c|c|c|}
\hline Name & Phone number & Name of contractor \\
\hline \multicolumn{3}{|c|}{$\begin{array}{l}\text { U.S. Department of Energy } \\
\text { Gas and Petroleum Technology } \\
\text { Oil and Gas Exploration and Production } \\
\text { 3E-028/FORS Washington, D.C. } 20585\end{array}$} \\
\hline \multicolumn{3}{|c|}{$\begin{array}{c}\text { Bartiesville Project Office } \\
\text { P. O. Box } 1398 \\
\text { Bartlesville, Oklahoma } 74005\end{array}$} \\
\hline Edith Allison & $918-337-4390$ & $\begin{array}{l}\text { National Institute for Petroleum and Energy Research } \\
\text { West Virginia University }\end{array}$ \\
\hline Jerry Casteel & $918-337-4412$ & $\begin{array}{l}\text { National Institute for Petroleum and Energy Research } \\
\text { New Mexico Institute of Mining and Technology }\end{array}$ \\
\hline Robert Lemmon & $918-337-4405$ & $\begin{array}{l}\text { Lawrence Berkeley Laboratory } \\
\text { National Institute for Petroleum and Energy Research } \\
\text { Sandia National Laboratories } \\
\text { University of Alaska } \\
\text { University of California, Berkeley } \\
\text { University of Michigan }\end{array}$ \\
\hline Rhonda Lindsey & $918-337-4455$ & $\begin{array}{l}\text { Brookhaven National Laboratory } \\
\text { Idaho National Engineering Laboratory } \\
\text { Ikwuakolam Energy Company Inc. } \\
\text { K\&A Energy Consultants, Inc. } \\
\text { National Institute for Petroleum and Energy Research } \\
\text { Texas A\&M University } \\
\text { University of Tulsa }\end{array}$ \\
\hline Chandra Nautiyal & $918-337-4409$ & $\begin{array}{l}\text { National Institute for Petroleum and Energy Research } \\
\text { University of Michigan }\end{array}$ \\
\hline R. Michael Ray & $918-337-4403$ & $\begin{array}{l}\text { Oklahoma Geological S: iney } \\
\text { Illinois Department of Energy and Natural Resources }\end{array}$ \\
\hline Thomas Reid & $918-337-4233$ & $\begin{array}{l}\text { Lawrence Livermore National Laboratory } \\
\text { National Institute for Petroleum and Energy Research } \\
\text { Stanford University Petroleum Research Institute } \\
\text { University of Southern California }\end{array}$ \\
\hline \multicolumn{3}{|c|}{$\begin{array}{l}\text { Idaho Operations Office } \\
785 \text { DOE Place } \\
\text { Idaho Falls, Idaho } 83415\end{array}$} \\
\hline L. S. McCoy & & Idaho National Engineering Laboratory \\
\hline \multicolumn{3}{|c|}{$\begin{array}{c}\text { Metairie Site Office } \\
900 \text { Commerce Road, East } \\
\text { New Orleans, Louisiana } 70123\end{array}$} \\
\hline Jerry Ham & $504-734-4906$ & $\begin{array}{l}\text { University of Texas } \\
\text { Western Research Institute }\end{array}$ \\
\hline E. B. Nuckols & $504-734-4806$ & University of Texas at Austin \\
\hline Gene Pauling & $504-734-4131$ & $\begin{array}{l}\text { Louisiana State University } \\
\text { University of Oklahoma }\end{array}$ \\
\hline
\end{tabular}


Morgantown Ensrgy Technology Center

P. O. Box 880

Morgantown, W. Va. 26505

Morgantown Energy Technology Center

New Mexico Institute of Mining and Technology

Stanford University 


\section{CHEMICAL FLOODING- SUPPORTING RESEARCH}

\section{FLUID DIVERSION AND SWEEP} IMPROVEMENT WITH CHEMICAL GELS IN OIL RECOVERY PROCESSES

\section{Contract No. DE-FG07-89BC14447}

New Mexico Institute of Mining and Technclogy Socorro, N. Mex.

Contract Date: May 1, 1989

Anticipated Completion: Aug. 1, $1: 792$

Principal Investigators:

Randall S. Seright

Frank S. Kovarik

F. David Martin

Project Manager: Jerry Casteel Bartlesville Project Office

Reporting Period: Apr. 1-June 30, 1992

\section{Objectives}

The objectives of this project are to identify the mechanisms by which gel treatments divert fluids in reservoirs and to establish where and how gel treatments are best applied. Several types of gelants were examined, including polymer-based gelants, a monomer-based gelant, and a colloidal silica gelant. This research is directed at gel applications in water injection wells, in production wells, and in high-pressure gas floods. The work will examine how the flow properties of gels and gelling agents are influenced by permeability, lithology, and wettability. Other goals include determining the proper placement of gelants, the stability of in-place gels, and the types of gels required for the various oil recovery processes and for different scales of reservoir heterogeneity.

\section{Summary of Technical Progress}

All tasks associated with the project are complete, and a final report has been submitted. 


\section{SURFACTANT FLOODING METHODS}

\section{Cooperative Agreement DE-FC22-83FE60149, Project BE4A}

\author{
National Institute for Petroleum \\ and Energy Research \\ Bartlesville, Okla.
}

Contract Date: Oct. 1, 1983

Anticipated Completion: Sept. 30, 1992

Funding for FY 1992: $\$ 600,000$

\author{
Principal Investigators: \\ Bonnie L. Gall \\ Feliciano M. Llave \\ Troy R. French

\section{Project Manager: \\ Jerry Casteel \\ Bartlesville Project Office}

Reporting Period: Apr. 1-June 30, 1992

\section{Objectives}

The objectives of this year's work are to (1) apply advanced enhanced oil recovery (EOR) technology based on mixed surfactant systems to improve oil recovery from Class 1 reservoirs, (2) extend the use of surfactant EOR to different salinity and temperature ranges by developing surfactant systems that are more adaptable to changes in chemical composition in selected reservoirs, and (3) develop costeffective chemical systems for selected field applications that may contain low concentrations of synthetic surfactants and alkaline additives. The emphasis of these studies will be on problem areas that may have adverse effects on the performance and economics of the chemical flooding processes in an effort to achieve a balance between cost and oil recovery effectiveness.

\section{Summary of Technical Progress}

\section{Mixed Surfactant Systems}

For task 1, phase inversion temperature (PIT) studies were conducted on a series of anionic and nonionic surfactant mixtures. Several nonionic surfactants were tested, including a series of Neodol, ${ }^{\circledR}$ Genapol, ${ }^{\circledR}$ and Igepal surfactants, with a hydrophile-lipophile balance (HLB) range of 7.8 up to 15.1. These surfactants were tested in combination with a primary anionic surfactant system, 5 wt \% TRS 10-410 and $3 \mathrm{wt} \%$ IBA. These experiments were conducted to evaluate the overall solution behavior as a function of the amount and type of secondary surfactants added. The behavior of the solutions when only the nonionic sur- factants were added was also observed. The PIT method has been used as a relatively fast screening method for estimating the relative proximity of optimum conditions for these solutions at a given set of salinity and temperature conditions. This type of screening was generally used on nonionic systems. For this study, mixtures of anionic and nonionic as well as the individual nonionic systems were tested. The results of these PIT tests were also compared with previous salinity scans of systems that have been tested.

The results of the comparison of the PIT values and the optimum salinity ranges measured using the salinity scan in phase tubes ${ }^{1,2}$ for selected systems were very good. Figure 1 is a plot of the solubilization parameters measured for the system containing $1 \mathrm{wt} \% \mathrm{~N}-25-7$ and $1 \mathrm{wt} \%$ of the primary surfactant with decane. The optimum salinity measured from the salinity scan was compared with the PIT measurements shown in Fig. 2. Figure 2 is a plot of the solution electrical conductivity as a function of temperature with the target being $50^{\circ} \mathrm{C}$. The optimum salinity was experimentally determined to be about $9.25 \% \mathrm{NaCl}$ using the conventional salinity scan compared with 9 to $10 \% \mathrm{NaCl}$ identified using the PIT experiment. Another example is the system containing $1 \mathrm{wt} \%$ DM-530 and $1 \mathrm{wt} \%$ of the primary surfactant with $n$-decane. The optimum salinity was determined to be about $3.0 \% \mathrm{NaCl}$ by salinity scan compared 3.5 to $4 \% \mathrm{NaCl}$ using the PIT experiment. The estimates of the optimum salinity ranges using the PIT method also show good agreement with extrapolated values of the optimum salinity from the phase tube salinity scans for the individual nonionic surfactants with $n$-decane. A series of phase-behavior tests is being conducted on these systems, particularly the individual nonionic systems and combinations of anionic and nonionic surfactants. The results from the $\mathrm{P}_{i}^{\cdots}$ screening were used as guides in conducting these salinity scan studies.

From these screening studies, trends in relative proximity of optimal salinity conditions were also examined, and

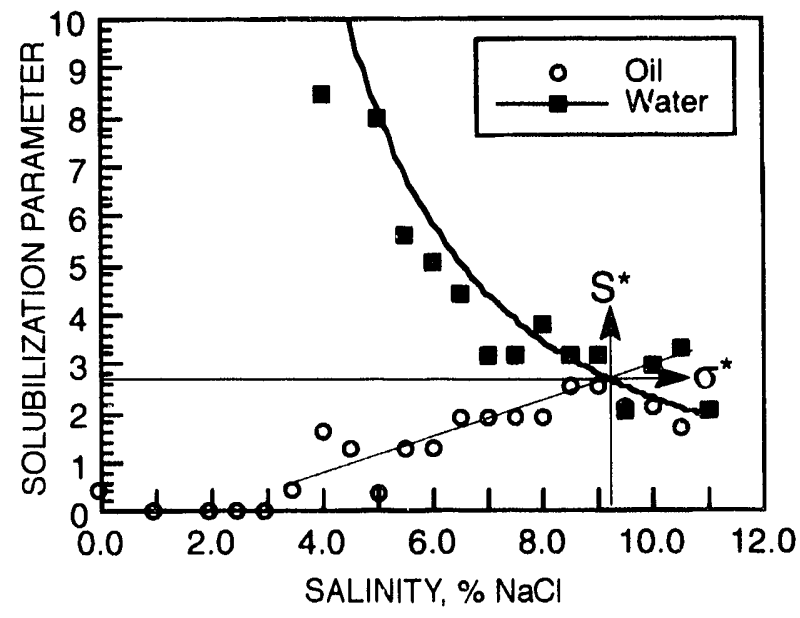

Fig. 1 Phase behavior measurement for 1 wt $\%$ N-25-7 and 1 wt \% TRS 10-410/IBA [5:3] with $n$-decane at $50^{\circ} \mathrm{C}$. 


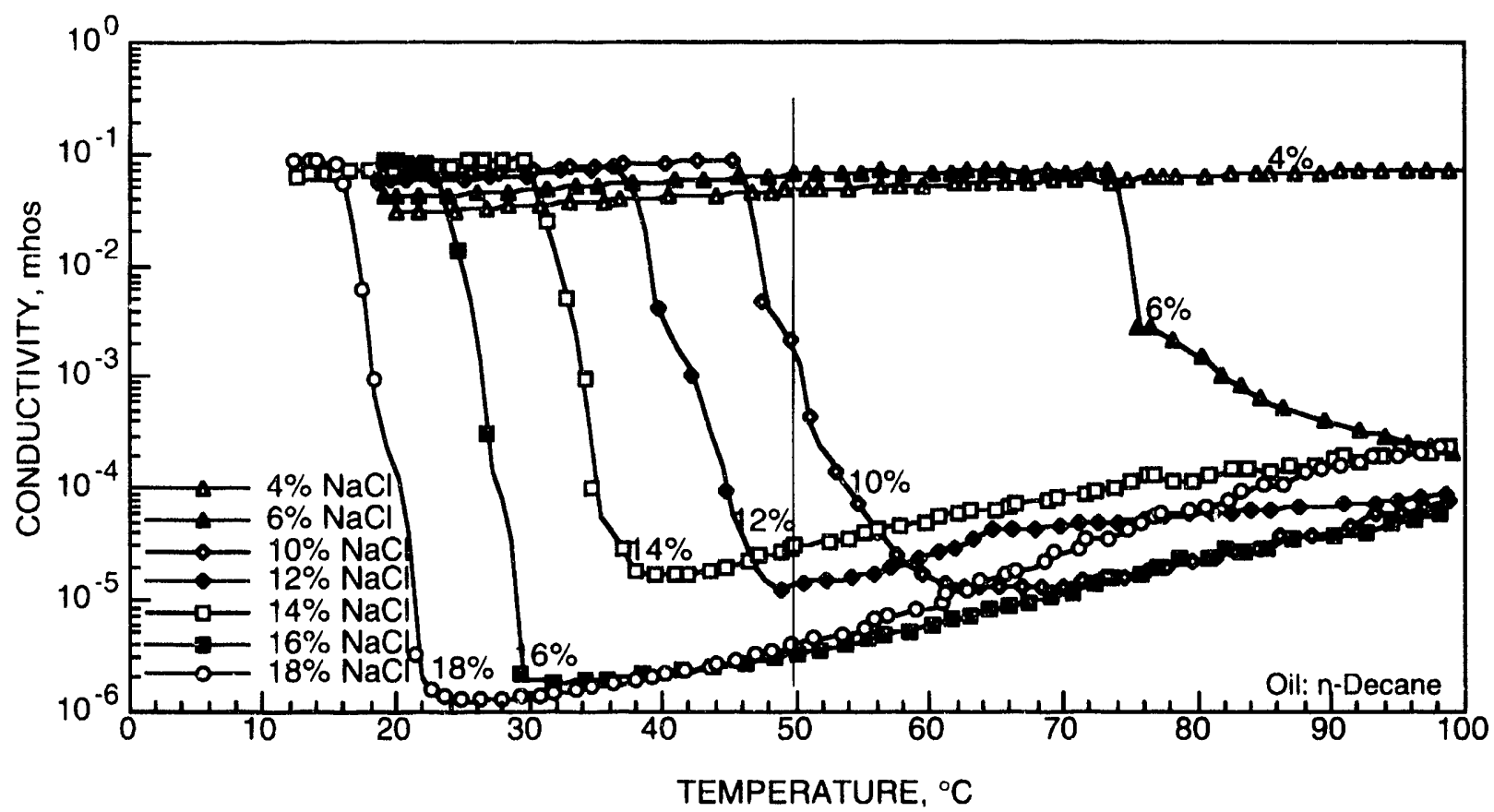

Fig. 2 Phase inversion temperatures measured for 1 wt $\%$ N-25-7 and 1 wt \% TRS 10-410/1BA [5:3] with n-decane. Hydrophilelipophile balance, 12:3.

the dependence of solution behavior on the chemical structure of nonionic species was being investigated. Figure 3 also is a plot of the optimum salinity of the different mixtures versus the HLB of the nonionic components. The linear alkyl alcohol ethoxylates, i.e., the $\mathrm{Neodol}^{\circledR}$ and Genapol ${ }^{\circledR}$ series, appear to exhibit a very distinct behavior from the dialkyl phenol surfactants, such as the Igepal series, at similar HLB levels. The Genapol ${ }^{\circledR}$ series also appears to show a more distinct pattern of behavior in terms of the dependence of the optimum salinity on the HLB of

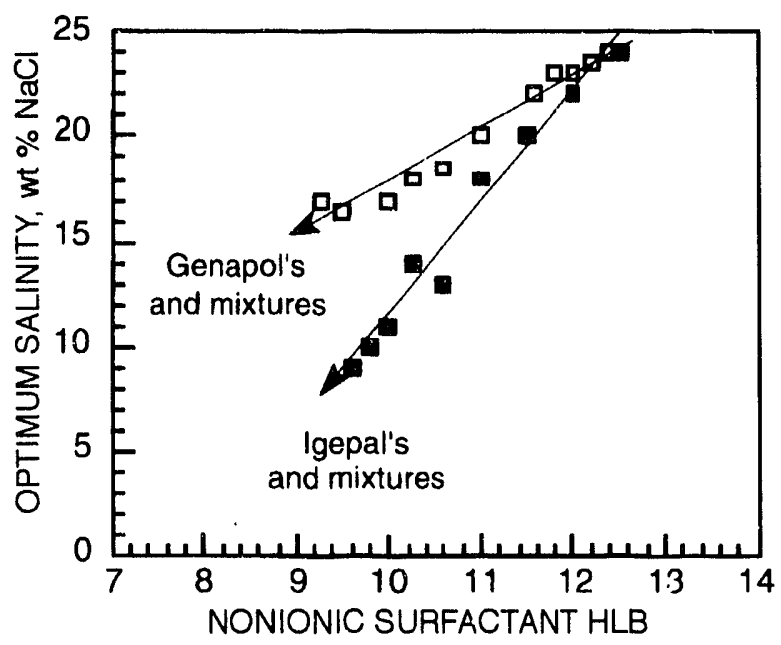

Fig. 3 Optimal salinity determined by phase inversion temperature method versus hydrophile-lipophile balance value of the nonionic component. the mixtures compared with that of the Neodol ${ }^{\circledR}$ in spite of being similar linear alkyl alcohol ethoxylates with a comparable range of alkyl chain length. The scatter of the data for the Neodol ${ }^{\circledR}$ series was considerably greater than that for the Genapol ${ }^{\circledR}$ series. Additional experiments will be conducted to confirm this.

Efforts to develop a surfactant-literature reference database have been steadily progressing. Additional help from an Associated Western Universities (AWU) summer student has been instrumental in providing much needed assistance in computer scanning literature/publications for electronic input into the database. The shell of the database was developed earlier in the year. Literature references on hand are being input into the database. A status report regarding the development of this database system is being written.

For task 2, three surfactants were selected and tested with oil from 2nd Wall Creek formation of NPR No. 3. These surfactants were Chevron XP-100, Chevron CF-100, and Stepan Petrostep B-105. All are anionic surfactants and are listed in order of increasing salt tolerance. Chevron XP100 is least salt tolerant and Petrostep B-105 is most tolerant of high salinity. Makeup water was synthetic Madison limestone aquifer water. Preliminary tests showed that carbonates precipitate from Madison water when the $\mathrm{pH}$ is raised. $\mathrm{NaHCO}_{3}$ concentrations up to $0.3 \%$ could be dissolved in the water without precipitation occurring. There was no tolerance to $\mathrm{Na}_{2} \mathrm{CO}_{3}$. Sodium tripolyphosphate, which is a complexing agent as well as a weak alkali, also caused precipitation. Chevron CF-100 and XP-100 surfactants were too insoluble in Madison water to test further 
without softening the water. Some experiments are now in progress to determine if these surfactants can be brought into solution with a cosurfactant. Petrostep B-105 was the only surfactant that was soluble in unsoftened Madison water. Low interfacial tension (IFT) values were measured for B-105 in unsoftened water but only when large amounts $(12.5 \%)$ of $\mathrm{NaCl}$ were added. This indicates that a surfactant that has intermediate salt tolerance is needed to formulate in unsoftened Madison water.

Petrostep B-105 was also tested in softened Madison water. Alkaline additives can be added to softened Madison water without carbonate precipitation. The results of IFT measurements are shown in Fig. 4. $\mathrm{Na}_{2} \mathrm{CO}_{3}$, a weak alkali, was used to adjust salinity. These results are encouraging because with $0.25 \%$ Petrostep B-105 fairly low IFT values were measured with reasonable concentrations of $\mathrm{Na}_{2} \mathrm{CO}_{3}$. Values of IFT around $50 \mu \mathrm{N} / \mathrm{m}$ were measured with $5 \% \mathrm{Na}_{2} \mathrm{CO}_{3}$.

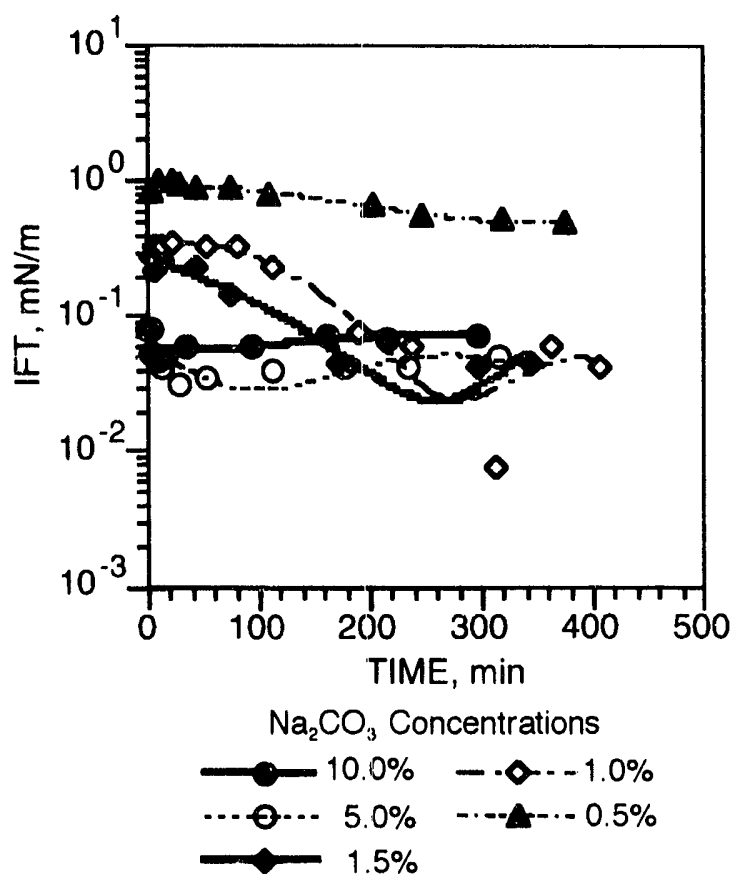

Fig. 4 Interfacial tension (IFT) between 2nd Wall Creek formation oil and Stepan Petrostep B-105 surfactant in synthetic softened Madison limestone aquifer water at $52{ }^{\circ} \mathrm{C}$ as a function of time for different concentrations of added sodium carbonate.

With softened water the surfactants CF-100 and XP-100 were sufficiently soluble to test. With $0.25 \%$ CF-100, IFT values in the $10-$ to $40-\mathrm{mN} / \mathrm{m}$ range were measured with 1.0 to $1.5 \% \mathrm{Na}_{2} \mathrm{CO}_{3}$ solutions. With $0.25 \%$ XP-100, IFT values were in the $20-$ to $40-\mathrm{mN} / \mathrm{m}$ range. These solutions were formulated in softened Madison water, and the $\mathrm{Na}_{2} \mathrm{CO}_{3}$ was used for salinity adjustment. These formulations should mobilize significant residual oil.

In summary, three chemical systems were identified as potentially useful in 2nd Wall Creek formation of NPR
No. 3. These systems were all formulated in softened Madison aquifer water and were (1) $0.25 \%$ Petrostep B-105 and $5 \% \mathrm{Na}_{2} \mathrm{CO}_{3}$, (2) $0.25 \% \mathrm{CF}-100$ and 1.0 to $1.5 \% \mathrm{Na}_{2} \mathrm{CO}_{3}$, and (3) $0.25 \% \mathrm{XP}-100$ and $1.0 \% \mathrm{Na}_{2} \mathrm{CO}_{3}$.

For task 3, a report, CT Imaging of Surfactant Enhanced Oil Recovery Experiments, was completed and is in review. Four corefloods have been conducted with computerized tomography (CT) imaging techniques to monitor oil saturation distributions at various times during the coreflooding operations. These tests provide a baseline for comparison for additional tests designed to examine the effect of chemical and core properties on oil recovery efficiency. Two tests examined oil saturation changes for surfactant systems known to provide high oil recovery in laboratory tests using two different oils. A third test altered the concentration of the mobility control polymer to provide unfavorable mobility. The fourth test examined oil mobilization with a surfactant formulation that was less effective in producing oil. All these tests were conducted in Berea sandstone cores at ambient temperature. The cores appeared to have at least some bedding layers that varied in porosity and permeability.

The most recent coreflood completed this quarter used the CT to monitor oil production for a "good" surfactant system for North Burbank Unit (NBU) oil, TRS10-410 and IBA $(5: 3)$. The coreflood was conducted in a Berea sandstone core with an average permeability of $290 \mathrm{mD}$. Average oil saturation after chemical flood as measured by $\mathrm{CT}$ oil saturation calculations was less than $5 \%$ of the original oil saturation. Average saturations along the core as measured with the CT imaging techniques are shown in Fig. 5. Volumetric measurement of oil production indicated that almost $100 \%$ of the oil introduced into the core was produced during the coreflood. Although oil saturation was low at the end of the test, the remaining oil was not distributed homogeneously throughout the core. Injected fluids advanced more rapidly along one bedding plane than others. The mobility control polymer (1500 ppm biopolymer), however, appeared to adequately sweep the core. This is in contrast to the oil recovery results reported previously with a mixed surfactant system with NBU oil where the majority of injected fluids appeared to channel through part of the core. ${ }^{3}$ More extensive comparisons of coreflooding results using the CT to monitor oil saturations, including CT images, are given in the CT imaging report.

For task 4, a report, Low-Concentration Surfactant Flooding: Partitioning of Sinthetic Surfactants, was completed and will be delivered to the Department of Energy after peer review. In this study there was no demonstrable effect of alkaline additives on the partitioning of synthetic surfactants between aqueous and oil phases. The partitioning of synthetic surfactants was distinctly different from that of carboxylic acid surfactants. which are $\mathrm{pH}$ dependent. The results showed that alkaline additives do significantly reduce surfactant adsorption and that IFT levels very favorable to the mobilization of residual oil can be achieved with dilute surfactant solutions that contain alkaline addi- 
tives. With alkaline additives it was easier to formulate very dilute $(0.1$ to $(0.5 \%)$ surfactant solutions that have the properties to mobilize residual oil and minimize surfactant adsorption.

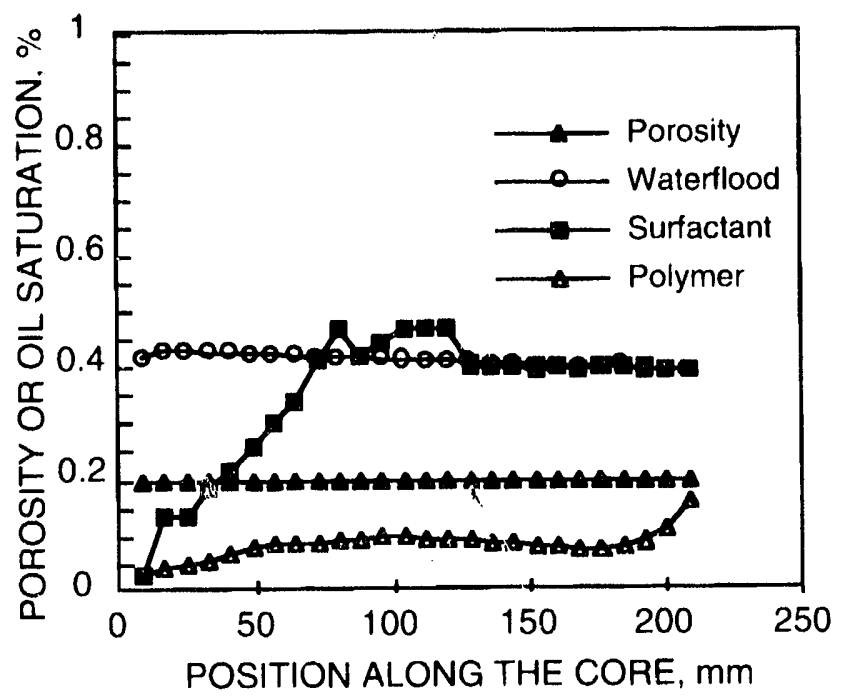

Fig. 5 Average porosity and oil saturation after waterflood, surfactant injection, and polymer injection for a coreflood using North Burbank Unit oil, the surfactant system TRS 10-410/IBA, and biopolymer in Berea sandstone core.

\section{References}

1. National Institute for Petroleum and Energy Research, Quarterly Te'hnical Report for October I December 31. 1991. Volume II, Energy Production Research, DOE Report NIPER-588, March 1992.

2. National Institute for Petroleum and Energy Research. Quarterly Technical Report for Ianuary I March 30, 1992, Volume II, Energy Production Research. DOE Report NIPER-595, June 1992

3. F. M. L.ave. B. L. Gall, T. R. French, L. A. Noll, and S. A. Munden, Phase Beharion and Oil Reconery Investigations Using Mixed and Alkaline-Enhanced Surfactam Sistems. DOE Report NIPIER-567, December $\mid 991$.
DEVELOPMENT OF IMPROVED

ALKALINE FLOODING METHODS

\section{Cooperative Agreement DE-FC22-83FE60149, Project BE4B}

\author{
National Institute for Petroleum \\ and Energy Research \\ Bartlesville, Okla. \\ Contract Date: Oct. 1, 1983 \\ Anticipated Completion: Sept. 30, 1992 \\ Funding for FY 1992: $\$ 195,000$ \\ Principal Investigator: \\ Troy R. French \\ Project Manager: \\ Thomas Reid \\ Bartlesville Project Office
}

Reporting Period: Apr. 1-June 30, 1992

\section{Objectives}

The main objective of this project is to develop costeffective and efficient chemical flooding formulations using surfactant-enhanced, weakly alkaline systems. Specific objectives for FY92 are to (1) determine the effect of variables on polymer propagation and retention during alkaline flooding and (2) perform studies designed to support a field test.

\section{Summary of Technical Progress}

\section{Application to Enhanced Oil Recovery}

The emerging technology in alkaline flooding for heavy oil recovery is the use of a combination of surfactant and alkali. Proper design of injection strategy can be viewed as near-term as well as long-term research. In the near term, this research will support design of the proposed surfactantenhanced alkaline flooding field pilot test that is being conducted under the Supplemental Government Program.

\section{Discussion}

The effect of alkaline chemicals on the retention and propagation of polymers in surfactant-enhanced alkaline flooding is complex. In addition to the effects as the result of $\mathrm{pH}$ level, ionic strength, crude oil properties, polymer properties, cosurfactant (alcohols) properties, and surfactant properties, the interactions that occur between polymers and surfactants could be the most significant. ${ }^{1,2}$ Periodic measurements continued on mixtures of polymers and surfactants, and the effect of oil on surfactant-polymer interaction was investigated. Previously, results were presented 
which showed that interactions occur between many polymers and surfactants. ${ }^{3}$ These interactions consisted of phase separations and/or formation of precipitates. The investigation of the interactions of $\mathrm{pH}$, polymer, and surfactant and the effects of these interactions on rheology continued. Rheology and $\mathrm{pH}$ of most of the polymer solutions have now been monitored periodically for 5 months. A Contraves low-shear viscometer was used for initial measurements. Because of mechanical problems with the Contraves, a Brookfield viscometer was used for later measurements.

Alcoflood 1135, a medium-molecular-weight anionic polymer that is furnished in solid form, was used for the tests. Alcoflood 1135 is a partially hydrolyzed polyacrylamide. The detrimental effects of salt solutions on the rheological properties of polyacrylamide polymers are well known. It is also known that certain interactions occur between anionic polymers and surfactants.

Chevron XP-100, an anionic surfactant, was used for the testing. The $\mathrm{pH}$ was adjusted with sodium hydroxide, a strong alkali. Weak, buffered alkalis have properties that are advantageous for field use. ${ }^{4}$ For these studies, however, the strong alkali is more useful because $\mathrm{pH}$ can be adjusted by adding small amounts of the strong alkali; therefore the ionic strength is changed only very little during $\mathrm{pH}$,istment. Ionic strength adjustments were accomplished with $\mathrm{NaCl}$.

Three 2000-ppm polymer solutions were prepared in 0.4 , 0.6 , and $1.2 \% \mathrm{NaCl}$. The $\mathrm{pH}$ of these solutions was not adjusted, and all three solutions had $\mathrm{pH}$ values of about $\mathrm{pH}$ 5.7. Initially, the viscosities of the solutions showed a very slight drift downward but after 5 months of periodic measurements appear to be essentially level. There was little or no change in $\mathrm{pH}$ values of these solutions. Viscosity and $\mathrm{pH}$ levels were basically stable for these solutions, and examples of the $\mathrm{pH}$ changes that occurred are shown in Fig. 1.

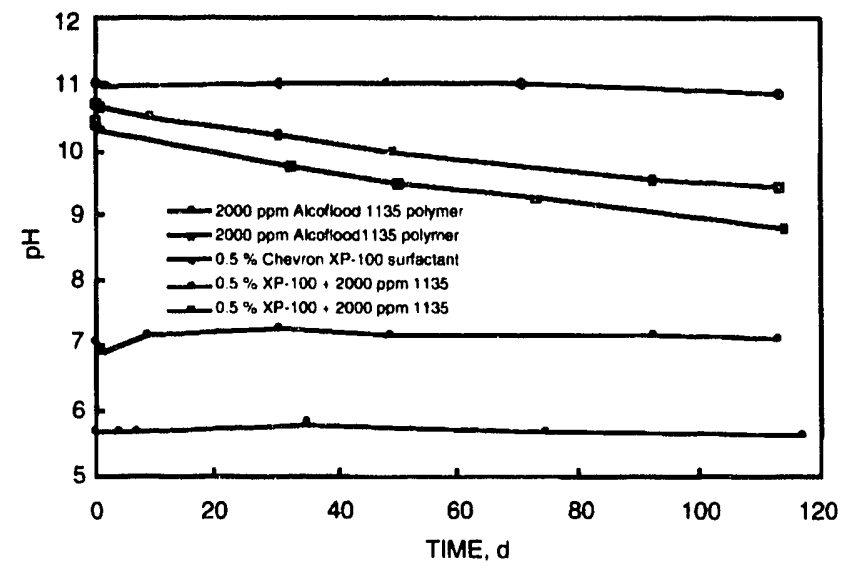

Fig. 1 pH of Alcoflood 1135 polymer and XP-100 surfactant mixtures.
The $\mathrm{pH}$ levels of three other polymer solutions were adjusted to $\mathrm{pH}$ 10.5. The viscosities of these polymer solutions were substantially increased over the viscosities measured at $\mathrm{pH}$ 5.7. The magnitude of the viscosity increases for $\mathrm{pH} 10.5$ polymer (compared with $\mathrm{pH} 5.7$ ) solutions in $0.4,0.6$, and $1.2 \% \mathrm{NaCl}$ were, respectively, 18,16 , and $8 \%$. Initially, the viscosities of these polymer solutions decreased slightly but were essentially stable during 5 months of periodic measurements. An example (for $0.4 \% \mathrm{NaCl}$ ) is shown in Fig. 2. The $\mathrm{pH}$ level decreased by about $1 \frac{1}{2} \mathrm{pH}$ units during this time. This indicates that some polymer hydrolysis is occurring. The extent of hydrolysis is apparently small because the rheological properties are not changing significantly. The $\mathrm{pH}$ of a control solution, without polymer, decreased only $0.2 \mathrm{pH}$ units over the same time interval.

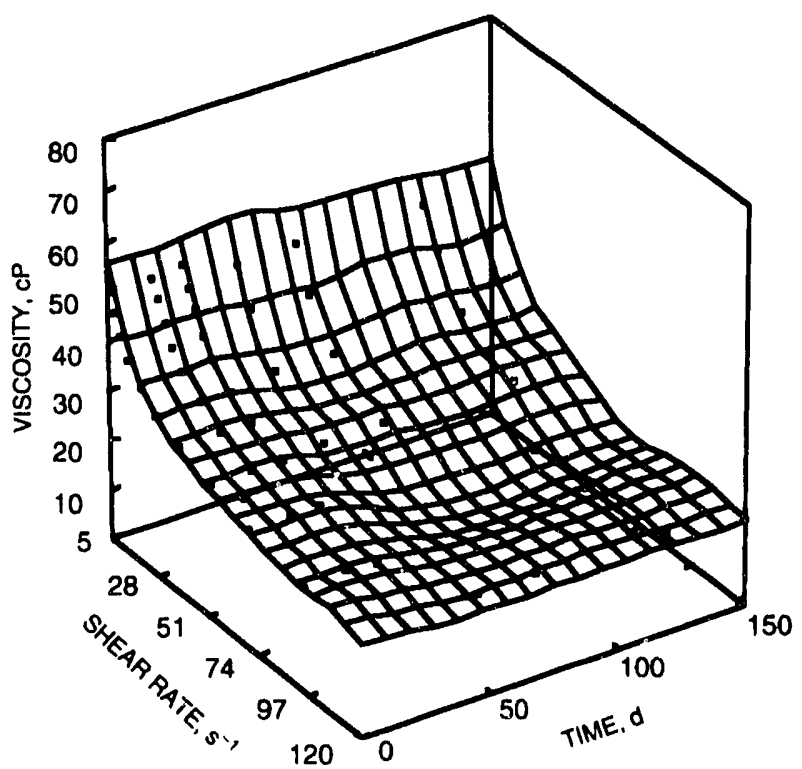

Fig. 2 Viscosity of 2000-ppm Alcoflood 1135 polymer in $0.4 \% \mathrm{NaCl}$, pH 10.4.

An aqueous solution of $0.5 \%$ Chevron XP-100, an anionic surfactant, was slightly alkaline and had a viscosity slightly above that of water. The $\mathrm{pH}$ of the surfactant solution remained nearly level for 5 months (see Fig. 1).

When $0.5 \%$ XP- 100 surfactant and 2000-ppm Alcoflood 1135 polymer were mixed in $\mathrm{NaCl}$ solutions, the rheological properties were different from those described previously for polymer and surfactant solutions. As previously reported, phase separation and precipitation were observed when anionic surfactants and polymers were mixed. When polymer-surfactant solutions were prepared in $0.4 \% \mathrm{NaCl}$, the viscosity increased for a short period of time and then decreased. This was true at $\mathrm{pH} 7.0$ and at $\mathrm{pH} 10.7$. In $1.2 \% \mathrm{NaCl}$, there was no initial increase in viscosity with time; however, the viscosity of the solution decreased over the entire time interval. During 5 months of periodic 
measurements, the viscosities decreased at low shear rates with a less severe decrease at high shear rates. An example for $0.4 \% \mathrm{NaCl}$ is shown is Fig. 3. This loss of viscosity in surfactant-polymer solutions occurred at both $\mathrm{pH}$ levels. Another result was that there was consistently more scatter in the viscosity measurements conducted with mixtures that contain both surfactant and polymer. This was consistent with visual observations that the mixtures were not homogeneous.

More homogeneous surfactant-polymer mixtures were obtained when oil was present in the system. There was also less scatter in the viscosity measurements. These mixtures contained polymer, surfactant, and $0.1 \%$ Hepler (Kansas) oil. Figure 4 shows the viscosity changes that occurred over a period of $1 \frac{1}{2}$ months. Viscosity appeared to be about level for this period of time, and there was very little scatter in the data. Therefore it appears that contact with crude oil in an oil reservoir may have a favorable effect on the rheological properties of surfactant-polymer mixtures.

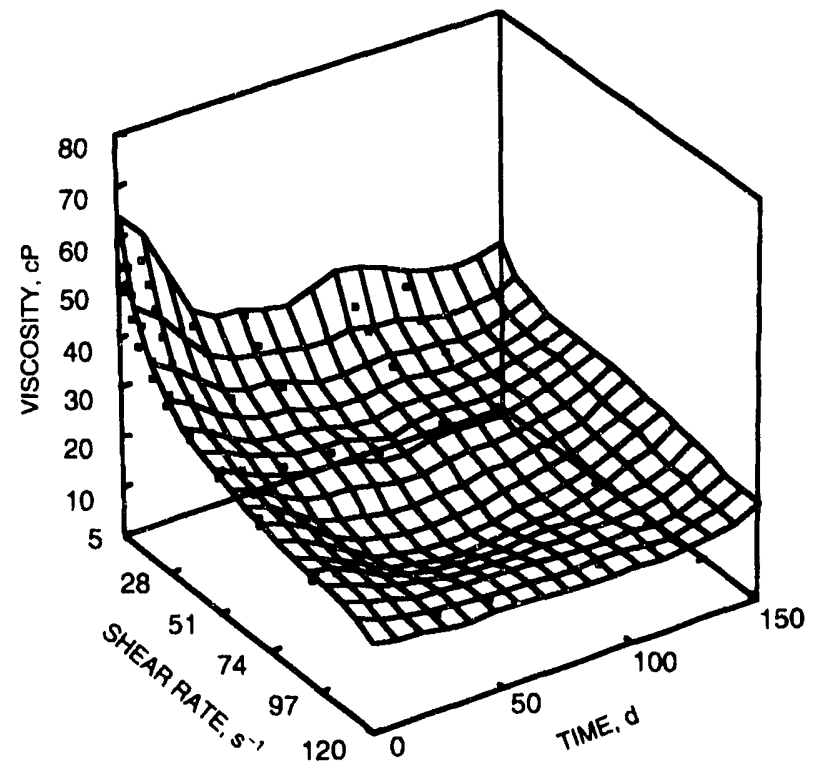

Fig. 3 Viscosity of 0.5\% XP-100 surfactant and 2000-ppm Alcoflood 1135 polymer in $0.4 \% \mathrm{NaCl}, \mathrm{pH} 10.7$.

\section{Observations and Conclusions}

1. In surfactant-enhanced alkaline flooding, polymersurfactant interaction has a detrimental effect on the rheological properties of the polymer.

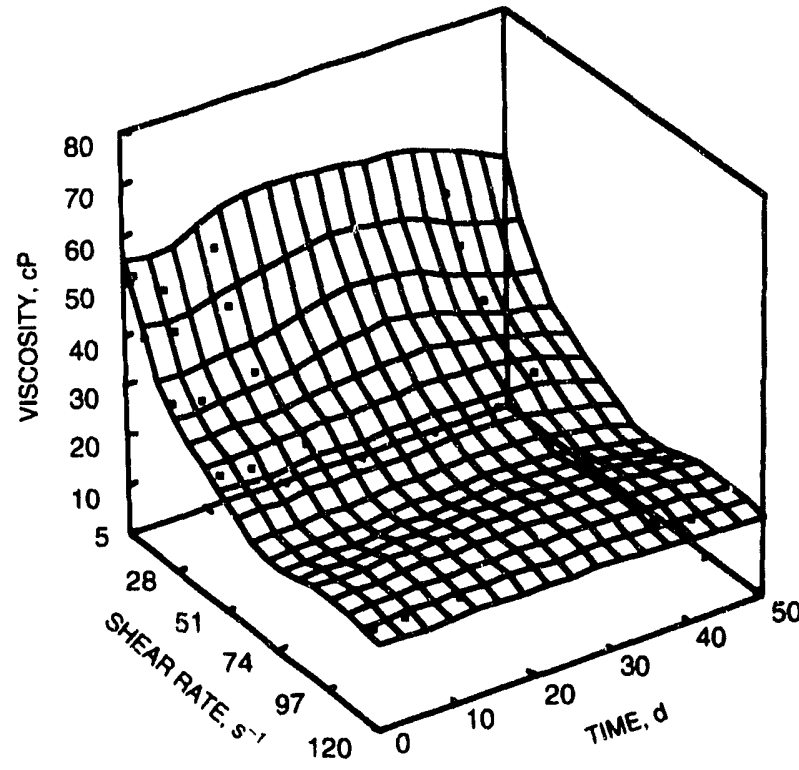

Fig. 4 Viscosity of 0.5\% XP-100 surfactant, 2000-ppm Alcoflood 1135 polymer, and $0.1 \%$ Hepler (Kansas) crude oil in $0.4 \% \mathrm{NaCl}$, pH 10.7 .

2. Adverse interactions between polymers and surfactants are difficult to eliminate. One way to minimize the interaction is to inject surfactant and polymer separately instead of in a single slug.

3. Polymer-surfactant interaction is expected to have the most detrimental effect on oil recovery when the permeability is low; however, this effect may be reduced in the presence of crude oil.

\section{References}

1. Scott P. Trushenski, Micellar Flooding: Sulfonate-Polymer Interaction, in Improved Oil Recovery by Surfactant and Polymer Flooding, D. O. Shah and R. S. Schecter (Eds.), pp. 555-575, Academic Press, New York, 1977.

2. Bayram Kalpakci, Flow' Properties of Surfactant Solutions in Porous Media and Polymer-Surfactant Interactions, a thesis in Chemical Engineering. Pennsylvania State University, November 1981.

3. National Institute for Petroleum and Energy Research, Quarterly Technical Report for October 1, 199/-December 31. 1992. Volume II, Energy Production Research, DOE Report NIPER-588, pp. 4-6, March 1992.

4. T. R. French and T. E. Burchfield, Design and Optimization of Alkalime Flooding Formulation.s, SPE/DOE paper 20238 presented at the Seventh Joint SPE/DOE Symposium on Enhanced Oil Recovery, Tulsa, Okla., April 1990. 


\section{MOBILITY CONTROL AND SWEEP IMPROVEMENT IN CHEMICAL FLOODING}

\section{Cooperative Agreement DE-FC22-83FE60149, Project BE4C}

\author{
National Institute for Petroleum \\ and Energy Research \\ Bartlesville, Okla. \\ Contract Date: Oct. 1, 1983 \\ Anticipated Completion: Sept. 30, 1992 \\ Funding for FY 1992: $\$ 200,000$ \\ Principal Investigators: \\ Troy R. French \\ Hong W. Gao \\ Project Manager: \\ Jerry Castoel \\ Bartlesville Project Office
}

Reporting Period: Apr. 1-June 30, 1992

\section{Objectives}

The objectives of this project are to develop improved methods for maintaining effective mobility control throughout the reservoir in chemical flooding and to use the permeability modification simulator to design cost-effective gel treatments using polymer gels.

\section{Summary of Technical Progress}

For the investigation of the effect of lamination angle on polymer retention, corefloods were conducted with two fired, rectangular Berea sandstone cores. The laminations of the first one were parallel to the longest axis of the core. The laminations of the second one were at $30^{\circ}$ from the longest axis of the core. Two slugs of a $1000-\mathrm{ppm}$ biopolymer solution in $53 \mathrm{meq} / \mathrm{L} \mathrm{NaCl}$ were injected into each core. Polymer retention in the second core was greater than that in the first core, which indicates that polymer retention increased with an increase in the lamination angle. The total amount of biopolymer retained in the second core was $324 \mathrm{~kg} / \mathrm{acre}-\mathrm{m}$, or $217.4 \mathrm{lb} / \mathrm{acre}-\mathrm{ft}$.

\section{Application to Enhanced Oil Recovery}

Understanding the effect of lamination angle on polymer retention will help to maintain effective mobility control throughout a reservoir in chemical flooding. Mechanical degradation of high-molecular-weight polyacrylamides is a problem in field applications. A mobility control system based on cross-linking a low-molecular-weight polyacrylamide may be much less susceptible to mechanical degradation. A permeability modification simulator is very use- ful to facilitate the design of cost-effective gel treatments and assess potential fields for permeability modification treatments with gelled polymers.

\section{Polymer Retention in Berea Cores}

For an examination of how lamination angle affects the polymer retention in cores, corefloods were conducted with two fired rectangular Berea sandstone cores. One core $(4.12 \times 4.01 \times 23.3 \mathrm{~cm}$; porosity, $19.75 \%$; air permeability, $250 \mathrm{mD}$; brine permeability, $220 \mathrm{mD}$ ) was cut along the longest axis of the core, and the other core $(3.81 \times 3.81 \times$ $24.13 \mathrm{~cm}$; porosity, $19.27 \%$; air permeability, $264 \mathrm{mD}$; brine permeability, $267 \mathrm{mD}$ ) was cut at $30^{\circ}$ from the longest axis of the core. Before the injection of a biopolymer solution into the core, each core was computerized tomography (CT) scanned to determine the exact locations and directions of the laminations and to identify areas of porosity contrast. After brine permeability was measured, tracer tests with $10 \%$ sodium iodide were conducted to determine the flow path of brine before polymer injection. The behavior of the tagged (sodium iodide) brine was monitored throughout its advance through the core by using conventional CT procedures and the rapid topogram scanning approach. The resulting data are being compared with those after the polymer flow.

For the rectangular core (core A) that was cut along the longest axis of the core, tracer tests were conducted before and after the injection of the first polymer slug and after the injection of the second polymer slug. For the other core (core B), tracer tests were conducted before the injection of the first polymer slug and after the injection of a second polymer slug.

The polymer solution used in the coreflood experiments was 1000 -ppm biopolymer in $53 \mathrm{meq} / \mathrm{L} \mathrm{NaCl}$, which was prepared from Pfizer's FLOCON 4800C. Brine concentration was $53 \mathrm{meq} / \mathrm{L} \mathrm{NaCl}$. Both biopolymer solution and brine contained $500 \mathrm{ppm}$ of $37.3 \%$ formaldehyde as a biocide. The effluents were collected with a fraction collector and analyzed for the amount of biopolymer produced. The effluent biopolymer concentration was determined by viscosity measurements at a shear rate of $20.4 \mathrm{~s}^{-1}$ using a Contraves Low Shear 30 viscometer. All corefloods were conducted at room temperature $\left(22.4^{\circ} \mathrm{C}\right)$.

In the previous quarter the first slug of a biopolymer solution was injected into core A followed by 5 PV of brine. ${ }^{\prime}$ To check whether the polymer-retention process was completed, a second slug of $3.17 \mathrm{PV}(241 \mathrm{~mL})$ of the same biopolymer solution was injected into core $\mathrm{A}$ followed by $5 \mathrm{PV}$ of chasing brine. The flow rate used was $5.25 \mathrm{~mL} / \mathrm{h}$ (apparent shear rate, $10 \mathrm{~s}^{-1}$ ). Figure 1 shows the normalized effluent concentration profiles for biopolymer from these two injections. As shown in the figure, the effluent concentration profile from the second injection led that from the first injection at the front. which indicates very little additional polymer was retained from the second injection. 


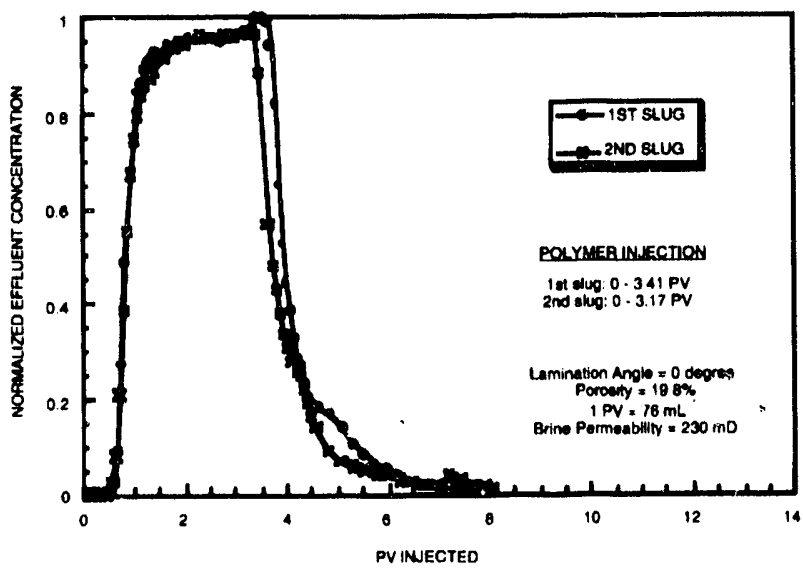

Fig. 1 Normalized effluent concentration profiles for biopolymer from core A.

Between about 1.1 and 2 PV, however, the effluent concentrations from the second slug were lower than those from the first slug, which indicates that more biopolymer was retained from the second slug than from the first slug. Calculated amounts of biopolymer retention in core $\mathrm{A}$ from these two slugs were $107.5 \mathrm{~kg} / \mathrm{acre}-\mathrm{m}$ (or $72.1 \mathrm{lb} / \mathrm{acre}-\mathrm{ft}$ ) and $219 \mathrm{~kg} / \mathrm{acre}-\mathrm{m}$ (or $147 \mathrm{lb} / \mathrm{acre}-\mathrm{ft}$ ), respectively. The retention of more biopolymer from the second slug than from the first slug could be caused by the high flow rate (frontal advance rate was $9 \mathrm{ft} / \mathrm{d}$ ) used during a tracer test before the second injection. During the tracer test some of the biopolymer that was retained from the first slug could be flushed out of the core by the high flow rate. Tracer tests between the two injections were eliminated in subsequent corefloods to avoid this problem.

For core B, tracer tests were conducted at a low flow rate $(1.39 \mathrm{ft} / \mathrm{d})$ and a high flow rate $(9 \mathrm{ft} / \mathrm{d})$. The low flow rate was about the same as that used during polymer injection. At the end of two polymer injections, tracer tests were conducted at a low flow rate and then at a high flow rate. The injection sequence during corefloods was $3.66 \mathrm{PV}$ $(247 \mathrm{~mL})$ of biopolymer solution, $10 \mathrm{PV}(675 \mathrm{~mL})$ of brine, $5.19 \mathrm{PV}(350 \mathrm{~mL})$ of biopolymer solution, and 8.9 PV $(600 \mathrm{~mL}$ ) of brine. The flow rate used was $5 \mathrm{~mL} / \mathrm{h}$ (apparent shear rate, $10 \mathrm{~s}^{-1}$ ). Figure 2 shows the normalized effluent concentration profiles for biopolymer from these two polymer injections. As shown in the figure, the second slug of biopolymer solution broke through earlier than the first slug, which indicates that less biopolymer was retained from the second slug than from the first slug. Calculated amounts of biopolymer retention from these two slugs were $212.7 \mathrm{~kg} /$ acre-m (or $142.6 \mathrm{lb} / \mathrm{acre}-\mathrm{ft}$ ) and $155.5 \mathrm{~kg} / \mathrm{acre}-\mathrm{m}$ (or $104.3 \mathrm{lb} /$ acre-ft), respectively. Comparison of the polymer retention from the first slug in core A with that in core B revealed that polymer retention, on the basis of data available. increased with an increase in the lamination angle.

A revised version of a manuscript, entitled Studies of the Effects of Crossflow and Initiation Time of a Polymer Gel

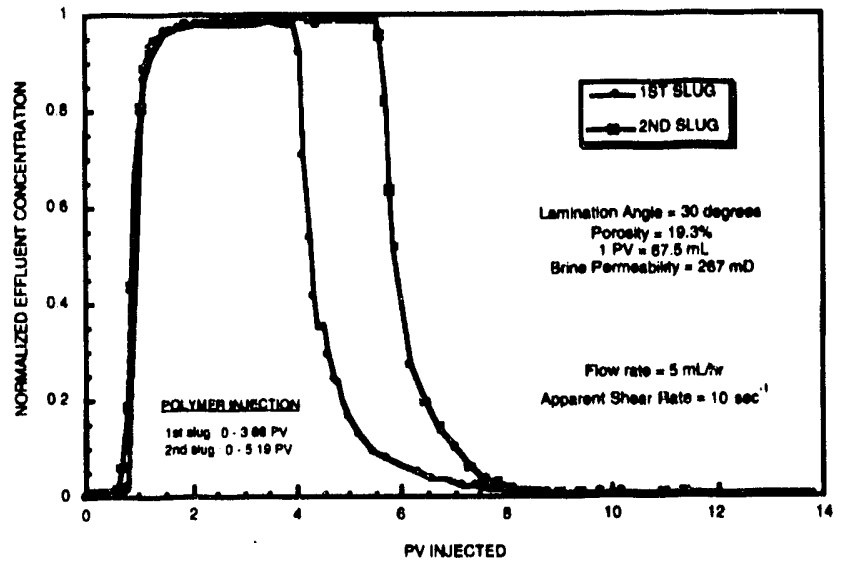

Fig. 2 Normalized emuent concentration profiles for biopolymer from core B.

Treatment on Oil Recovery in a Waterflood Using a Permeability Modification Simulator, was submitted to the Society of Petroleum Engineers Editorial Review Committee for publication in SPE Reservoir Engineering as SPE paper No. 20216.

\section{Reference}

1. National Institute for Petroleum and Energy Research, Quarterly Technical Report for Jan. I-Mar. 31. 1992, Volume 11, Energy Production Research, DOE Report NIPER-595, May 1992.

SURFACTANT-ENHANCED ALKALINE FLOODING FIELD PROJECT

Cooperative Agreement DE-FC22-83FE60149, Project SGP41

National Institute for Petroleum

and Energy Research

Bartlesville, Okla.

Contract Date: July 18, 1990

Anticipated Completion: Sept. 30, 1993

Principal Investigator:

Troy R. French

Project Manager:

Thomas Reid

Bartlesville Project Otfice

Reporting Period: Apr. 1-June 30, 1992 


\section{Objectives}

The objectives of this pilot project are to (1) obtain information and data that will help demonstrate the applicability of surfactant-enhanced alkaline flooding as a costeffective enhanced oil recovery (EOR) method, (2) transfer the surfactant-enhanced alkaline flooding technology that has been developed under the sponsorship of the Department of Energy (DOE) to the petroleum industry, and (3) obtain information regarding proced ures for designing and applying this technology that will assist independerit producers in sustaining production from mature producing oil fields rather than abandoning marginal wells.

\section{Summary of Technical Progress}

\section{Application to Enhanced Oil Recovery}

Commercial and technological benefits will be achieved for all participants if this project is successful. The project will help move surfactant-enhanced alkaline flooding toward commercial reality in a Class I, fluvial-dominated deltaic reservoir. However, the low permeability and heterogeneity of Class I reservoirs reduce the likelihood of mobilizing large amounts of tertiary oil in this field project. If successful, the project will increase oil production in the Midcontinent region of the United States and reduce the rate of resource abandonment.

\section{Discussion}

Hepler (Kansas) oil field was selected for the field test. The Tucker sand of Hepler field is a Class I, fluvialdominated deltaic reservoir. This reservoir is compartmentalized and is typical of many oil reservoirs in this area of the Midcontinent.

In April, during the Tulsa Society of Petroleum Engineers conference, a scheduled meeting with the field operator was held. The plan for two new injection wells was confirmed. It was agreed that one of the two well sites will be drilled and cored after completion of the environmental assessment for the area; however, a categorical exclusion (CX) has since been approved, and drilling can be commenced before completion of the assessment. The core will be analyzed and evaluated at the National Institute for Petroleum and Energy Research (NIPER) and at Russell Petroleum Company's laboratory in Chanute, Kans.

The field operator conducted a tracer test in the pilot area. The tracer test was conducted and totally funded by the field operator, and no DOE funds were used. A concentrated slug of tracer was injected in well J-2, which is an injection well. Samples were periodically taken from the adjacent and guard wells before and after tracer injection. Apparently there was not significant channeling between the injection and production wells. The samples were analyzed at the University of Kansas.

Environmental assessment began the first of May. Baseline water and soil samples were taken from several locations on the site. Numerous photographs were taken on site. These will he kept on file for future reference. Letters that describe the type of project and project location were sent to appropriate governmental and regulatory agencies. The environmental assessment and the National Environmental Protection Agency compliance activities continued through June.

During June the field work and sampling of soil and surface water for the Hepler field pilot EOR demonstration project were completed. A survey was conducted for endangered flowering plant species, Mead's milkweed (Asclepias meadii Torr.) and the Western prairie fringed orchid (Platanthea praeclara Shevik \& Bowles). The survey was conducted by Kansas Natural Heritage Inventory, Kansas Biological Survey, The University of Kansas, Lawrence, Kans.: Russell Petroleum Co., Chanute, Kans.; and Illinois Institute of Technology Research Institute (IITRI)/NIPER, Bartlesville, Okla. A CX was approved by the DOE Pittsburgh Energy Technology Center (PETC) and returned to IITRI/NIPER. The CX is for the drilling of evaluation wells in the producing pattern in Hepler field, under the class of actions at B3.7, "Siting construction, and operation of new infill exploratory and experimental (test) oil, gas and georhermal wells, which are to be drilled in a geological formation that has existing operating wells." The CX is part of new DOE regulations approved in late May 1992 (Ref. 1).

Analyses of surface-water samples and soil samples taken in Hepler field to establish a baseline before implementing the field pilot project were received from Williams Brothers Laboratories, Tulsa, Okla. Confirmation letters concerning the environmental impact of the Hepler field pilot EOR project were received from the following agencies: Kansas State Historical Society, Kansas Wildlife \& Parks Operations Office, Pittsburgh (Crawford County, Kans.) Chamber of Commerce, State of Kansas Department of Health and Environment, Department of The Army, Kansas City District, Corps of Engineers, Kansas Biological Survey, the Kansas Geological Survey (concerning groundwater), and the Kansas Corporation Commission (concerning groundwater protection by surface casing). Writing of the Environmental Assessment (EA) report will begin during July 1992. This EA will request a finding of no significant impact from the DOE PETC for the Hepler field pilot EOR project.

\section{Summary}

Most of this reporting period was consumed by activities related to environmental assessment of the pilot area. A CX was approved by PETC and returned to IITRI/NIPER. The $\mathrm{CX}$ is for the drilling of evaluation wells in the producing pattern in Hepler field; this will allow drilling to commence on the two additional injection wells required for the pilot project.

\section{Reference}

1. U.S. Department of Energy, Section D, DOE NEPA Implementing Procedures, Vol. 57, pp. I51-155. May 1992. 


\section{GAS DISPLACEMENT- SUPPORTING RESEARCH}

\section{CYCLIC $\mathrm{CO}_{2}$ INJECTION FOR LIGHT OIL RECOVERY: PERFORMANCE OF A COST-SHARED FIELD TEST IN LOUISIANA}

Contract No. DE-FG22-89BC14204

Louisiana State University

Baton Rouge, La.

Contract Date: Nov. 21, 1988

Anticipated Completion: Nov. 30, 1992

Government Award: $\$ 499,000$

Principal Investigator:

Zaki A. Bassiouni

Project Manager:

Gene Pauling

Metairie Site Office

Reporting Period: Apr. 1-June 30, 1992

\section{Objectives}

The ultimate objective of this research is to provide a base of knowledge on the $\mathrm{CO}_{2}$ huff ' $n$ ' puff process for the enhanced recovery of Louisiana crude oil. Project goals include laboratory corefloods to investigate several parameters important to the process and numerical simulation to interpret coreflood results. Additional activities include construction and analysis of a field test database to facilitate target reservoir screening and to identify sensitive operational parameters. The information from laboratory corefloods and database evaluations will be used in the design and implementation of a Department of Energy (DOE)sponsored field test. The results of all laboratory and field evaluations will be made available to the industry through workshops, periodic reports, and meetings.

\section{Summary of Technical Progress}

\section{Performance of Field Test}

$\mathrm{CO}_{2}$ was injected into the Frank J. Bollich et al., No. 5 , located in Acadia Parish, La., on July 1, 1991. After injection, the well was shut in for a soak period, and production was resumed on July 29,1991 . The well produced only gas for $3 \mathrm{~d}$, then production ceased and the well was placed on a pump. Fluid production was substantially impaired in comparison with pretest production. The well produced $15 \mathrm{bbl}$ of fluid per day (10 STB oil and $5 \mathrm{bbl}$ water) after $\mathrm{CO}_{2}$ injection, as compared with $177 \mathrm{bbl}$ of fluid per day (17 STB oil and $160 \mathrm{bbl}$ water) before injection of $\mathrm{CO}_{2}$.

The fluid produced at the surface appeared to be a foam/emulsion of $\mathrm{CO}_{2}$, oil, and water that readily broke at surface conditions. Production impairment was attributed 
to poor mobility of the viscous emulsion within the formation.

Samples of produced fluids were submitted to Petrolite Corporation for evaluation. Petrolite Corporation suggested that the well be treated with a mixture of deemulsifier and asphaltene/paraffin remover to restore lost production.

Before implementing the treatment suggested by Petrolite Corporation, it was decided to determine if fluid flow could be improved by lowering the pump. When the well was originally placed on a pump, the pump was set at approximately $3000 \mathrm{ft}$. It was decided to lower the pump to $4000 \mathrm{ft}$. The initial results were encouraging when the pump was lowered, but fluid production rapidly decreased.

When the pump was pulled in preparation for lowering it to $4000 \mathrm{ft}$, a scale that appeared to be calcium carbonate was noted on the pump. Later, when the tubing was pulled before implementation of the treatment recommended by Petrolite Corporation, a large quantity of scale was found in the lower $20 \mathrm{ft}$ of the mud anchor and in the perforated sub. It was therefore decided to treat the well with $15 \% \mathrm{HCl}$ to dissolve the scale after injecting the treatment mix recommended by Petrolite. Plans are to implement this treatment scheme in early July 1992.

\section{GAS FLOOD PERFORMANCE PREDICTION IMPROVEMENT}

\section{Cooperative Agreement DE-FC22-83FE60149, Project BE5A}

\author{
National Institute for Petroleum \\ and Energy Research \\ Bartlesville, Okla.
}

Contract Date: Oct. 1, 1983

Anticipated Completion: Sept. 30, 1992

Funding for FY 1992: $\$ \mathbf{2 5 0 , 0 0 0}$

\section{Principal Investigator: Ting-Horng Chung}

\section{Project Manager: Jerry Casteel \\ Bartlesville Project Office}

Reporting Perlod: Apr. 1-June 30, 1992

\section{Objectives}

The objectives of this project are to (1) develop improved prediction techniques for asphaltene deposition during gas flooding and (2) conduct a feasibility study for the application of gas displacement in Naval Petroleum Reserve oil reservoirs.

\section{Summary of Technical Progress}

\section{Asphaltene Solubility Determinations}

An asphaltene sample from the bottom of a producing well was used in this experiment. The solid sample was redissolved in toluene and filtered through a $0.45-\mu \mathrm{m}$ Millipore HAWP cellulose acetate filter to separate all undissolved solid particles before $n$-pentane $\left(n \mathrm{C}_{5}\right)$ tit:ation because the raw sample contained other impurities and solid particles. The precipitate obtained from pentane titration was filtered and dried at $50{ }^{\circ} \mathrm{C}$. The molecular weight distribution of the ${ } \mathrm{C}_{5}$-asphaltene was determined by gelpermeation chromatography (GPC) using Waters Ultrastyragel packing columns (linear and $500 \AA$ in series) to allow separation on the basis of molecular size. The solvent used was tetrahydrofuran, and the flow rate was $1 \mathrm{~mL} / \mathrm{min}$. Polystyrenes and high molecular weight normal alkanes were used as standards to correlate the elution volume with molecular weight. The molecular weight distribution of the asphaltene sample is shown in Fig. 1. The weightaverage molecular weight of the asphaltene sample was 6.378. More detailed discussion about the GPC technique for the determination of molecular weight distribution is given in references $I$ and 2 . The purified asphaltene sample was used in the following experiments to determine solubility.

The solubilities of asphaltenes in $n \mathrm{C}_{5}$ and toluene mixtures were determined by first dissolving an accurately weighed asphaltene sample in a certain amount of toluene and then adding ${ } \mathrm{C}_{5}$. The solution was then filtered through the $0.45-\mu \mathrm{m}$ cellulose acetate filter, and the cake was dried and weighed. The difference in weight between the original sample and the cake was the part dissolved in the solution. The same procedure was applied with $n$-heptane $\left(n \mathrm{C}_{7}\right)$ and $n$-decane $\left(n \mathrm{C}_{10}\right)$ and with crude oil as solvents. The measured solubility data are given in Table 1 and Figs. 2 and 3. As shown, the solubilities of asphaltene in the n-alkanetoluene mixtures decrease exponentially with increase in n-alkane concentration. Because the solubilities are very small, experimental errors are relatively high. Therefore, for consistent data, experiments were carefully conducted and repeated. The data obtained were used to test the model developed in this project.

\section{Prediction Technique Development for the Description of Asphaltene Deposition}

A prediction model for asphaltene precipitation was developed. The solubility of asphaltene in organic solutions is written as"

$$
\begin{aligned}
& x_{i}^{L}=\exp \left[-\frac{\Delta h_{i 1}^{\prime}}{R T}\left(1-T / T_{i 1}^{l}\right)-\frac{v_{i}^{1}}{R T}\left(\delta_{m}^{l}-\delta_{i 1}^{l}\right)^{2}\right. \\
& \left.-\ln \frac{v_{i}^{l}}{v_{m}}-1+\frac{v_{i}^{l}}{v_{m}}\right]
\end{aligned}
$$




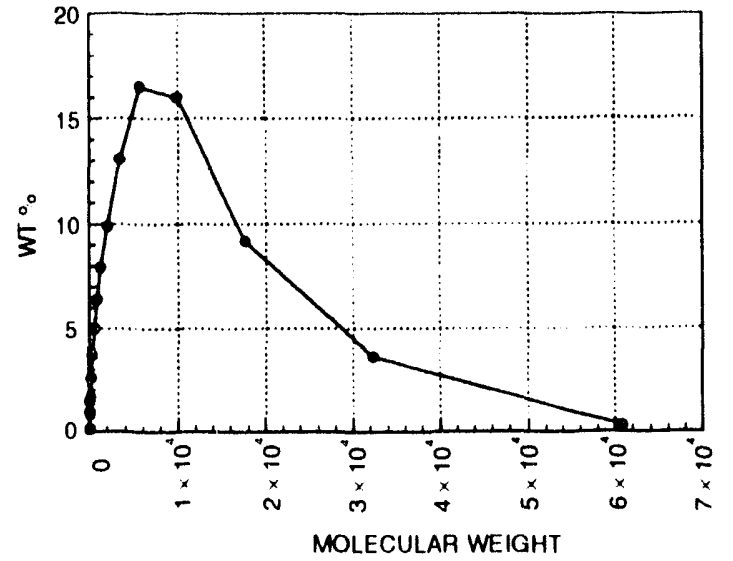

Fig. 1 Molecular weight distribution of asphaltene sample.

\section{TABLE 1}

Asphaltene Solubility in Toluene-Alkane Mixtures

\begin{tabular}{|c|c|c|}
\hline $\begin{array}{c}\text { Asphaltene, } \\
\text { mol \% }\end{array}$ & $\begin{array}{l}\text { Toluene. } \\
\text { mol \% }\end{array}$ & $\begin{array}{c}\text { n-Alkanes. } \\
\text { mol \% }\end{array}$ \\
\hline \multicolumn{3}{|c|}{ n-Pentane } \\
\hline $0.028 \times 2$ & 67.23252 & 32.73866 \\
\hline (1.0)25.56 & 6.3 .01081 & 36.96 .383 \\
\hline 0.01042 & 50.77881 & 49.21077 \\
\hline $0.0(x)(0) 1$ & 46.99 .56 .5 & 52.995 .34 \\
\hline $0 .(x) 610$ & 44.92489 & $55 .(6)(0) 1$ \\
\hline $0 .(x) 401$ & 39.88661 & $6(1) .109 .38$ \\
\hline $0 .(x)(x) 74$ & 22.1628 .3 & 77.9364 .3 \\
\hline $0 .(x x) \geq 6$ & 18.24755 & 81.75219 \\
\hline \multicolumn{3}{|c|}{$n \cdot$ Heptane } \\
\hline 0.12052 & 62.25726 & 37.72222 \\
\hline $0.016+10$ & 59.90469 & 40.07891 \\
\hline $0.01+13$ & 56.32614 & 43.6 .5973 \\
\hline $0.01 \mid 2(x)$ & 53.74757 & 46.2398 .3 \\
\hline $0.1 \times) 687$ & 46.58166 & 53.41147 \\
\hline 0.10$) 6+49$ & 39.92524 & $60.06 \times 27$ \\
\hline $0 .(x) 275$ & 32.72183 & 67.27542 \\
\hline $0 .(K) \mid 50$ & $25.926+2$ & 74.07208 \\
\hline (). (KK)K & 19.167074 & 80.93224 \\
\hline \multicolumn{3}{|c|}{ n-Decane } \\
\hline 0.015 .39 & $62.0 \times(x) 99$ & 37.98 .362 \\
\hline $0.1 \times 07.36$ & $.50 .8+368$ & 49.14896 \\
\hline $0 .(x) \mid 8.3$ & 22.27111 & 77.72716 \\
\hline $0 .(x) 1.38$ & 14.351 .34 & $x 5.6+72 x$ \\
\hline
\end{tabular}

The solubility data of the asphaltene in $n \mathrm{C}_{5}$-toluene mixtures were matched with the developed model (Eq. 1). by tuning the parameters of $T_{a}^{1}, \Delta h_{d}^{1}, V_{a d}^{1}$, and $\delta_{d}^{l}$. Figure 2 shows the best fit of the model for this system. For the application of the model to this system. asphaltene was treated as a one-component solute with molecular weight of 6.378. whereas toluene and n-pentane were considered as solvents. The model of Eq. 1 reasonably fits the data. 'When the mole fraction of toluene is less than 0.5 , the accuracy of data decreases because of the small value of the solubilities. The parameters for asphaltene determined from the data fitting (Table 2) were used to predict the solubilities of the asphaltene in other systems. Figure 3 shows the predicted results for the asphaltene solubilities in $n \mathrm{C}_{7}$-toluene mixtures and $n \mathrm{C}_{111}$-toluene mixtures. The predictions agree well with experimental data.

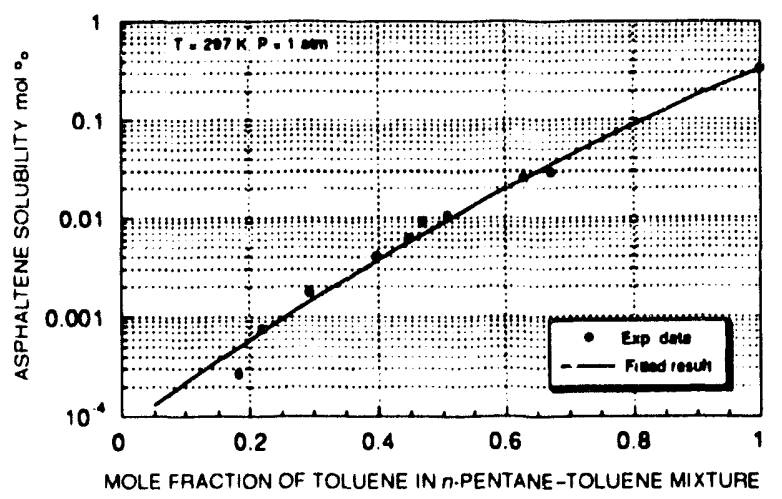

Fig. 2 Asphaltene solubility in n-pentane-toluene mixtures.

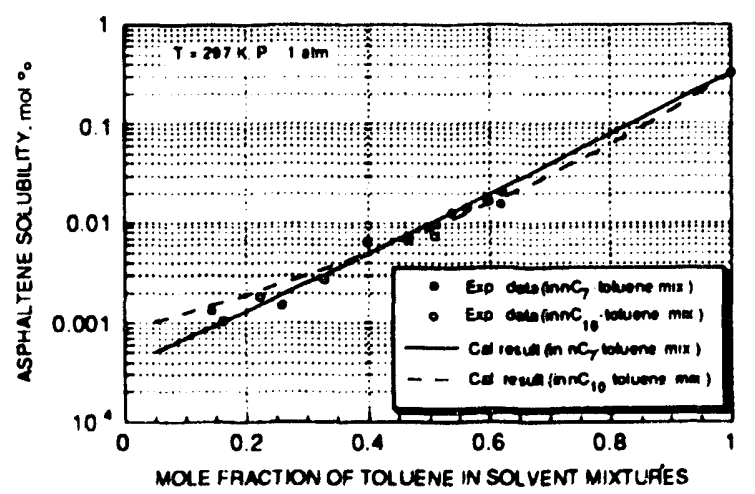

Fig. 3 Asphaltene solubility in $n$-heptane-toluene, $n$-decanetoluene mixtures.

TABLE 2

Characterization Parameters for Asphaltene and Organic Solvents

\begin{tabular}{|c|c|c|c|c|c|}
\hline Parameters & Asphaltene* & Toluene & $\boldsymbol{m C}_{3}$ & $\boldsymbol{n} \mathbf{C}_{\mathbf{7}}$ & $m C_{10}$ \\
\hline Wh. cal/mol & 9635 & & & & \\
\hline T. K & 452 & & & & \\
\hline V. $\mathrm{cm}^{3} / \mathrm{mol}$ & 498 & 107.0 & 116.0 & 147.0 & 196.0 \\
\hline$\delta\left(\mathrm{cal} / \mathrm{cm}^{3}\right)^{\prime}=$ & 10.54 & 8.90 & 7.05 & 7.45 & 7.73 \\
\hline Molecular weight & 6378 & 92.1 & 72.1 & 100.2 & 142.3 \\
\hline
\end{tabular}

From data regression. 
In the preceding cases, the solvents are well-defined hinary systems. Properties of these solvents are available in the literature. For crude oil, because its composition is complicated, such techniques as the continuous thermodynamic approach ${ }^{4-6}$ must be used to characterize the crude oil. In this work an example of applying a continuous distribution method to characterize a crude oil and predict the asphaltene solubility in the crude is presented. The asphaltene sample was the same as that used in the preceding binary systems. and the experimental procedure was also the same. The composition of the oil (stock-tank oil) is plotted vs. molecular weight in Fig. 4. An exponential distribution function was used to represent the molar distribution for $\mathrm{C}_{8+}$. The oil composition is then expressed by a semicontinuous mode as

$$
x_{1}+x_{2}+\int_{l_{11}}^{\infty} F(I) d l=1
$$

and

$$
F(I)=7.596 \times 10^{-3} \exp \left[-8.485 \times 10^{-3}(I-114.23)\right]
$$

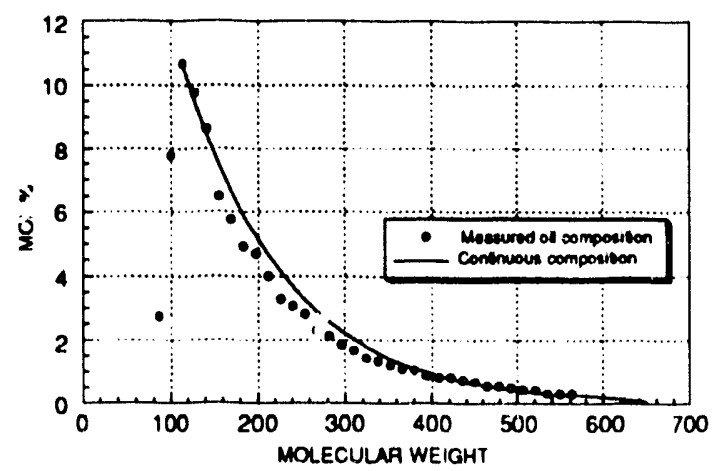

where I, the molecular weight of the component, is the variable in the distribution function and $x_{1}$ and $x_{2}$ are the mole fractions of $C_{6}$ and $C_{7}$, respectively. With the application of the Laguerre-Gauss (L-G) quadrature approximation, ${ }^{7}$ the integration part can be represented by two pseudocomponents, $x_{3}$ and $x_{4}$. Therefore the oil can be considered as a four-component mixture. The values of $x_{3}$ and $x_{4}$ were obtained from the weighting factors of the twopoint L-G quadrature formula, and the corresponding molecular weights of the two pseudocomponents were from the zeros of the L-G formula. The obtained compositions and their molecular weights for the four components of the oil are

$$
\begin{aligned}
& x_{1}=0.0272 \\
& M W_{1}=86.18 \\
& x_{2}=0.0776 \\
& \mathrm{MW}_{2}=100.21 \\
& x_{3}=0.7641 \\
& \mathrm{MW}_{3}=183.27 \\
& x_{4}=0.1311 \\
& \mathrm{MW}_{4}=516.61
\end{aligned}
$$

The molecular weight of the sample oil is about 218 . The measured asphaltene solubility in the oil is $1.117 \times$ $10^{-4}$ mol \%. Predictions were performed in two cases: one with the assumption that the oil is represented with a fourcomponent system and the other treating the oil as one component with molecular weight of 218 . Predicted asphaltene solubility is $1.031 \times 10^{-4} \mathrm{~mol} \%$ with the fourcomponent assumption and $0.905 \times 10^{+4} \mathrm{~mol} \%$ with the one-component assumption. The four-component approach gives a better prediction of the asphaltene solubility than the one-component approach.

The preceding tests have demonstrated that the model is accurate and self-consistent because all the predictions were performed with the same set of parameters. Because no asphaltene samples are exactly the same, the parameters obtained from one asphaltene sample may not be applicable to others. The following experiments and data regression are needed to apply the developed technique for the prediction of asphaltene precipitation from crude oil:

1. Determine the total asphaltene content of crude oil by $11 \mathrm{C}_{5}$ titration.

2. Perform composition analysis and characterize the asphaltene-free crude oil with pseudoization techniques or continuous thermodynamic approach.

3. Determine the average molecular weight of the asphaltene by GPC or other methods.

4. Conduct experiments to measure the solubilities of the asphaltene in well-defined organic solvents.

5. Determine the model parameters for asphaltene by matching the solubility data with the model.

With all the needed information available from the preceding procedure. the calculation is straightforward and simple. The quantity of asphaltene precipitation is equal to the difference between the total asphaltene content and the amount of asphaltene dissolved in the oil.

\section{Observations and Conclusions}

A generalized predictive model for wax and asphaltene precipitation was developed on the basis of the thermodynamic principle. The model is self-consistent and was tested to be accurate for the predictions of asphaltene solubilities in organic solvents and crude oil.

A method to apply this predictive model for asphaltene precipitation prediction was presented. The prediction technique is simple and applicable for real systems because all required inputs are obtainable through simple experiments.

Further improvement to the prediction technique can be achieved by developing more accurate correlations for $\Delta \mathbf{h}_{\mathrm{i}}^{j}, \mathrm{~T}_{1}^{j}, \mathrm{~V}_{\mathrm{i}}$, and $\delta_{\mathrm{i}}$.

\section{References}

1. P. A. Rengers, A. L. Creagh. M. M. Prange, and J. M. Prausnile. Moleculi. Weight Distributions for Heavy Fossil Fuels from Cel- 
Permeation Chromatography and Characterization Data, Ind. Eng. Chem. Res., 26111): 2312-2318 (1987).

2. S. H. Huang and M. Radosz., Phase Behavior of Reservoir Fluids IV: Molecular Weight Distributions for Thermodynamic Modeling. Fluid Phase Equilibria. 66: 23-40) (1991).

3. T. H. Chung. Thermodynamic Modeling for Organic Solid Precipitaiim. paper SPE-24851 to be presented at SPE Annual Technical Conference and Exhibition. Washington. D.C., Oct. 4-7, 1992.

4. R. L. Cotterman, R. Bender, and J. M. Prausnitz, Phase Equilibria for Mixtures Containing Very Many Components, Development and Application of Continuous Thermodynamics for Chemical Process Design, Ind. Eng. Chem. Process Des. Dev., 24(1): 194-203 (1985).

5. R. L. Cotterman and J. M. Prausnitz, Flash Calculations for Continuous or Semicontinuous Mixtures Using an Equation of State, Ind. Eng. Chem. Processs Des. De'.. 24(2): 434-443 (1985).

6. C. H. Whitson. T.F. Anderson, and I. Soreide, $C_{7+}$ Characterization of Related Equilibrium Fluids Using the Gamma Distribution, in $C_{7+}$ Fraction Characterization, L. G. Chom and G. A. Mansoori (Eds.), pp. 35-56, Taylor \& Francis, New York. 1989.

7. M. Abramowitz and I. A. Stegun, Handbook of Mathematical Functions, Dover Publications, New York, 1972.

\section{MOBILITY CONTROL, PROFILE MODIFICATIONS, AND SWEEP IMPROVEMENT IN GAS FLOODING}

\section{Cooperative Agreement DE-FC22-83FE60149, Project BE5B}

\author{
National Institute for Petroleum \\ and Energy Research \\ Bartlesville, Okla.
}

Contract Date: Oct. 1, 1983

Anticipated Completion: Sept. 30, 1992

Funding for FY 1992: $\$ 370,000$

\section{Principal Investigator: \\ Clarence Raible}

\author{
Project Manager: \\ Jerry Casteel \\ Bartlesville Project Office
}

Reporting Period: Apr. 1-June 30, 1992

\section{Objectives}

The objectives of this project are to (1) develop experimental models to investigate placement of polymer gels for profile modification of $\mathrm{CO}_{2}$ gas floods, (2) conduct laboratory investigations to select the polymer gel systems applicable to $\mathrm{CO}_{2}$ gas flooding conditions, (3) conduct laboratory experiments to selectively place gel polymer systems for profile modification, and (4) use the National Institute for Petroleum and Energy Research's (NIPER's) three-phase flow simulator to investigate the effect of polymer gels on gas-flow profile.

\section{Summary of Technical Progress}

\section{Materials and Test Conditions}

Whittington and $\mathrm{Naae}^{\mathrm{l}}$ reported that a blend of hydroxypropyl cellulose (HPC) and sodium dodecyl sulfate (SDS) formed a gel when mixed with brine. The gel was formed by increasing the salinity of the polymer-surfactant blend. This gel has the advantage of not requiring a crosslinking agent such as a heavy metal. In addition, the gel does not require a specific solution $\mathrm{pH}$ to form a gel. The HPC polymer was obtained from Aqualon Company, which markets the polymer under the trade name Klucel. A highmolecular-weight and viscous grade of the product (Klucel H) was used for this study. The SDS surfactant was a chemically pure grade of SDS (99\%). The brines were made with reagent-grade $\mathrm{NaCl}$. Gel properties of the HPC-SDS gel were reported previously. ${ }^{2}$

\section{Profile Modification with Sandpacks and HPC-SDS Gels}

Profile modification tests with the HPC-SDS gel were made with sandpack floods. For these tests, alternating slugs (0.05 PV) of $1 \%$ polymer-surfactant solution and a $7 \%$ brine were injected into a sandpack. About 0.3 PV of the polymer-surfactant solution was injected. The strategy was to promote intimate mixing of the two solutions to form a gel. Injection rates were maintained at a constant flow rate of 1 to $2.3 \mathrm{ft} / \mathrm{d}$, and the differential pressure across the sandpack was monitored as a measure of changes in the sandpack permeability. Although the resistance factor after gel treatment was typically 200 , the gels were largely located near the inlet section of the sandpack. Because the gel is formed immediately when the HPC-SDS solution is mixed with brine, the gel formed and plugged the sandpack only a short distance from the inlet.

The gel must be placed at some distance away from the wellbore in high-permeability channels for profile modification treatments. Various strategies, including displacement with slugs of fresh water, were used to place the HPC-SDS solution away from the sandpack inlet before brine contact and gel formation. Freshwater displacement effectively reduced the gel resistance factor, however, presumably because of dilution of the HPC-SDS solution. Also, an SDS surfactant solution in fresh water was used as a displacement fluid for the HPC-SDS slug. The SDS surfactant slug was then followed by a high-concentration brine to contact the HPC polymer and form a gel. However, the brine caused precipitation of the surfactant when the brine exceeded $3 \%$ $\mathrm{NaCl}$. This was demonstrated by both sandpack flow and bottle tests. The use of SDS in fresh water as a displacement fluid also caused the HPC polymer to become phase 
unstable. The HPC polymer will precipitate from brine solutions without the SDS surfactant. The effluent from sandpack flow tests initially contained precipitated SDS surfactant followed by precipitated HPC polymer.

\section{Bottle Tests with HPC-SDS Gels}

Bottle tests were made with several ethoxylated cosurfactants to stabilize and overcome the problems associated with SDS surfactant precipitation and to improve HPCSDS gel stability. Also, the presence of divalent cations $\left(\mathrm{Ca}^{2+}\right.$ and $\left.\mathrm{Mg}^{2+}\right)$ will cause precipitation of such anionic surfactants as the SDS surfactant. As discussed previously, the precipitation of the SDS surfactant can cause the HPC polymer to precipitate. Tests were made with an ionic ethoxylated cosurfactant (Neodol 25-3S) to improve salt tolerance of the solutions. For a solution containing $0.5 \%$ SDS and $0.3 \%$ Neodol $25-3 \mathrm{~S}$ as a cosurfactant, the salt tolerance was increased to nearly $9 \% \mathrm{NaCl}$. Small quantities of precipitate were observed with $9 \% \mathrm{NaCl}$ at $24{ }^{\circ} \mathrm{C}$. This was an improvement in SDS salt tolerance from $3 \%$ $\mathrm{NaCl}$ without the cosurfactant.

Additional bottle tests were made to determine the effect of the ethoxylated cosurfactant on HPC-SDS gel properties. For previous gel tests with no cosurfactant, a maximum gel viscosity was obtained with $3.5 \% \mathrm{NaCl}$. No further improvement in gel viscosity was indicated for gels containing higher brine concentrations. Solutions of $0.5 \%$ HPC and $0.5 \%$ SDS were prepared with $0.17 \%$ Neodol $25-3 \mathrm{~S}$ in various brine concentrations. When the cosurfactant (Neodol 25-3S) was added, solutions with lower viscosities were produced. A gel was not formed with $3.5 \% \mathrm{NaCl}$. Only a small increase in solution viscosity was indicated. Solutions containing the cosurfactant and higher concentrations of brine $(5$ to $10 \% \mathrm{NaCl}$ ) formed weak gels, although the viscosity was lower than gels without the cosurfactant.

Another problem was noted with the cosurfactant gel system. Gel samples heated to $50{ }^{\circ} \mathrm{C}$ degraded with time. This was indicated by the formation of a white precipitate. Gel viscosities decreased with time at higher temperatures of $50{ }^{\circ} \mathrm{C}$. The rate of gel degradation increased for gels containing higher brine concentrations.

Another nonionic ethoxylated surfactant (Neodol 91-2.5) was used as a potential cosurfactant candidate for increasing salt tolerance of the gels. This cosurfactant improved salt tolerance of the SDS surfactant solutions, but gels were not formed when combined with the HPC polymer. A small improvement in solution viscosity was shown with brine concentrations up to $5 \% \mathrm{NaCl}$. A fibrous precipitate was formed for solutions containing concentrations greater than $5 \% \mathrm{NaCl}$.

These tests indicated that the addition of an ethoxylated cosurfactant resulted in either gels with lower viscosities or unstable gel mixtures. The use of an ethoxylated cosurfactant does not appear to be a satisfactory method for improving salt tolerance of the HPC-SDS gels.
In summary, the experimental results show that the HPCSDS gel can be formed by the injection of suitable brines and HPC-SDS solutions. Because the gels form immediately when the HPC-SDS solution is mixed, however, gel plugging extends only a short distance from the point of injection. This gel system does not appear to be a practical method for profile modification because of the inability for deep penetration and placement of HPC-SDS solutions in a reservoir.

\section{Bottle Tests with $\mathrm{Cr}(\mathrm{III})$ and Xanthan Gels}

Other gel system. were investigated as potential candidates for profile modification applications. A gel system is required that causes the cross-linking reaction to occur in the reservoir. Ideally, the gel system has a low viscosity during injection, which allows for deep penetration of the solution before forming a gel. Screening tests were made to determine gel properties and the time required to form gels. Gels were made with xanthan polymer and $\mathrm{Cr}(\mathrm{III})$ as a cross-linking agent. The xanthan polymer was supplied by Pfizer as a concentrated broth. Chromic chloride used as the $\mathrm{Cr}(\mathrm{III})$ cross-linker was purchased from Fisher Scientific. Stock solutions of the biopolymer and chromic chloride were prepared in brines with a concentration of $6.6 \%$ $\mathrm{NaCl}, 1.5 \% \mathrm{CaCl}_{2}$, and $0.5 \% \mathrm{MgCl}_{2}$. Each of the stock solutions was $\mathrm{pH}$ adjusted with dilute $\mathrm{HCl}$ and $\mathrm{NaOH}$ before mixing.

The rate of gelation and gel strength was measured by observation of the samples according to the properties described in Table 1. The gel descriptions are similar to those reported by Sydansk. ${ }^{3}$ Although the gel strength descriptions are subjective observations, the bottle tests provided a qualitative method for rapid screening of the gel formulations. The $\mathrm{pH}$ of the solutions was an important variable that controlled both the rate of gelation and precipitation of chromium. Samples adjusted to a $\mathrm{pH}$ of 5.5 resulted in chromium precipitation. These experiments indicated that before gelation this gel system can be applied only when gel solutions do not exceed a pH of about 5.0.

Some of the results of gel bottle tests are shown in Table 2. As shown in the table, faster gelation rates were observed not only for higher concentrations of $\mathrm{Cr}$ (III) but also gelation rates, which increased as the $\mathrm{pH}$ of the gel solutions increased from 4.0 to 5.0. Therefore gelation rates may be controlled by varying the $\mathrm{Cr}$ (III) concentration and $\mathrm{pH}$ of the solutions. Adjustment of the solution $\mathrm{pH}$ could be a useful method for controlling the gelation rate in reservoir applications. For example, gelation could be delayed by injecting a solution with a relatively low $\mathrm{pH}$. Then, as the polymer solutions contact the reservoir rocks, the gel solution by diffusion would react with rock minerals, such as clays and carbonates, to increase the $\mathrm{pH}$ and gelation rate to form solid gels.

Other bottle tests were conducted with the use of chromic acetate as a cross-linking agent. Chromic acetate has 
TABLE 1

Physical Description of Gel Strength for Xanthan Polymer and $\mathrm{Cr}$ (III) Cross-Linker Solutions

\begin{tabular}{cc}
$\begin{array}{c}\text { Gel strength } \\
\text { code }\end{array}$ & Description of gel strength \\
\hline A & $\begin{array}{c}\text { No gel formed. The gel appears same viscosity as the } \\
\text { original polymer solution. } \\
\text { Highly flowing gel. The gel appears to be only slightly } \\
\text { more viscous than the initial polymer solution. } \\
\text { B }\end{array}$ \\
Clowing gel. Detectable gel with the gel rapidly flowing \\
to the bottle cap upon inversion. \\
D & $\begin{array}{c}\text { Moderately flowing gel. Gel does not readily flow to the } \\
\text { bottle cap upon inversion. }\end{array}$ \\
E & $\begin{array}{c}\text { Barely flowing gel. Gel slowly flows to the bottle cap } \\
\text { upon inversion. }\end{array}$ \\
F & $\begin{array}{c}\text { Highly deformable nonflowing gel. Gel readily deforms } \\
\text { but does not flow upon inversion. }\end{array}$ \\
G & $\begin{array}{c}\text { Slightly deformable nonflowing gel. Gel surface slightly } \\
\text { deforms upon inversion. }\end{array}$ \\
H & $\begin{array}{c}\text { Rigid gel. No gel surface deformation upon inversion } \\
\text { with gel syneresis. }\end{array}$ \\
\hline
\end{tabular}

TABLE 2

Reaction Time and Physical Description of Gels With 2000 ppm Xanthan Polymer and Various Cr(III) Cross-Linker Concentrations

\begin{tabular}{|c|c|c|c|c|c|}
\hline \multirow{2}{*}{$\begin{array}{c}\text { Solution, } \\
\text { pH }\end{array}$} & \multirow{2}{*}{$\begin{array}{c}\text { Reaction } \\
\text { time, } h\end{array}$} & \multicolumn{4}{|c|}{$\mathrm{Cr}$ (III) concentration, $\mathrm{ppm}$ * } \\
\hline & & 25 & $\mathbf{5 0}$ & 75 & 100 \\
\hline \multirow[t]{7}{*}{4.0} & 1 & A & A & A & A \\
\hline & 8 & A & A & A & A \\
\hline & 24 & A & A & B & $\mathrm{C}$ \\
\hline & 48 & A & B & B & $\mathrm{C}$ \\
\hline & 96 & $A-B$ & C & $\mathrm{C}$ & $\mathrm{F}$ \\
\hline & 192 & B & $\mathrm{C}$ & $\mathrm{C}$ & $\mathrm{F}$ \\
\hline & 312 & $\mathrm{C}$ & $\mathrm{C}$ & C-D & F-G \\
\hline \multirow[t]{8}{*}{4.5} & 1 & A & A & A & $A \cdot B$ \\
\hline & 2 & A & $A \cdot B$ & $A \cdot B$ & B \\
\hline & 4 & $A-B$ & $\mathrm{C}$ & $\mathrm{D}$ & $\mathrm{E}$ \\
\hline & 8 & B & $\mathrm{E}$ & $\mathrm{F}$ & F-G \\
\hline & 24 & $\mathrm{E}$ & F-G & G & $\mathrm{G}$ \\
\hline & 48 & $\mathrm{~F}$ & $\mathrm{~F}-\mathrm{G}$ & G & G \\
\hline & 96 & $\mathrm{~F}$ & G-H & G-H & G.H \\
\hline & 192 & G & G-H & G-H & $\mathrm{G}-\mathrm{H}$ \\
\hline \multirow[t]{9}{*}{$5 .()$} & 0.5 & A & $A-B$ & $\mathrm{C}$ & $D$ \\
\hline & 1 & B & $B-C$ & $D$ & $E$ \\
\hline & 2 & $\mathrm{C}$ & $\mathrm{E}$ & $\mathrm{F}$ & $\mathrm{F}$ \\
\hline & 4 & $C \cdot D$ & $\mathrm{~F}$ & G & $\mathrm{G}$ \\
\hline & 8 & $(-D)$ & $\mathrm{F}-\mathrm{G}$ & $\mathrm{G}$ & $G$ \\
\hline & 24 & $\mathrm{E}$ & G & G & G \\
\hline & 48 & $\mathrm{H}$ & G & G-H & G.H \\
\hline & 96 & $\mathbf{F}$ & $\mathrm{G}-\mathrm{H}$ & $\mathrm{G}-\mathrm{H}$ & G-H \\
\hline & 192 & G & $\mathrm{H}$ & $\mathrm{H}$ & $H$ \\
\hline
\end{tabular}

* See Table I for description of gel strength codes. been used as a cross-linking agent with acrylamide polymers. ${ }^{2}$ The chromic acetate as a carboxylate complex was readily soluble in brine solutions. No precipitation of chromium was observed in solutions with a $\mathrm{pH}$ up to approximately 6.5. Bottle tests with xanthan polymer and chromic acetate cross-linker are in progress. Preliminary results indicated that gel cross-linking required higher concentrations of chromic acetate than polymer gels made with chromic chloride. Also, longer times were required to form gels with chromic acetate solutions. For field applications, the extended $\mathrm{pH}$ range without chromium precipitation and longer cross-linking time may be an advantage for using chromic acetate as a cross-linker.

\section{References}

1. L. E. Whittington and D. G. Naae, Conformance Control Gels-Formation By Contact with Brine, presented at the 6th European EOR Symposium, Stavenger, Norway, May 21-23, 1991.

2. National Institute for Petroleum and Energy Research, Quarterly Technical Report for Jamuary I-March 31, 199I. Vol. II, Energy Production Research, DOE Report-595, pp. 13-15, July 1992.

3. Robert D. Sydansk, A Newly Developed Chromium(III) Gel Technology, Soc. Pet. Eng. Reserv. Eng., 346-352 (August 1990).

\section{QUANTIFICATION OF MOBILITY CONTROL IN ENHANCED RECOVERY OF LIGHT OIL BY CARBON DIOXIDE}

\author{
Morgantown Energy Technology Center \\ Morgantown, W. Va.
}

FY92 Total Project Cost: $\$ 300,000$

Principal Investigator:

Duane H. Smith

Project Manager:

Royal Watts

Morgantown Energy Technology Center

Reporting Period: Apr. 1-June 30, 1992

\section{Objectives}

The objectives of this work are to develop the in-depth knowledge needed to improve miscible and near-miscible $\mathrm{CO}_{2}$ flooding and related processes and to assist industry and others in the commercialization of new technologies based on this new knowledge. Primary emphasis is on (1) scaling thermodynamics, (2) models of fluid flow and miscible fingering that also conform to current scaling 
theory, and (3) experiments and modeling for the development of surfactant-based mobility control on the basis of either leave-behind lamellae or fluid dispersions (two- and three-phase emulsions and foanıs).

\section{Summary of Technical Progress}

\section{Morphologies of Emulsions of Three Liquid Phases}

Emulsions are commonly thought of as being composed of just two liquids, oil and water, and of having just two possible morphologies, oil-in-water $(\mathrm{O} / \mathrm{W})$ and water-in-oil (W/O). However, it is now well-established that many combinations of an amphiphile, an oil, and water can simultaneously form three liquid phases over a range of temperatures and compositions. ${ }^{1-3}$ These phases are called (according to their relative densities) the top phase (T), middle-phase microemulsions (M), and bottom phase (B), respectively, and can form emulsions of three liquid phases. Because they contain one more phase, three-phase emulsions form "new" morphologies that cannot occur when only two phases are present. This quarter the first determinations of the morphologies of emulsions formed by three liquid phases and the first dispersion morphology diagram for dispersions of three fluids are reported.

Figure 1 illustrates that the middle phase does not wet the interface between top and bottom phases, ${ }^{4.5}$ the three different three-phase morphologies that are predicted. They are the top-and-middle-in-bottom $|(T+M) / B|$, top-andbottom-in-middle $[(\mathrm{T}+\mathrm{B}) / \mathrm{M}]$, and middle-and-bottom-intop $[(M+B) / T]$ morphologies. From these predictions and from measurements and theory for the dispersion morphology diagrams of the limiting two-phase emulsions that bound each side of the three-phase tietriangle, ${ }^{6.7}$ it is anticipated that the three-phase dispersion morphology diagram will have three regions and that the continuous phase of a threephase dispersion will tend to be the phase present in the largest phase-volume fraction.

These initial studies have used the amphiphile 2-(2hexyloxyethoxy)-ethanol, $\mathrm{C}_{6} \mathrm{H}_{13}\left(\mathrm{OC}_{2} \mathrm{H}_{4}\right)_{2} \mathrm{OH}$, n-tetradecane, and water (aqueous $10 \mathrm{mM} \mathrm{NaCl}$ ) to form top, middle, and bottom phases at $25.0^{\circ} \mathrm{C}$. Steady-state, three-phase emulsions were formed and their electrical conductivities measured with techniques and apparatuses similar to those previously used ${ }^{7-9}$ for two-phase emulsions. In this technique the emulsions are prepared from preequilibrated phases and the emulsion conductivities are measured and plotted as a function of measured phase-volume fractions. By the phase rule (at constant pressure), the phase compositions of threephase emulsions are uniquely determined by the temperature. Hence, with the experimental design used, a knowledge of the phase compositions is useful, but not necessary, when performing the measurements and plotting the experimental results.

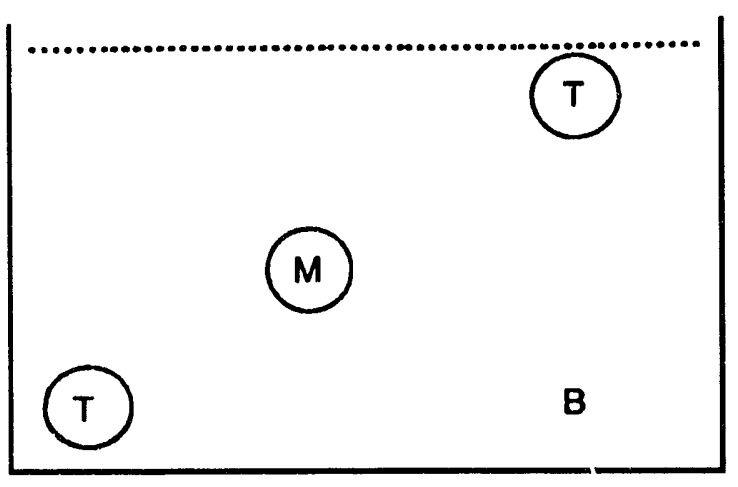

(a)

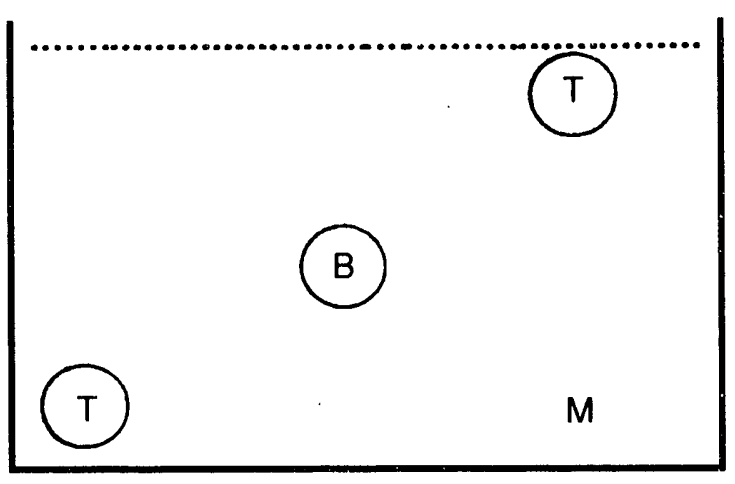

(b)

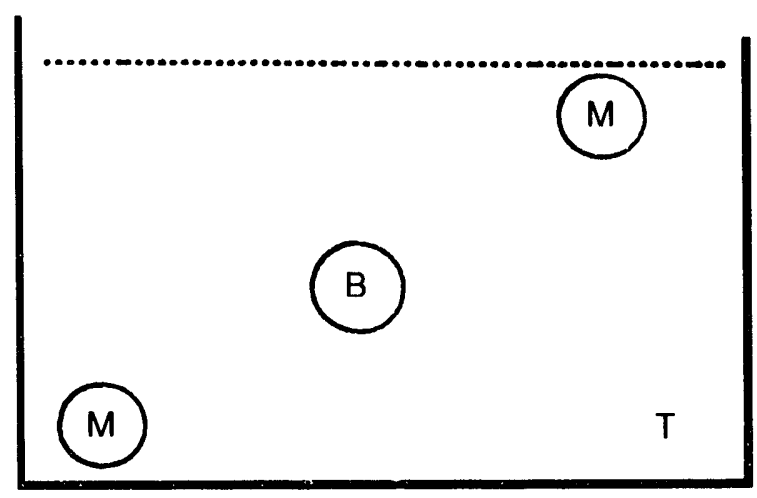

(c)

Fig. 1 Illustration of the three-phase morphologies predicted when none of the fluids wets the interface between the other two. (a) Topand-middle-in-bottom $[(T+M) / B]$. (b) Top-and-bottom-in-middle $[(T+B / M)]$. (c) Middle-and-bottom-in-top $[(M+B) / T]$.

Figure 2 illustrates a typical set of electrical conductivity data obtained for a series of steady-state, three-phase emulsions. Slow, smooth decreases of conductivity result when the phase-volume fraction(s) of the less-conductive phases( $\mathrm{s})$ is increased without any change of the emulsion morphology. Discontinuous changes of conductivity, however, indicate the occurrence of a sudden change of emulsion morphology (when the volume fraction of the continuous phase becomes too small). The smooth conductivity 
changes shown in Fig. 2 are analogous to conductivity effects predicted by effective-medium models and observed for noninverting two-phase emulsions, ${ }^{10}$ whereas the conductivity discontinuities correspond to similar effects for two-phase emulsions produced by inversions between the $\mathrm{O} / \mathrm{W}$ and W/O morphologies. ${ }^{7,11,12}$ (The hysteresis in the phase-volume fraction at which the morphology and conductivity change discontinuously also is observed for twophase inversions. ${ }^{7,11,12}$ )

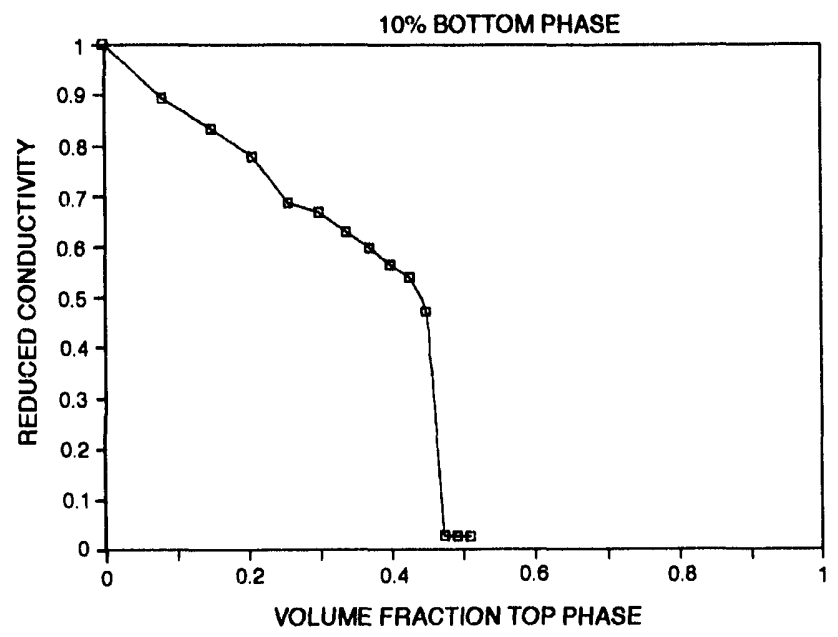

Fig. 2 Electrical conductivity vs. phase-volume fraction measured for three-phase emulsions. $\mathrm{C}_{6} \mathrm{E}_{2} / \mathrm{C}_{14} / 10 \mathrm{mM}$ brine at $25^{\circ} \mathrm{C}$.

Figure 3 illustrates the dispersion morphology diagram that results when many measurements of the type shown in Fig. 2 are combined. Just as each point in the triangular phase diagram of a three-component system represents the fractional concentration of each component, each point in the equilateral triangle of Fig. 3 represents the volume fraction of each phase in a three-phase dispersion. The phasevolume fractions at which emulsion morphology changes occurred in Fig. 2, and similar measurements are plotted in the triangular phase-volume fraction coordinates. (For clarity, the narrow hysteresis regions are omitted from Fig. 3.)

Thus the dispersion morphology diagram (Fig. 3) indicates that three different emulsion morphologies were observed. Figure 3 also shows the phase-concentration lines that mark the respective boundaries of the $[(T+M) / B]$, $[(T+B) / M]$ and $[(M+B) / T]$ morphologies of the threephase emulsions.

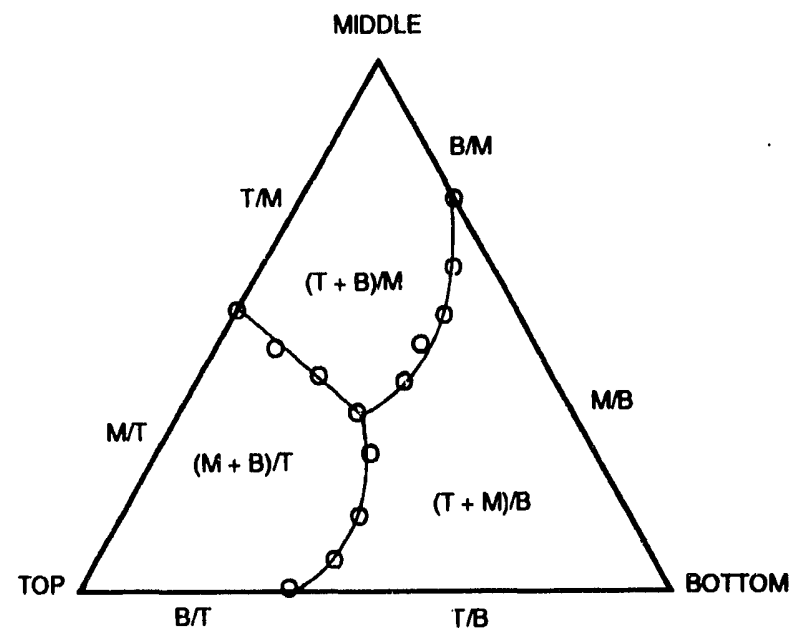

Fig. 3 Dispersion morphology diagram for emulsions formed by the top (T), middle (M), and bottom (B) phases of the system 2-(2hexyloxyethoxy) ethanol $/ n$-tetradecane/aqueous $10 \mathrm{mM} \mathrm{NaCl}$ at $25.0^{\circ} \mathrm{C}$.

\section{References}

1. B. M. Knickerbocker, C. V. Pesheck, H. T. Davis, and L. E. Scriven, J. Phys. Chem., 83: 1984 (1979).

2. M. Kahlweit, R. Strey, P. Firman, D. Haase, J. Jen, and R. Schomaecker, Langmuir, 4: 499 (1988).

3. D. H. Smith, J. Colloid Interface Sci., 102: 435 (1984).

4. D. H. Smith and G. L. Covatch, J. Chem. Phys., 93: 6870 (1990); D. H. Smith, G. L. Covatch, and W. E. Lowry, Soc. Petrol. Eng. Form. Eval., 1992 (in press); see D. H. Smith, G. L. Covatch, and W. E. Lowry, SPE paper 21043 presented at the Society of Petroleum Engineers International Symposium on Oilfield Chemistry, Anaheim, Calif., Feb. 20-22, 1991.

5. M. Kahlweit and G. Busse, J. Chem. Phys., 91: 1339 (1989).

6. D. H. Smith, S. N. Nwosu, G. K. Johnson, and K.-H. Lim, Langmuir, 8: 1076 (1992).

7. D. H. Smith and K.-H. Lim, J. Phys. Chem., 94: 3746 (1990).

8. D. H. Smith and K.-H. Lim, Soc. Pet. Eng., Prod. Eng., 5: 265 (1990).

9. D. H. Smith and K.-H. Lim, Langmuir, 6: 107 (1990).

10. K.-H. Lim and D. H. Smith, J. Dispersion Sci. Technol., 11: 529 (1990).

11. J.-L. Salager, in Encyclopedia of Emulsion Technology, P. Becher (Ed.), p. 79, Marcel Dekker, New York, 1988.

12. D. H. Smith, G. L. Covatch, and K.-H. Lim, Langmuir, 7: 1585 (1991). 


\section{SCALEUP OF MISCIBLE FLOOD PROCESSES}

\section{Contract No. DE-FG21-89MC26253}

\author{
Stanford University \\ Stanford, Calif.
}

Contract Date: July 1989

Anticipated Completion: July 1992

Government Award: \$756,000

\section{Principal Investigator: \\ F. M. Orr, Jr. \\ Project Manager: \\ Royal Watts \\ Morgantown Energy Technology Center}

Reporting Period: Apr. 1-June 30, 1992

\section{Objective}

The objective of this research effort is to develop improved procedures for scaling predictions of miscible flood performance from laboratory scale, where the process is experimentally accessible, to field scale, where more accurate performance predictions are needed.

\section{Summary of Technical Progress}

This project is a systematic research effort aimed at quantifying the interactions of physical mechanisms that control the scaling behavior of miscible floods. Displacement performance in a miscible flood is the result of a complex set of competing and interacting mechanisms. Phase behavior is of fundamental importance because the transfer of components from the oil to the injected fluid (as in most $\mathrm{CO}_{2}$ floods) or from the injected fluid to the oil (as in rich gas floods) can generate mixture compositions that avoid the two-phase region. In one-dimensional (1-D) flow, the favorable effects of phase behavior can lead to displacement efficiencies that approach $100 \%$. Displacements in reservoir rocks are anything but one- dimensional, however. The rocks themselves are heterogeneous, and even if they were homogeneous, most miscible floods are subject to a hydrodynamic instability that results from displacement of oil by gas with lower viscosity. The result is nonuniform flow whether the cause is viscous fingering. reservoir heterogeneity, or some combination of the two. When flow is nonuniform, there is the potential for cross flow between zones of fast and slow flow. Such cross flow can result from diffusion and dispersion, gravity segregation, or viscous cross flow and can cause mixing of fluids of different composition. That mixing, in turn. causes mixture compositions that occur during a multidimensional dis- placement to differ from the corresponding compositions in a 1-D displacement. Because the composition route can strongly influence local displacement efficiency, cross flow and the resulting induced mixing will influence recovery performance in field-scale floods. The magnitude of the influence depends on the lengths over which cross flow occurs, the rate at which fluids are moved, and the phase behavior of the resulting mixtures. The goal of this project, therefore, is to make more accurate quantitative predictions of the impact of nonuniform flow, cross flow, and phase behavior in flows in heterogeneous reservoir rocks.

Understanding of such a complex problem requires merging of many disciplines; thus the current research effort is divided into three areas:

1. Phase behavior, fluid properties, and flow.

2. Interaction of nonuniform flow, cross flow, and phase behavior.

3. Patterns and scales of nonuniform flow.

The research results for this quarter concern how dispersion, pr:rmeability heterogeneity, and viscous instability interart to determine displacement performance in miscible floods are summarized.

\section{Results}

In laboratory tracer $(\mathbf{M}=1)$ displacement experiments, the effect of variations in flow velocity at the microscopic (pore) scale manifests itself as a transition zone between the displacing and displaced fluids. When the transition zone along the mean flow direction is symmetric about the mean displacement position $(x=\bar{u} t)$, the growth of the transition zone can be modeled by a 1-D convection-dispersion equation (Eq. 1).

$$
\frac{\partial c}{\partial t}+\bar{u} \frac{\partial c}{\partial x}-D_{L} \frac{\partial^{2} c}{\partial x^{2}}=0
$$

Equation 1 describes a transition zone in which the concentration follows a normal distribution with a variance proportional to time. Use of Eq. 1 is appropriate when the correlation length of the local flow velocity is small compared with the flow length. 1.2 In addition, the dispersion coefficient is frequently assumed to be the sum of two contributions. One is due to molecular diffusion and the other is assumed to be proportional to the average flow velocity $\left(D_{L}=\alpha_{L} \bar{u}+D_{m}\right)$. The dispersivity $\left(\alpha_{L}\right)$ can be taken as a property of the porous medium.' For a homogeneous (uniform permeability) medium. the dispersivity describes the pore structure length scale. whereas for a randomly heterogeneous (random permeability distribution) medium, the dispersivity reflects the length scale required to sample the permeability distribution.

Laboratory cores used in displacement experiments may or may not satisfy the assumptions inherent in Eq. 1, namely, 
1-D flow and small correlation lengths compared with the flow length. Experimental measurements of dispersion coefficients rarely examine whether the flow is really onedimensional. Instead, effluent composition data, which are, in effect, transversely averaged concentration measurements at a single location, are fit to Eq. 1. This report contains a summary of the investigation of the applicability of Eq. 1 for stable displacements.

For a study of the interaction between dispersive mixing and viscous fingering, the experimental results discussed in Ref. 3 are used. Acoustic measurements of transversely averaged mixture composition histories were obtained at several locations along sandstone and limestone core samples. For values of $M>1$, the displacements were unstable, and viscous fingering contributed to the transition zone growth. In addition, displacement results for a variety of superstable $(\mathrm{M}<1)$ displacements were obtained. Results from particle-tracking simulations of the displacement experiments were then used to interpret their experimental results and to show that the dependence of $\alpha_{L}$, on $M$ (or lack thereof) indicates whether significant correlation of permeability exists at the scale of the displacement.

Local concentration history data are compared with predictions obtained from a random-walk particle-tracking simulation technique. The particle-tracking simulation method used here is that used in Ref. 4. Details of the implementation appear in Refs. 5 and 6. The code was implemented on a massively parallel machine. The outlines of the implementation are given in Ref. 7. The results of both experiment and simulation show how permeability heterogeneity, dispersion, and viscous fingering interact as the viscosity ratio $(\mathrm{M})$ varies in miscible displacements.

\section{Stable and Unstable Displacements: Acoustic Measurements and Particle-Tracking Simulations}

An acoustic technique, the details of which are given in Ref. 8, was used to study the space and time dependence of concentration during stable and unstable miscible displacements. Figure 1 is a schematic of a cross section across the apparatus. The concentration at a particular cross section is determined from velocity variations of a longitudinal sound wave. Ten transmitter-receiver transducer pairs generate and record the signal as a function of time. The ten locations are sampled in less than $1 \mathrm{~min}$. Calibration curves relating variations in the sound velocity to volumetric concentration are accurate to within $1 \%$ with a resolution of $3 \mathrm{~mm}$ in the width of the sampled section. As a result, complete transversely averaged concentration history curves at ten locations along the core sample provide detailed information on the concentration distribution in the transition zone.

Displacement experiments under stable $(M \leq 1)$ and unstable $(M>1)$ conditions for a wide range of mobility ratios and rates were performed. All the experimental curves presented are for displacements at rates that are well into

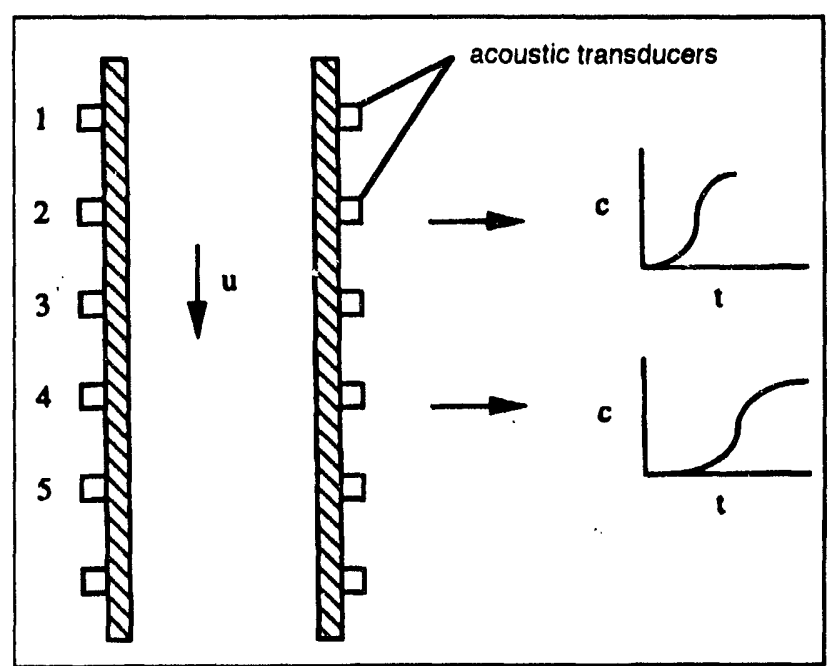

Fig. I Schematic of a cross section across the experimental apparatus.

the region where the contribution of molecular diffusion to the dispersion coefficients is negligible. Consequently the effect of rate on fingering behavior is not considered. Acoustic measurements on limestone and millstone core samples were obtained. The limestone sample was 4.5 by 4.5 by $25.4 \mathrm{~cm}^{3}$. The transducer pairs were placed at ten equally spaced locations $\left[x_{i}=2.55+2.1(i-1) \mathrm{cm}\right]$ along the core length. The millstone was 4.1 by 4.05 by $25.4 \mathrm{~cm}^{3}$, and the transducers were placed at $x_{i}=1.5+2.5(i-1) \mathrm{cm}$.

A limestone core sample $\left(4.5\right.$ by 4.5 by $\left.25.4 \mathrm{~cm}^{3}\right)$ from the same block as the sample on which the experiments were performed was obtained, and minipermeameter measurements were made on three faces. The permeameter was $1 \mathrm{~cm}$. Similar measurements were also made on a slab of millstone $\left(1.0\right.$ by 8.0 by $\left.25.0 \mathrm{~cm}^{3}\right)$. The permeability maps are shown in Fig. 2. Although these measurements do not provide a detailed description of the permeability distribution in the truly three-dimensional (3-D) cores used in the displacement experiments, they do indicate the major features of the two rock types under investigation.

CAT scan measurements of the porosity at six cross sections along the length of the limestone core were also performed. The standard deviation about the mean at a particular cross section was $4 \%$; the average standard deviation about the overall mean was also $4 \%$. These measurements indicate a nearly homogeneous porosity distribution in the limestone core sample.

Figure 3 shows dispersivities for a variety of mobility ratios obtained by regression fits of concentration data of the form shown in Fig. 1 to Eq. 1. The reported value of $\alpha_{L}$ at each mobility ratio is the average of the values at ten locations. $\alpha_{L}$ was essentially independent of $M$ in the millstone. The value of $\alpha_{1}$ decreased noticeably with mobility in the limestone core. In the limestone the dispersivity $\left(\alpha_{\mathrm{L}}\right)$ decreased by a factor of 2.5 as $M$ varied from 0.8 to 0.04 . The dependence of $\alpha_{1}$, on $M$ in the limestone core is the direct result of the heterogeneity of the sample. 


\section{Millstone}

0

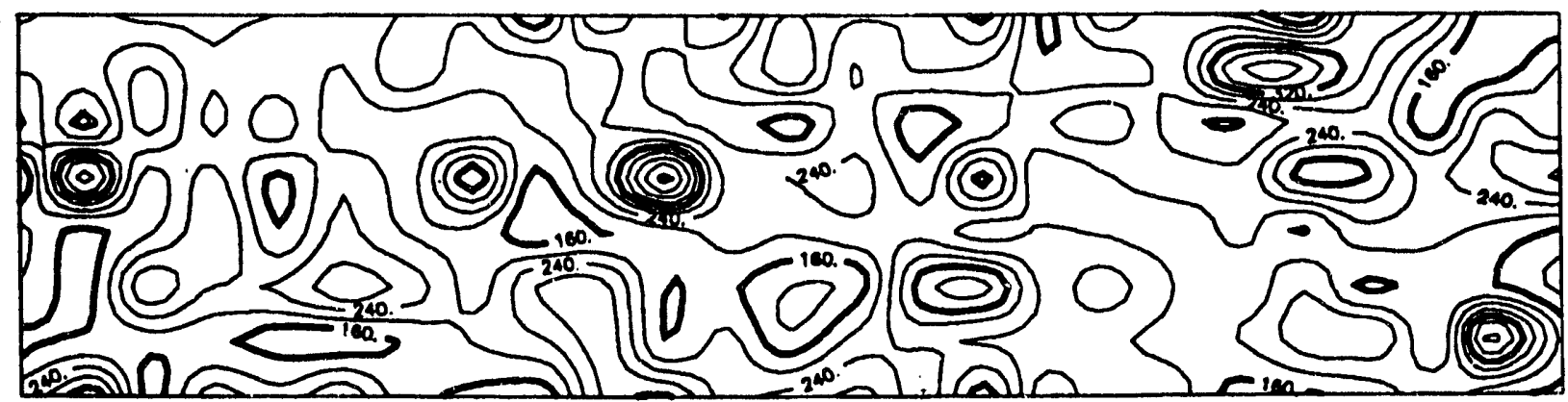

0.

Limestone Face 1

o.

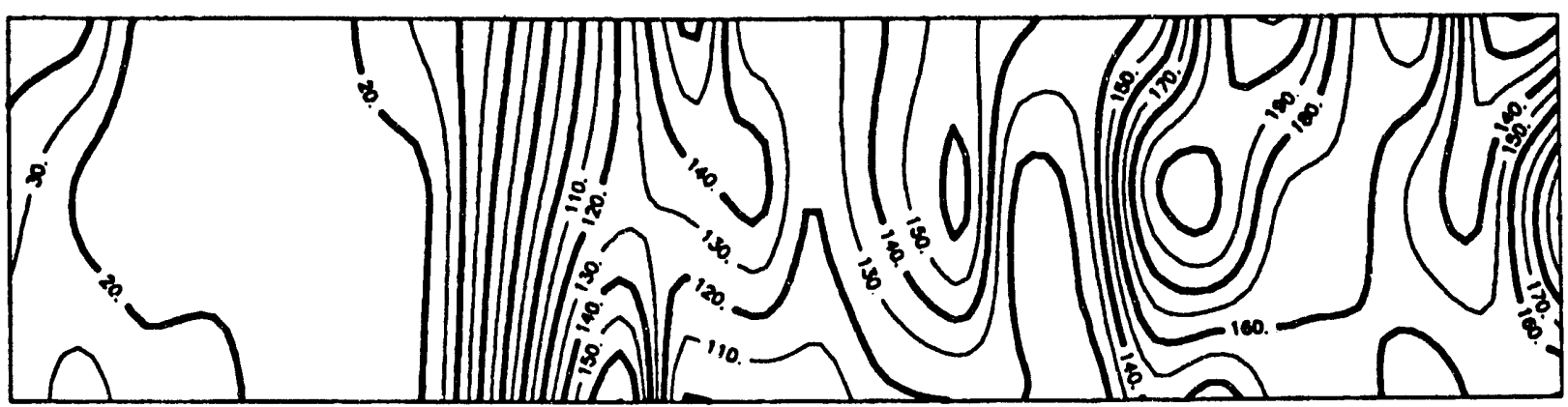

0.

Limestone Foce 2

0.

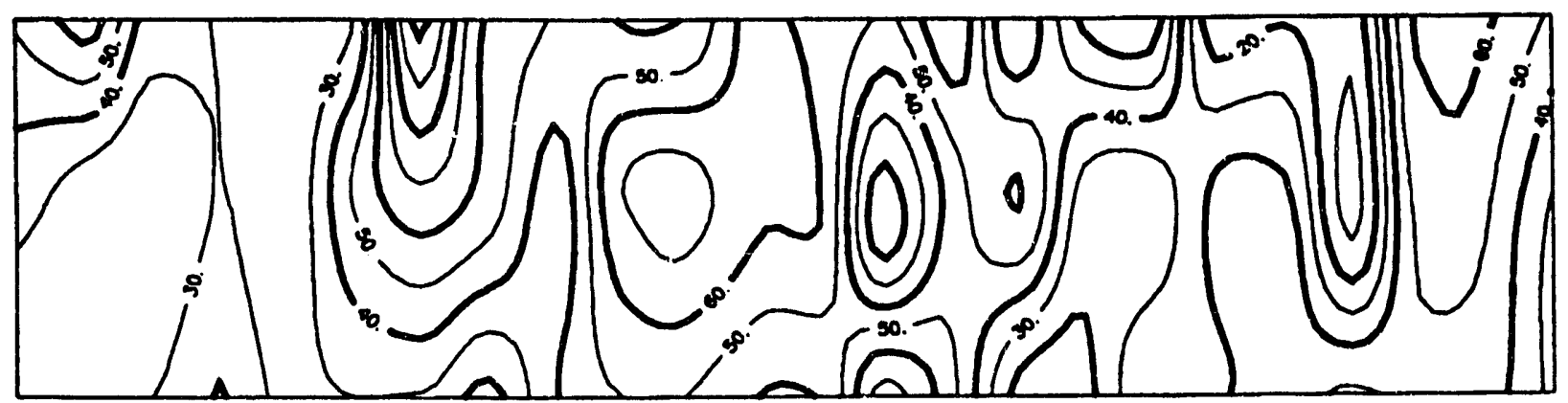

0.

Limestone Face 3

o.

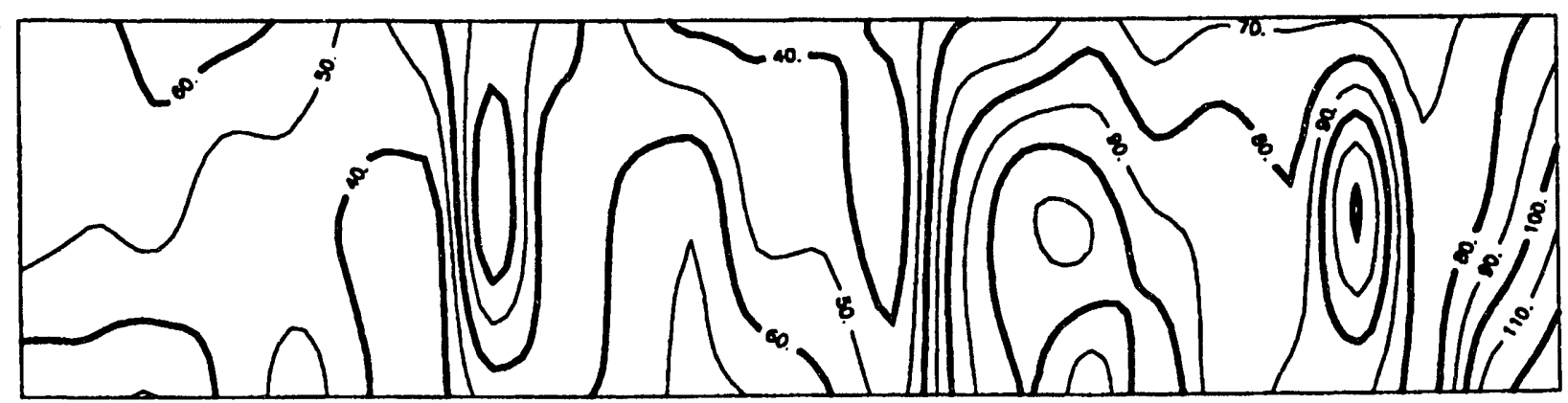

o.

Fig. 2 Permeability maps of the millstone slab and three faces of a limestone core.

Semi-variograms of the permeability distributions shown in Fig. 2 confirm the visual observation that the millstone core is randomly heterogeneous with correlation lengths smaller than the resolution of the measurements, whereas the limestone is much more heterogeneous with much larger correlation scales. Moreover, it is clear that significant dif- 


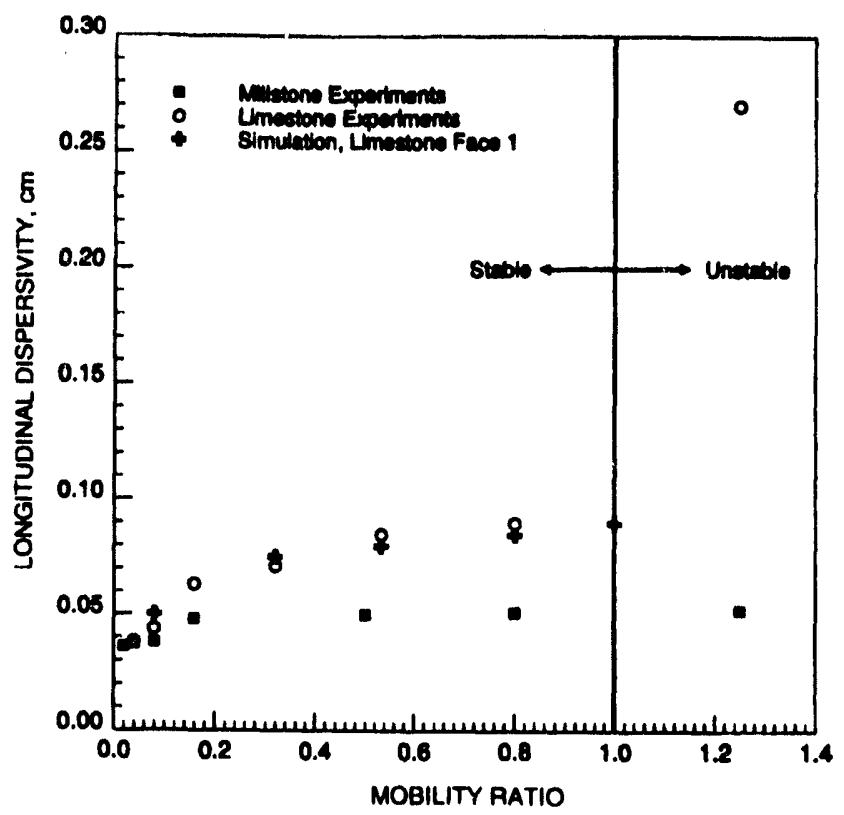

Fig. 3 Dispersivity vs. mobility ratio from now experiments in the millstone and limestone cores and from simulations using limestone face 1.

ferences in the permeability structure occur in the third dimension, as reflected by the differences between the faces of the limestone core.

Concentration histories from fine-grid particle-tracking simulations of the facial permeability distributions were used to estimate longitudinal dispersivities using a regression fit to Eq. 1. Limestone face 1 showed dispersive behavior for all simulated displacements with $M \leq 1$. The average apparent dispersivities for face 1 are also plotted in Fig. 3.

The dependence of $\alpha_{\mathrm{L}}$ on the mobility ratio in superstable $(\mathrm{M}<1)$ heterogeneous media with large correlation lengths is due to cross flow. The reason is illustrated in Fig. 4, which shows the pressure distribution for a stable displacement $(M=0.1)$ for the initial composition shown in the schematic above it: Viscous cross flow slows down the penetration of the high-viscosity fluid near its front end and deprives the high-viscosity layer from support near its back end. These combined actions act to shrink the transition zone, which leads to smaller dispersivities as $M$ is reduced below unity.

When $M>1$, the displacement is unstable. Viscous fingering then interacts with whatever heterogeneity is present to cause much faster transition-zone growth than would be observed for displacements where $\mathbf{M} \leq 1$.

Figure 5 shows the concentration histories at ten locations along both the millstone and limestone cores. The mobility ratios are 3.125 and 3.4 for the millstone and limestone cores, respectively. The dips and kinks in Fig. 5 are more pronounced for the limestone histories than for the millstone. For a fixed location, the time difference between the arrival times of the leading and trailing edges will be

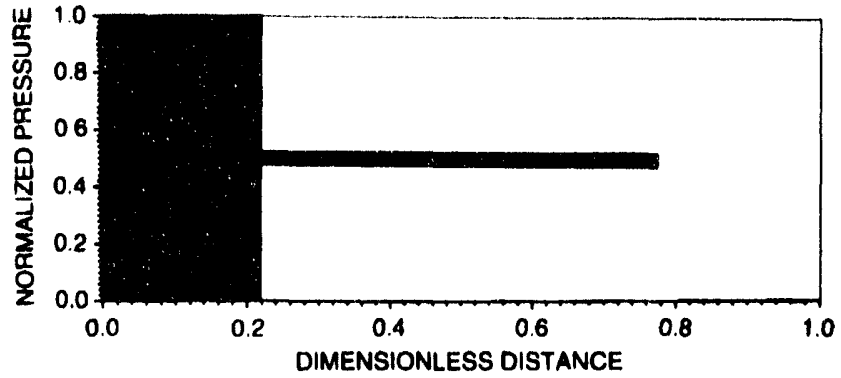

(a)

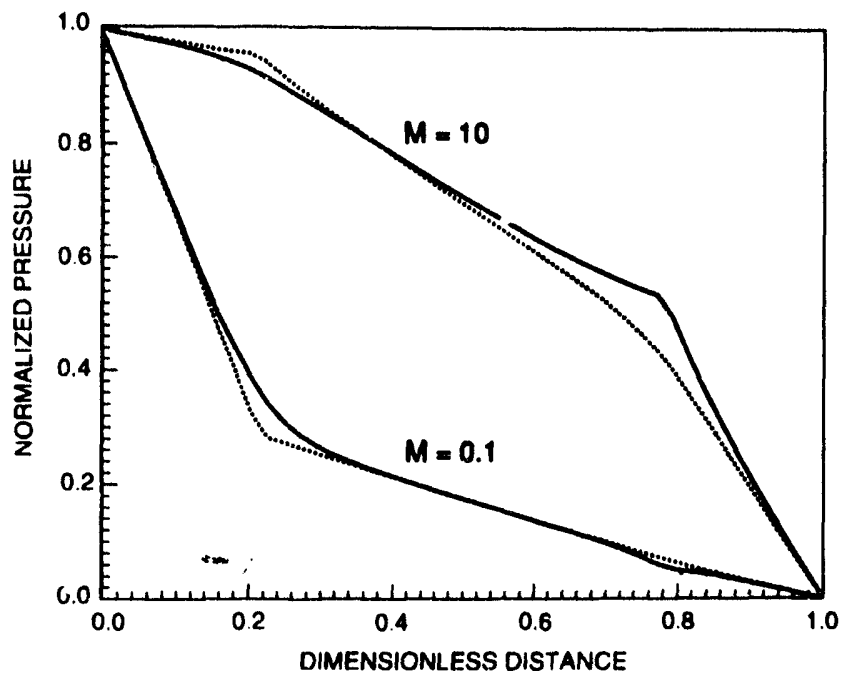

(b)

Fig. 4 (a) Concentration distribution (black $=1$ and white $=0$ ) and (b) pressure distribution for unstable (mobility ratio, 10) and stable (moblitity ratio, 0.1 ) displacements. - , inside the finger. $\cdots \cdot$, outside the finger.

referred to as the "fingered zone time-size." The fingered zone time-sizes for the limestone core are consistently larger than their counterparts in the millstone core at comparable locations and mobility ratios. The observations deduced from Fig. 5 indicate clearly that the fingering is more severe in the limestone core. A particle-tracking simulator was used to study the physical reasons for these differences.

On the basis of the observations for the millstone, simulations of the millstone core were performed with a homogeneous permeability field. The longitudinal dispersivity value used in the simulations was $0.05 \mathrm{~cm}$. The simulations at mobility ratios of 3.125 and 13.5 are shown in Figs. 6 and 7, respectively. These figures show that the agreement in arrival times between simulation and experiment is good and that the concentration distribution in the fingered zone as a function of time and space is adequately predicted by the simulations.

The experiments in the millstone core incorporate the 3-D nature of fingering (cross section 4.1 by 4.05 ). The fine-grid two-dimensional (2-D) particle-tracking simulations seem to capture the important aspects of fingering behavior in the millstone core. Although the third dimension 


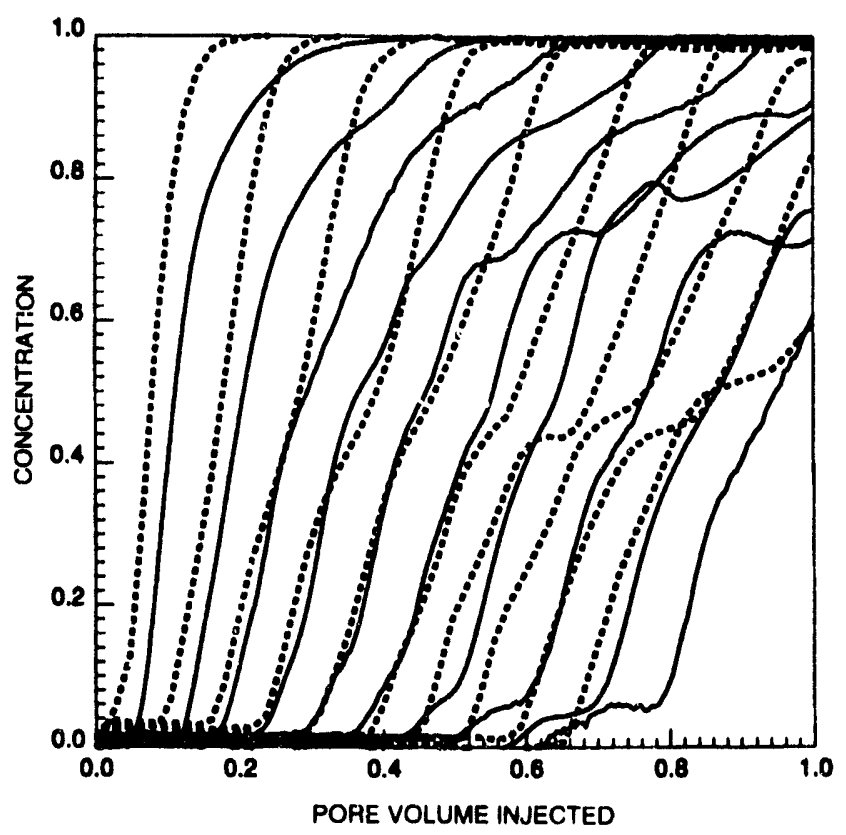

Fig. 5 Experimental concentration histories at the 10 locations for the millstone (mobility ratio, 3.125) (....) and limestone (mobility ratio, 3.4) (-) cores.

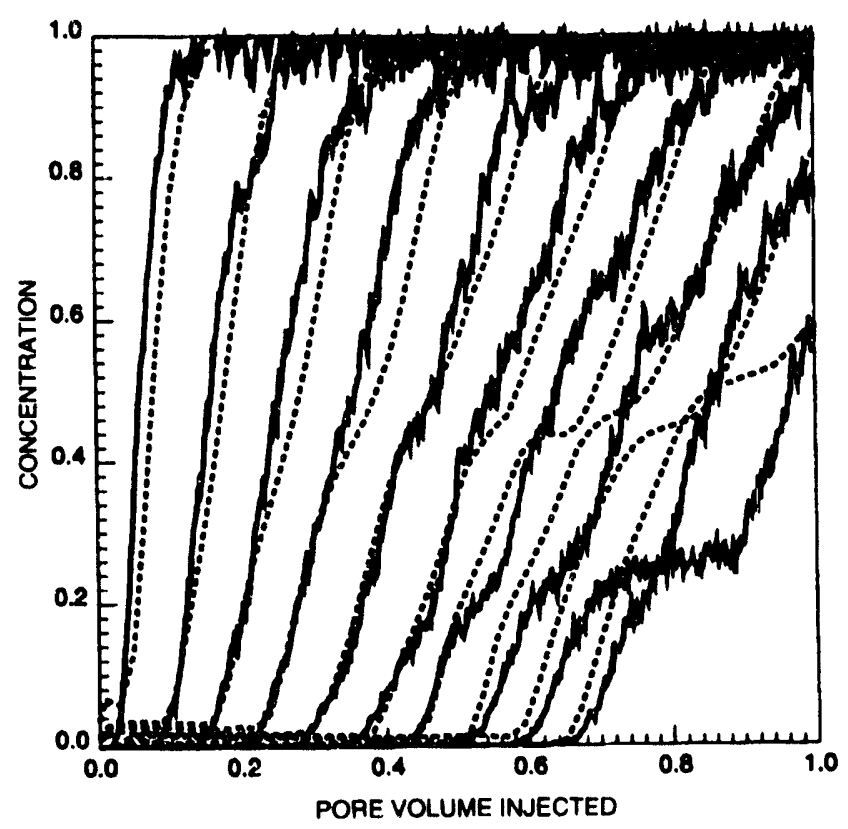

Fig. 6 Millstone core. Experimental ( . . .) and simulation (-) concentration histories. Mobility ratio, 3.125.

influences fingering behavior, in homogeneous and randomly heterogeneous media in the absence of gravity, it is expected that cross-sectionally averaged concentrations in 3-D flow will be similar to the transversely averaged concentrations obtained in 2-D displacements. The millstone is nearly homogeneous, and the simulation results confirm that expectation.

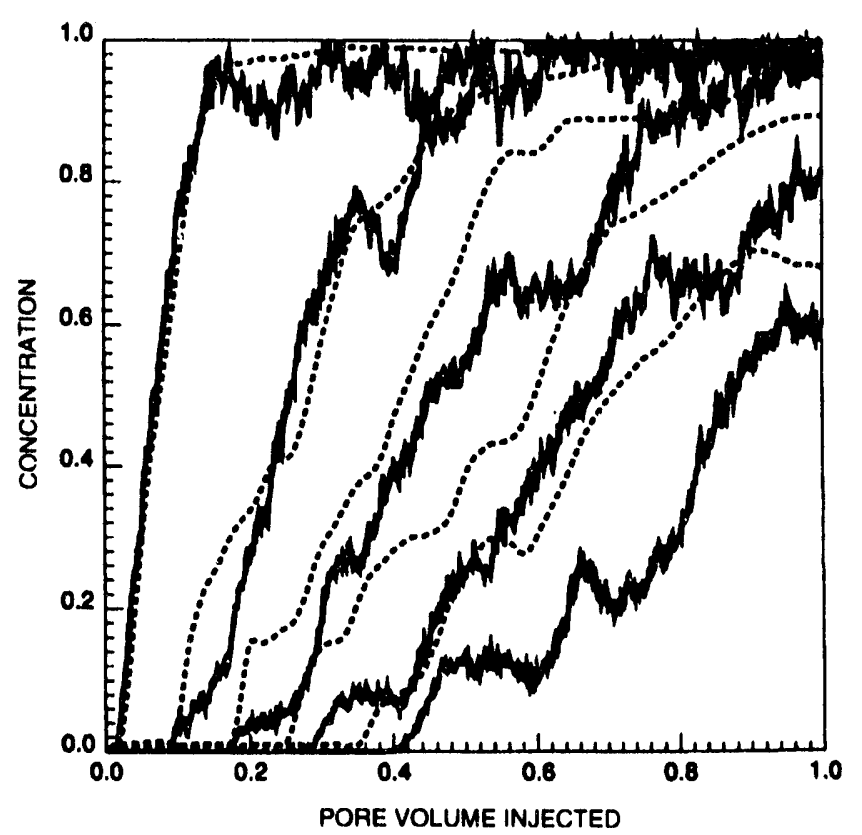

Fig. 7 Millstone core. Experimental (....) and simulation (-) concentration histories. Mobility ratio, 13.5; lccations 1, 3, 5, 7, and 9.

Figure 8 plots the concentration histories for the limestone core at the five even locations $\left[x_{i}=4.65+4.2(i-1) \mathrm{cm}\right]$ for three mobility ratios, 2.2, 3.4. and 12.5. As expected, fingering is more pronounced for the higher mobility ratios. The permeability distribution of face 1 was used to simulate the displacement at a mobility ratio of 3.4. Figure 9 compares the history curves from this simulation with the experimental curves at the five even locations for a mobility ratio of 3.4. The experimental and simulation curves of Fig. 9 show reasonable agreement. It is encouraging that a 2-D simulation using the permeability distribution on face 1 seems to capture with some success the evolution and growth of the fingered zone in a 3-D porous medium at this mobility ratio.

The increase in the mixing zone time-size at a particular location as the mobility ratio increases is evident in Fig. 8, and a trend of slightly earlier arrival times as the mobility ratio increases is detected. Numerical simulations using face 1 at a variety of mobility ratios greater than the 3.4 case shown in Fig. 9 also agree reasonably well with the experimental observations in terms of mixing zone time-sizes. However, comparisons between simulation and experiment based on arrival times begin to differ significantly for mobility ratios greater than 3.4. The agreement between simulation and experiment in the case of the limestone is not as favorable as that of the millstone. The poorer agreement is clearly due to the heterogeneous character of the 3-D limestone core. As a result, in order to model accurately the behavior in the heterogeneous limestone core, a detailed description of the permeability distribution in three dimensions is needed. The 3-D parallel particle-tracking code developed in this project can then be used to make accurate predictions. 


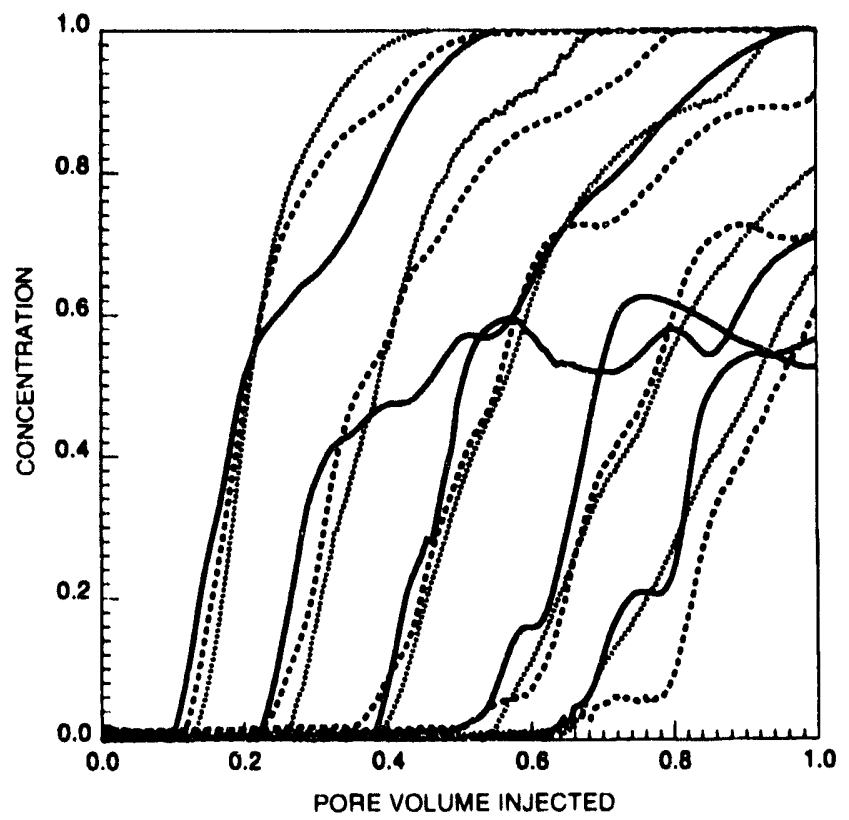

Fig. 8 Experimental concentration histories at locations $2,4,6,8$, and 10 in the limestone core at mobility ratios of $2.2(\cdots \cdots), 3.4(\ldots)$, and $12.5(-1$.

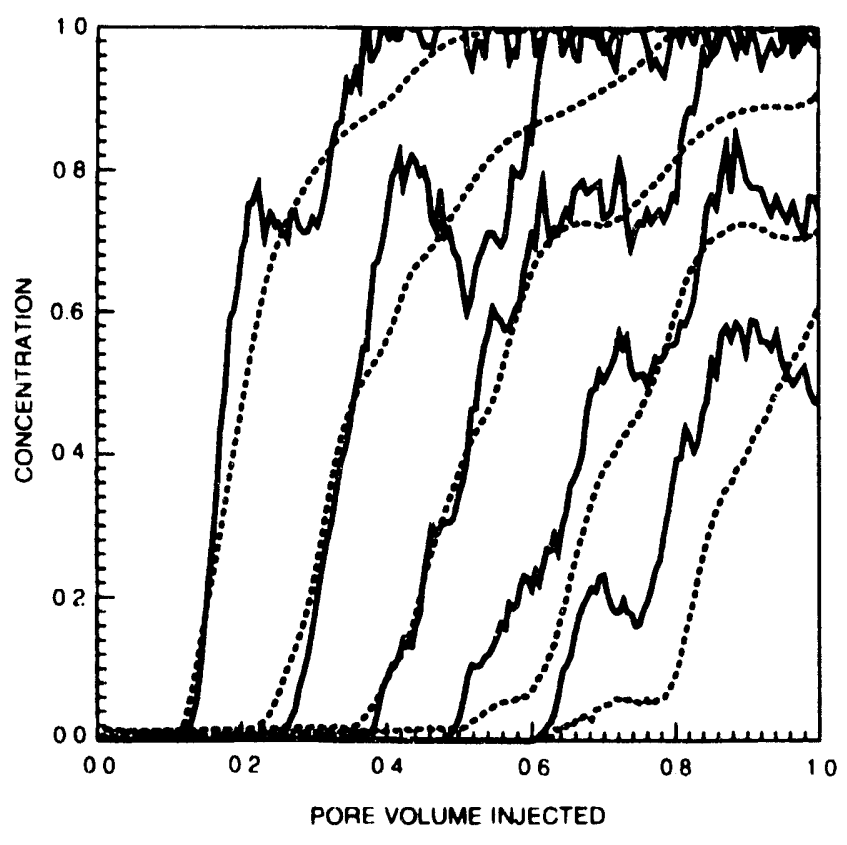

Fig. 9 Limestone experimental concentration histories $(\ldots$.$) and$ face 1 simulation $(-)$ at locations $2,4,6,8$, and 10 for a mobility ratio of 3.4.

For field-scale displacements, the ideal procedure would be to find a representative outcrop from which variograms could be constructed. Such variograms when integrated with field data yield conditional stochastic permeability distributions in three dimensions. Simulations in domains with such distributions could then be used to quantify the influence of heterogeneity on displacement processes. Moreover, the stochastic nature of the problem requires that the uncertainty in the observed influence be assessed.

\section{Conclusions}

The experimental observations and numerical simulations of stable and unstable displacement experiments in millstone and limestone cores indicate that

- Convective cross flow reduces the size of the transition zone during super stable $(M<1)$ displacements in heterogeneous porous media with significant correlation length scales. This is reflected in apparent dispersivity values that decrease as the mobility ratio decreases below unity.

- Fine-grid 2-D random-walk particle-tracking simulations of I, nstable displacements in the millstone core, which exhibited random heterogeneity, represent with reasonable accuracy the scale, size, and growth of the viscous fingers in the nonlinear regime. Two-dimensional simulations seem to capture the essence of 3-D unstable flow in homogeneous and randoml; huterogeneous media.

- The observed experimental differences between the millstone and limestone cores were due to the heterogeneity of the limestone.

- In 3-D heterogeneous media with significant correlation lengths, a detailed description of the permeability field is required for an accurate prediction of fingering behavior. If such a description is available, the particle-tracking technique can be used to make quantitative predictions.

\section{Nomenclature}

c Concentration of the injected component

$D_{\mathrm{l}}$. Longitudinal dispersion coefficient

$D_{m}$ Effective molecular diffusion coefficient

k Permeability

M Mobility ratio

1 Time

$\overline{\mathbf{u}}$ Mean displacement velocity

$x$ Distance

$\alpha_{1}$. Longitudinal dispersivity

\section{References}

1. J. Bear, Dynamics of Fluids in Porous Media. American Elsevier, New York, 1972.

2. L. W. Gelhar and C. L. Axness. Three-Dimensional Stochastic Analysis of Macrodispersion in Aquifers, Water Resour. Res., 19(1): 161. 180 (1983).

3. N. Rakotomalala, D. Salin, and R. Woumeni, personal communication. 1990), 1991.

4. U. G. Araktingi and F. M. Orr, Jr., Viscous Fingering in Heterogeneous Porous Media, paper SPE 18095 presented at the 1988 Society of Petroleum t.ngineers Annual Technical Conference and Exhibition. Houston. Tex., October 2-5, 1988.

5. H. A. Tchelepi, Simulation of Viscous Fingering in Heterogeneous Porous Media. Annual Repon No. DOE/viC/26253-5, U.S. DOE Grant No. D):-H(21-89MC26253, U.S. Department of Energy, Bartlesville. ()hla. | 1941: Chap. 4.2 in Sicale-Up of Miscible Flood Processes. 
6. H. A. Tchelepi, Scaling of the Grow'th of Viscoms Fingers in Linear Flow. Annual Report No. DOE/MC/26253-9, U.S. DOE Grant No. DE-FG21-89MC26253, U.S. Department of Energy, Bartesville. Okla., 1992; Chap. 4.1 in Scale. Up of Miscible Flood Processes.

7. H. A. Tchelepi, Simulation of Three-Dimensional Viscous Fingering, Annual Report No. DOE/MC/26253-9, U.S. DOE Grant No. DE-FG21. 89MC26253, U.S. Department of Energy, Bartesville, Okla., 1992: Chap. 4.2 in Sccle. Up of Miscible Flood Processes.

8. J. C. Bacri, N. ¿ ২akotomalala, D. Salin, M. Bourlion, R. Lenormand. and A. Soucemarianadin, Ultrasonic Diagnustics in Porous Media and Suspensions, J. Phyr. III (Paris), I: 674 (1991).

\section{FIELD VERIFICATION OF $\mathrm{CO}_{2}-$ FOAM}

Contract No. DE-FG21-89MC26031

Now Mexico Institute of Mining and Technology
Petroleum Recovery Research Center
Socorro, N. Mex.

Contract Date: September 1989

Anticlpated Completion: September 1993

$\begin{array}{lr}\text { Total Project Cost: } & \\ \text { DOE } & \$ 2,000,000 \\ \text { Contractor } & 2,000,000 \\ \text { Total } & \$ 4,000,000\end{array}$

Principal Inveatigators:

F. David Martiri

John P. Heller

William W. Welss

Project Manager:

Royal Watts

Morgantown Energy Technology Center

Reporting Period: Apr. 1-June 30, 1992

\section{Objectives}

This project is a cooperative effort of industry, university, and government to transfer emerging technology from promising laboratory research to field application. The primary objective of the project is to evaluate the efficacy of applying foam mobility control in a field-scale $\mathrm{CO}_{2}$ flood.

\section{Summary of Technical Progress}

The East Vacuum Grayburg/San Andres Unit (EVGSAU), operated by Phillips Petroleum Company, was the site selected for a comprehensive evaluation of the use of foam for improving the effectiveness of a $\mathrm{CO}_{2}$ flood. The 4-yr project is jointly funded by the EVGSAU Working Interest Owners, the U.S. Department of Energy (DOE), and the state of New
Mexico. The Petroleum Recovery Research Center, a division of the New Mexico Institute of Mining and Technology, is providing laboratory and research support for the project. A Joint Project Advisory Team (JPAT) composed of technical representatives from several major oil companies provides input, review, and guidance for the project.

Results of laboratory work leading to the seiection of a specific foaming surfactant for application at EVGSAU and additional background on the project were presented' this quarter at the Society of Petroleum Engineers (SPE)/DOE Eighth Symposium on enhanced oil recovery (EOR). A second paper $^{2}$ outlining the field operating plans, design criteria, foam injection schedule, data collection program, and performance criteria is being prepared for presentation in October 1992 at the SPE Annual Technical Conference and Exhibition.

The design developed for the EVGSAU field test calls for the injection for 3 months of a pre-foam surfactant pad to satisfy the adsorption requirement of the reservoir followed by the injection of an $80 \%$ quality $\mathrm{CO}_{2}$-foam during 4 months of a rapid surfactant-alternating-gas (SAG) cycle. The rapid SAG cycle, consisting of $3 \mathrm{~d}$ of surfactant solution injection followed by $12 \mathrm{~d}$ of $\mathrm{CO}_{2}$, should avoid operational problems of coinjection while achieving the benefits of simultaneous injection. Surfactant concentration in the pre-foam pad and in the surfactant solution for the SAG cycle will be $2500 \mathrm{ppm}$ Chevron Chaser CD-1045 ${ }^{\star}$.

\section{Project Plans and Schedule}

A meeting of the JPAT was held in Hobbs, N. Mex., on Apr. 8, 1992, to finalize plans for the surfactant injection program and approve contingency plans for responding to a number of operational scenarios. The current project schedule is shown in Fig. 1. Monitoring for the foam field test involves a data collection program designed to evaluate the reduction of mobility of the injected $\mathrm{CO}_{2}$ and the improvement in pattern sweep efficiency and/or production performance. Injection rates and pressures are monitored daily at the pattern injector (Well 3332-001). Oil, water, and gas production is monitored weekly for the eight producing wells in the pattern. At the end of each cycle, an injection well profile is obtained to assess where fluids are leaving the wellbore, production logs are obtained in the "offending" producing well (3332-032) to determine where fluids are entering that wellbore, and logging of the observation (at well 3332-003) is conducted to monitor saturation changes at that wellbore. Before and after the foam test, both waterphase and gas-phase tracers are injected in Well 3332-001. Results of all these tests are used to monitor the effects of the foam injection and to detect any significant changes in fluid flow through different intervals in the reservoir.

\section{Injection Well Performance}

The pre-foam surfactant pad injection was started on Apr. 14, 1992. The injected surfactant concentration has been 


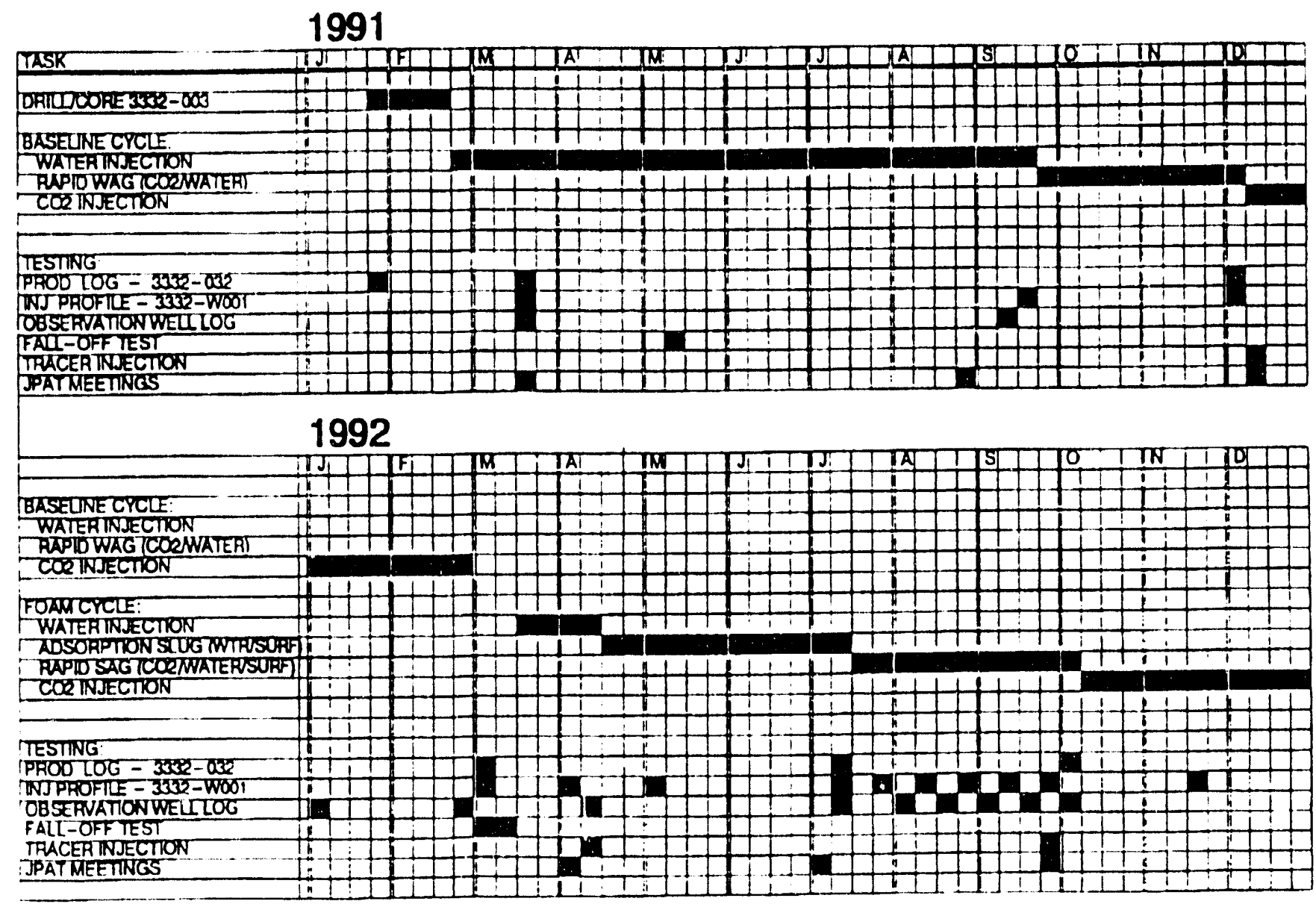

Fïg. I EV(iSAll CO $)_{2}$-foum project schedule. (Rev. June 12, 1992.)

maintained close to the design of $25(x)$ ppm. An injection well profile conducted on May 1, 1992. showed no significant change from previous tests, so the surfactant solution is leaving the wellbore in the same zones that had previously received water only. Approximately $6.5 \%$ of the injected fluid is entering Zone $C^{2}$ and the lower portion of Zone $C 3$, which are the higher permeability zones at EVGSAU. This distribution of injected fluids is consistent with the permeability distribution obtained from analysis of the reservoir core taken from the observation well localed $150 \mathrm{ft}$ from the injector. During surfactant injection a wellhead pressure recorder was installed to monitor pressure continuously. Figure 2 shows the injection well performance through the baseline period and into the injection of the pre-pad surfactant solution. These data suggest that the rapid water alternating gas (WAG) may have reduced the mobility of water slightly, but no significant changes in pressure have been observed after initiation of the surfactant solution.

\section{Interwell Tracers and Fluid Sampling}

An interwell tracer program was designed to show any changes in fluid transit times from the injector to the produc. ers as a result of foam generation. Tracers were injected in

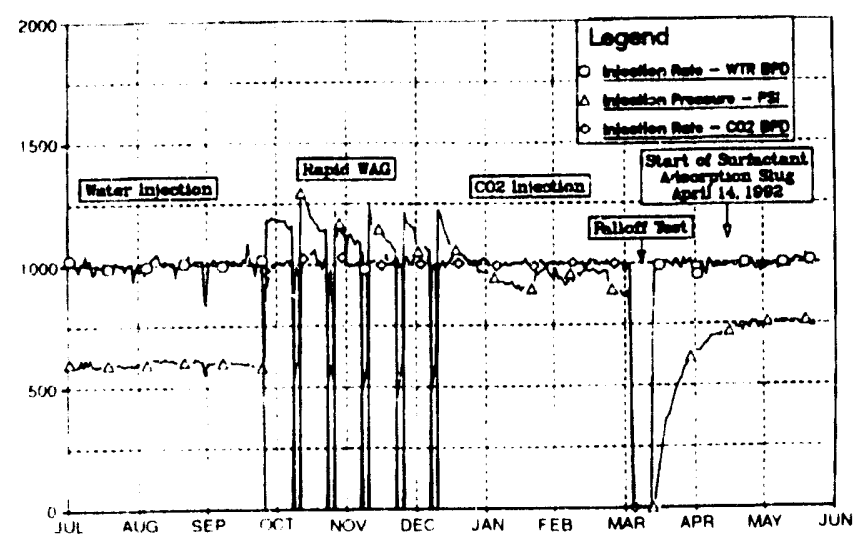

Fig. 2 Well 33.32-(K)1 injection pressure and rate for July 1, 1991, to May 21, 1992.

early December 1991 after the rapid WAG portion of the baseline cycle. The the gas phase and tritium $(9 \mathrm{Ci})$ in the water phase. An additional tracer of $0.15 \mathrm{Ci}$ of $\mathrm{Co}^{(x)}$ was injected in the water phase just hefore the start of the adsorption slug of surfactant in mid-April 1992. If the surfactant does propagate through 
the reservoir, the difference in arrival times between the nonadsorbing radioactive tracer $\left(\mathrm{Co}^{6()}\right)$ and the surfactant may help quantify surfactant adsorption in the reservoir.

Gas samples were collected from the two side producers in the foam pattern that have shown the most rapid and severe $\mathrm{CO}_{2}$ breakthrough problems. Produced gas samples are taken daily for 5 weeks, twice per week for about 3 months, and weekly thereafter. Water samples are taken from all eight pattern producers on the same frequency. Results from these tracers will be compared with a similar set of tracers to be injected after the rapid SAG portion of the foam injection cycle.

\section{Production Well and Observation Well Performance}

As of early June no surfactant had been detected in any of the producing wells in the pattern. Neither the water-phase nor the gas-phase tracer injected had been detected in fluid samples taken and analyzed as of May 15 , 1992. This indicates that there is probably not a direct fracture communication between the injector and producer in this pattern.

Flowing production logs are run at the end of each injection cycle in the offending well (3332-0032). The production log consists of flowing temperature, 1-h decay temperature. 2-h decay temperature, cross-flow checks, radioactive tracer, flowing capacitance, and shut-in capacitance. An indication of successful foam performance would be increased production from less prolific zones in the offending well that are not now contributing very much as a result of the high pressure and large volume of gas produced from the high-permeability zones (Zone $\mathrm{C} 2$ and the lower portion of Zone C3). About $60 \%$ of the produced fluids is indicated to be coming out of these zones, so the production log profile is very similar to the injection tracer survey.

A series of logging runs made in the observation well during the baseline cycle indicates that the largest saturation changes are occurring in the same high-permeability zones, where the maximum fluid injection and production are in Wells 3332-001 and 3332-032, respectively. All these results are consistent with the geological interpretation of the pattern area.

\section{Future Plans}

The next JPAT meeting is scheduled for the first week of July, before initiation of the rapid SAG cycle. Results obtained to date will be reviewed, and plans for foam generation will be finalized. The rapid SAG cycle is scheduled to commence on July 14, 1992.

\section{References}

1. F. D. Martin, J. P. Heller, W. W. Weiss, and J. Tsau. $C O_{2}$-Foom Field Verification Pilot Test at EVGSAU Injection Project Phase 1: Project Plamming and Inirial Results. paper SPE/DOE 24176 presented at the Eighth Symposium on Enhanced Oil Recovery. Tulsa. Okla.. Apr. 22 24. 1992.

2. J. E. Stevens, K. J. Harpole, D. R. Zornes, and F. D. Marin. $C O$, Foam Field Verification Pilot Test at EVGSAU Phase II: Foum Injer. tion Design and Operaning Plan. paper SPE 24642 to be presented at the 67th Annual Technical Conference and Exhihition of the Societs of Petroleum Engineers, Washington. D.C.. Oct. 4-7. 1992. 


\section{THERMAL RECOVERY - SUPPORTING RESEARCH}

\section{RESEARCH ON OIL RECOVERY MECHANISMS IN HEAVY OIL RESERVOIRS}

\section{Contract No. DE-FG22-90BC14600}

\section{Stanford University}

Petroleum Research Institute

Stanford, Calif.

Contract Date: Feb. 23, 1990

Anticipated Completion: Feb. 22, 1993

Government Award: \$740,000

(Current year)

Principal Investigators:

\section{W. E. Brigham}

K. Aziz

H. J. Ramey

L. M. Castanier

\section{Project Manager:}

Thomas Reid

Bartlesville Project Office

Reporting Period: Apr. 1-June 30, 1992

\section{Objectives}

The goal of the Stanford University Petroleum Research Institute (SUPRI) is to conduct research directed toward increasing the recovery of heavy oils. Presently SUPRI is working in five main directions:

1. Flow properties research-to assess the influence of different reservoir conditions (temperature and pressure) on the absolute and relative permeability to oil and water and on capillary pressure.

2. In situ combustion studies-to evaluaie the effects of different reservoir parameters on the in situ combustion process. This project includes the study of the kinetics of the reactions.

3. Additives to improve steam injection-to investigate the mechanisms of the process using commercially available surfactants for reduction of gravity override and channeling of steam.

4. Reservoir definition-to investigate and improve techniques of formation evaluation such as tracer tests and pressure transient tests.

5. Field support services-to provide technical support for design and monitoring of DOE-sponsored or industryinitiated field projects. 


\section{Summary of Technical Progress}

\section{Flow Properties Studies}

Work continued on the $(r, z)$ numerical simulation of the oil-water relative permeability experiments to aid understanding of the results from previous runs and prediction of the saturation distributions in future runs. These simulations included the effects of the distribution plugs at the inlet and outlet ends of the core. The results indicate that the drainage displacements at low rates are dominated by capillary forces, whereas the higher rate runs show fingering at the center of the core because of uneven injection. More simulation runs will be made before the next set of experiments is conducted. The next set of experiments will be used to predict whether saturation distributions are correct and to determine the boundary conditions and the relative permeabilities. Meanwhile, capillary pressure curves are being measured with the porous plate method.

The experiment aimed at fracture-matrix transferfunction measurements is being temporarily suspended. Testing of the epoxy compounds to coat cores is continuing, but construction of the apparatus will be delayed.

\section{In Situ Combustion}

Kinetics experiments showed hydrogen/carbon $(\mathrm{H} / \mathrm{C})$ ratios of less than 1, whereas field and tube data showed values between 1 and 2 . To solve this discrepancy, kinetics experiments were carried out to simulate conditions ahead of the combustion front as follows. The rate of temperature increase was set to $150^{\circ} \mathrm{C} / \mathrm{h}$, and nitrogen was injected up to the temperature of $320^{\circ} \mathrm{C}$, after which air was injected. In both experiments the $\mathrm{H} / \mathrm{C}$ ratio was still under 1 . A systematic set of tube runs and kinetics experiments has been planner in which sand mix, air flux, and pressure will be the same, and runs will be made next quarter. A new thermocouple assembly was built that proved superior to the old one.

The results of four tube runs with metallic additives were reported in a technical report that will be sent to the Department of Energy (DOE) for review in September. An interesting result was that the addition of iron made combustion possible for $34^{\circ} \mathrm{API}$ California oil that would not burn without additives.

\section{Steam with Additives}

Mathematical analysis of the model developed for onedimensional (1-D) transient foam flow in porous media has been finalized. A paper on this project will be presented at the Society of Petroleum Engineers (SPE) Fall meeting in Washington, D.C., in October 1992. A report summarizing this project has been published by DOE.

A new report on steam-foam characterization in the 1-D model is in preparation. It includes effects of slug size, concentration, and steam quality on the pressure gradients generated by four different surfactants in a sandpack, with residual oil at about $12 \%$ saturation. Apparently the propagation rate of the foam can be correlated with the pressure gradients generated.

A report on the design and construction of the threedimensional (3-D) steam injection model for use under computerized axial tomography (CAT) scan was sent to DOE for review. Numerical simulation of the steam injection runs has continued using STARS, a commercial simulator. The preliminary results give slower steam zone growth rates than the experimental results. This shows the need to better incorporate heat losses in the simulator. In addition, steamwater relative permeability curves also need to be improved before reliable simulation can be obtained.

During this period the literature was searched on the matrix-fracture transfer functions for both isothermal (black oil) and thermal simulators. The aim was to determine the crucial variables for modeling matrix-fracture flow and to clarify measurements needed during experiments. With the use of the STARS thermal simulator, base-case fine-grid simulations were run for the system to be constructed, along with sensitivity studies to determine optimum experimental conditions and a comparison between the homogeneous and fractured cases. On the basis of these simulations, the core dimensions to be used in the experiments were determined. Two sizes of Boise sandstone blocks were ordered; one has dimensions of $20 \times 20 \times 4 \mathrm{~cm}$ for a two-dimensional (2-D) model, and the other has dimensions of $20 \times 8 \times 10 \mathrm{~cm}$ for a 3-D model.

\section{Formation Evaluation}

Numerical simulation of gravity drainage well testing has continued. No results have been obtained as yet because of problems in adapting existing numerical models to solve this complex problem. Setting the correct boundary conditions is an especially difficult problem that is currently being addressed.

\section{Field Support Services}

A nonlinear multivariate optimization algorithm is being used to study a system of separator, producing well and reservoir to maximize the economics. One surprising result of this work is that it appears economical to change tubing during the life of a project. Future work will include moredetailed economic information, muitiple well production, flowline and compietion effects, and artificial lift systems. A report on the preliminary results of this project is in the draft stage.

Data from the calibration runs on the test loop for downhole two-phase flow metering compare well with the known rates in single phase, which show that the flowmeter designed for gas-flow measurements can also accurately meter liquid flow. Tests are being run to determine the upper and lower range limits of the ultrasonic device. Testing of the flowmeter has started in air-water, two-phase flow conditions. 


\section{MODIFICATION OF RESERVOIR CHEMICAL AND PHYSICAL FACTORS IN STEAMFLOODS TO INCREASE HEAVY OIL RECOVERY}

\section{Contract No. DE-FG22-90BC14600}

\author{
University of Southern California \\ Los Angeles, Calif.
}

Contract Date: Feb. 23, 1990

Anticipated Completion: Feb. 22, 1993

Government Award: $\$ 150,000$

(Current year)

\section{Principal Investigator: \\ Yanis C. Yortsos}

\section{Project Manager: \\ Thomas Reld \\ Bartlesville Project Office}

Reporting Period: Apr. 1-June 30, 1992

\section{Objectives}

Thermal methods, particularly steam injection, are currently recognized as the most promising for the efficient recovery of heavy oil. Despite significant progress, however, important technical issues remain open. Still lacking is the knowledge of the complex interaction between porous media and the various fluids of thermal recovery (steam, water, heavy oil, gases, and chemicals). The interplay of heat transfer and fluid flow with pore- and macro-scale heterogeneity is largely unexplored.

The objectives of this contract are to continue previous work and to carry out new fundamental studies in the following areas of interest to thermal recovery: the displacement and flow properties of fluids involving phase change (condensation-evaporation) in porous media, flow properties of mobility control fluids (such as foam), and the effect of reservoir heterogeneity on thermal recovery. The specific projects are motivated by and address the need to improve heavy cil recovery fror: typical reservoirs as well as less conventional fractured reservoirs producing from vertical or horizontal wells.

\section{Summary of Technical Progress}

\section{Vapor-Liquid Flow}

Both experimental and theoretical work in the area of vapor-liquid flow continued. Displacement experiments were conducted in Hele-Shaw cells, pore network micromodels, and glass-bead-packed cells. During the past quarter emphasis was placed on the understanding of the oscillatory behavior observed during steam injection in the Hele-Shaw cells. The importance of inertia in controlling this phenomenon was investigated. It was generally found that oscillations are enhanced when the displacement is unstable, although the degree of oscillation is mitigated by the presence of the pore structure. The relevance of this mechanism to the steam injection process is under study. In parallel, the three-phase flow characteristics of steam-water-oil flow in a steam injection process with the use of glass micromodels and glass-bead packs are being investigated. Mass transfer and steam distillation effects are under study. Boiling experiments in glass micromodels also continued. During this quarter a technical paper and a topical report were prepared.'

The theoretical effort using pore network models continued. The pore network simulator is complete and has been used to understand and delineate the displacement regimes during vapor-liquid flow. As anticipated, percolation-like regimes predominate during the early stages of steam growth. Construction of phase diagrams that delineate the percolation boundary with the use of the bubble size, the ratio of thermal conductivities, and the dimensionless group $\alpha \mu /(\kappa \gamma)^{1 / 2}$ as parameters, where $\alpha$ is thermal diffusivity, $\mathrm{K}$ is permeability, $\mu$ is viscosity, and $\gamma$ is the interfacial tension, has proceeded. The flow regime that develops above this boundary appears to be more compact, and it is currently under investigation. These investigations are computationally intensive; thus alternative, simpler statistical descriptions that capture the essential aspects of the growth and displacement process in vapor-liquid flows are being explored. This work is conducted in parallel with the effort in solution gas drive. A technical paper on these subjects was presented. ${ }^{2,3}$

\section{Heterogeneity}

Experiments on heterogeneous systems focused primarily on fractured models, with micromodel geometries, and on sandpacks. A series of primary drainage experiments was completed in an element representing a matrix blockfracture configuration but in the absence of gravity. The theoretical expectation is that this process is akin to gradient percolation, a critical capillary number required before the onset of matrix penetration, the extent of which is dependent on the capillary number. Theoretical pore-network models have been used to test the theoretical predictions with quite satisfactory results, given the uncertainty involved in the knowledge of the micromodel geometry. These results are currently being summarized.

Experiments were conducted in collaboration with other colleagues $^{4}$ to test the previous theory of the effects of capillary heterogeneity on immiscible displacement processes. The agreement between experiment and theory appears excellent, as shown in Fig. 1 and summarized in a technical paper. ${ }^{4}$ The pore network model previously developed to describe displacement in a heterogeneous 
medium was used to analyze the process at the pore level. A good agreement was found between the macroscopic (continuum) and the microscopic (pore-level) predictions, which suggests that the continuum theory can be useful for an adequate description. Work is also complete on the modeling of secondary imbibition at the pore level to explain various "hyperdiffusive" phenomena. The analogy between gradients in permeability and gradient percolation was further pursued. Finally, a topical report on the effect of capillary heterogeneity on vapor-liquid counterflow and heat pipes was prepared during the past quarter. ${ }^{5}$

Work on heterogeneity and on its interaction between viscous and gravity forces continued. During the past quarter a technical paper was presented ${ }^{6}$ that extended previous work on the subject of Vertical Equilibrium to moregeneral enhanced oil recovery (EOR) processes. The applicability of this technique to steam injection processes is currently under study. Finally, investigations continued on the feasibility of fractal geometry description to naturally fractured systems. A technical paper summarizing field data where such an approach appears to be valid was prepared. ${ }^{7}$

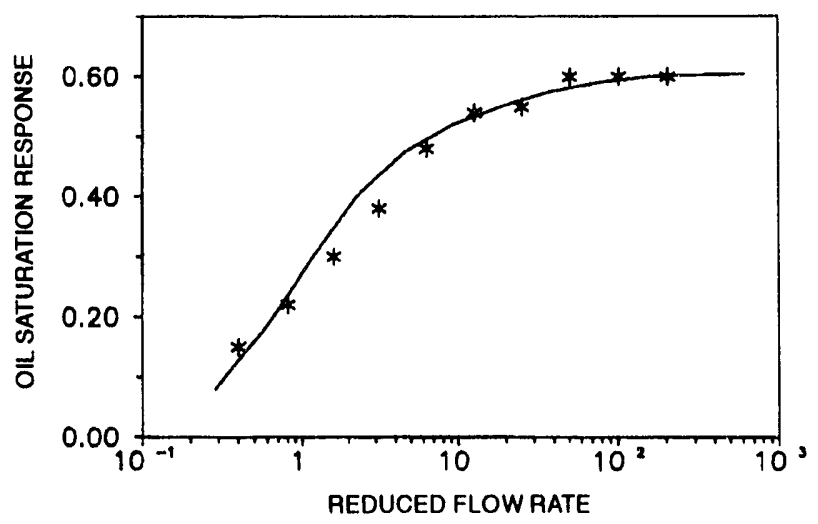

Fig. 1 Oil saturation response vs. reduced flow rate. $*$, experimental data; - , numerical prediction.

\section{Chemical Additives}

Work was completed in one area of chemical additives, and it is continuing in two other areas. Work on the use of alkaline agents at elevated temperatures was completed with the final preparation of two Ph.D. theses on the subject. ${ }^{8.9}$ No further work is considered in this area in view of the less-than-promising results obtained. ${ }^{10}$ On the other hand, the study of the flow behavior of non-Newtonian fluids in porous media has continued. Focus has been on the development of rigorous expressions for the representation of single-phase power-law fluids in porous media with the use of homogenization theory among other techniques. In parallel, the task to construct a phase diagram for the displacement of one power-law fluid by another of the same rheology in networks of straight capillaries is complete. This diagram extends that of Lenormand to power-law fluids. Experiments on non-Newtonian displacements in Hele-Shaw cells are under way. Finally, work continued on the numerical modeling of foam generation and propagation in porous media.

\section{References}

1. X. Kong, M. Haghighi, and Y.C. Yortsos, Flow Visualization of Steam Injection in Hele-Shaw Cells, Fuel (accepted 1992).

2. Y. C. Yortsos, Bubble Growth in Porous Media, Stanford University, Department of Petroleum Engineering, May 19, 1992.

3. Y. C. Yortsos, Bubble Growth in Porous Media, University of California, Santa Barbara, Department of Chemical and Nuclear Engineering. May 21, 1992.

4. M. Chaouche, N. Rakotomalala, D. Salin, and Y. C. Yortsos, Capillary Effects in Immiscible Flows in Heterogeneous Porous Media, Europhys. Lett. (submitted 1992).

5. A. K. Stubos, C. Satik, and Y. C. Yortsos, Effects of Capillary Heterogeneity on Vapor-Liquid Counterflow in Porous Media, Int. J. Heat Mass Transfer (in press) (1992).

6. Y.C. Yortsos, Analytical Studies for Processes at Vertical Equilibrium. paper presented at the 3rd European Conference on the Mathematics of Oil Recovery, June 17-19, 1992, Delft, Holland.

7. J. A. Acuna, I. Ershaghi, and Y. C. Yortsos, Practical Application of Fractal Pressure Transients Analysis in Naturally Fractured Reservoirs, paper SPE 24705.

8. R. Aflaki, Ph and Chemical Composition Profiles During Alkaline Flooding at Different Temperatures and Extended Residence Times, Ph.D. Thesis, University of Southern California, July 1992.

9. S. Saneie, Alkaline Assisted Thermal Oil Recovery: Kinetic and Displacement Studies, Ph.D. Thesis, University of Southern California, August 1992.

10. R. Aflaki and L. L. Handy, in preparation, 1992.

\section{ENHANCED OIL RECOVERY SENSING}

\section{Lawrence Livermore National Laboratory Livermore, Calif.}

Contract Date: Oct. 1, 1984

Anticipated Completion: Oct. 1, 1992

Principal Investigator:
Mike Wilt

Project Manager:

Thomas Reid

Bartlesville Project Office

Reporting Period: Apr. 1-June 30, 1992

\section{Objeetive}

The objective of this project is to monitor in situ changes in the electrical conductivity in an oil reservoir during enhanced oil recovery (EOR) operations. The goal of this 
project is to develop practical tools for geophysical monitoring of an ongoing EOR operation. Cross-borehole electromagnetic (EM) induction is being used to provide an image of electrical conductivity changes associated with an encroaching steam front. This technique is being adapted to the hostile conditions in an oil field during EOR operations.

\section{Summary of Technical Progress}

During the third quarter of 1992 the project focus was again on field activities at Richmond Field Station. Wells drilled during the first quarter of 1992 were used for an extensive saltwater injection monitoring experiment in which cross-hole EM induction was used to track an injected slug of salt water. In addition to a large set of EM measurements, an extensive suite of background data was collected, including other surface geophysical data and borehole resistivity logs. In addition to the Richmond work, a new computer code was developed for a simple analysis of field data. The new code fits EM profiles to a dipping-layered model, which is a more realistic model for field environments than the presently applied flat-layered model. Finally, some field testing of a new design for the borehole transmitter has been done. The new source coil generates the transmitted signal within the tool, and only d-c power is supplied from the surface. Field tests with this selfoscillating transmitter design show that it is less noisy than the present system.

\section{Saltwater Injection Monitoring at Richmond Field Station}

The design of this 1992 saltwater injection experiment at Richmond is similar to that used in 1991, although the 1992 experiment was considerably more ambitious in scope. First, two new observation wells were drilled to a depth of $70 \mathrm{~m}$ (EMNW and EMSE in Fig. 1), and a second injection well (INJ1) was drilled $5 \mathrm{~m}$ westward from well INJ, also to a depth of $70 \mathrm{~m}$ (Fig. 1). The second injection well was necessary because the original injection borehole was drilled only to a depth of $40 \mathrm{~m}$ and had steel screening in the open interval; it would therefore be unsuitable for deployment of an EM transmitter. The cross-hole EM measurements were made with a five-well set with the transmitter deployed in the central borehole (INJ1) and the other boreholes (EMNE, EMNW, EMSE, and EMSW) used for the receiver tool. This arrangement provides the first-order cylindrical symmetry required by the present imaging code. ${ }^{2}$ In addition to the expanded cross-hole measurements, an expanded set of supporting data was also collected. This includes induction resistivity logs in all holes before and after saltwater injection, a set of cross-hole resistivity measurements (using wells RES1 and RES2), measurements of water conductivity in all the wells before and after injection, and a set of waterlevel measurements during the extraction and recovery stages of the experiment.

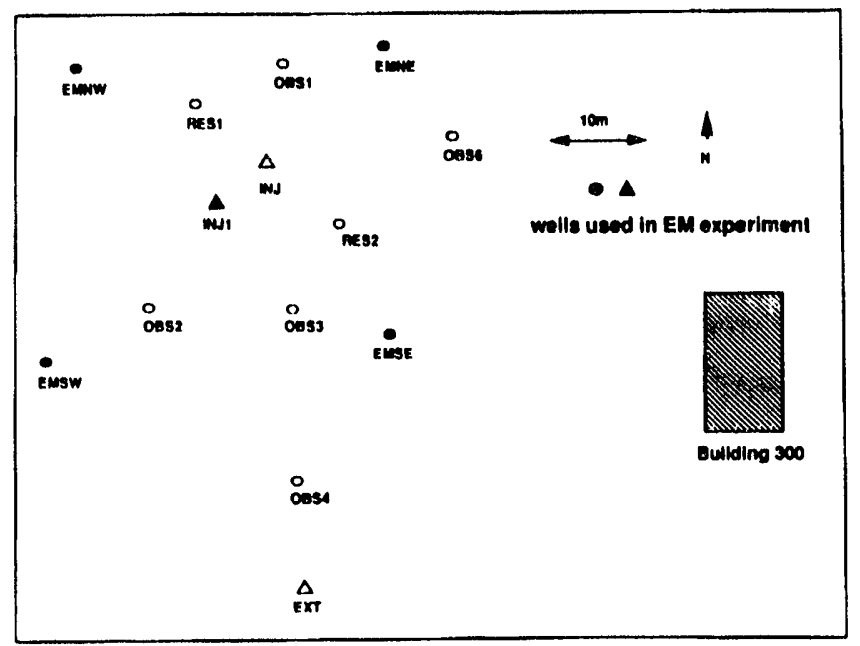

Fig. 1 Plan view of the Richmond well field.

The 1992 experiment proceeded in much the same manner as previous experiments. That is, data were collected before the fluid was injected, after injection, and after it was withdrawn. After initial system setup and a 2-week debugging session of the system, a baseline cross-hole EM data set was collected in April and May 1992. The baseline set consisted of four cross-hole profiles using well INJl for the transmitter and the outer four observation holes for deployment of the receiver tool. Data were collected at a frequency of $18,500 \mathrm{~Hz}$ using a receiver tool spacing of $5 \mathrm{~m}$, from the surface to a depth of $55 \mathrm{~m}$, and a transmitter tool spacing of $0.5 \mathrm{~m}$. Next, a volume of water was mixed with water-softening salt in a 100,000 -gal holding pond until the water resistivity was lowered to $1 \Omega-m$. This fluid was injected into borehole INJ1 at a rate of $10 \mathrm{gal} / \mathrm{min}$ for $4 \mathrm{~d}$; the total injected volume was 50,000 gal. A second set of cross-hole EM and well-log data was collected for a 4-week period after injection. Finally, the water was withdrawn and pumped into nearby San Francisco Bay. If a porosity of $30 \%$ is assumed, the injected water would sweep a cylindrical space $3 \mathrm{~m}$ high and $8 \mathrm{~m}$ in radius.

In Fig. 2 two induction logs from borehole INJ1 were examined. One of these logs was collucted before saltwater injection and the other after; the difference between them indicates the change in resistivity around the injection caused by the salt water. Figure 2 indicates that more than an $8-\mathrm{m}$ thick zone, from a depth of 23 to $31 \mathrm{~m}$, has significantly decreased in resistivity because of the saltwater injection. A comparison of the logs in the injection interval shows a mirror image, where the higher resistivity sands and gravels before the injection have become the lower resistivity units after the saltwater injection. The largest decrease is observed in a 4-m-thick sandy-gravel aquifer at a depth of 26 to $30 \mathrm{~m}$. This is the zone where the well is perforated and the rock has decreased in resistivity from 15 to $3.5 \Omega-\mathrm{m}$. Calculations from Sandia National Laboratories ${ }^{2}$ predicted that the salt water should change the formation resistivity to 


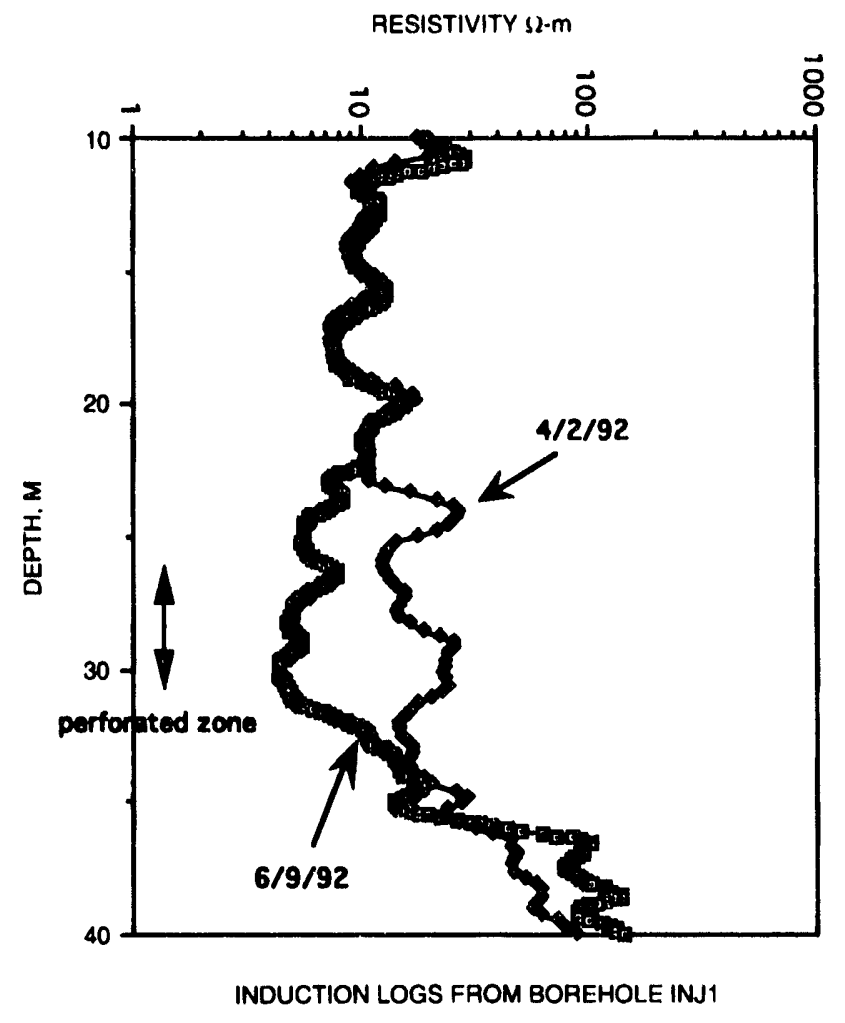

Fig. 2 Borehole induction logs in well INJ1 before and after saltwater injection.

$3 \Omega-\mathrm{m}$. These calculations were done assuming a rock porosity of $25 \%$, clay content of $20 \%$, and saltwater conductivity of $1 \mathrm{~S} / \mathrm{m}$.

Figure 3 shows the difference in EM field amplitudes for data sets collected before and after the saltwater injection. The plot gives the percent difference in amplitude with receivers positioned in borehole EMNW with the transmitter located in borehole INJ1. The profile plot shows a maximum difference of more than $30 \%$ in amplitude in a narrow zone centered around the injection zone ( 26 to $30 \mathrm{~m}$ ). These results are very much in accord with predicted results from modeling by Alumbaugh and Morrison ${ }^{1}$ and suggest that their imaging code could be effectively applied on this data set. More-complex patterns were observed for other profiles before and after saltwater injection.

\section{New One-Dimensional Inversion Scheme}

Because oil fields seldom are configured as flat-lying layered structures, a one-dimensional (layered) interpretation of cross-hole EM data often only has limited value. The next step of complexity is to include formation dip in

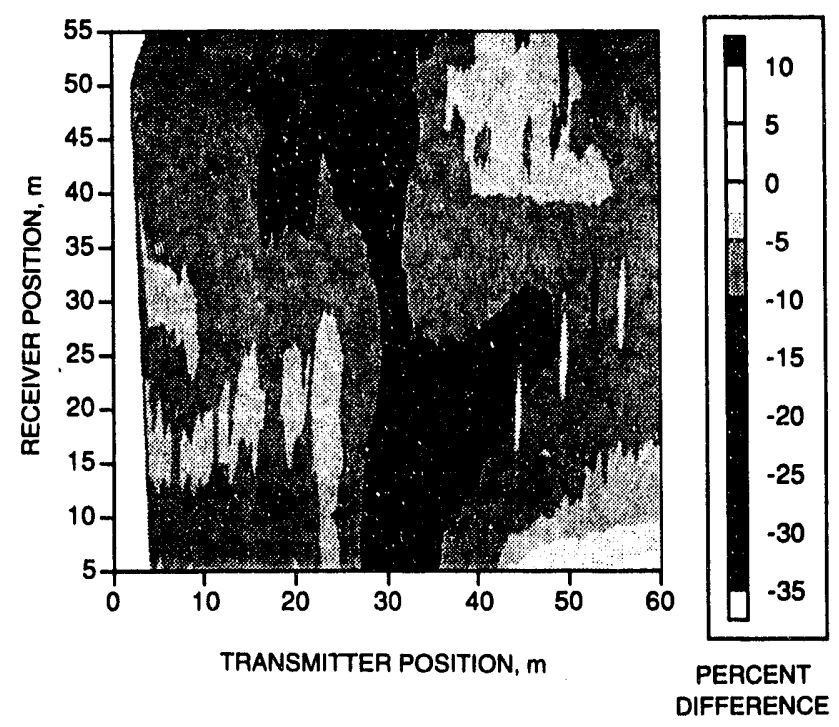

Fig. 3 Amplitude difference for profile EMNW before and after saltwater injection.

the layered model interpretation. The standard flat-layered model inversion now includes this option.

The updated model was applied to the EM data set collected at the Lost Hill No. 3 oil field, ${ }^{3}$ and a closer fit to the field data and a better match with the borehole induction log were obtained with this model than with the previous flat-lying layered model.

\section{New Transmitter Tool Design}

The recent measurements at the Richmond Field Station have shown that, at higher frequencies, this system is still susceptible to 2 to $3 \%$ noise through surface-coupling of the source signal to the receiver. By making use of a design whereby the coil self-oscillates and only d-c power is supplied from the surface can this source of noise be eliminated. This design was recently tested in field trials at Richmond, and the results are encouraging. A new high-power borehole transmitter is presently being built using this design and should be ready for testing by October 1992.

\section{References}

1. M. J. Wilt, Enhanced Oil Recovery Sensing, Enhanced Oil Recovery, Progress Review, April-June 1991, DOE Report DOE/BC-91/3, 1992.

2. D. L. Alumbaugh and H. F. Morrison, Tomographic Imaging of Cross Well EM Data, Extended abstracts from the Society of Exploration Geophysicists 1992 Annual Meeting, New Orleans, La., 1992.

3. M. J. Wilt, Enhanced Oil Recovery Sensing, Enhanced Oil Recovery, Progress Review, January-March 1992, DOE Report DOE/BC-92/2, 1993. 


\section{THERMAL PROCESSES FOR LIGHT OIL RECOVERY}

\section{Cooperative Agreement DE-FC22-83FE60149, Project BE11A}

\author{
National Institute for Petroleum \\ and Energy Research \\ Bartiesville, Okla.
}

Contract Date: Oct. 1, 1983

Anticipated Completion: Sept. 30, 1992

Funding for FY 1992: $\$ 295,000$

Principal Investigator:
David K. Olsen

Project Manager:

Thomas Rold

Bartlesville Project Office

Reporting Period: Apr. 1-June 30, 1992

\section{Objectives}

The FY92 objectives are to (1) develop a procedure and apparatus for measuring dynamic saturation changes in steamfloods using an X-ray computerized tomography (CT) scanner and incorporate temperature and pressure measurements to calibrate a numerical simulator for predictive purposes; (2) conduct laboratory research in support of $\mathrm{Na}$ val Petroleum Reserve (NPR) No. 3, Teapot Dome (Wyoming) field light oil steamflood; (3) conduct laboratory research in support of NPR No. 1, Elk Hills (California) field light oil steamflooding pilot; (4) transfer technology developed from this project to others in the field of thermal oil production; and (5) participate in the Annex IV meetings between the Department of Energy (DOE) and the Venezuelan Ministry of Energy and Mines.

\section{Summary of Technical Progress}

Research on objectives $1,3,4$, and 5 was pursued this quarter. The Mar. 27, 1992, review of the National Institute for Petroleum and Energy Research's (NIPER's) steamflood laboratory by the DOE/NIPER self-assessment Environmental Safety and Health (ES\&H) Group resulted in suspension of construction until detailed schematics and operating guidelines were prepared and approved.

Schematics and operating guides were prepared and examined by the Configuration Review Committee and have provided a better understanding of the ES\&H risks and limitations for the experiments. The titanium steamflood model being constructed may contain as much as 2 gal of light crude oil at temperatures as high as $520^{\circ} \mathrm{F}$ and pressures to 812 psi. These limits are imposed by the thermal stability of the insulating material used on the inside of the model. Higher temperature and pressure are achievable when Kalrez is used as the insulating material. Three reports addressing the configuration and uperation,' status of laboratory construction, ${ }^{2}$ and software ${ }^{3}$ developed for data acquisition-control-analysis-presentation were completed. Safety and operational concerns have prompted reexamination of the location of the laboratories and examination of the modular software developed to operate this laboratory. This laboratory automation was designed so that the program would be general and could be configured to a wide variety of laboratory-pilot-plant automation applications. NIPER developed the background and extensive applications using object-oriented programming software with National Instruments ${ }^{\mathrm{TM}}$ LabVIEW $^{\circ}$ as the programming platform.

Results of research ${ }^{4}$ conducted over the last 18 months as task 52 on light oil steamflooding were compiled. This research was presented to the DOE/Venezuelan Ministry of Energy and Mines as part of the Annex IV technology transfer. This report ${ }^{4}$ included analysis of a personal computer based semianalytical steamflood predictive model. ${ }^{5-7}$ Laboratory research included the results of three two-dimensional (2-D) steamflood experiments conducted to test steamflooding and steamflooding conducted after waterflood on NPR No. 1, Shallow Oil Zone (SOZ) core and oil. The SOZ was the site of a steamflood pilot test ${ }^{8}$ undertaken to determine the feasibility of thermal recovery of some of the 100-million-barrel reserve of $28^{\circ} \mathrm{API}$ crude in the eastern portion of the SOZ at NPR No. 1 (Ref. 8). Experiments were initiated in 1990, and research was discontinued before termination of the steamflood field pilot in the fourth quarter of 1991. NIPER's 2-D laboratory experiments reflected behavior and other problems similar to those observed in the field pilot.

These experiments used friable core-sand from well $115 \mathrm{~W}-10 \mathrm{G}$. The larger pieces were crushed and sieved to 10 to 40 mesh before being packed into the NIPER 2-D steamflood model. A description and operation of the laboratory model were previously described. ${ }^{9}$ Because of the large mesh size and the high clay, carbonate, and oil content of the sand, the model was packed open-faced.

The first steamflood in the 2-D model used the friable core-sand from a depth of 2828 to $2831 \mathrm{ft}$ (well 115W10G). Dean Stark analysis showed that the core material packed into the model had an oil content of $7.5 \mathrm{wt} \%$. This account is for $10.9 \%$ of pore volume (PV). The model was saturated with the simulated formation brine. The pore volume and porosity of the model were $55.0 \%$. Permeability was $581 \mathrm{mD}$. The model was heated externally to $125^{\circ} \mathrm{F}$, and the brine in the model was displaced with oil in a recycling system (i.e., produced oil was reinjected) to achieve $61 \%$ oil saturation [original oil in place (OOIP)]. The backpressure on the 2-D model was set to $150 \mathrm{psi}$, which corresponds to a steam temperature of $355^{\circ} \mathrm{F}$. 
A steamflood of the 2-D sandpack was conducted for over $21 \mathrm{~h}$ with an average cold-water equivalent (CWE) steam injection rate of $4.65 \mathrm{~mL} / \mathrm{min}$. Steamflood recovered $55.3 \%$ of the OOIP and thus reduced the oil saturation from 61.0 to $27.3 \%$, as shown in Fig. 1. Nearly half the recovered oil was recovered within $5 \mathrm{~h}$, with the majority being produced between hours 3 and 5. When compared with NIPER's 2-D steamfloods in Quartz sands, this is a very early production of the oil bank. Differential pressure in the 2-D model averaged $20 \mathrm{psi}$ higher during this run than in 2-D steamfloods of 1.5to 3-darcys permeability Quartz sands. Adjustments in the cold-water pump rate to feed the steam generator were made to keep the differential pressure from becoming excessively high. At the time the abnormally high differential pressure was thought to be caused by swelling clays or reaction of steam with some of the carbonaceous material in the sand.

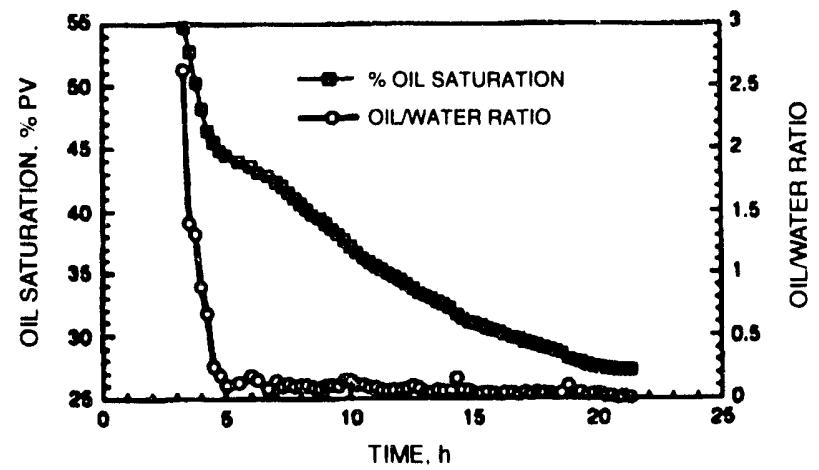

Fig. 1 Results of steamflood only in 2-D model with Shallow Oil Zone core (depth of 2828 to $2831 \mathrm{n}$ ), brine and oil.

Throughout the steamflood, an excess of carbon dioxide was produced at the outlet.

Second and third 2-D floods on SOZ sandpacks were designed to test the effectiveness of conducting a steamflood after a waterflood. These floods also used SOZ core from well $115 \mathrm{~W}-10 \mathrm{G}$ but from a depth of 2823 to $2825 \mathrm{ft}$. Dean Stark analysis showed that the sand charged to the model contained $9.1 \%$ PV of oil and $8.3 \%$ PV of brine. The model was externally heated to $150^{\circ} \mathrm{F}, 25^{\circ} \mathrm{F}$ higher than the previous test. The permeability was $482 \mathrm{mD}$. After an extensive $(>30 \mathrm{~h})$ oil injection, the oil saturation reached only $51.1 \%$. The waterflood recovered $38.1 \%$ of the OOIP. This waterflood oil recovery corresponded to a reduction in oil saturation from 51.1 to $31.6 \%$. The majority of the oil was once again recovered very early (i.e., within $3.5 \mathrm{~h}$ of the start of the run). The size of the waterflood recovery (Fig. 2) was similar to that of the previous run (Fig. 1, steamflood only from the beginning), which indicates that a waterflood was nearly as effective as a steamflood under these laboratory conditions. After the waterflood, a steamflood was initiated. The average rate of steam injection during the steamflood was $4.62 \mathrm{~mL} / \mathrm{min}$ (cold-water equivalent). Although the steamflood reduces

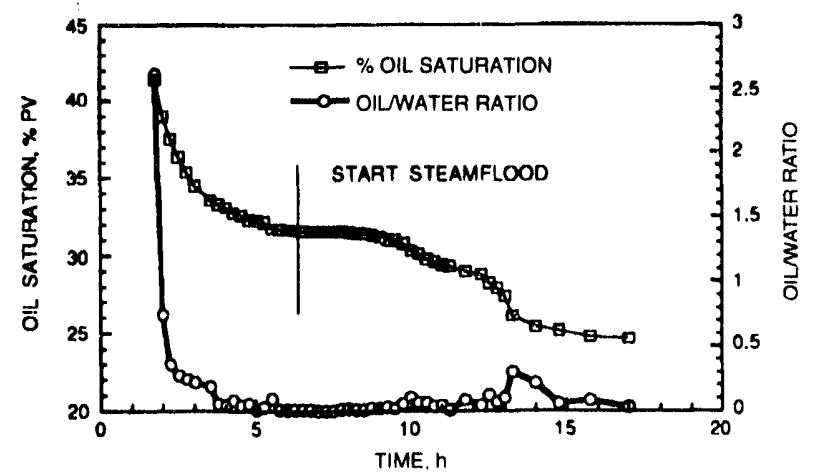

Fig. 2 Results of steamflood in 2-D model with Shallow Oil Zone core (depth of 2823 to $2825 \mathrm{ft}$ ), brine and oil where the model is first waterflooded to residual oil saturation and then steamflooded. Down time for acidization is not included in time.

the oil saturation to a lower level, on the basis of these two laboratory tests, steam looks to be an expensive way to achieve about the same oil recovery as a waterflood. Implementation of steam after a waterflood does not look feasible because of the low oil saturation remaining after the waterflood.

In the second test the steamflood was initiated $3 \mathrm{~d}$ after the waterflood. Three hours after the start of steam injection, the steam injection rate had to be reduced because the pressure within the model had increased, approaching the upper pressure safety limit of NIPER's 2-D model. After the first hour high, $\mathrm{CO}_{2}$ production was noticed which continued throughout the experiment. Diagnosis of the pressure problem showed that the major pressure drop in the system was occurring at the production end of the model, where several stainless steel screens are placed to prevent sand from moving down the production line. Steam injection into the model was temporarily halted, and the pressure in the model was reduced. The production end of the model was treated (backflushed) with $10 \mathrm{~mL}$ of dilute hydrochloric acid $(\mathrm{HCl})$. Lines were reconnected, and steam was diverted back to the model. A large quantity of fines was produced, which caused plugging of the downstream filter. Produced fluids were then diverted to a second set of parallel filters. This acid treatment was an attempt to remove carbonate scale buildup on the production end of the model. Production of hot oil and water proceeded normally after acidization for nearly $2 \mathrm{~h}$, at which time the pressure again increased, and within $3 \mathrm{~h}$ of the initial acidization, overpressuring of the model reached the model's safety limit. Acidization and replacement of the filters were repeatedly tried, but the problem of pressure buildup occurred within a few hours and persisted throughout the duration of the experiment.

Analysis of the plot of the second steamflood (Fig. 2) indicated that a small volume of oil is produced $3 \mathrm{~h}$ after steam injection ( $9.5 \mathrm{~h}$ cumulative time), just as the production end of the model becomes hot and steam breaks 
through to the producer. Steam breakthrough was assumed to occur when the temperature of the thermocouple in the production stream (connecting line from the 2-D model) was within $10^{\circ} \mathrm{F}$ of the steam injection temperature. This is when plugging problems occurred at the screens located at the production end of the 2-D model. A second small slug of oil is produced during hours 6 to $7(12.5$ to $13.5 \mathrm{~h}$ cumulative time), at which time the model again experienced plugging at the production end of the model. The volume of this second slug was larger because the model had been heated more thoroughly but experienced rapid pressure buildup ( 5 min to increase $100 \mathrm{psi}$ ) because of plugging of the screens when the steam broke through to the producing end. The steamflood was terminated after $11 \mathrm{~h}$ of steam injection ( $17.5 \mathrm{~h}$ cumulative time) with only an additional $7.6 \%$ PV or $13.7 \%$ of OOIP produced. The waterflood and steamflood recovered only $51.8 \%$ of OOIP. This is only $3.5 \%$ less than the first run with only a steamflood without a waterflood. The oil produced during the steamflood amounted to $22.1 \%$ of the oil left in the model after waterflood. The final oil saturation of the model at the end of steamflood was $24.6 \%$.

\section{References}

I. D. K. Olsen, S. M. Mahmond, P. S. Sarathi, and E. B. Ramzel, Operating Guide and Specifications for NIPER Steamflond Laboratory, DOE Report NIPER-603. June 1992.

2. S. M. Muhmood and D. K. Olsen, General-Purpose Automation Programming: A Case Study on Using a Graphic Language, NIPER-596, June 1992.

3. D. K. Olsen, S. M. Mahmood, P. S. Sarathi, and E. B. Ramzel, Status of Reconstruction of Steamflond Laboratory. DOE Report NIPER-612, July 1992.

4. D. K. Olsen, P. S. Sarathi, S. M. Mahmood, E. B. Ramzel, and S. D. Roark, Research of Task 52 Research on Light Oil Steamflooding. NIPER-605, June 1992.

5. R. J. Gajdica, A Semianalytical Model for Linear Steam Drive, Ph.D. Thesis, Stanford University, 1990.

6. R. J. Gajdica, W. E. Brigham, and K. Aziz, A Semianalytical Model for Linear Steam Drive, SUPRI-TR75, DOE Report DOE/BC/1412621. May 1990.

7. P. Sarathi, Thermal Processes for Heavy Oil Recovery, NIPER-566, September 1991.

8. F. J. Gangle, G. V. Weyland, J. P. Lassiter, and E. J. Veith, Light Oil Steamdrive Pilot Test at NPR-1. Elk Hills, Califomia, paper SPE 20032 presented at the $(6)$ th California Regional Meeting. Ventura, Calif., Apr. 4-6, 1990

9. P. S. Sarathi, S. D. Roark, and A. R. Strycker, Light-Oil Steamflooding: A Laboratory Study, Soc. Pet. Eng. Reserv. Eng.. 177-184 (May 1990).

\section{THERMAL PROCESSES FOR HEAVY OIL RECOVEAY}

\section{Cooperative Agreement DE-FC22-83FE60149, Project BE11B}

\author{
National Institute for Petroleum \\ and Energy Research \\ Bartlesville, Okla.
}

Contract Date: Oct. 1, 1983

Anticipated Completion: Sept. 30, 1992

Funding for FY 1992: $\$ 200,000$

\section{Principal Investigator:}

Partha Sarathi

Project Manager:

Thomas Reid

Bartlesville Project Oftice

Reporting Period: Apr. 1-June 30, 1992

\section{Objectives}

The FY92 objectives are to (1) evaluate computer modeling groups (CMG) "STARS" steamflood simulator, (2) conduct model and reservoir studies to determine the applicability of thermal enhanced oil recovery (EOR) technique in the Nacatoch sands of Arkansas and Louisiana, and
(3) collect information-data on the resource and economical rec'svery of heavy oil from the West Sak reservoirs in Alaska.

\section{Summary of Technical Progress}

\section{Compilation of the Steamflood Operator's Guide}

As part of the technology transfer work under thermal processes for heavy oil recovery, a handbook on the practical aspects of steam injection processes (NIPER-580) was prepared. The final review of the manuscript was completed in early June. Copies of the final report will be submitted to the Bartlesville Project Office in early July.

\section{Evaluation of the Steamflood Potential in Nacatoch Sands of Arkansas}

The principal objective of this task is to conduct an indepth simulation study to assess the viability of the steam injection process in the thin, moderately heavy oil Nacatoch reservoirs of Arkansas. If the study establishes the technical and economic viability of the process, it may encourage independent operators who own these leases to implement this proven technology in their leases to increase recovery.

In the last quarter, through the use of the Department of Energy's (DOE's) steamflood predictive models, five Nacatoch heavy oil reservoirs were identified as potential steamflood candidates. The screening studies showed that Charavari Creek, Elliott-South, Irma, Sandy Bend, and TroyOld reservoirs have the greatest potential for enhancing oil 
recovery through the use of steam. Predictive models are screening tools and as such cannot be used to further delineate the prospects. The viability of the steam injection process can be established only through reservoir performance analysis. Numerical simulators are valuable tools for predicting reservoir performance under various operating strategies. Field-scale steam injection simulation study, however, is a slow and complicated process and does require significantly more engineering and computer time than screening studies.

Time and manpower constraints, however, preclude the in-depth performance analysis of all the identified prospects. The project objectives can be met by confining the simulation studies to one or more target reservoirs. Hence two reservoirs, Charavari Creek and.Irma, were selected for in-depth study. The selection was based on the availability of needed data for simulation and the existence of prior steam injection history, if any.

In this quarter the geology and the rock-fluid data on Charavari Creek field were reviewed to assemble needed data for simulation. Preliminary cyclic steam injection simulations were also performed to assess the responsiveness of the reservoir to steam injection.

\section{Reservoir Geology}

Charavari Creek field is about 35 miles northeast of El Dorado in the lowes part of Bradley County, Ark. Bradley County is in the southern portion of the state, within the Mississippi Alluvial Plain and the Gulf Coastal Plain. The field is in T17S, R10W, Secs. 6 and 7 and R11W, Secs. 1 and 12. The total extent of the field is 540 acres, of which 300 acres are productive.

Charavari Creek field production is obtained from the Nacatoch sand at a depth of $2350 \mathrm{ft}$. The Nacatoch formation is Upper Cretaceous in age and is approximately $80 \mathrm{ft}$ thick. The upper $30 \mathrm{ft}$ is nonproductive. The balance of the pay is divided into 5 zones. Zones 1 to 4 are in communication with each other. Zone 5 is isolated from the upper zones by a 2 - to 8 -ft-thick shale bed.

Zones 2 and 3 are the important oil-producing zones with a combined gross pay of $20 \mathrm{ft}$ and net pay of $18 \mathrm{ft}$. The sand is relatively clean fine-grained quartz with varying amounts of silt. Zone 1 is also predominantly finegrained quartz sand interbedded with shale, siltstone, and limestone. Most of the shale and all the limestone are deposited as an erodal type and not as a bed. Zone 1 is a minor oil-producing zone with a gross pay of $3 \mathrm{ft}$ and a net of $2 \mathrm{ft}$. Zone 4 is isolated by a $2-\mathrm{ft}$ shale from the upper zones and carrier water and no oil. The average gross pay of this zone is $13 \mathrm{ft}$ with no net pay. Zone 5 is very silty and shaley and carries only water.

The trap for the oil accumulation is stratigraphic. The oil-bearing sand pinches out east, west, and south. The north boundary of the sand is truncated by a fault. The oil-water contact appears to be somewhat erratic from -2289 to
$-2.348 \mathrm{ft}$. For betler understanding of the reservoir, new isopach maps of the net pay and east-west and north-south structure maps were prepared. The new maps offered a much clearer description of the field. On the basis of the information from the new maps, approximately 100 acres of undeveloped productive area was identified. The reservoir has no active water drive.

\section{Rock and Fluid Properties}

The reservoir permeability ranges from a low of 27 to a high of $900 \mathrm{mD}$. The average permeability is $250 \mathrm{mD}$. Porosity ranges from 20 to $35 \%$ with an average porosity of $29 \%$. The oil is paraffinic in nature, and the gravity ranges from 16 to $19^{\circ} \mathrm{API}$, with an average of $18^{\circ}$. The viscosity of the crude is $202 \mathrm{cP}$ at bottomhole temperature of $110^{\circ} \mathrm{F}$. The average reservoir parameters are summarized in Table 1. These parameters were derived from an analysis of log and core data furnished by the current operator of the field (Emco Operating Co. Inc., Shreveport, La.). The crude oil distillation analysis is summarized in Table 2 . The formation water analyses are depicted in Table 3 . The crude and formation water analyses were furnished by Phillips Petroleum Co., Bartlesville, Okla. The viscosity-temperature relations are shown in Table 4.

\section{TABLE 1}

\begin{tabular}{ll} 
Average Reservoir Parameters for the \\
Steamfloodable Area Charavari Creek \\
(T17S, R11W, Secs. 1 and 12) Field, \\
\multicolumn{2}{c}{ Bradley County, Ark.* } \\
\hline Productive acreage, acres & 100 \\
Depth, ft & 2.350 \\
Current oil in place. MMSTB & 2.12 \\
Oil gravity, ${ }^{\circ}$ API & 18 \\
Reservoir temperature, ${ }^{\circ}$ F & 110 \\
Reservoir pressure, psig & $2(00$ \\
Net pay thickness, ft & 21 \\
Oil viscosity at reservoir temperature, cP & 202 \\
Oil saturation, bbl/acre-ft & 1,012 \\
Porosity, \% & 29 \\
Average permeability, mD & 250 \\
Estimated oil saturation. \% & 45 \\
Estimated water saturation, \% & 55 \\
\hline
\end{tabular}

*See Ref. 1.

\section{Cyclic Steam Injection Simulation Results}

A cyclic steam simulation of an existing well (Potlatch A4, located in T17S, R11W, Sec. 12) was conducted using the "STARS" simulator to assess the responsiveness of the reservoir to steam. This preliminary simulation study indicated that the reservoir will respond favorably to steam, and a significant improvement in oil production rate is possible. 
TABLE 2

\begin{tabular}{ll} 
Charavari Creek Crude Oil Test Summary** \\
\hline General crude tests & Paraffin \\
Type & 19.6 \\
Gravity, ${ }^{\circ} \mathrm{API} @ 60^{\circ} \mathrm{F}$ & 3.2 \\
Sulfur, \% & 30 \\
Pour point, ${ }^{\circ} \mathrm{F}$ & 348 \\
Av. mol wt & \\
Distillation yields (Hempel) & \\
Gasoline: (424 ${ }^{\circ} \mathrm{F}$ - EP) & 14.1 \\
Percent & 61.8 \\
API @ 60 ${ }^{\circ} \mathrm{F}$ & $<0.02$ \\
Sulfur, \% & 17.2 \\
Kerosene: & 41.8 \\
Percent & 0.6 \\
Gravity, ${ }^{\circ} \mathrm{API} @ 60^{\circ} \mathrm{F}$ & \\
Sulfur, \% & 37.2 \\
Gas-oil & 25.2 \\
Percett & 2.6 \\
Gravity, ${ }^{\circ} \mathrm{API} @ 60^{\circ} \mathrm{F}$ & \\
Sulfur, \% & 31.5 \\
Still residue: & 6.0 \\
Percent & \\
Sulfur, \% & \\
\hline
\end{tabular}

*See Ref. 2.

TABLE 3

\begin{tabular}{ll}
\multicolumn{2}{c}{$\begin{array}{l}\text { Charavari Creek Formation } \\
\text { Water Analysis* }\end{array}$} \\
\hline Constituents & ppm \\
\hline Sodium & 21.660 \\
Calcium & 3.406 \\
Magnesium & 743 \\
Iron & 10.1 \\
Barium & 11.4 \\
Chloride & 41.561 \\
Bicarbonate & 73.5 \\
\hline
\end{tabular}

*See Ref. 2.

TABLE 4

Charavari Creek Crude Temperature-Viscosity Relation*

\begin{tabular}{cr}
$\begin{array}{c}\text { Temperature, } \\
{ }^{\circ} \mathbf{F}\end{array}$ & $\begin{array}{c}\text { Viscosity, } \\
\text { cP }\end{array}$ \\
\hline 60 & $1,391.7$ \\
110 & 201.9 \\
160 & 54.5 \\
210 & 21.4 \\
260 & 10.5 \\
310 & 5.9 \\
\hline
\end{tabular}

${ }^{*}$ See Ref. 3.
Figure 1 shows the cumulative oil production and oil/steam ratio as a function of time for this simulation. For this 3-cycle simulation, the average daily oil production increased from $3 \mathrm{bbl} / \mathrm{d}$ before steam stimulation to $25 \mathrm{bbl} / \mathrm{d}$ after stimulation. The cumulative oil recovery was $5000 \mathrm{bbl}$ at the end of $400 \mathrm{~d}$. Further studies are in progress.

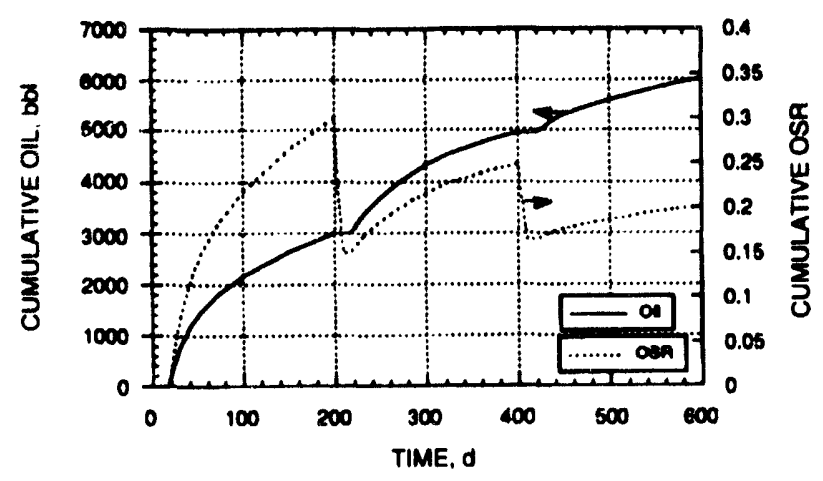

Fig. 1 Cumulative oil and cumulative oll/steam ratio (OSR) histories for Potlatch A-4 well in Charavari Creek field under the candition of no hydraulic fracturing in the well.

\section{References}

1. Emco Operating Co. Inc., Shreveport, La., June 1992.

2. David R. Zornes, Phillips Petroleum Co., Bartlesville, Okla., personal communication, June 1992.

3. Charavari Creek Crude, Laboratory Analysis Data, Emco Operating Co. Inc., Shreveport, La., June 1992.

FEASIBILITY STUDY OF HEAVY OIL RECOVERY IN THE MIDCONTINENT REGION: OKLAHOMA, KANSAS, AND MISSOURI

Cooperative Agreement DE-FC22-83FE60149, Project SGP37

National Institute for Petroleum and Energy Research

Bartlesville, Okla.

Contract Date: Apr. 1, 1990

Anticipated Completion: June 1, 1992

Funding for FY 1992: $\$ \$ 839, \mathbf{4 0}$

Principal Investigator: David K. Olsen

Project Manager:

Thomas Reld

Bartlesville Project Office

Reporting Perlod: Apr. 1-June 30, 1992 


\section{Objectives}

The objectives of this research program are to (1) determine the known heavy oil resources of the United States. (2) evaluate the refinery capabilities, and (3) determine if steam or other enhanced oil recovery (EOR) processes are applicable to economic production of this resource.

\section{Summary of Technical Progress}

\section{Healy Oil Database}

A study was initiated to assess the potential impact on the U.S. refining industry if additional heavy oil resources were developed. The study also considers the economic limitations on production of heavy oil on a regional basis to determine what regions of the country have the greatest potential for increased production of heavy crude oil. This effort included a study of and a comparison with the resource in California because most of the domestic heavy oil is currently being produced in California.

The first phase of heavy oil data collection for California reservoirs was completed this quarter. A review of the data indicates that some of the information may be in error and additional information is needed. All the data collected to date were derived from published sources. ${ }^{1-11}$ Some discrepancies and inconsistencies between information sources are being reviewed, and, where available, original maps and logs of selected reservoirs are being consulted.

Initially, the purpose was to identify all the possible heavy oil reservoirs in C.lifornia with oil in place (OIP) exceeding 10 million bbl. Upon completion of this initial effort, a review was initiated to determine which of these reservoirs should be excluded (light oil reservoir erroneously reported as heavy oil, revised reservoir parameters showing less than 10 million bbl of OIP, etc.). Average reservoir parameters are currently being updated and revised.

On the basis of the initial set of data, a general comparison of heavy oil reservoirs between different states was made and is given in Table 1. Most of the heavy oil produc- tion activities have been and are currently being concentrated in California. As shown in Table 1, California has the best reservoir characteristics of all the states. Most of the known heavy oil reservoirs are in California, and these reservoirs have the highest saturation values (average $1250 \mathrm{bbl} / \mathrm{acre}-\mathrm{ft}$ ). In addition, most of these reservoirs are unconsolidated or friable sands. Previous reviews of heavy oil activities under this program have shown that chances of economic success decrease for production of heavy oil from consolidated reservoirs. A majority of the heavy oil reservoirs in California are less than $3000 \mathrm{ft}$ deep, and nearly all of them are less than $5000 \mathrm{ft}$. Steamflooding is the most commercially successful process used to recover heavy oil, and when steam is applied to deeper reservoirs, the profit margin of the process decreases.

In contrast to heavy oil reservoirs in California, heavy oil reservoirs in other states are less attractive for one or more reasons. For example, many of the reservoirs in Arkansas have thin net pay zones. Consequently only $6 \%$ of the reservoirs in Arkansas exceed the minimum saturationthickness criteria $\left[\left(\phi * S_{0}\right)>0.08\right.$ and net pay $>20 \mathrm{ft} \mid$. All the other categories look attractive for Arkansas. Many of the reservoirs are unconsolidated or friable. most of the reservoirs are shallow, and the average saturations show some production potential. Indeed, some reservoirs have previously been steamed on a pilot or commercial basis in Arkansas.

Except for California, Texas shows the best promise for increased heavy oil development. Many of the reservoirs are unconsolidated or friable, many of the reservoirs are sufficiently shallow, and the average saturation value is the next highest to that of California in the United States. This suggests that many of the reservoirs in Texas have a sufficiently high saturation of heavy oil to economically justify further consideration. As with Arkansas, however, many of the reservoirs are thin. Thin reservoirs are less attractive for steamflood applications because of higher heat losses in the reservoir and less oil production per barrel of steam injected.

TABLE 1

Co nparison of Heavy Oil Reservoirs Between Different States of the United States

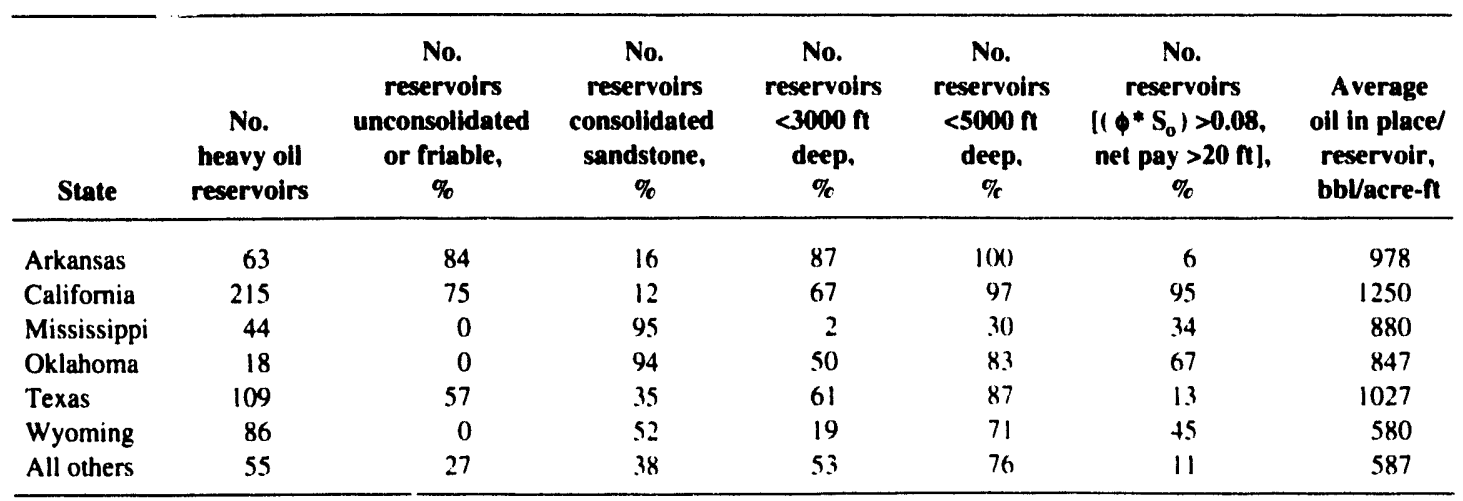


All other areas of the country are less attractive to major expansion of heavy oil recovery. Reservoirs in Mississippi are mostly consolidated, much deeper than those in California, Arkansas, or Texas, and somewhat lower in average saturation values. Reservoirs in Oklahoma are similarly consolidated with lower saturation values. Aver:".e saturation values in Wyoming and other states are much wwer, showing little promise for major expansion. Furthermore, these reservoirs are also predominantly consolidated and somewhat lower in net pay values. Isolated cases of attractive reservoirs do exist within these regions, but overall these areas do not show significant potential for increased heavy oil production.

\section{Reports on Heavy Oil Feasibility}

Review'2 of the Appalachian, Illinois, and Michigan basins shows that there are only seven heavy oil reservoirs listed in the literature that have an API gravity between $10^{\circ}$ and $20^{\circ}$. This makes these basins a very small target for future potential heavy oil production. Several reservoirs have low pour point oils that fit the definition of heavy oil on the basis of oil viscosity $(100)$ to 10,000$) \mathrm{cP}) .^{13}$ The magnitude of this latter resource has not been defined because of the lack of publicly available oil viscosity data in the area.

Bonner and Moore Management Science was subcontracted to analyze the potential effects on the U.S. refining industry on the basis of NIPER's projected increase ${ }^{14}$ in heavy oil production. ${ }^{15}$ The critical effect of oil composition on this analysis was demonstrated. Unfortunately the composition of the projected recoverable heavy oil is of higher sulfur content than that currentiy produced. Additional simulations of the numerical refining model will be conducted at higher sulfur concentrations to determine the impact (investment level needed) to accommodate the projected increases in heavy oil.

The economics of thermal heavy oil production is illustrated in Fig. 1, which is a plot of the posted price for the

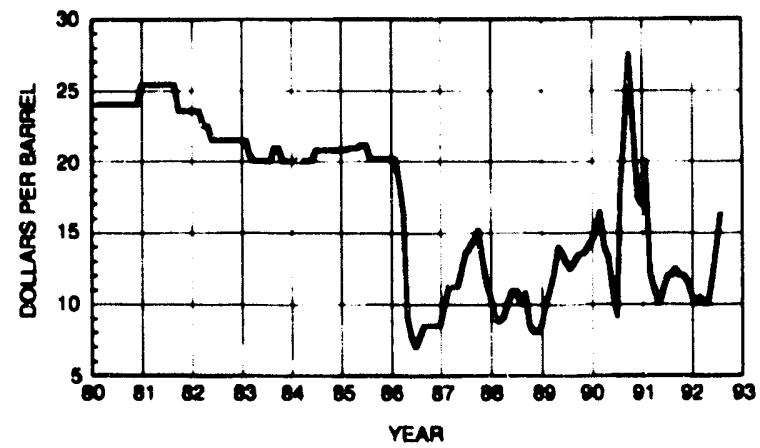

Fig. 1 Posted prices for $13{ }^{\circ}$ API gravity, Kern River, California, oil. ${ }^{16-17}$ benchmark California heavy oil, $13^{\circ} \mathrm{API}$ gravity, Kern River crude. ${ }^{16-17}$

Since thermal operations rely upon long-term investment in heat (steam), a constant cash flow is critical. From March 1992 to June 1992, the Kern River oil price has increased from $\$ 10.00$ to $\$ 16.25$ per barrel. The posted price early this year reflects an extremely depressed market, which significantly deviated from the average of two-thirds of the price of West Texas Intermediate. The cyclic price for oil at or near the break-even price for thermal heavy oil production discourages the high long-term investment necessary to develop domestic heavy oil.

\section{References}

1. Califomia Department of Conservation. Division of Oil and Gas, 76th Annual Report of the State Oil and Gas Supervisor. 1990 (also for 1988 and 1989 ).

2. Califomia Department of Conservation, Division of Oil and Gas, California Oil and Cas Fields: Central California. Vol. 1. 1985.

3. California Department of Conservation, Division of Oil and Gas, California Oil and Gas Fields: Southern. Central Coastal, and Offshore California. Vol. 2, 1985 and 1991.

4. Califomia Department of Conservation, Division of Oil and Gas. California Oil and Gas Fields: Norrhem California. Vol. 3, 1983.

5. B. L. Crysdale and C. J. Schenk, Heavy Oil Resources of the United States, U.S. Geol. Surv.. Bull., 1885 (1990).

6. Conservation Comrnittee of California Oil Producers. Annual Review of California Oil and Gas Production. 1990 and 1991 (also for years 1987 (0 1989).

7. W. D. Dietzman, M. Carrales, Jr., and C. J. Jirik, Heavy Crude Oil Reservoirs in the United States: A Sunvey. U.S. Department of the Interior, Bureau of Mines. Information Circular 826.3. 1965.

8. International Oil and Gas Development, International Oil Scouts Association, Mason Map Service Inc., Austin. Tex.. Yearbook Review of 1988 Production (also for 1987).

9. P. Kujawa, Heavy Oil Reservirs Recoverable by Thermal Technology: Vol. 1. DOE Report DOE/ET/12380-1. 1981.

10. P. Kujawa, Heavy Oil Resenoirs Recoverable by Thermal Technolog!. Vol. 2. DOE Repon DOE/ET/12380-1, 1981.

11. P. Kujawa. Heary Oil Reservoirs Recoverable by Thermal Technolog.: Vol. 3. DOE Repon DOE/ET/12380-1. 1981.

12. D. K. Olsen. V. Rawn-Schatzinger, and E. B. Ramzel, Feasibilin Siudy of Heavy Oil Recoven in the Appalachian. Black Warrior. Illinois and Michigan Basins. Repon NIPER-584, June 1992.

13. Group of Experts, UNITAR Proposal for the Definition of Heavy Crude and Tar Sands and Addendum, presented at the Second International Conference on Heavy Oil and Tar Sands, Caracas, Venezuela. February 1981 .

14. D. K. Olsen. Estimates of Future Heary Oil Production at Three Production Rates-Background Information for Assessing Effects on the U.S. Refining Indusin: Report NIPER-606, June 1992.

15. Bonner and Moore Management Science, Refinery Expansion Evaluation for U.S. Heav'y Oil Recovery. Assessment Market Capacity for Specific Regions with Predefined Increases in Heavy Oil for the Years 1992 Through 2010. Project No. MS91-582, Vol. I. April 1992.

16. Weekly Listing of U.S. Crude Prices, Oil Gas J.

17. Chevron USA Inc.. Crude Oil Price Bulletin. 
SIMULATION ANALYSIS OF STEAM-FOAM PROJECTS

Cooperative Agreoment DE-FC22-83FE60149, Project SGP58.

National Inatitute for Petroleum and Energy Research

Bartlesvilie, Okla.

Contract Date: June 1, 1992

Anticlpated Completion: May 31, 1994

Funding for FY 1992: $\$ 350,000$

Principal Investigator:

Partha Sarathl

Project Manager:

Thomas Reld

Bartlesville Project Otfice

Reporting Period: Apr. 1-June 30, 1992

\section{Objectives}

The objectives of this research program are to (1) conduct a study on the viability of the steam-foam process by analyzing data from selected completed steam-foam projects and (2) assess under what conditions the process is likely to succeed, both technically and economically.

\section{Summary of Technical Progress}

The project just started. A literature search was initiated to collect information on completed steam-foam field pilots and previous steam-foam simulation studies. Analysis of the gathered information is in progress. 


\section{GEOSCIENCE TECHNOLOGY}

\section{GEOPHYSICAL AND TRANSPORT PROPERTIES OF RESERVOIR ROCKS}

Contract No. DE-AC22-89BC14475

\author{
University of California \\ Berkeley, Calif.
}

Contract Date: Sept. 22, 1989

Anticipated Completion: Sept. 21, 1992

\section{Principal investigator:}

Neville G. W. Cook

Project Manager:

Robert Lemmon

Bartlesville Project Office

Reporting Period: Apr. 1-June 30, 1992

\section{Objectives}

The definition of reservoir characteristics, such as porosity, permeability, and fluid content, on the scale of meters, is the key to planning anis control of successful enhanced oil recovery (EOR) operations. Equations relating seismic and electrical properties to pore topology and mineral-fluid interactions are needed to invert geophysical images for reservoir management. Both the geophysical and transport properties of reservoir rocks are determined by pore topology and the physics and chemistry of mineral-fluid and fluid-fluid interactions. The objective of this research is to understand, through analysis and experiment, how fluids in pores affect the geophysical and transport properties of reservoir rocks.

\section{Summary of Technical Progress}

During this quarter research was carried out in the following areas: pore microgeometry-based analytical calculations of the capillary pressure-saturation curves for Berea sandstone, numerical simulations of fluid flow in porous rock using graph theory, laboratory measurements of the pore compressibility of Berea sandstone subjected to differential stress conditions, and the development of a numerical algorithm for simulating wave propagation in granular rock.

The analytic solution for the capillary pressure vs. saturation depends on the distribution of the pore hydraulic radius and the area-perimeter power-law relationship. These quantities have been measured directly from scanning electron microscope (SEM) photomicrographs. In the twodimensional (2-D) sections under consideration, however, the pore cross sections are randomly oriented with respect to the directions of the channel axes. The orientation effect has been corrected by means of geometrical and stereological considerations. The predictions of the analytical 
expression were compared with the laboratory capillary pressure curve of Berea sandstone. Results were analyzed in terms of the actual rock pore structure and the observed nonwetting fluid distributions at equilibrium pressures. $\mathrm{Nu}$ merical experiments concerning nonwetting phase inversion continued so that the behavior of preferred paths could be understood. The experiments studied this quarter included Raleigh and exponential distributions with and without spatial correlation. Spatial correlation is an important phenomenon in the formation of preferred paths that account for a disproportionate fraction of the permeability. Experiments on seismic wave velocities and attenuation were continued under uniaxial and hydrostatic stress with specimens saturated with brines having concentrations above and below the critical concentration at which the solution affects clays and thus allows them to migrate.

\section{Predicting Capillary Pressure of Sedimentary Rocks from Microgeometry}

The analytic solution for the capillary pressure vs. saturation depends on the distribution of the pore hydraulic radius and the area-perimeter power-law relationship. These quantities were measured directly from SEM photomicrographs. In the 2-D sections under consideration, however, the pore cross sections are randomly oriented with respect to the directions of the channel axes. The orientation effect has been corrected by means of the following geometrical and stereological considerations, which are exact for the case of circular cross sections. ${ }^{1}$

For the hydraulic radius,

$$
\left(R_{H}\right)_{\text {actual }}=\frac{(2)^{1 / 2}}{2}\left\langle\frac{1}{\left(1+\cos ^{2} \theta\right)^{1 / 2}}\right\rangle^{-1}\left(R_{H}\right)_{\text {measured }}
$$

where the brackets denote a spherical average for pore of random orientation, i.e.,

$$
\left\langle\frac{1}{\left(1+\cos ^{2} \theta\right)^{1 / 2}}\right\rangle=\frac{\int_{0}^{\pi} \int_{0}^{\theta_{\max }} \frac{a^{2} \sin \theta}{\left(1+\cos ^{2} \theta\right)^{1 / 2}} d \theta d \phi}{\int_{0}^{\pi} \int_{0}^{\theta_{\max }} a^{2} \sin \theta d \theta d \phi}
$$

with $\theta_{\max }=\arctan (\mathrm{L} / \mathrm{D})$, where $\mathrm{L} / \mathrm{D}$ is the maximum ratio of pore length to diameter. With an average value of $L / D=5$, as estimated from the micrographs, the following is obtained:

$$
\left(R_{H}\right)_{\text {actual }}=0.85\left(R_{H}\right)_{\text {measured }}
$$

\section{Applications}

On this section the analytical capillary pressure function for Berea sandstone from microgeometry is calculated to be compared with the experimental function, the complete rock pore structure, and the fluid distributions at equilibrium pressures. A typical SEM of Berea sandstone is shown in Fig. 1. Computerized analysis of Berea sandstone image (Fig. 2) shows pore space contours from which the perimeter-area power-law relationship (Fig. 3) and the pore hydraulic radius distribution were obtained (Fig. 4). The pore space contours of Fig. 2 are the same contours from which the transport properties (hydraulic and electric) were previously calculated. ${ }^{2}$ The analytical capillary pressure function for Berea sandstone was computed using $\varepsilon=0.40 \mathrm{~N} / \mathrm{m}$ (surface tension), $\gamma=1.49$ (perimeter-area power-law noninteger

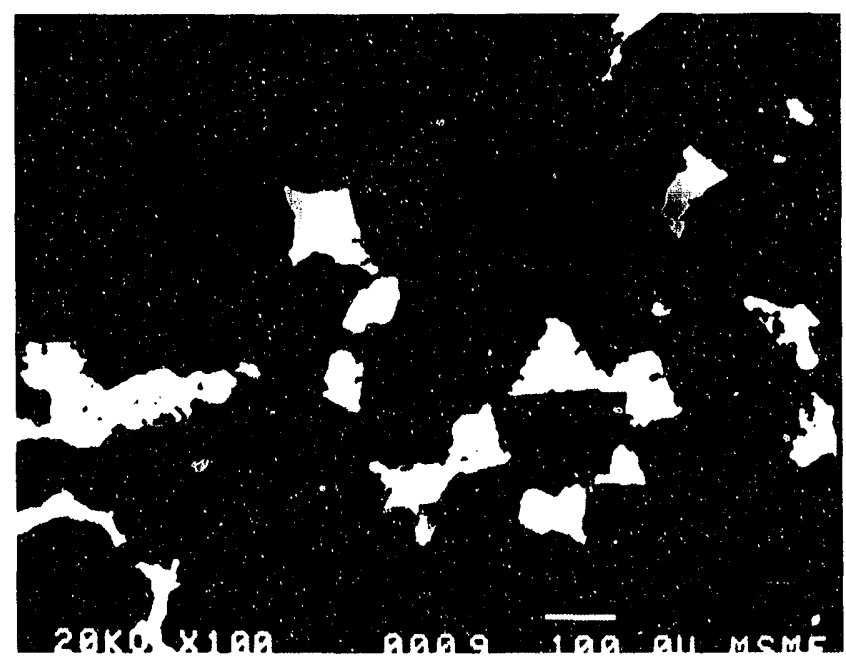

Fig. 1 Typical micrograph of Berea sandstone. The rock is composed mainly of quartz grains (dark-gray phase), feldspar grains (mediumgray phase), and products of grain dissolution (light-gray phase). The rock pore space has been impregnated with Wood's metal alloy (white phase) and epoxy (black phase) (XBB 908-6348).

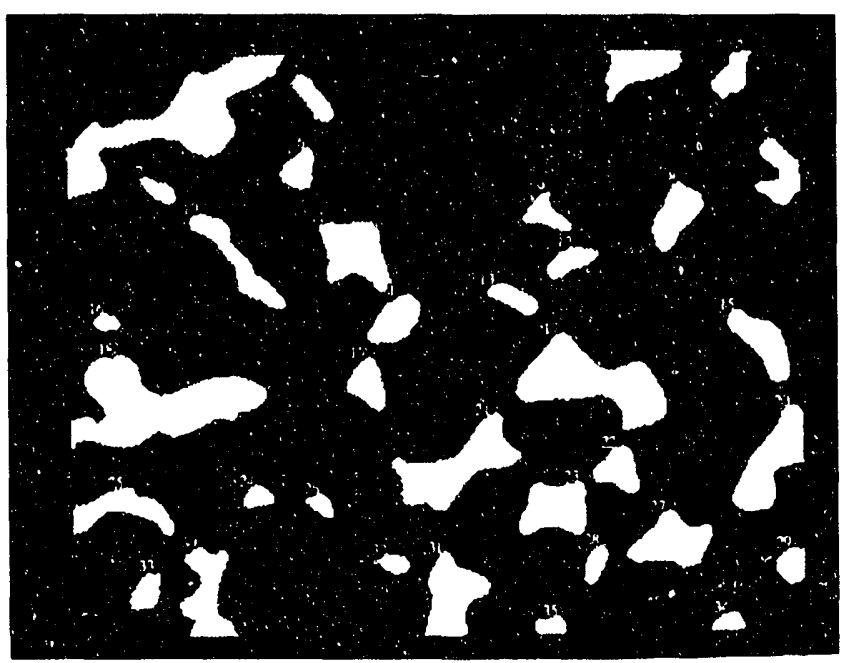

Fig. 2 Computerized analysis of Berea sandstone micrograph showing pore space contours from which transport properties (hydraulic and electric) are calculated. This is the same section used in Fig. 1 (XBB 908-6348A). 


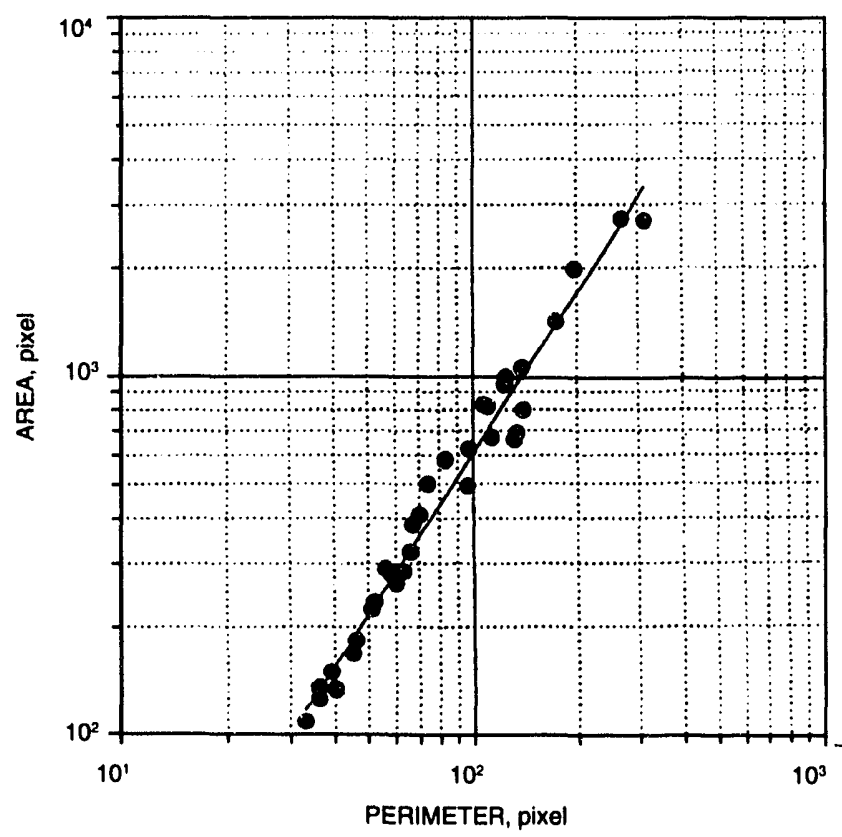

Fig. 3 Perimeter-area power-law relationship for Berea sandstone obtained from pore space contours shown in Fig. 2 (XBB 908-6348A).

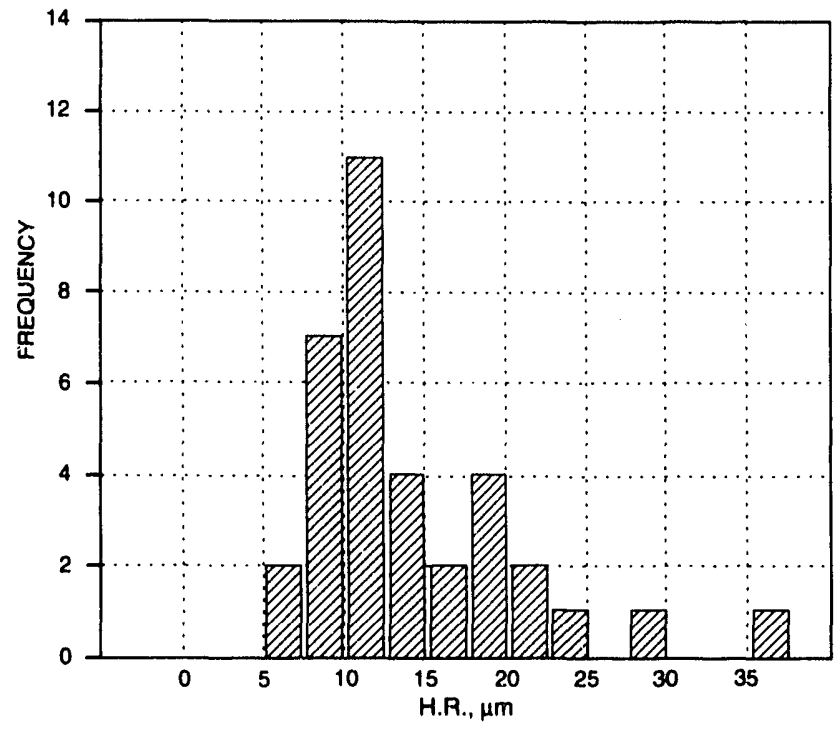

Fig. 4 Pore hydraulic radius frequency distribution for Berea sandstone obtained from pore space contours shown in Fig. 2.

slope), $R_{\mathrm{Hm}}=12.8 \mu \mathrm{m}$ (mean hydraulic radius), $\sigma=0.41$ (standard deviation), and $\left(R_{H}\right)_{\text {actual }} /\left(R_{H}\right)_{\text {measured }}=0.85$ (stereological correction). Preliminary results are shown in Fig. 5. As shown, the predicted capillary pressure function from the given pore hydraulic radius distribution does not fit the experimental capillary pressure. To fit the analytical to the experimental function, a distribution represented by $R_{H m}=6.6 \mu \mathrm{m}$ and $\sigma=0.14$ is needed. The mean hydraulic radius of such a distribution, $\mathrm{R}_{\mathrm{Hm}}=6.6 \mu \mathrm{m}$, corresponds to the mean hydraulic radius of the larger throats of the medium, the same throats that largely control intrinsic permeability. ${ }^{2}$ Visual observation and analysis of the complete Berea sandstone pore structure by means of a pore cast (Fig. 6) reveal that it is composed of small grain contact throats (thin sheets) connected to larger intergranular pore segments and pore throats. However, simple statistical analysis of a nonwetting fluid distribution at equilibrium pressure (Fig. 7) shows that there are many large pore segments connected by the smaller throats that do not contribute to the flow of the nonwetting phase in the rock. In fact, a few pore conduits connected by the larger throats are conducting most of the nonwetting phase in the rock, which

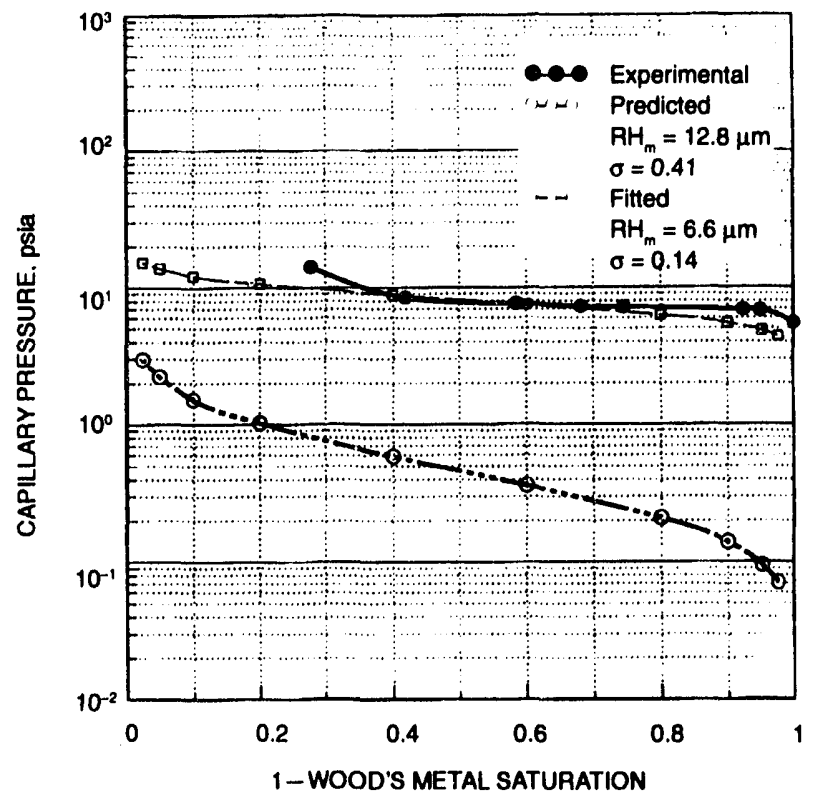

Fig. 5 Experimental vs. predicted capillary pressure function. To obtain the experimental capillary pressure function, the rock was impregnated with a nonwetting fuid (Wood's metal) at different equilibrium pressures and solidified in place. The procedure allows for direct observation and analysis of the fuid distribution at a nxed pore pressure and saturation level.

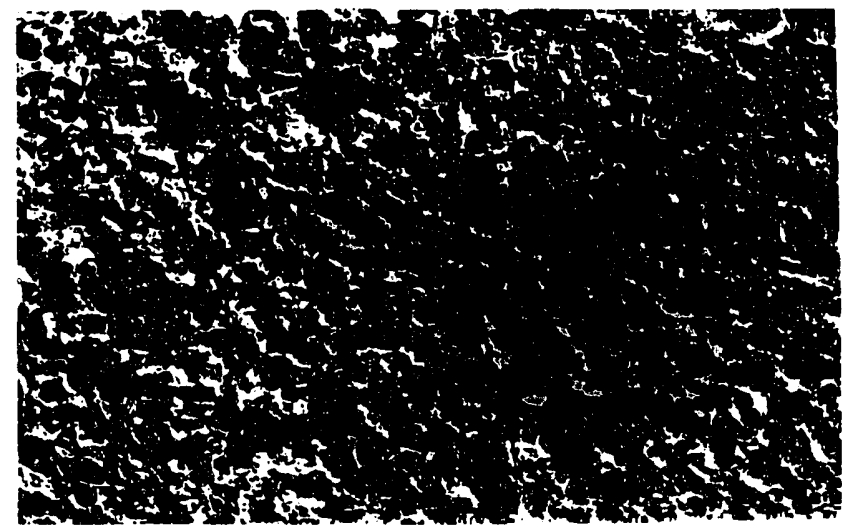

Fig. 6 Pore cast of Berea sandstone rock. The sample pore space is fully saturated with Wood's metal alloy and the rock matrix dissolved with acids to allow direct observation of the rock pore structure. 



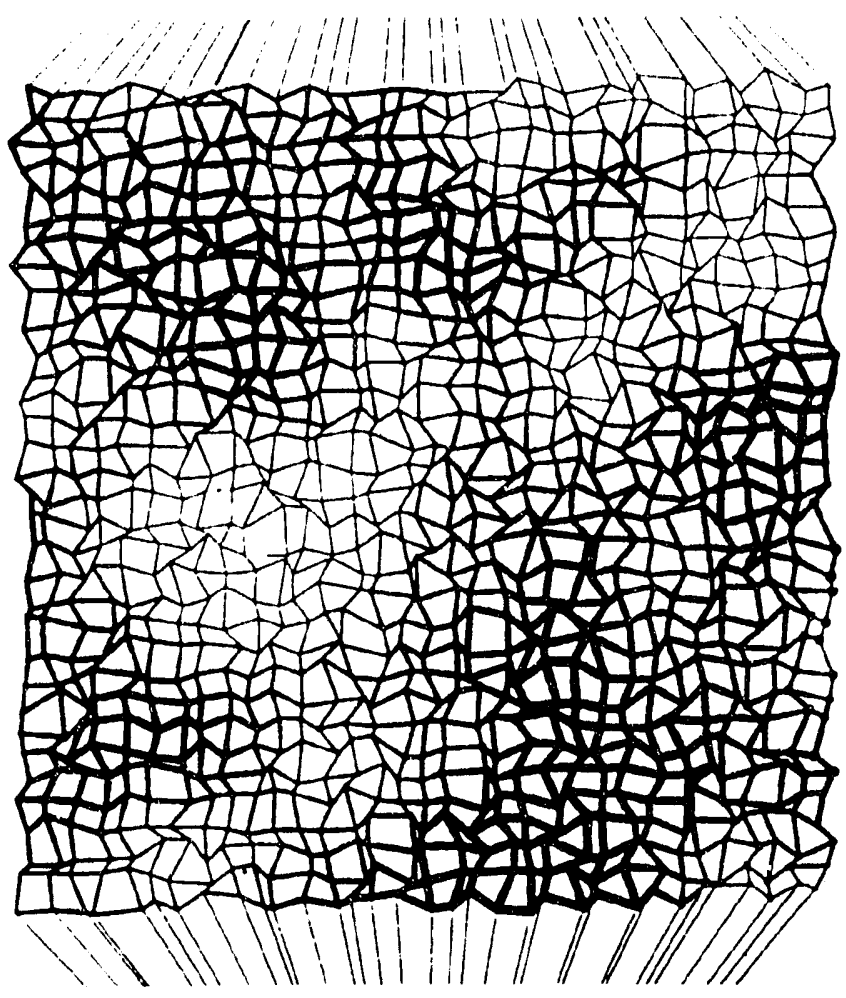

(a)

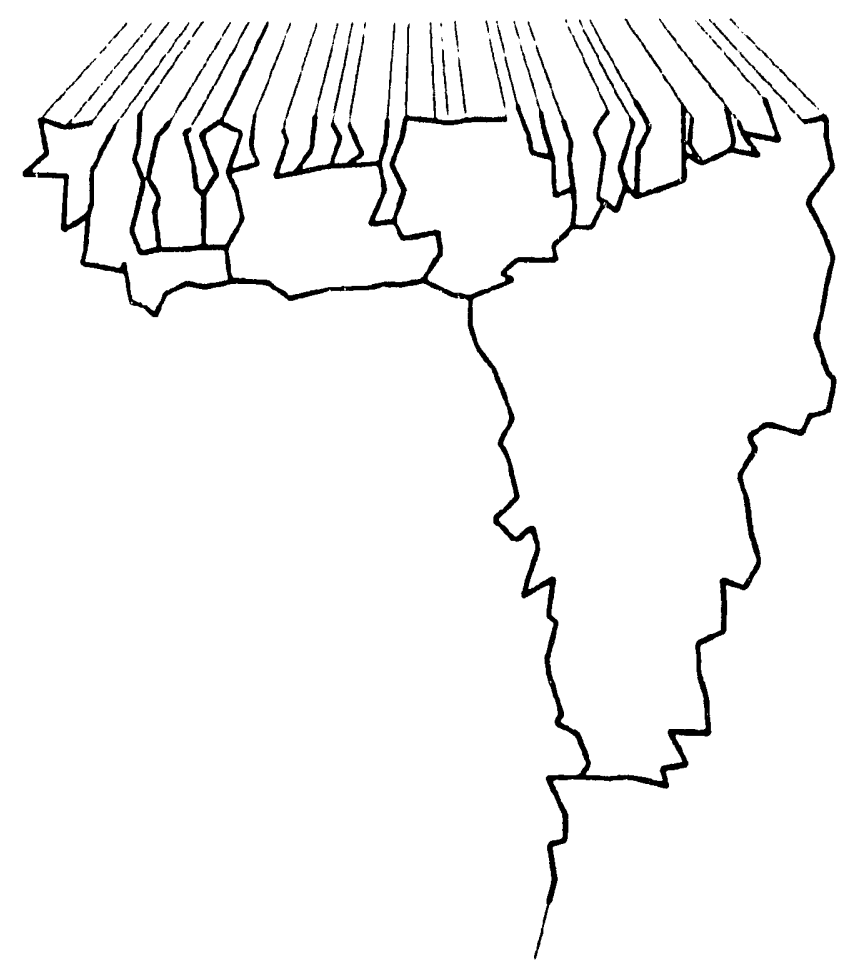

(b)

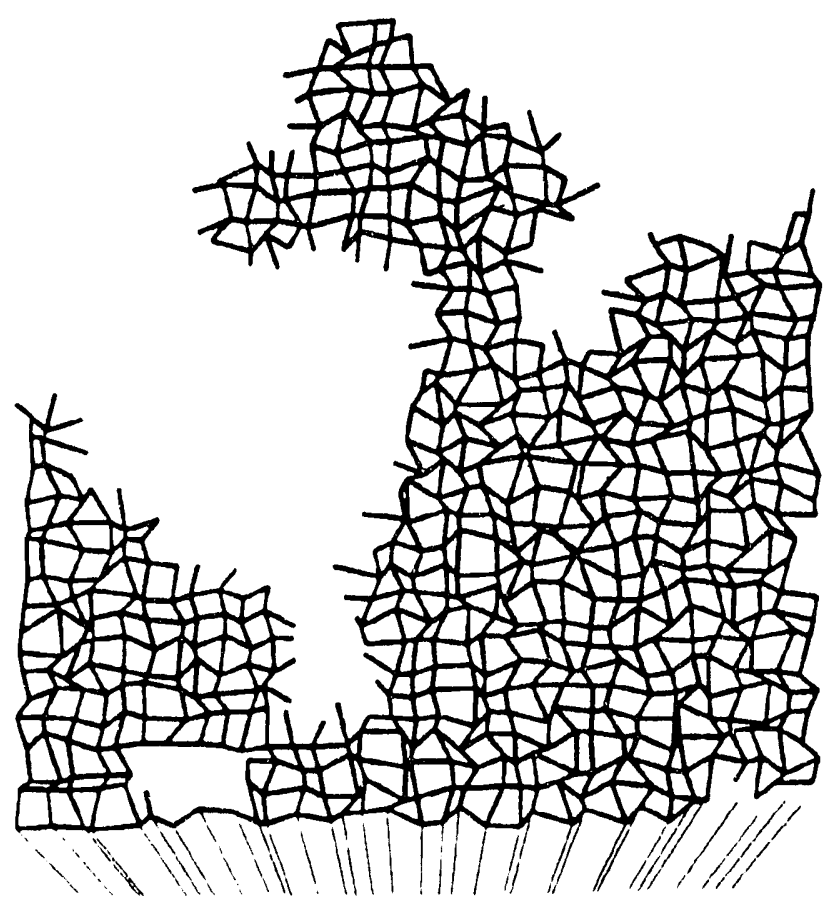

(c)

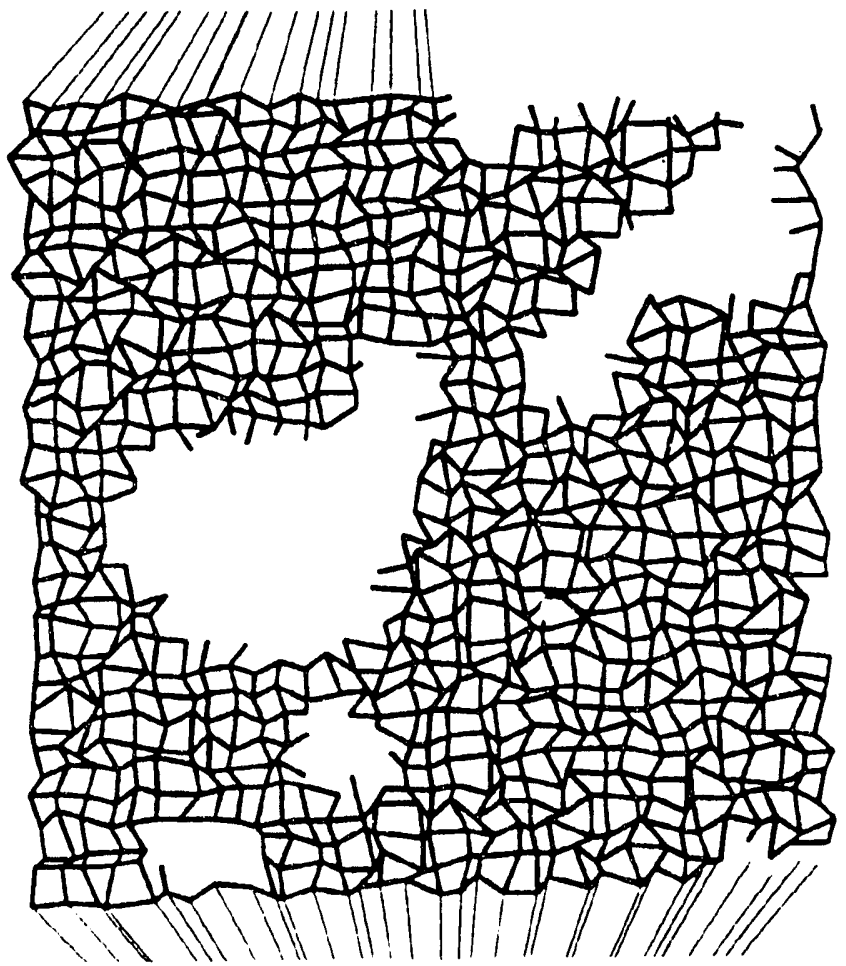

(d)

Fig. 8 ('omputer simulation results. (a) Kandom network with spatial correlation. (b) The easiest breakthrough paths from top (with minimum capillary pressure). (c) Simulation of invasion process (frozen). (d) Simulation of invasion process (completed). 


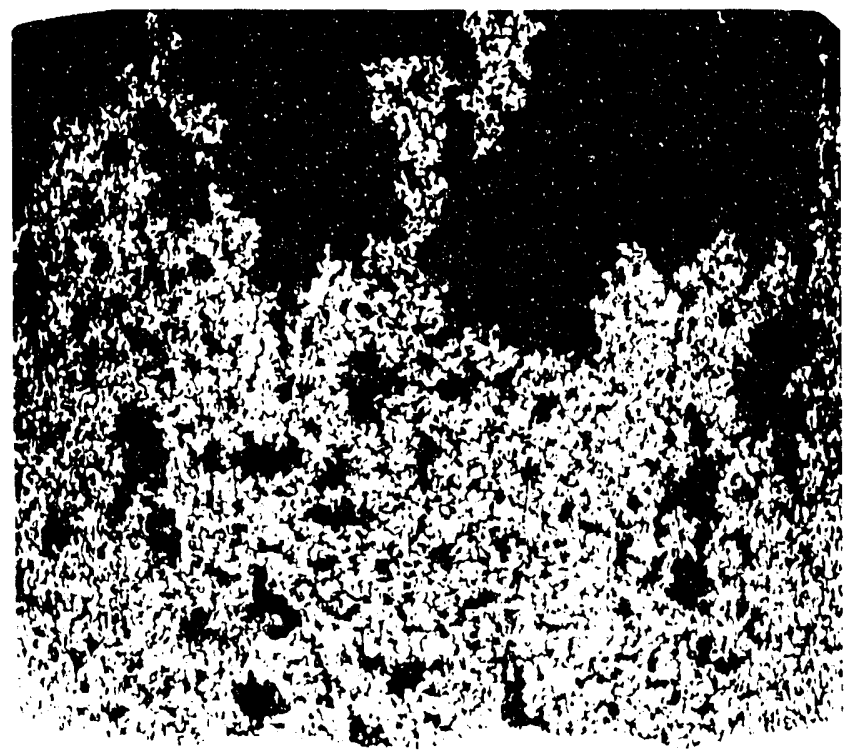

Fig. $y$ Wood's metal invasion experiment (frozen once Woed's metal reaches top).

\section{Laboratory Measurements of Pore Compressibility}

Measurements of pore compressibility in Bereat sandstone continued. These measurements are important becaluse they can be used to infer changes in the geometry of the intergranular pore space an gram microstructure is deformed under stress.
Derme this quarter measurements were made on spece men KBSS17. which wals realed with a hrass jacked and silturated with distilled waller. The sitne procedures dexcribed in the las getarterly report nere followed. In adderions. both cores (KBSI6 and KBSI7) were meatsured at two different brince concentrations. The ese hrme concentrattom hracketed the critical sall concentration of $0.017 \mathrm{M}$. The critical salt concentration is defined as the concentratum where the so lution affects the in silu clays and thes allow shem to mi gralle. The measured compressibilities from these experi ments atgreed with those in the list report for core KBSilo.

concurrent fo measurement of the compressihilutes. sed mic datit were collected trom the cores. The cores were also

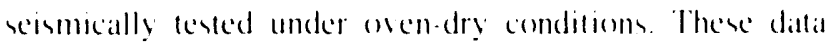
were recently analyed.

The calculated P-Walle velecitien from each test for hy

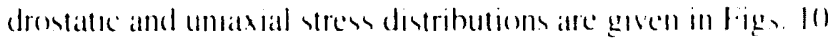
and 11, respectively. The P. wate velecites ate higher in flund-saturated conditions thatn in dry condtions for hoth stress distributions. This results from the stiffening effect of flund at grain contacts under compression. The P-uase ve locities at similar axial loads are in the same range for hydrostatic or unlaxial stress distributions. This suggeste that the P. wave velecily is most dependent on the stress in the direction of propagation

The calculated S-uate eledectien from each test are shown in Fige. 12 and 1.3 for hydroutatic and uniaxial stres destrihutions. reepectively. In contrant to the P-uave data. the s-uave velocitien de not eparate into dry and theidsaturated regioms. The latch of difference call be attrihuted

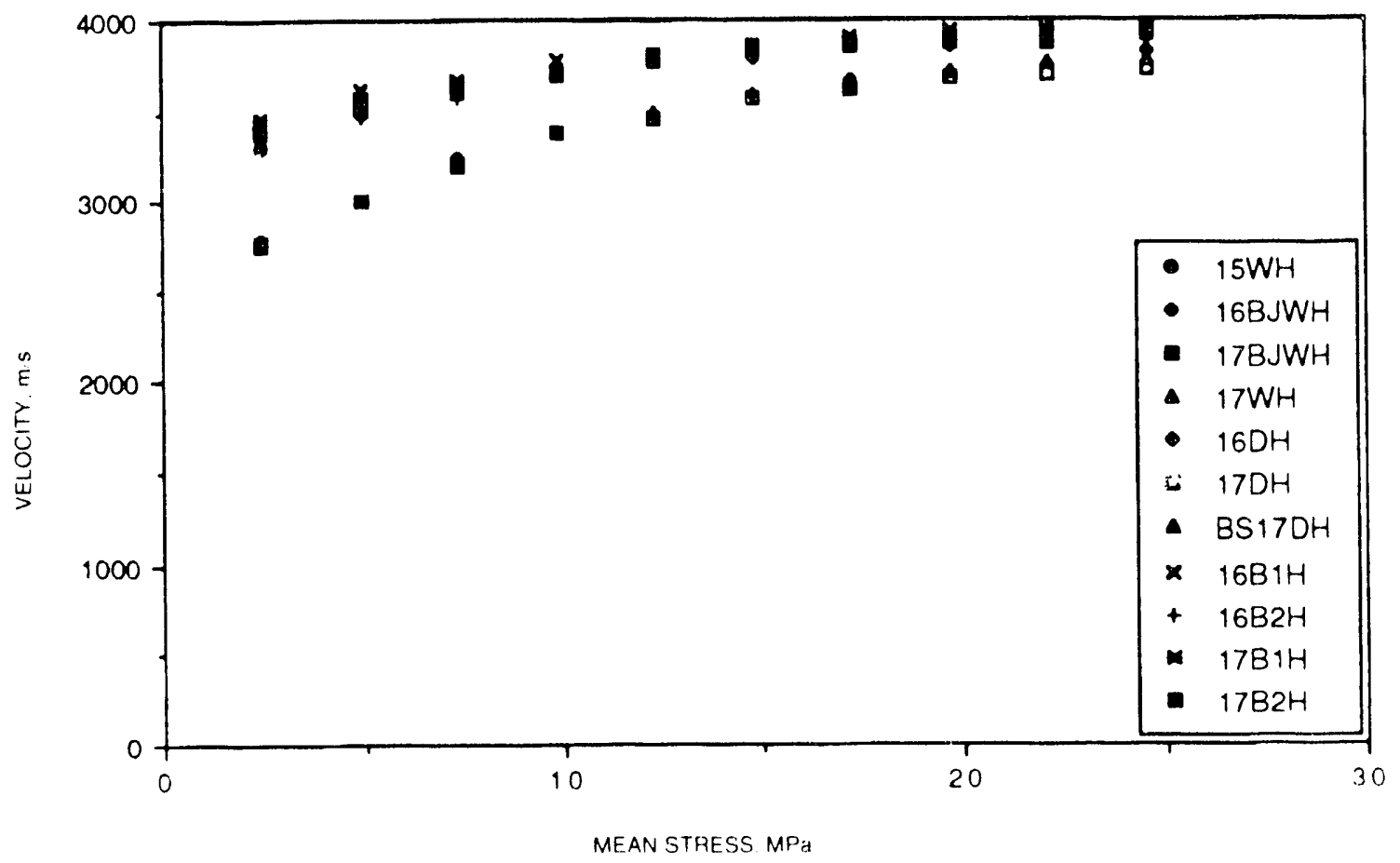

Fig. 10 Calculated P-uave velecitien w. mean stress for tests with hydrostatic stress distributions. 


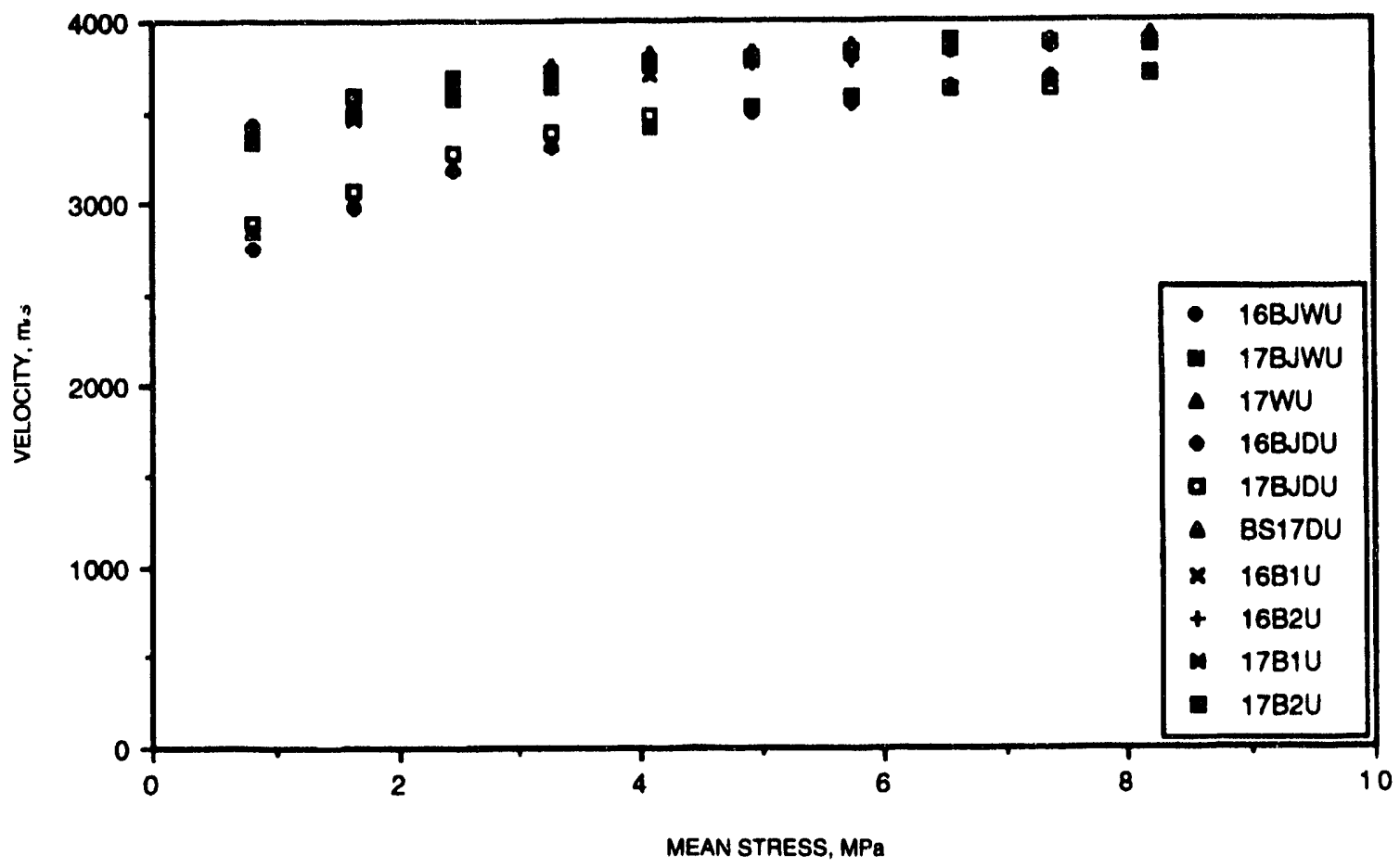

Fig. 11 Calculated P-wave velocities vs. mean stress for tests with uniaxial stress distributions.

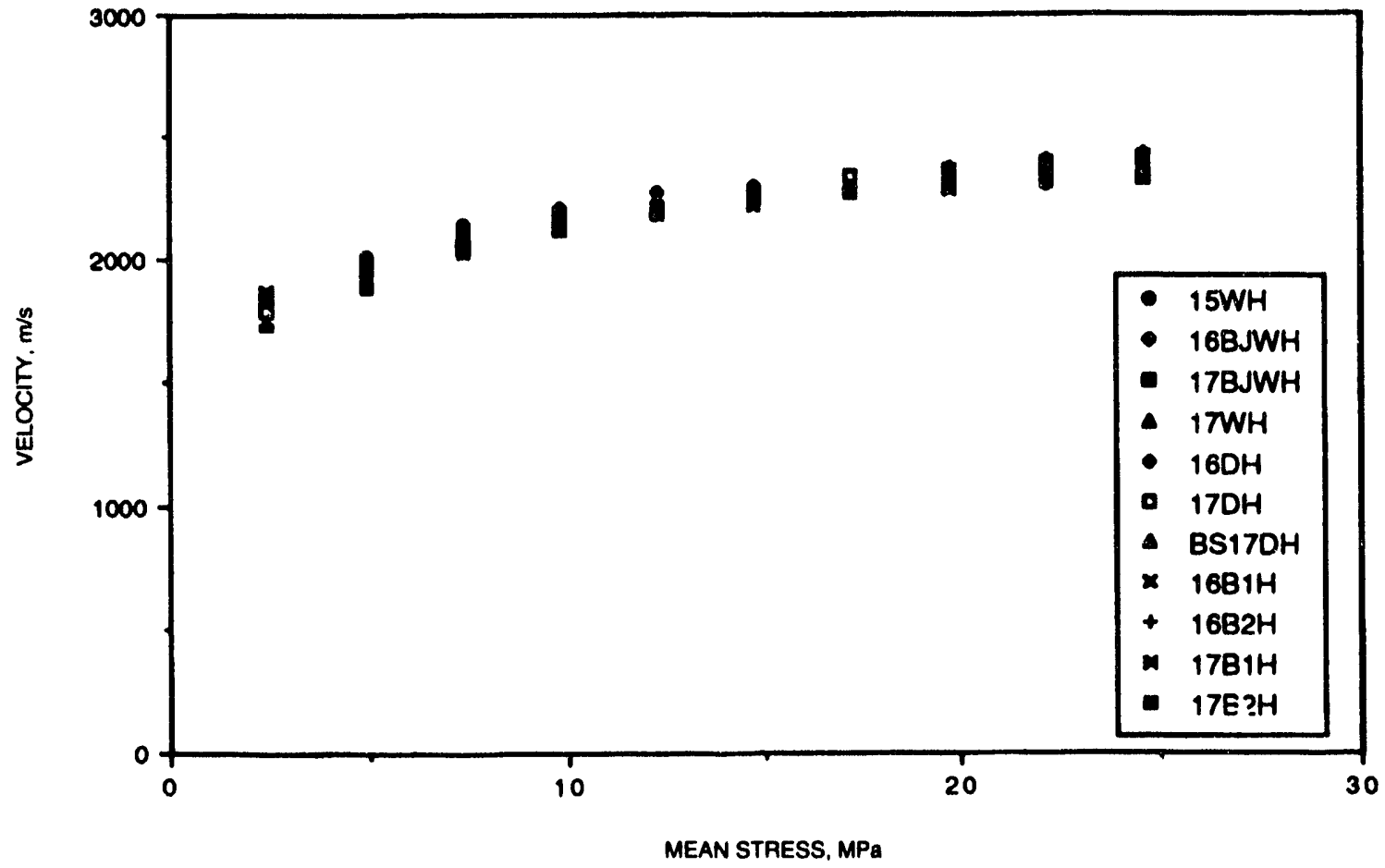

Fig. 12 Calculated S-wave velocities vs. mean stress for tests with hydrostatic stress distributions.

to the inability of fluid to support shear. This prevents them from affecting the rigidity of the granular framework. The S-wave velocities at similar mean stresses are in the same range. This suggests that the $\mathrm{S}$-wave velocity is most dependent on the overall stress in the specimen rather than on a particular directional stress.

Figures 14 and 15 show the measured amplitude data for P- and S-waves, respectively. The individual tests were 


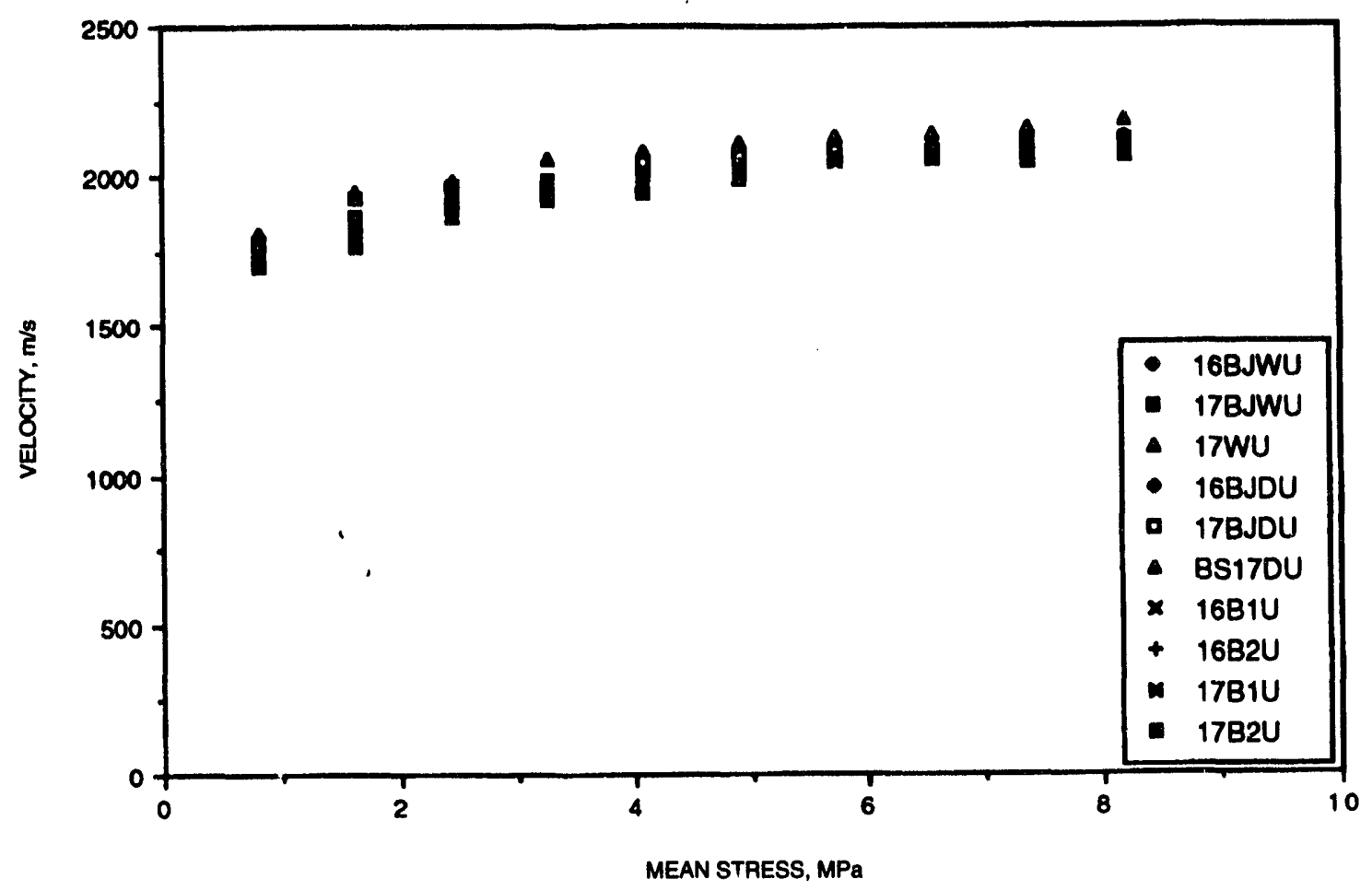

Fig. 13 Calculated S-wave velocities vs. mean stress for trots with uniaxial stress distributions.

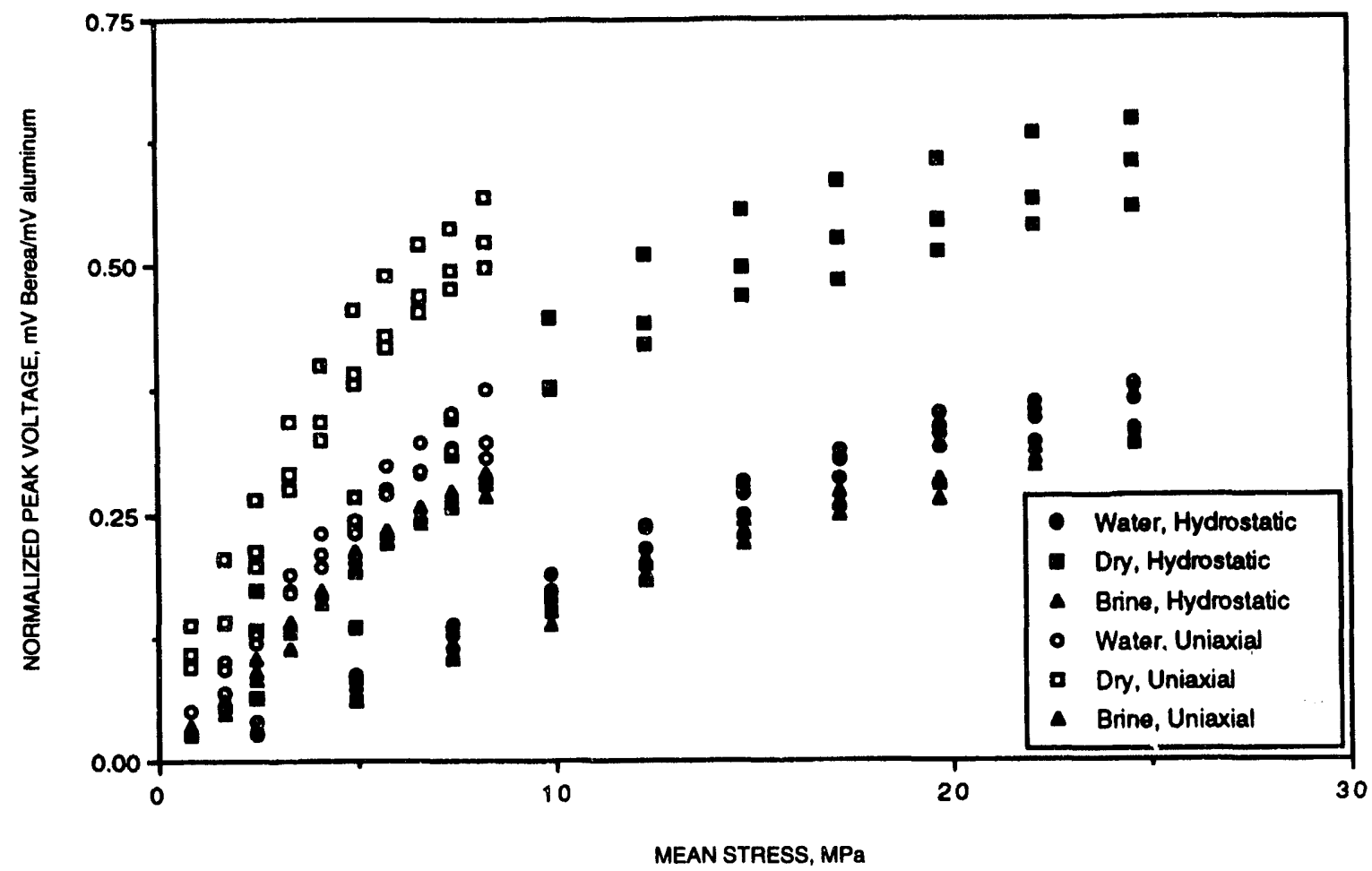

Fig. 14 Measured P-wave normalized peak-to-peak voltage amplitudes for all tests. 


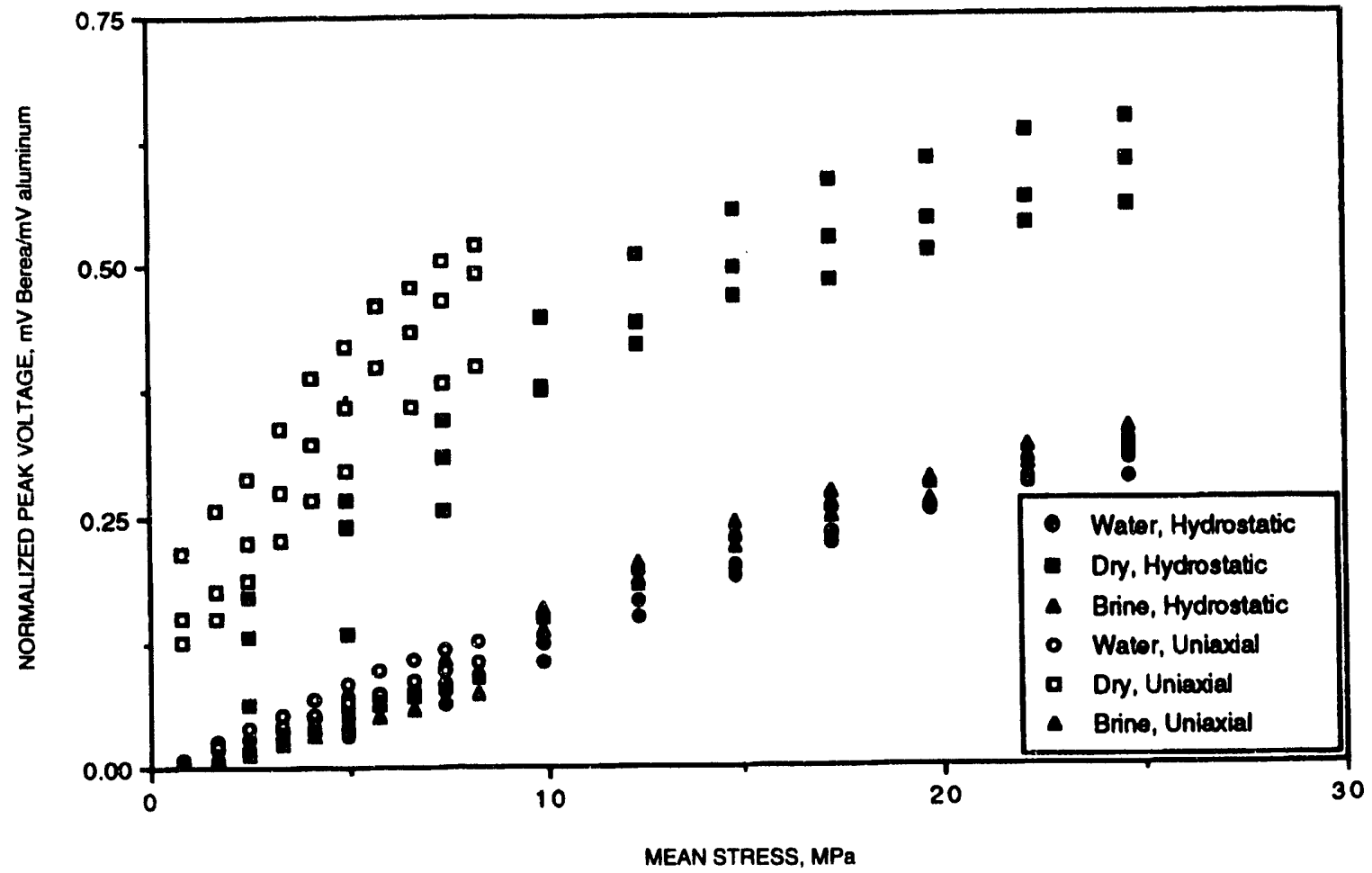

Fig. 15 Measured S-wave normalized peak-to-peak voltage amplitudes for all tests.

grouped by fluid type and stress distribution for clarity. The Berea sandstone amplitudes were normalized by amplitudes measured in identically dimensioned aluminum standards either directly preceding or directly following the Berea test. This procedure should provide a more significant measure of attenuation by removing variations caused by changes in both signal strength and environmental factors.

The dry amplitudes are higher than the fluid-saturated ampiitudes for both wave types within each stress distribution. This indicates that fluid introduces a loss mechanism into sei! mic propagation. The $\mathrm{P}$-wave amplitudes for uniaxial stress distributions appear to be larger than those for hydrostatic distributions. This apparent anomaly is a result of plotting against mean stress when P-wave propagation is primarily influenced by axial stress. For the uniaxial tests, the grain contacts in the direction of propagation have three times the mean stress. If compared by axial stress, the uniaxial amplitudes are in the same range as the hydrostatic amplitudes. The hydrostatic and uniaxial fluid-saturated $S$-wave amplitudes are in the same range when plotted vs. mean stress. This suggests that S-wave propagation is influenced by mean stress. The difference between the hydro- static and uniaxial dry measurements is currently under investigation. A preliminary analysis of the overall data suggests that the static corilpressibility is five times as large as the dynamic compressibility. Further analysis will extend to each individual test. In addition, compressibility and seismic experiments are currently being undertaken on the same cores in biaxial distributions of stress.

\section{References}

1. E. E. Underwood, Quantitative Stereology, Addison-Wesley, Reading, Mass.

2. E. Schlueter, R. W. Zimmerman, N. G. W. Cook, and P. A. Witherspoon, Predicting Permeability and Electrical Conductivity of Sedimentary Rocks from Microgeometry, in Proceedings of the 32nd U.S. Symposium on Rock Mechanics, Norman, Okla., 1991.

3. E. Schlueter. R. W. Zimmerman, N. G. W. Cook, and P. A. Witherspoon, Predicting Capillary Pressure of Sedimentary Rocks from Microgeometry, Lawrence Berkeley Laboratory, Berkeley, Calif., report in preparation.

4. D. L. Agrawal, N. G. W. Cook, and L. R. Myer, The Effect of Percolating Structures on the Petrophysical Properties of Berea Sandstone, in Proceedings of the 32nd U.S. Symposium on Rock Mechanics, Norman, Okla., pp. 345-354, 1991.

5. K-J. S. Kung, Preferential Flow in a Sandy Vadose Zone: 1. Field Observation, Gerderma, 46: $51-58$ (1990). 


\section{RESERVOIR CHARACTERIZATION OF PENNSYLVANIAN SANDSTONE RESERVOIRS}

Contract No. DE-AC22-90BC14651

\author{
University of Tulsa \\ Tulsa, Okla.
}

Contract Dato: Aug. 9, 1990

Antlcipated Completion: Aug. 8, 1993

Government Award: \$108,207

Principal Investigator:

Balmohan G. Kelkar

Project Managor:

Rhonda Lindsey

Bartlesville Project Office

Roporting Porlod: Apr. 1-June 30, 1992

\section{Objectives}

The overall objectives of this work are to (1) investigate the impsrtance of various qualities and quantities of data on the optimization of waterflooding performance and (2) study the application of newly developed, geostatistical techniques to analyze available production data to predict future prospects of infill drilling.

Specifically, to satisfy the first objective, the feasibility of applying fractal geometry concepts to characterize individual formations will be studied; a three-dimensional (3-D) conditional simulation program to define reservoir properties at various scales will be developed; a method to integrate the data collected at various scales, including the well test and the core data, will be established; and the use of outcrop data in the description of subsurface reservoir details will be investigated. To satisfy the second objective, various techniques to use the production data, including initial potential and the production decline, will be investigated so that a possible location for a future infill well can be proposed. The techniques investigated will include geostatistical analyses. The study will be restricted to Pennsylvanian sandstone reservoirs commonly found in Oklahoma.

\section{Summary of Technical Progress}

The technical progress is subdivided into several sections on the basis of tasks in the original project.

\section{Collection of Data}

The data collection phase is complete. The data were collected from the Burbank and the Glenpool fields. Both fields produce from the Pennsylvanian sandstone reservoirs.
The depositional environments for both reservoirs are fluvially dominated deltaic environments. Both core and modern log data were collected from both fields. Initial potential data from the Burbank field and production history from Glenpool field are also available.

\section{Waterflooding Optimization}

\section{Characterization with the Use of Fractals}

The primary goal of this work is to study the feasibility of applying the fractal geometry technique to characterize producing formations. The characteristic dimension to be investigated is called an intermittency exponent, $\mathrm{H}$ (Ref. 1 ). Several techniques are available to estimate the value of $\mathrm{H}$ on the basis of available data. These techniques include rescaled range (R/S) analysis, spectral analysis, box counting method, and variogram analysis. A computer program to analyze the trace data and estimate the intermittency coefficient is complete.

Previous quarterly reports ${ }^{2.3}$ described the procedure adopted to test the feasibility of various methods in determining the intermittency coefficient of the wellbore data. On the basis of the results, R/S analysis and box counting are the two most reliable methods for the determination of the intermittency exponent. Of these two methods, the boxcounting method seems to fit the variogram data better. As a result, the box-counting method has been adopted for the analysis.

The applicability of various techniques in analyzing wellbore data is being investigated. Burbank field was selected for primary investigation. In addition, for comparison purposes, two carbonate fields were selected. Following Feder ${ }^{4}$ the approach is to remove the local variations in the means as a result of the changes in facies and analyze the data of residuals. This includes identifying the geological distinctions within wellbore data before applying any method to determine the intermittency exponent. The results indicate that, if local variation is subtracted from the observed wellbore data, the intermittency exponents show a more consistent trend for a given field than otherwise possible. For example, after subtracting the local variations from the wellbore data in the Burbank field, $90 \%$ of the intermittency exponents lie between 0.75 and 0.80 . In contrast, an analysis of the raw wellbore data shows that the variation between the intermittency exponents is much larger. The analysis of the data from the carbonate field is also complete. The results indicate smaller intermittency exponent values (less than 0.8 ) than sandstone fields. On the basis of these results, it may be possible to identify, at least, gross variations in depositional environments with fractal geometry.

These values were validated by comparing the vertical wellbore variograms with the calculated variograms with the use of an fGn model. The match between the two is reasonable. In addition, the use of these models in describing areal heterogeneities was also tested. For this purpose. 
either $\mathrm{fGn}$ or $\mathrm{fBm}$ models will represent the areal heterogeneities. With these models and with the help of simulated annealing. several two- and three-dimensional (3-D) descriptions were generated, and the simulated results were compared with the actual wellbore data at various locations. This approach was investigated for two sandstone and two carbonate fields. The goodness of fit was quantified using the previously described ${ }^{2}$ correlation coefficient.

On the basis of exhaustive comparison, observations show that, in general, fGn models describe the areal heterogeneities in carbonate reservoirs better, whereas $\mathrm{fBm}$ models adequately describe the sandstone reservoirs. This observation may be important in constructing a 3-D reservoir descriptions when very limited data are available.

\section{Three-Dimensional Conditional Simulation}

For a description of the reservoir in three dimensions, a method of simulated annealing was selected. Originally proposed by Farmer, ${ }^{5}$ the method is based on the principle of swapping randomly generated values having the same histogram as the sampled values. After every swap, a predefined energy function is calculated and compared with the energy function in the previous step. If the new function is srnaller, the swap is accepted. If the new energy function is greater, the swap may still be accepted, depending on the probability function. The process of swapping will continue until a desired level of energy function is reached. The method is fast, flexible, and allows incorporation of various constraints when generating the reservoir properties.

The computer program for conducting simulated annealing was developed. The program has been extensively tested using synthetic as well as field data. The results indicate that the program is capable of reproducing the univariate as well as bivariate distributions under varied scenarios.

Although the technique of annealing is robust, one of the potential problems in using annealing simulation is its speed. Compared with other simulation programs, the program of annealing is relatively slow. Several alternatives exist to speed the program: (1) only accept the threshold if the difference between swapped values is greater than certain minimum, (2) use a different initial distribution, (3) adjust the range of investigation, (4) modify the swapping techniques. and (5) take advantage of specific hardware on which the program is run.

One of the alternatives that shows promising results is the use of different initial distribution. In this approach. instead of using a completely random distribution as the initial distribution, a distribution based on a simple linear interpolation is created. In three dimensions, data are taken at each datum in each conditioning well, and a linear extrapolation is used to create a smooth surface at that datum. A stack of surfaces will generate a 3-D distribution. After generating the initial distribution to match the generated distribution with the distribution of the conditioning data, a random component at each location is added on the hasis of the average variance of the differences between the conditioning data points at each datum. The calculation of the initial distribution takes a few minutes and is a small overhead on the total computations. With the newly created distribution, a simulated annealing procedure is initiated. Instead of using a conventional method, a greedy algorithm was used to increase the speed of the program. When compared with the conventional annealing method, this modified method takes only 15 to $20 \%$ of the time of the original method.

To make the program more flexible, an investigation is under way to determine the possibility of incorporating other types of data when describing reservoir characteristics. In addition to conditional data and the variogram models, other important input data that can be used for reservoir description are the well test data. Well test data are collected over a much larger volume than the core data and are a much closer representation of the grid-block values than the core data. Unfortunately, conventional kriging and associated conditional simulation methods cannot incorporate the well test data in reservoir description. Simulated annealing is flexible enough to accommodate the well test data through an appropriate objective function. This objective function should include the well test data as some representative average of nearby wellbore data.

Before using the representative average as an objective function, the type of average the wellbore data represents must be determined. Recently, Oliver ${ }^{6}$ presented an analytical technique to estimate the well test permeability value for heterogeneous reservoirs. The method is restricted to certain simplifying assumptions. With the use of the Oliver solution, the instantaneous permeability determined from the well test data was compared with different averaging schemes to calculate effective permeability from small-scale heterogeneities. For these purposes, the ECLIPSE 100 simulator was used. This procedure was tested over a wide range of heterogeneities. The Dykstra-Parsons coefficient was varied between 0.2 and 0.8 , and the normalized scale length was varied between 0 and 0.5 . The results indicate that Oliver's method is valid if the geometric average of the permeability values is used. In most cases the difference between the well test value and the average value was less than $10 \%$. Implementation of this constraint in the annealing program will begin soon.

\section{Effective Properties for a Grid Block}

Reservoir properties are measured on various scales. Core data are collected on a size of 2 in., whereas the well test data are collected on a reservoir size of thousands of cubic feet. From a simulation point of view, a determination of the grid-block properties would be of interest. A typical grid-block size may vary between 10 and $1000 \mathrm{ft}$.

Both analytical and numerical methods are being used to investigate the estimation of an effective property of a grid block. On the analytical side, a method was developed to 
predict an effective tensor of a grid hlock with the smallscale heterogeneities present in the grid block. With four small grid blocks. each having a separate permeahility, and with the use of Darcy's law and some simplifying assumptions, an analytical expression can be developed for the effective permeability tensor. The validity of the analytical method was lested by comparing the results with the numerical results obtained with a finite-element simulator.

The analytical results were compared with the numerical results for the case where all the small-scale values have different, anisotropic permeability values. The comparison shows that the analytical and numerical results are very close. Since the last quarterly report, this method has been extended to account for the cross-bedded reservoirs. The method first searches for the large-scale variations and their directions. Depending upon these variations, first, the global pressure gradients are estimated. The local variations in the pressure gradient are estimated by successive scaling up of small-scale variations. The results of this new method indicate an excellent comparison between the numerical and analytical methods. The method captures the effect of crossbedding under various scenarios. The method is also tested by simulating unit mobility ratio, miscible displacement flood, and comparing the effluent and recovery profiles using the detailed small-scale heterogeneities and the effective properties. The comparison is very good.

The results have been extended to a waterflooding example. A five-spot pattern in a heterogeneous eservoir is constructed. Waterflooding is conducted in a quarter of a five-spot pattern. Numerical simulations were conducted with both in the presence of small-scale heterogeneities and with the scale-up properties. The comparison between the two results is excellent, which indicates the applicability of the upscaling method for immiscible displacements as well.

\section{Outcrop Studies}

An outcrop called a Bluejacket sandstone and located approximately 45 miles northeast of Tulsa was selected for further studies. This outcrop contains the same Red Fork sand as that from which Glennpool field is producing. The outcrop was surveyed, and the data are being input in a mapping program. The detailed mapping will allow identification of the geological facies distribution. On the basis of the mapping, a systematic coring program will be developed. In addition, a few permeability readings from the outcrop were also taken with a minipermeameter. The results indicate a significant variation between the permeability values measured across different facies.

In addition to collecting permeability data from the outcrop, 12 wells were drilled behind the outcrop. The typical distance between two wells is less than $50 \mathrm{ft}$ with the exception of one well, which is drilled about $4(x)$ ft behind the outcrop to get a complete geological section. The typical depth of a well is in the range of 50 to $80 \mathrm{ft}$. All these wells have been cored, and suites of logs have been run in these wells, including gamma-ray and neutron density. In addition, a Formation Micro-Scanner (FMS) log was run through one of the wells.

The whole cores were slabbed and photographed. In addition, more than $I(X X)$ minipermeameter readings were taken to quantify the vertical variability of permeability distributions. Approximately 200, 1-in. core plugs, some of them vertical, were taken. Additionally, plans are under way to collect roughly $1(0(0)-2000)$ minipermeameter readings on the outcrop as well. The analysis will begin following the collection of all the data. Some preliminary results will be available by the next report.

\section{Infill Drilling}

A synthetic reservoir will be used to develop a procedure to locate infill drilling prospects. The main advantage of using a synthetic reservoir is that there is no concern for production and operational constraints imposed upon the actual production. Further, drilling and the location of the wells can be controlled.

Data from the Burbank field were used to generate a synthetic but realistic reservoir. Part of the Burbank field (approximately 1900 acres) was selected. After the log and the core data were collected from all the wells located in that part, facies present at each well location were identified. Ten facies were identified.

With the use of the facies description, a spatial relationship for each facies is developed. With the use of the core data, a semi-log relationship between permeability and porosity was developed for each facies. With the use of a method of conditional simulation, a 3-D description of the reservoir was developed. To account for scale-up from core-level permeability-porosity relationship to block-level permeabilityporosity relationship, several synthetic simulations of a grid block were conducted. With the use of Darcy's law, the effective grid-block permeability was calculated. With the use of the arithmetic mean, the effective porosity of a grid block was calculated. A comparison of the core permeability-porosity relationship with the block permeability-porosity relationship

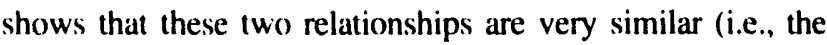
spatial correlations of reservoir properties for the case under investigation have little impact on the determination of the effective permeability). The relationships developed on core level can be effectively used to determine the permeability if the porosity of a grid block is known. This allows for estimation of small-scale porosities in reservoir using available spatial relationships, arithmetic averaging of small-scale porosities to calculate the block porosity, and determination of the block permeability.

With the simulations, the data will be analyzed to predict possible in-fill locations within the reservoir. One of the techniques currently being explored is the use of the connectivity function to define relative continuity in the reservoirs. On the basis of the reservoir performance parameters, such as breakthrough, water/oil ratio, or 
injection rate, a qualitative description of the reservoir continuity is possible. If this continuity can be quantified, this information can be used in the conditional simulation method to describe the reservoir. One method flexible enough to incorporate this continuity function is simulated annealing.

Several simulation runs with synthetic data were conducted. Some of the performance parameters were related to the continuity functions. Results indicate that the continuity function is closely related to the performance of the reservoir. Also, if the continuity function is incorporated in the annealing program, the level of uncertainty in the reservoir performance can be reduced. Such function has been incorporated in the simulated annealing program. The comparison between the "truth case" simulation and the simulation carried out with alternate images of the reservoir indicates that the continuity function is extremely important in characterizing flow behavior of the reservoir. One disadvantage of adding additional constraint in the annealing program is that it slows down the speed of the program. However, with some additional simplifications a code has been developed that only takes 10 to $20 \%$ more time to generate the reservoir description incorporating the connectivity function.
On a short-term basis, the application of the indicator kriging technique to locate a possible in-fill location in a typical sandstone reservoir is being investigated. Further, the technique may be extended to account for the decline in the rates as a function of time.

\section{References}

1. T. A. Hewett, Fractal Distributions of Reservoir Heterogeneity and Their Influence on Fluid Transport, paper SPE 15386 presented at the 1986 SPE Annual Technical Conference and Exhibition, New Orleans, La., Oct. 5-8, 1986.

2. Quanterly DOE Report, Reservoir Characterization of Pennsylvanian Sundstone Reservoirs, (Contract No. DE-AC22-90BC14565i), Jan. 1Mar. 31, 1991.

3. Quarterly DOE R.port, Reservoir Characterization of Pennsylvanian Sandstone Reservoirs, (Contract No. DE-AC22-90BC14651), Apr. 1June 30, 1991.

4. J. Feder, Fractals, Chap. 10, Plenum Press, New York, 1988.

5. C. L. Farmer, Numerical Rocks, paper presented at the Joint IMA/SPE European Conference on the Mathematics of Oil Recovery, Robinson College, Cambridge University, July 25-27, 1989.

6. D. S. Oliver, Estimation of Radial Permeability Distribution from Well Test Data, paper 20555 presented at the 1990 SPE Annual Technical Conference and Exhibition, New Orleans, La., Sept. 23-26, 1990.

\section{OIL RECOVERY ENHANCEMENT \\ FROM FRACTL'RED, LOW - PERMEABILITI' IIESERVOIRS}

\section{Contract No. DE-FG07-89BC14444}

\section{Texas A\&M University \\ College Station, Tex.}

Contract Date: June 13, 1989

Anticipated Completion: Sept. 1, 1992

Government Award: \$256,000

(Current year)

\section{Principal Investigator: \\ S. W. Poston}

Project Manager:

Rhonda Lindsey

Bartlesville Project Office

Reporting Period: Apr. 1-June 30, 1992

\section{Objective}

The objective of this project is to develop and advance new concepts and technology to increase oil and possibly gas recovery from fractured, low-matrix permeability reser- voirs. The overall study is to encompass geological, geophysical, laboratory, and imaging flow studies and analytical and computer modeling as well as field trials.

\section{Summary of Technical Progress}

A technology transfer meeting was held June 3, 1992, at the Texas A\&M University campus. Presentations were on geophysical, geological, and petroleum engineering aspects of the Department of Energy (DOE)-sponsored research. There were 194 people in attendance, representing 52 oil companies and 26 service companies. Another meeting is scheduled for October.

\section{Interpreting and Predicting Natural Fractures}

Work has continued to improve the determination of the orientation of vertical fractures with the horizontal components of displacement from a Vertical Seismic Profile (VSP). Substantial improvements in determining the fracture orientation (strike) are possible. Accurate determination of the strike using a four-component VSP data set is obtained when the geophone couplings are assumed to be the same for each orientation.

The production of synthetic data without noise allowed the exact source/strength ratio, the geophone/coupling ratio, and fracture orientations to be obtained. These effects were achieved by minimizing the trace amplitude of the offdiagonal terms of the four-component data $s t$, which was 
accomplished by the rotation of the data around the principal axes.

Ten independent noise traces were added to each of the four synthetic-seismic-data traces to test for the effects of noise. The signal/noise ratio ( $\mathrm{S} / \mathrm{N}$ ) for each trace was only $10 \mathrm{~dB}$, a relatively low value. The geophone/coupling ratios $\left(G_{1} / G_{C}\right)$ for each experiment are reasonably close to the exact ratio of 1.25 . The mean value $(1.20)$ of the 10 experiments conducted is within $4 \%$ of the exact value and each individual value is within $10 \%$. The determined source/ strength ratios $\left(S_{\mid} / S_{C}\right)$ have individual values generally within $20 \%$ of the exact value of 0.67 . The mean value for the 10 experiments $(0.66)$ is within $2 \%$. The most important parameter, the orientation of the fractures $(\theta)$, shows an error that is generally less than $2 \%$ with a mean value $\left(54.4^{\circ}\right.$ ) within $1 \%$ of the correct $60^{\circ}$ value. The estimated variances are less than the measured value. Efforts to determine the reasons for this disagreement are under way. Portions of this work performed under this subtask were presented at the Symposium on the Austin Chalk Producing Trend held at Texas A\&M University June 3, 1992.

Progress on geological studies during the period has been related to the analysis of Formation Microscanner Surveys (FMS) and experimental rock deformation.

Approximately $200^{n} \mathrm{ft}$ of FMS from a horizontal borehole in the Giddings area wa. unalyzed to determine fracture spacing and orientation. Figure 1 is an equal-area projection illustrating the orientation of over 1200 fractures. The orientation pattern of two sets of fractures with common strike $\left(\mathrm{N} 75^{\circ} \mathrm{E}\right)$ and with a dihedral angle of $10^{\circ}$ to $20^{\circ}$ is very simple. This fracture pattern would be expected to be associated with a $\mathrm{N} 75^{\circ} \mathrm{E}$-striking normal fault or monoclinal flexures. It is less complicated because other fracture sets typically developed on outcrop were not observed in the subsurface.

The fracture spacing calculated from over 1000 fractures from the FMS data is statistically identical to the fracture spacing measured along horizontal scan lines placed on vertical outcrops all along the Austin Chalk outcrop trend. Figure 2 compares FMS data with data sets obtained from 14 locations along the Austin Chalk outcrop trend.

If these early results are confirmed, two major conclusions related to the extrapslation of outcrop data to the subsurface fracture patterns will be warranted: (1) the fracture patterns at depth will be similar to the major patterns observed on the outcrop but vastly simplified and therefore more predictable and (2) the fracture spacing measured on outcrop will be similar to that found in the subsurface.

Bed containment of the fractures characterizes poor vertical communication of hydrocarbons within the chalk, even along fault zones. This fact, in turn, dictates the design of borehole trajectories.

Experiments were conducted to investigate the conditions required for the ductile layer, shale or marls in the Austin Chalk, to contain fractures propagating within the brittle layers. A schematic of the specimen configuration is

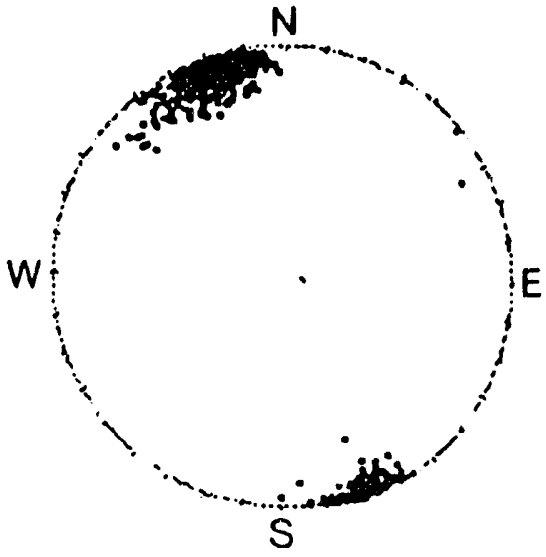

Fig. 1 Normals of fracture plans plotted in upper-hemisphere, equal. area projection.

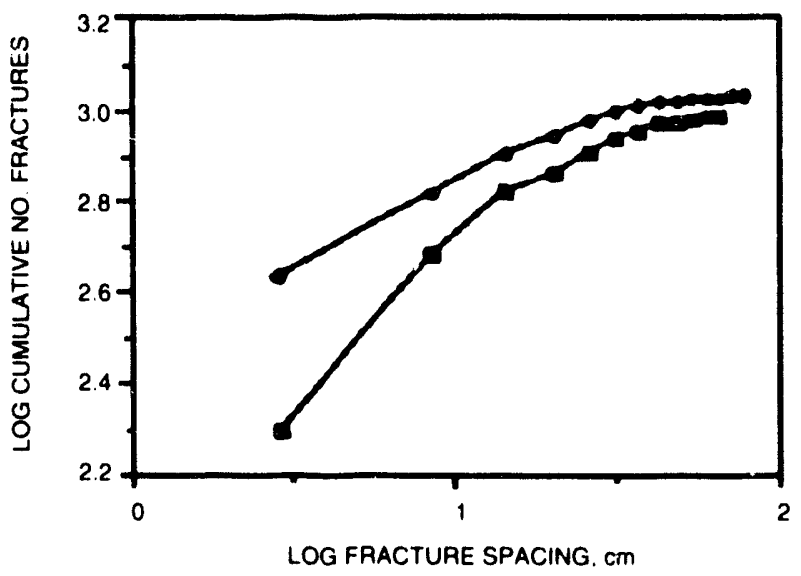

(a)

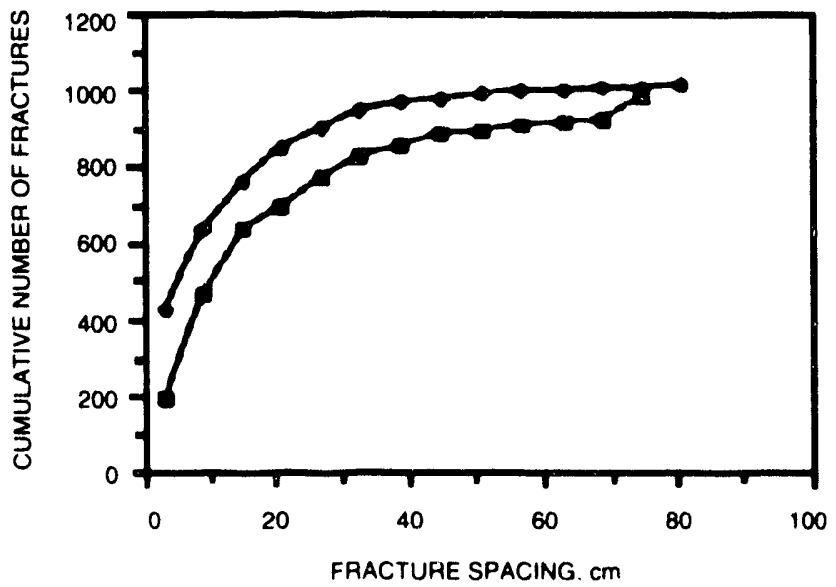

(b)

Fig. 2 Comparison of (a) Formation Microscanner Survey data and (b) outcrop fracture spacing data.

shown in Fig. 3. and the experimental conditions and results are given in Table 1. The specimen consists of a notched block of brittle rock and a precompacted ductile layer 


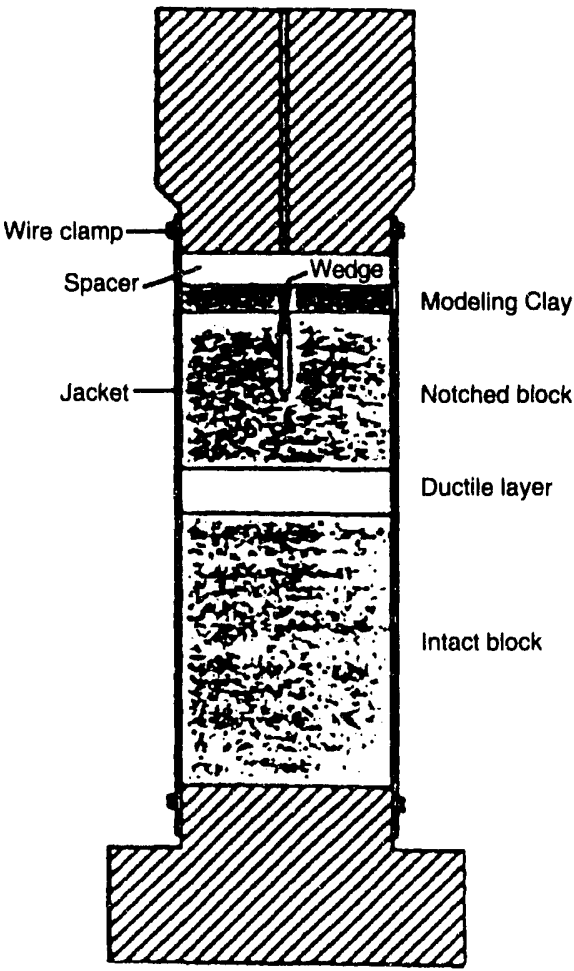

Fig. 3 Schematic drawing of experimental setup.

TABLE 1

Experiments on Fracture Containment

\begin{tabular}{ccl}
$\begin{array}{c}\text { Efrective } \\
\text { confining pressure, } \\
\mathbf{M P a}\end{array}$ & $\begin{array}{c}\text { Thickness of } \\
\text { room-dry clay } \\
\text { bed, } \mathbf{m m}\end{array}$ & \multicolumn{1}{c}{ Fracture } \\
\hline 10 & 0.0 & Propagates through clay \\
50 & 0.0 & Propagates through clay \\
10 & 5.1 & Contained within host \\
50 & 3.8 & Propagates through clay \\
10 & 10.9 & Contained within host \\
50 & 10.6 & Propagates through clay \\
50 & 15.2 & Contained within host \\
\hline
\end{tabular}

(bentonite clay) of varied thickness. A tensile fracture is initiated at the tip of the notch by a wedge inserted into the notch, and this fracture propagates toward the ductile layer.

A study of Table 1 shows that the fracture propagates at both effective confining pressures of 1450 and 7250 psi ( 10 and $50 \mathrm{MPa}$ ) when there is no clay. The fracture is contained only at the lower confining pressure $(\mathrm{Pe})$ when clay is thin (4 to $10 \mathrm{~mm})$. The fracture is contained even at the higher Pe when the clay is thicker than $15 \mathrm{~mm}$. These results suggest that bed containment of fractures in the Austin Chalk will occur when $\mathrm{Pe}$ is low (i.e., near surface brittle deformation or deformation at depth but with high formation pressure).

Portions of this work were presented at the Symposium on the Austin Chalk Producing Trend held at Texas A\&M
University June 3,1992, and previously to geologists, geophysicists, and petroleum engineers at Stanford University, the University of Oklahoma, in a short course for Union Pacific Resources Company (UPRC), in a lecture at AMOCO's research laboratory in Tulsa, and during discussion sessions at the 33rd U.S. Symposium on Rock Mechanics, Santa Fe, N. Mex., June 8-10, 1992.

\section{Relating Recovery to Well-Log Signatures}

Interpretation of well logs and production in the Giddings field was completed during April. The results are summarized in Ref. 1. New cores from Austin Chalk vertical as well as horizontal wells became available during June. These new cores will be examined in detail to relate rock properties to well-log response because cores of the Austin Chalk are rare. Some geochemical (pyrolysis) data were measured on existing core samples to understand the previously established correlations.

New cores of the Austin Chalk will be described for the occurrence of fractures and solution seams and their possible relation to saturation, well-log response, and oil production. Additional geochemical data on these cores would be useful. Work performed under this subtask was presented at the Symposium on the Austin Chalk Producing Trend held at Texas A\&M University June 3, 1992.

Austin Chalk production decline curves from East rexas wells were obtained from Arco Exploration and Production Co. and Maersk Energy Co. The curves are being analyzed to show the use of daily well tests in place of the normal monthly production records.

Portions of this work were presented at the Symposium on the Austin Chalk Producing Trend held at Texas A\&M University on June 3, 1992.

\section{Laboratory Studies of the Imbibition Process}

Six papers concerning the carbonated water imbibition technique were presented at various technical society meetings during the quarter. ${ }^{2-7}$ Additionally, a discussion of imbibition process was presented at the Symposium on the Austin Chalk Producing Trend held at Texas A\&M University on June 3, 1992.

Imbibition experiments are being designed and implemented to compare oil production as the result of carbonated and pure water imbibition. This new set of experiments is to investigate the effects of internal fractures of the matrix blocks, fractures that might never be contacted by the wetting fluid during a $\mathrm{CO}_{2}$-enriched waterflood. Some oil flow was observed from a simulated fracture on the back of the rock samples studied to the water imbibing face.

\section{Mathematical Modeling}

The dual-porosity compositional simulator used to simulate the $\mathrm{CO}_{2}$-enriched waterflood in fractured reservoir was 
tested for volatile oils. The capability is needed to accurately mimic reservoir processes when the reservoir pressure has a chance to go below the bubble point. The volatile oil data published by Peng ${ }^{8}$ was used to test the simulator. Reservoir and fluid data are tabulated in Table 2. Figure 4 shows the average reservoir pressure vs. cumulative oil production for a single-porosity simulation at a constant producing bottom-hole pressure. The simulation results present a good agreement with the published data. The time step required to achieve convergence in dual-porosity simulation for the mentioned test case was very small, in the order of $1 \times 10^{-5}$ days. Further testing is needed.

TABLE 2

\section{Rock and Fluid Properties of Fracture and Matrix Systems}

\begin{tabular}{lll}
\hline Reservoir area & $160 \mathrm{acres}$ \\
Reservoir thickness & $100 \mathrm{ft}$ \\
Hydrocarbon components & 17 \\
Initial reservoir pressure & $6000 \mathrm{psi}$ \\
Bubble point pressure & $5390 \mathrm{psi}$ \\
Bottom hole flowing pressure & $2000 \mathrm{psi}$ \\
Grid system & $5 \times 5 \times 1$ \\
Location of producing well & $5 \times 5 \times 1$ & \\
Grid block size & $528 \times 528 \times 100$ \\
\multicolumn{1}{c}{ System properties } & Fracture & Matrix \\
Horizontal permeability, $\mathrm{mD}$ & 60 & 1 \\
Vertical permeability, $\mathrm{mD}$ & 30 & 0.5 \\
Horizontal extent, $\mathrm{ft}$ & 528 & 5.7 \\
Vertical extent, $\mathrm{ft}$ & 100 & 5.7 \\
Initial water saturation & 0 & 0.1 \\
Porosity & 0.01 & 0.4 \\
Transfer function & 0.04 & 1.0 \\
\hline
\end{tabular}

\section{References}

1. C. D. Behrseresht, Correlation of Log Response to Productivity in the Austin Chalk, M.S. Thesis, Texas A\&M University, College Station, Tex., 1992.

2. J. Perez, S. W. Poston, and Q. Sharif, Carbonated Water Imbibition Flooding-An Enhanced Oil Recovery Process for Fractured Reser-

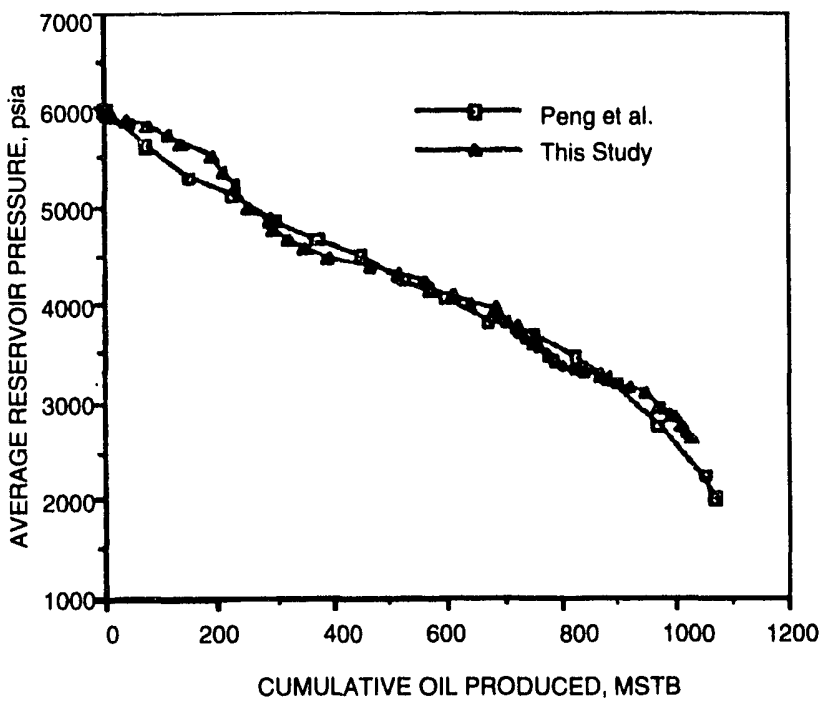

Fig. 4 Comparison of the volatile reservoir simulations.

voirs, paper SPE/DOE 024164 presented at the Eighth SPE/DOE Symposium on Enhanced Oil Recovery, Tulsa, Okla., Apr. 22-24, 1992.

3. J. Perez, S. W. Poston, and O. Sharif, Studies of Carbonated Water Imbibition-Using MRI Methods, paper SCA 9221 presented at the SCA/SPWLA Joint Annual Conference, Oklahoma City, Okla., June 14-17, 1992.

4. S. W. Poston, Imaging Methods Applied to Core Studies for Petroleum Engineering Applications, presented at the Society of Sigma XI Interdisciplinary Workshop, Texas A\&M University, College Station, Tex., Apr. 7, 1992.

5. S. W. Poston, J. Perez, and Q. Sharif, Carbonated Water Imbibition Flooding: An Enhanced Oil Recovery Process for Fractured Reservoirs, presented at the Eighth Wyoming Enhanced Oil Recovery Symposium, Casper, Wyo., May 20-21, 1992.

6. S. W. Poston, J. Perez, C. Edwards, and A. Hervas, MRI Studies of Differential Fluid Movement in Homogeneous and Variable Permeability Cores, presented at the Eighth Wyoming Enhanced Oil Recovery Symposium, Casper, Wyo., May 20-21, 1992.

7. J. Perez, S. W. Poston, and M. A. Barrufet, Studies of Carbonated Water Imbibition Using MRI, paper SCA 9221 presented at the SCA/ SPWLA Joint Annual Conference Society of Core Analysts, Oklahoma City, Okla., June 14-17, 1992.

8. C. P. Peng, J. L. Yanosik, and R. E. Stephenson, A Generalized Compositional Model for Naturally Fractured Reservoirs, SPERE, 5(2): 221226 (May 1990). 


\section{DISPERSION MEASUREMENT AS A METHOD OF QUANTIFYING GEOLOGIC CHARACTERIZATION AND DEFINING RESERVOIR HETEROGENEITY}

\section{Contract No. DE-AC22-90BC14652}

\author{
University of Oklahoma \\ Norman, Okla.
}

Contract Date: July 12, 1990

Anticipated Completion: July 1, 1993

Government Award: \$332,871

\section{Principal Investigator: \\ Donald E. Menzie}

\section{Project Manager: \\ Gene Pauling \\ Metairie Site Office}

Reporting Period: Apr. 1-June 30, 1992

a dense fluid is used to displace a less dense fluid. Under these conditions, the mixing zone length is shorter than when a light fluid is used to displace a more dense fluid. The shape of the concentration profile changes as the density difference of the two mixing fluids increases.

In this study the original purpose was to measure dispersion using two fluids with equal viscosity and density. In fact, the two mixing fluids had the same viscosity, but the difference in density was $0.04 \mathrm{~g} / \mathrm{cm}^{3}$ (Table 1). Two observations of the effect of gravity segregation on dispersion were obtained from the laboratory experiments. The first observation was obtained using the computerized tomography scanning method, where MN919 (density, $0.76 \mathrm{~g} / \mathrm{cm}^{3}$ ) was displaced by ID1090 (density, $0.80 \mathrm{~g} / \mathrm{cm}^{3}$ ) in a horizontal displacement in a core. The CT images shown in Fig. 1 indicate that the injection fluid (ID1090) mixes with the displaced fluid (MN919) from the bottom of the core to the top of the core. This indicates that gravity segregation plays an important part in the dispersion process not only in vertical displacement but also in horizontal displacement. In addition, a slight difference (such as $0.04 \mathrm{~g} / \mathrm{cm}^{3}$ ) in density could still affect the dispersion process.

TABLE 1

\section{Properties of Fluids Used in Computerized Tomography Scanning}

reservoir heterogeneities by measuring dispersion of miscible fluids flowing through porous media. This laboratory study will attempt to establish dispersivity or the concentration profile (i.e., the S-shape curve) as an oil rock property and to use this reservoir rock property to aid in enhanced oil recovery (EOR) operations. The study will involve measuring dispersion coefficients and dispersivities in consolidated porous media by measuring the degree of mixing of two miscible fluids as one fluid displaced the other. An attempt will be made to develop new ways to measure and interpret the dispersivity or the concentration profile, including use of ${ }^{18} \mathrm{O}$ water analysis, $\mathrm{X}$-ray imaging core scanning method, well-log analysis, and miscible gas displacements. A standard method of measuring dispersivity in the field between wells will be developed. This quarterly technical progress report presents the results of the effect of gravity segregation on the dispersion process. It is believed that these results can be used toward measuring the transverse dispersivity of a given porous medium.

\section{Summary of Technical Progress}

Gravity segregation plays an important part in miscible displacement. The mixing zone length is different for fluids of different densities, depending on the favorable and unfavorable density displacements. The favorable density displacement occurs when a heavier fluid is used to displace a lighter density fluid, whereas the unfavorable density displacement occurs when a lighter fluid is used to displace a heavier density fluid. Optimum displacement occurs when

\begin{tabular}{lcc}
\hline \multicolumn{1}{c}{ Material } & $\begin{array}{c}\text { Density }\left(\mathbf{g} / \mathrm{cm}^{3}\right) \\
\text { at } 74^{\circ} \mathbf{F}\end{array}$ & $\begin{array}{c}\text { Viscosity (cP) } \\
\text { at 74 }\end{array}$ \\
\hline Naphtha (N) & 0.75 & 0.57 \\
Mineral oil (MO) & 0.86 & 27.9 \\
Iododecane (ID) & 1.257 & 3.6 \\
MN919 (9\% MO + 91\% N) & 0.76 & 0.69 \\
ID1090 (10\% ID + 90\% N) & 0.80 & 0.69 \\
\hline
\end{tabular}

The second observation of the gravity segregation effect was obtained from the comparison of the two experimental runs (Run 1 and Run 2), which were measured using the X-ray linear core scanning method. In Run 1, MN919 (density, $0.76 \mathrm{~g} / \mathrm{cm}^{3}$ ) was displaced by ID1090 (density, $0.8 \mathrm{~g} / \mathrm{cm}^{3}$ ). This was a favorable density displacement because the heavier liquid, ID1090, was used to displace the lighter liquid, MN919. In Run 2, ID1090 was displaced by MN919, which was an unfavorable density displacement. The injection rate of these two runs was the same.

Figure 2 shows three concentration profiles over the length of the YH1 Berea sandstone core $(15.5 \mathrm{~cm}$ in length and $5.1 \mathrm{~cm}$ in diameter) during a favorable density displacement (Run 1). The mixing lengths $\left(\mathrm{x}_{90}-\mathrm{x}_{10}\right)$ of these concentration profiles were $3.0,4.1$, and $5.6 \mathrm{~cm}$ for pore volume injections (PVI) of $0.32,0.62$, and 0.94 , respectively. The breakthrough time of this run occurred at 0.88 pore volume (PV). Figure 3 shows four concentration profiles over the length of the YH1 Berea core during an unfavorable density displacement (Run 2). 


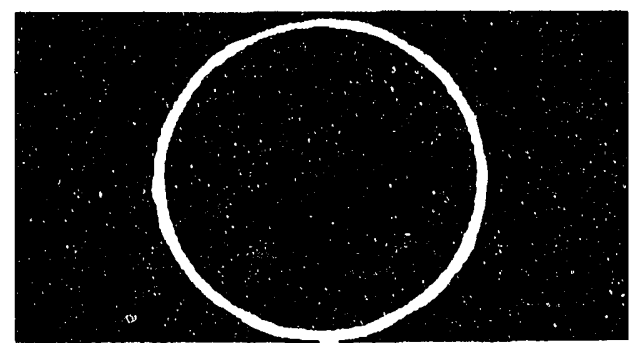

(a) 0\% 101090 Concentration

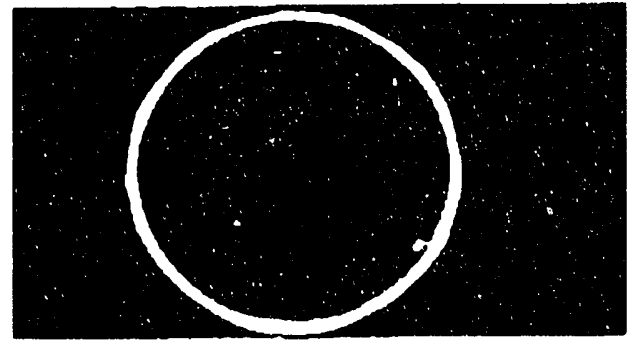

(b) $5.4 \%$ ID1090 Concentration

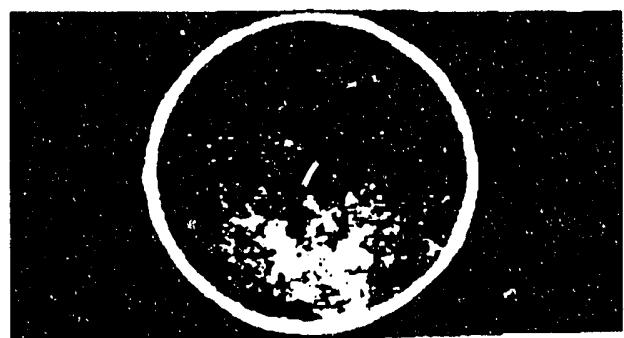

(c) $23 \%$ ID1090 Concentration

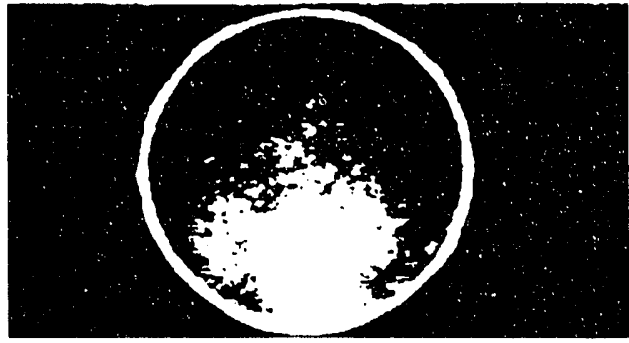

(d) $52 \%$ ID1090 Concentration

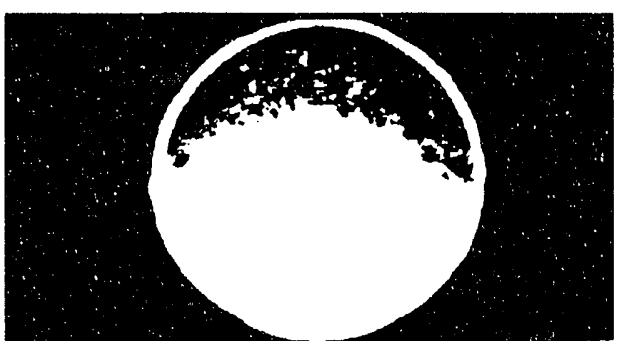

(e) $73 \%$ W1090 Concentration

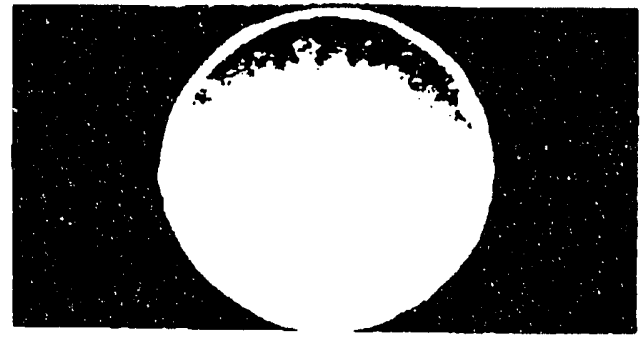

(f) $89 \%$ W1090 Concentration

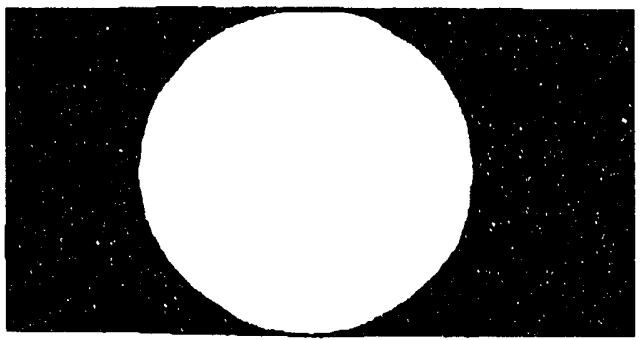

(g) 96\% DD1090 Concentration

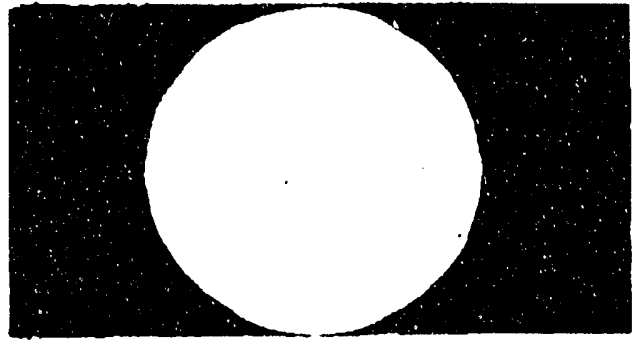

(h) $100 \% \mathrm{WD} 1090$ Concentration

Fig. 1 Computerized tomography images measured at $7.2 \mathrm{~cm}$ Incation on Y $B 8$ Berea sandstone core.

The mixing lengths $\left(\mathrm{x}_{(x)}-\mathrm{x}_{10}\right)$ of these concentration profiles were $2.8,6.9,9.1$, and $8.9 \mathrm{~cm}$ at PVI of $0.2,0.4,0.68$, and 0.84 , respectively. The breakthrough time of this run occurred at 0.68 PV. Before breakthrough the mixing length increased with time. After breakthrough the mixing length decreased with time. After two or three PVIs, the mixing length was reduced to zero. As shown by a comparison of the two runs, the breakthrough occurred earlier in the unfavorable density displacement.
Two curves are shown in Fig. 4: one is the mixing zone length vs. pore volume injected at a favorable density displacement (Run 1 ) and the other is the mixing zone length vs. pore volume at an unfavorable density displacement (Run 2). At a given pore volume. the mixing zone length of the favorable density displacement (Run l) is much shorter than that of an unfavorable density displacement. For example, at ().5 PV. the mixing zone length of Run 1 (favorable) was $3.4 \mathrm{~cm}$. whereas that of Run 2 (unfavorable) was $7.4 \mathrm{~cm}$. These 


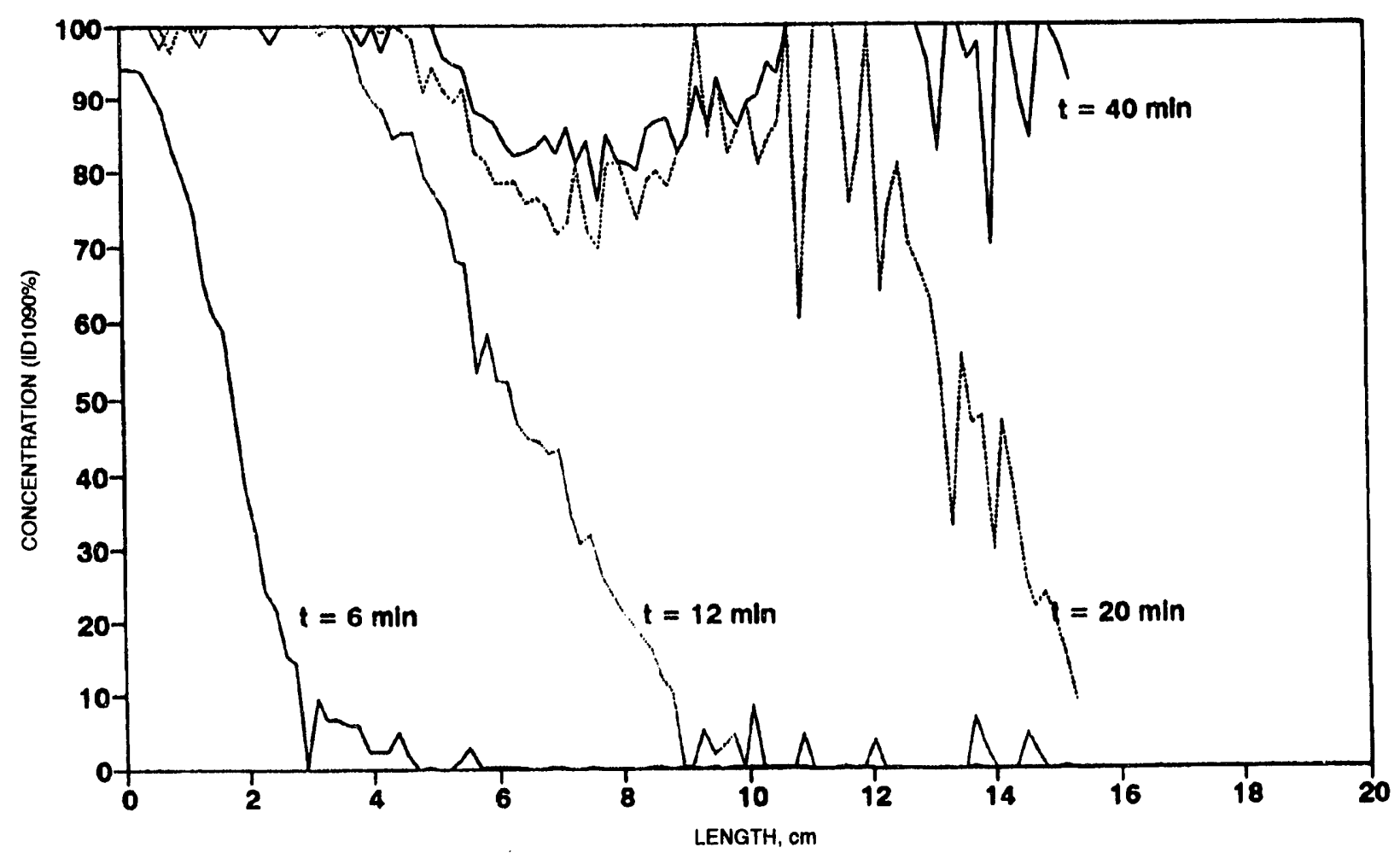

Fig. 2 Concentration curves measured on YH1 Berea sandstone core under favorable density displacement. MN919 displaced by ID1090 $\left(q, 0.039 \mathrm{~cm}^{3} / \mathrm{s}\right)$.

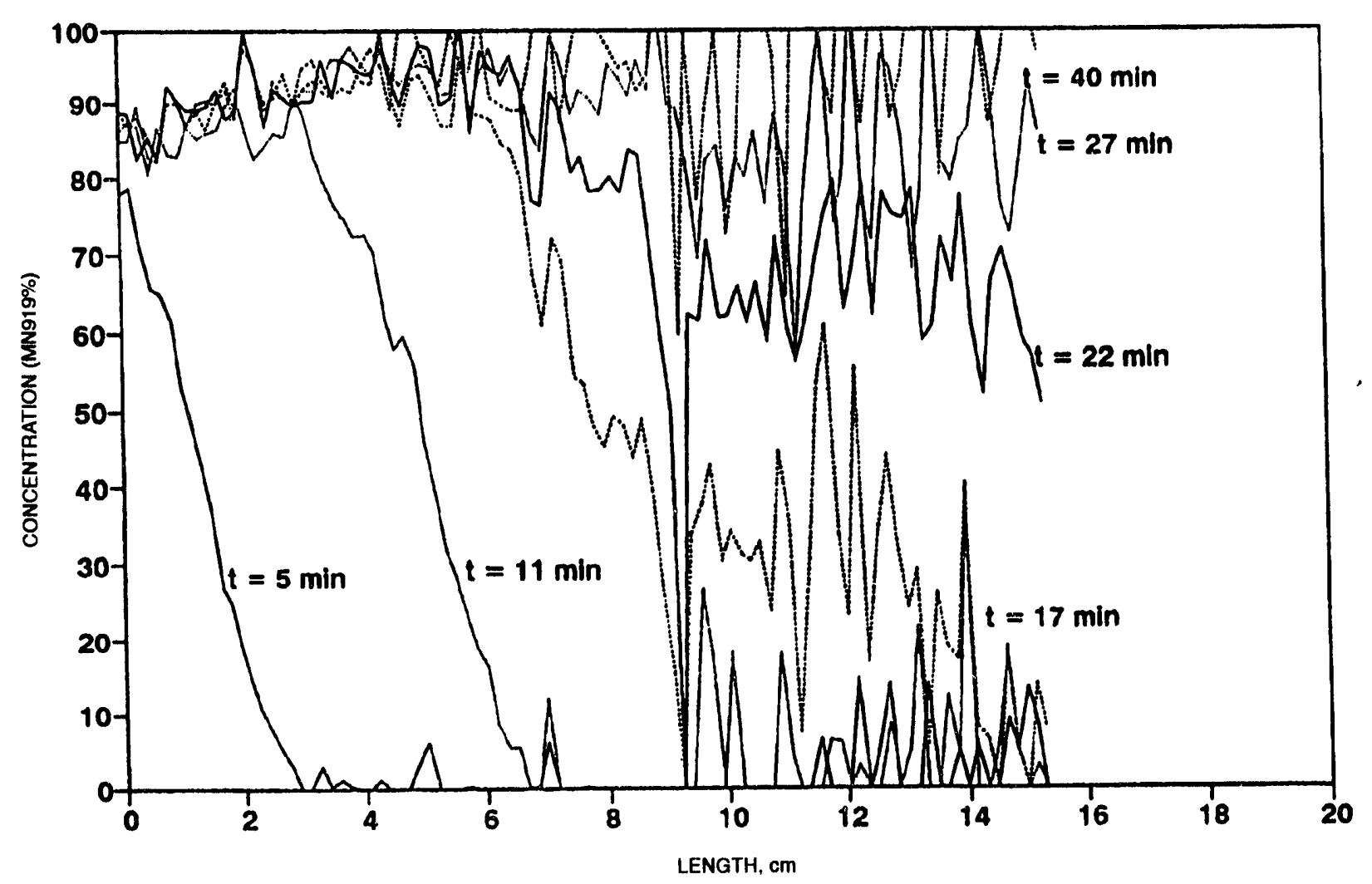

Fig. 3 Concentration curves measured on YH1 Berea sandstone core under unfavorable density displacement. ID1090 displaced by MN919 (q, $0.039 \mathrm{~cm}^{3} / \mathrm{s}$ ). 


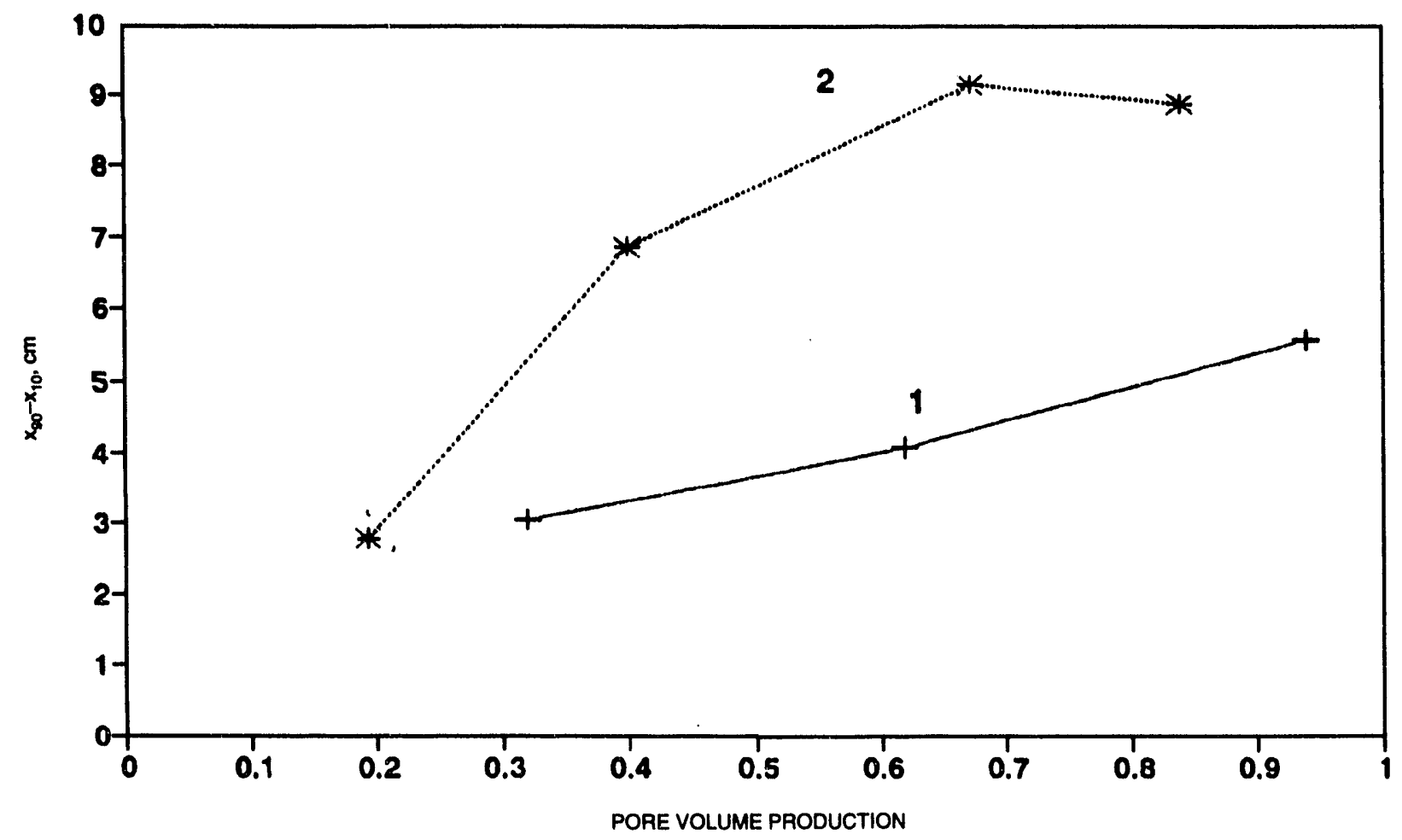

Fig. 4 Efrect of gravity segregation on dispersion X-ray linear core scanning on YH1 Berea core. Mixing length ( $\left.\mathbf{x}_{90} \mathbf{x}^{-x_{10}}\right)$ vs. pore volume injection. 1 , favorable density displacement; 2 , unfavorable density displacement.

two curves also show that the slopes of the mixing zone lengths are different. The speed of the mixing zone length increases during favirable density displacement at $3.4 \mathrm{~cm} / \mathrm{PV}$ and during unfavorable injection at $13.2 \mathrm{~cm} / \mathrm{PV}$.

In summary, the effect of gravity segregation on dispersion was observed in this study. Dispersion behavior is shown to be strongly affected by the density of the displacing fluid. CT images show that dense liquid mixes with lighter liquid from the bottom to the top of a core. When the displacing fluid is more dense, the mixing zone is short, breakthrough time occurs late, and the growing rate of the mixing zone length is slow. In contrast, when a less dense displacing fluid is used, the mixing zone is long, breakthrough time occurs early, and the growing rate of the mixing zone is high.

Work continued on (1) the experiments to determine the relationships between the flow system, dispersivity or dispersion coefficient, and the degree of presence of a second fluid phase, which in this case is the connate water; (2) the establishment of a method to measure the transverse dispersion in a block of consolidated porous medium; and (3) the experiments to measure dispersion of gas-gas displacements on the core samples on which the concentration profiles were obtained from liquid-liquid displacements. 


\section{ELECTRICAL AND ELECTROMAGNETIC METHODS FOR RESERVOIR DESCRIPTION AND PROCESS MONITORING}

\author{
Lawrence Berkeley Laboratory \\ University of Callfornia \\ Berkeley, Calif.
}

Contract Date: Oct. 1, 1990

Anticipated Completion: Sept. 30, 1993

Funding for FY 1992: $\$ 200,000$

Principal Investigators:

H. Frank Morrison

KI Ha Lee

Alex Becker

Project Manager:

Robert Lemmon

Bartlesville Project Office

Reporting Period: Apr. 1-June 30, 1992

\section{Objectives}

This project is part of an integrated effort by Lawrence Berkeley Laboratory (LBL)-University of California at Berkeley (UCB), Lawrence Livermore National Laboratory (LLNL), and Sandia National Laboratories (SNL) in the electrical and electromagnetic (EM) geophysical method development research and development (R\&D) program for petroleum reservoir characterization and process monitoring. The overall objectives of the program are to (1) integrate research funded by the Department of Energy (DOE) for hydrocarbon recovery into a focused effort to demonstrate the technology in the shortest time with the least cost; (2) assure industry acceptance of the technology developed by having industry involvement in the planning, implementation, and funding of the research; and (3) focus the research on real-world problems that have the potential for solution in the near term with significant energy payoff.

Research conducted through this integrated effort focuses on five general activities:

1. Electromagnetic (EM) forward modeling development.

2. Data interpretation methods development.

3. Hardware and instrumentation development.

4. Enhanced Oil Recovery (EOR) and reservoir characterization.

\section{Controlled field experiments.}

The LBN-UCB research is focused on activities 1, 2, and 5. The primary focus is in the development of reliable inversion and imaging schemes that can yield conductivity distribution from measured electrical and EM field data. The development of accurate forward modeling algorithms and the acquisition of high-quality scale-model data are necessarily the early part of the inversion scheme development for ultimately monitoring the front tracking in existing reservoirs.

\section{Summary of Technical Progress}

Significant progress was made in the third quarter research at LBL. This quarter's progress report consists of crosshole EM measurements at the Richmond Field Station (RFS), application of improved Born inversion algorithm to Devine (Texas) field data, and the time-domain electromagnetic (TEM) scale-model development. In particular, the field experiment at RFS has been very successful and is the highlight of this quarter.

\section{Crosshole Electromagnetic Measurements at the Richmond Field Station}

More than 50,000 gal of $1 \mathrm{~S} / \mathrm{m}$ saltwater was injected into the injection well (INJ1) at RFS (Fig. 1) in the middle of June 1992. Crosshole EM measurements in the four boreholes (EMNW, EMSW, EMSE, and EMNE) were made before and after the injection. When making these measurements, the receiver was held fixed at a point between 5 and $55 \mathrm{~m}$ with a sampling interval of $5 \mathrm{~m}$, whereas the magnetic-dipole transmitter was being lowered down from 4 to $60 \mathrm{~m}$. For more confidence in the field data, the postinjection measurements for most configurations were taken twice. The interval between the repeat was about 2 weeks, and the repeatability was satisfactory.

Some significant changes in the $\mathrm{Hz}$ field can be observed by comparing the measurements taken before and after the injection. Figures 2 and 3 are two samples of the measured $\mathrm{Hz}$ field before and after the injection. These two figures represent the $\mathrm{Hz}$ field measured at the depth of $30 \mathrm{~m}$ in boreholes EMNW and EMSE, respectively. By subtracting the preinjection field amplitude from that of the postinjection, a clear anomaly can be observed (Fig. 4) at around $30 \mathrm{~m}$. This is exactly at the depth of the injection where a saltwater plume would be formed. The anomaly can be observed

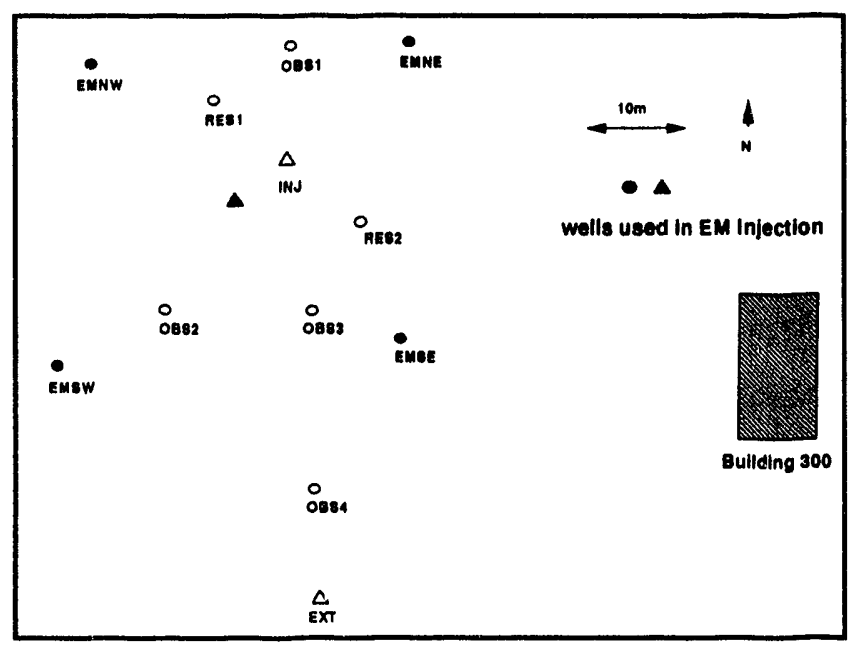

Fig. 1 Richmond Field Station Wellneld. 


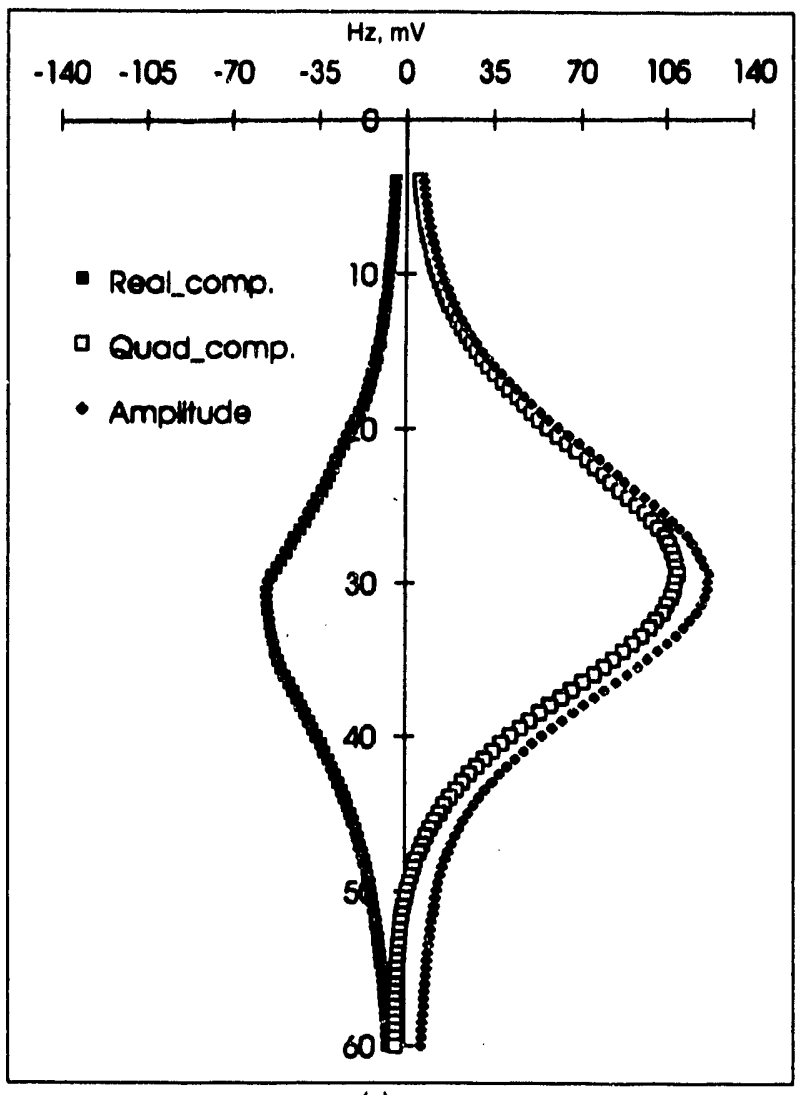

(a)

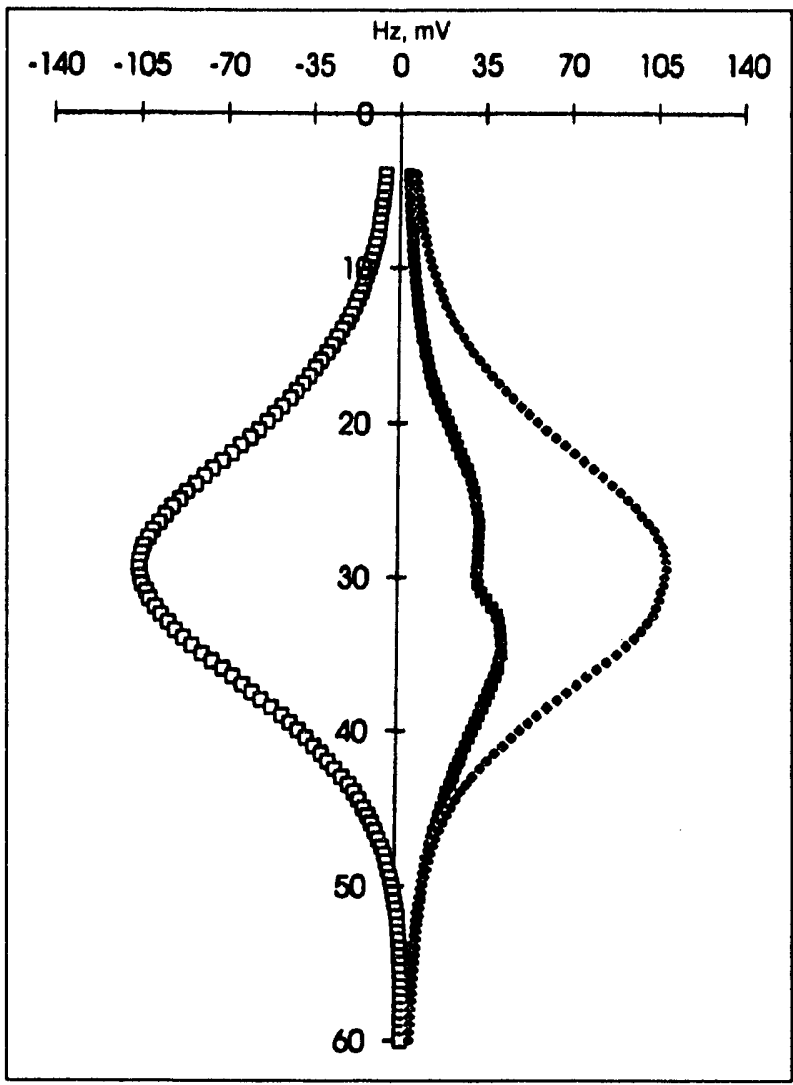

(b)

Fig. 2 Hz in EMNV (a) before and (b) after injection.
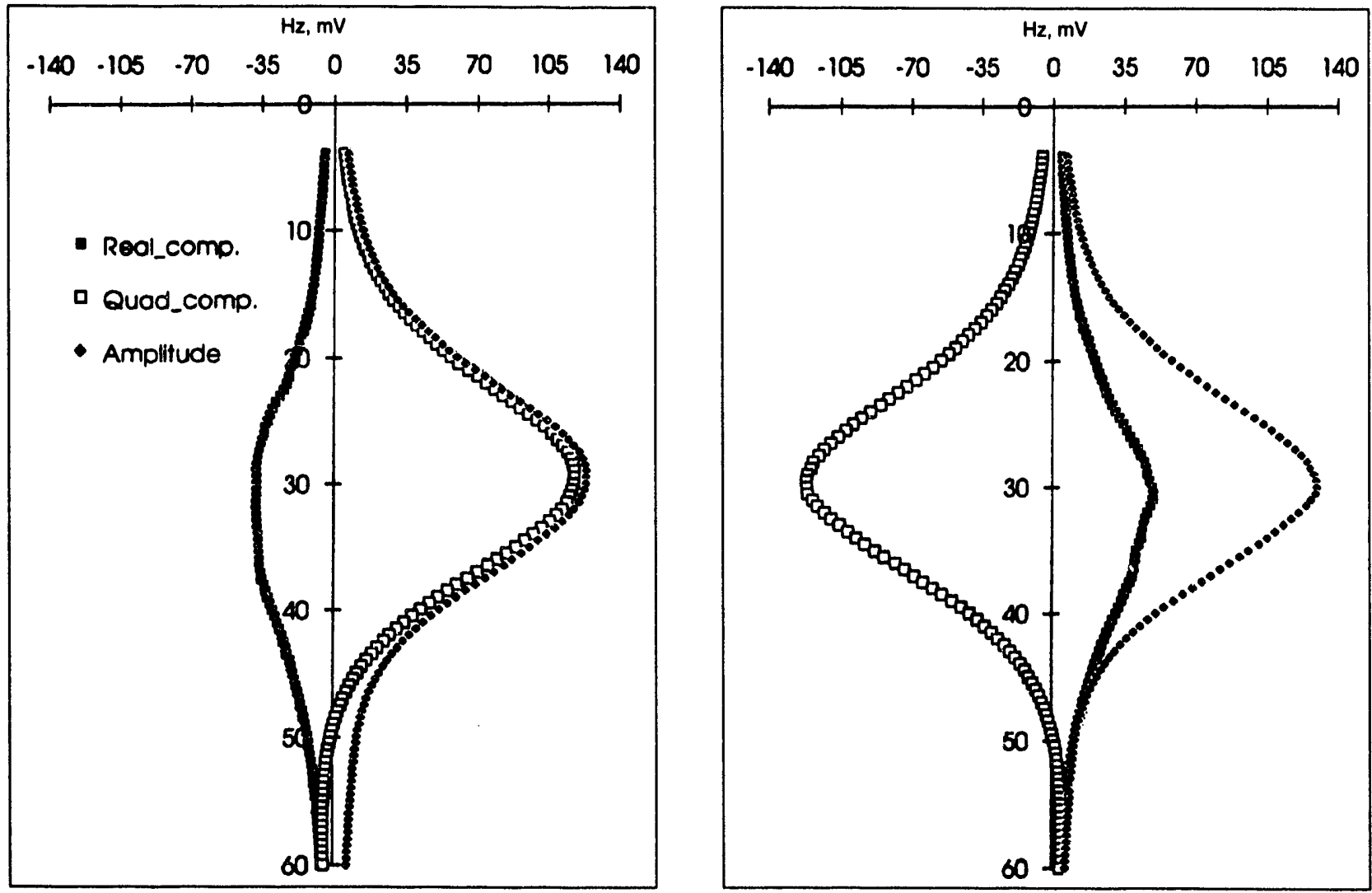

Fig. 3 Hz in EMSE (a) before and (b) after injection. 


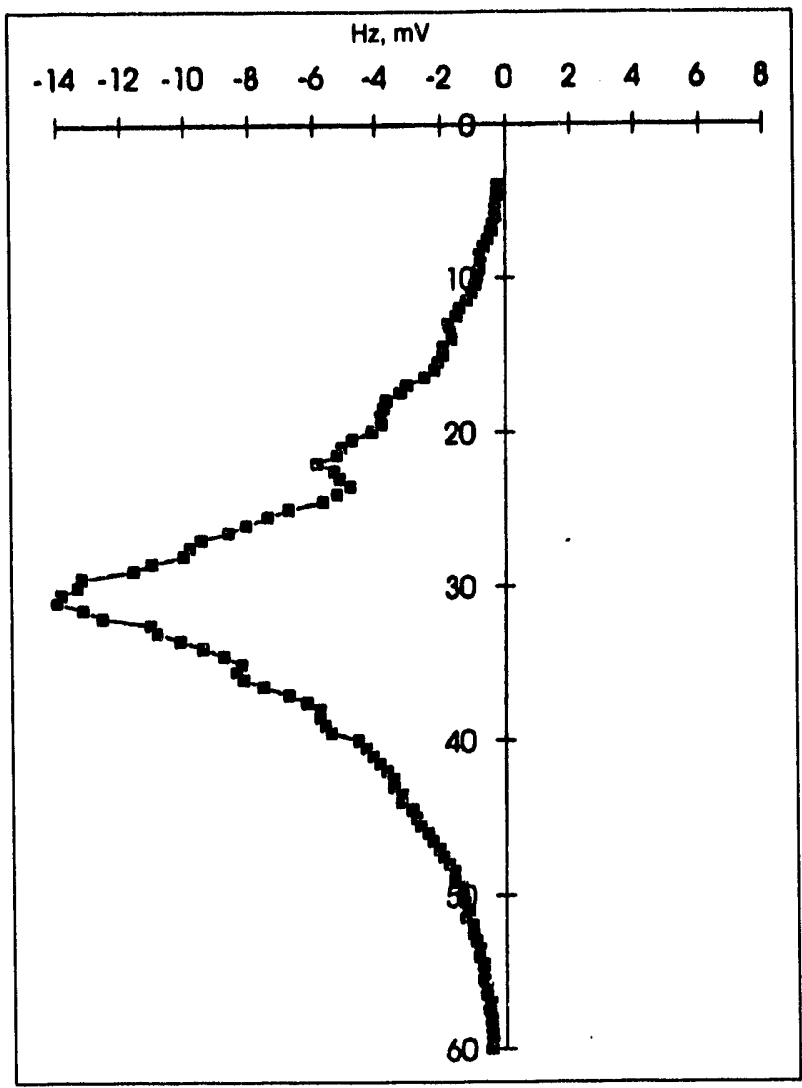

(a)

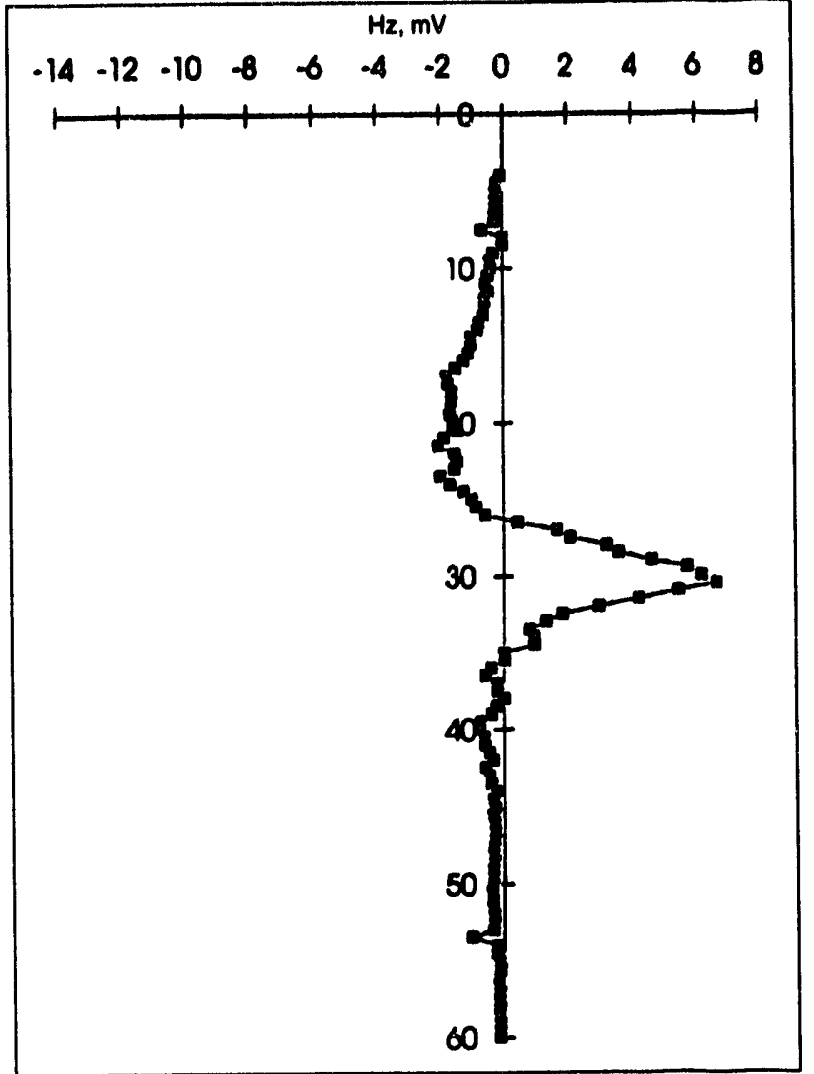

(b)

Fig. $4 \mathrm{~Hz}$ (a) in EMNW before and after injection and (b) in EMSE before and after injection.

in all four boreholes, but the interesting phenomenon is that it changes its sign systematically. Negative anomalites can be observed in boreholes EMNW and EMNE (north to the INJ1), whereas the other two boreholes show positive anomalies. A preliminary numerical model study suggests that this may be the result of the saltwater plume extended slightly more to the south of the injection well (INJ1) at the time of the measurements. Further quantitative analysis is required to assert this initial interpretation.

\section{Application of Iterative Born Inversion to the Devine Data Set}

In September 1990 the first set of cross-well EM measurements was collected with the LBL-LLNL system at the British Petroleum test site near Devine, Tex. ${ }^{1}$ Examination of the well logs indicates that the geology at the site consists of interbedded sandstones, shales, and limestones, which are continuous and flat lying across the area. Resistivities of the rocks range from 1 to $300 \Omega-\mathrm{m}$. The survey was conducted in two boreholes separated by $100 \mathrm{~m}$. The boreholes are lined with plastic from $160 \mathrm{~m}$ to the bottom at $900 \mathrm{~m}$. The cross-borehole survey was conducted from a depth of approximately 549 to $669 \mathrm{~m}$ spanning a series of 2 to $3 \Omega$-m sands and shales to a 30 -m-thick, $10 \Omega$-m section of limestone and back to sands and shales. The data were collected by fixing the receiver location in one borehole and then moving the transmitter over the same $120-\mathrm{m}$ section in the other well while continuously making measurements. Thirteen profiles at 512 and $2048 \mathrm{~Hz}$ were obtained in this manner with approximately $8 \mathrm{~m}$ between successive receiver positions. Figure 5 shows an expanded section of the well log from one of the holes with a onedimensional (1-D) interpretation of the EM data.

The image resulting from the iterative Born inversion of the $512-\mathrm{Hz}$ data is shown in Fig. 6. The Born inversion algorithm applied here assumes a radial symmetry. Notice that, although the image does not show perfectly flatlying beds, it does show a resistive area separating two

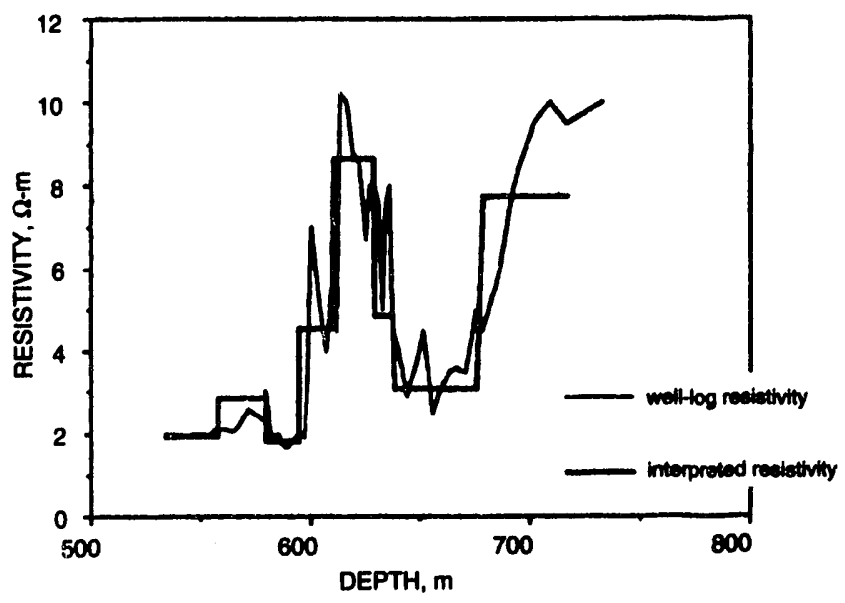

Fig. 5 Model vs, induction log resistivity. 
conductive zones, the positions of which coincide very well with the well $\log$ and I-D inversion. Because the integral equation theory is developed for isolated bodies rather than extensive conductivity anomalies, these results are believed to be excellent. Inversions of the $2048-\mathrm{Hz}$ data and simultaneous inversions of both frequencies show similar results.

\section{Time-Domain Electromagnetic Scale Model}

Development of the TEM scale model continued. This quarter was focused on determining the optimal design of the surface coils by analyzing the analytical solution of the transfer function of the coil. The analysis, along with numerical computations, allows the determination of the theoretical effect of the nonideal properties of the coil, such as distributive capacitance, inductance, and series and parallel resistance. Coil parameters were selected so that the effect of these potentially crippling properties could be minimized. Figure 7 compares the theoretical solution and laboratory

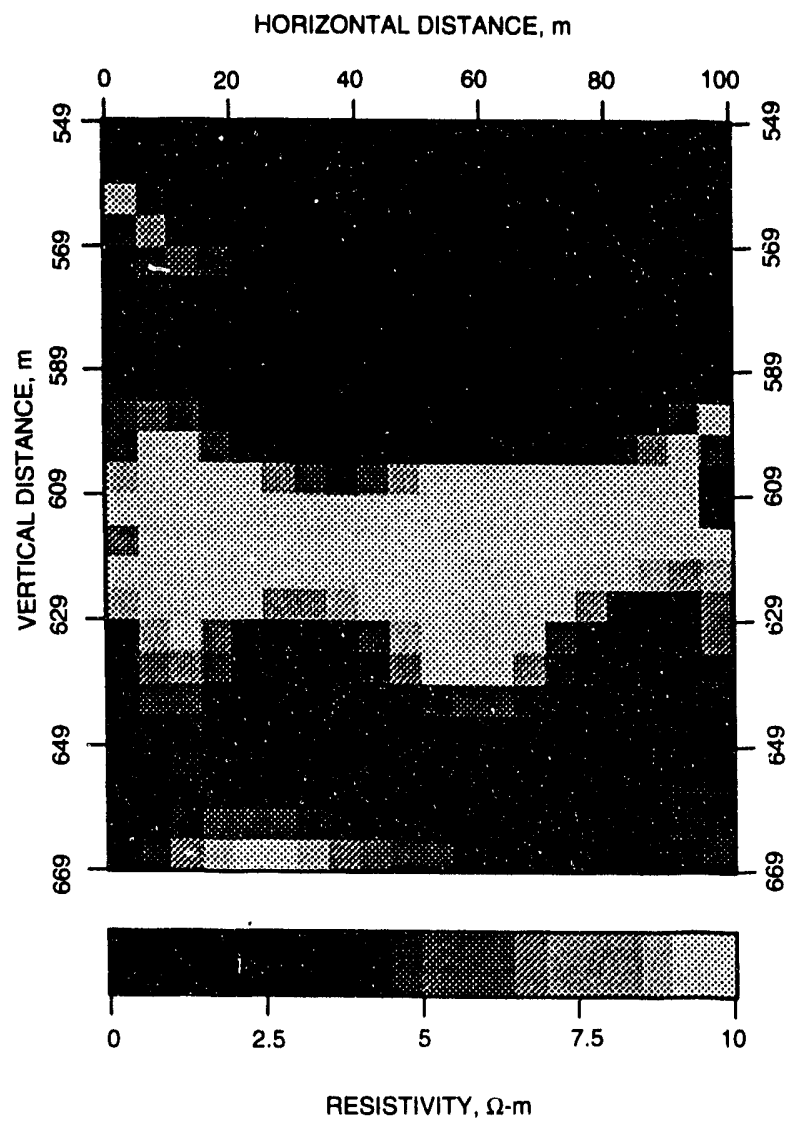

Fig. 6 Image resulting from iterative Born inversion of $512-\mathrm{Hz}$ data. measurements and demonstrates the success of this approach. The theoretical curve was obtained by convolving Ward and Hohmann's analytical solution with the transfer function. The solution was Fourier transformed into the frequency domain, multiplied by the frequency-dependent transfer function, and finally inverse Fourier transformed back to the time domain.

Gain-ranging of the receiver amplifier was determined to be a viable solution to the late-time degeneration of the signal. Figure 7 shows where the signal reaches the least bit of the 14-bit analog/digital converter. A secondary solution of this problem will be to average over time windows in late time.

Subsurface measurements are now being taken to ensure applicability of the coils and to see if the subsurface will shield the receiver coil sufficiently from electrostatic effects of the transmitter. The shielding should cure the early time problem noticeable in Fig. 7. Once this is completed the coils will be mounted to an already existing step-motor rig to allow for fully automated data acquisition.

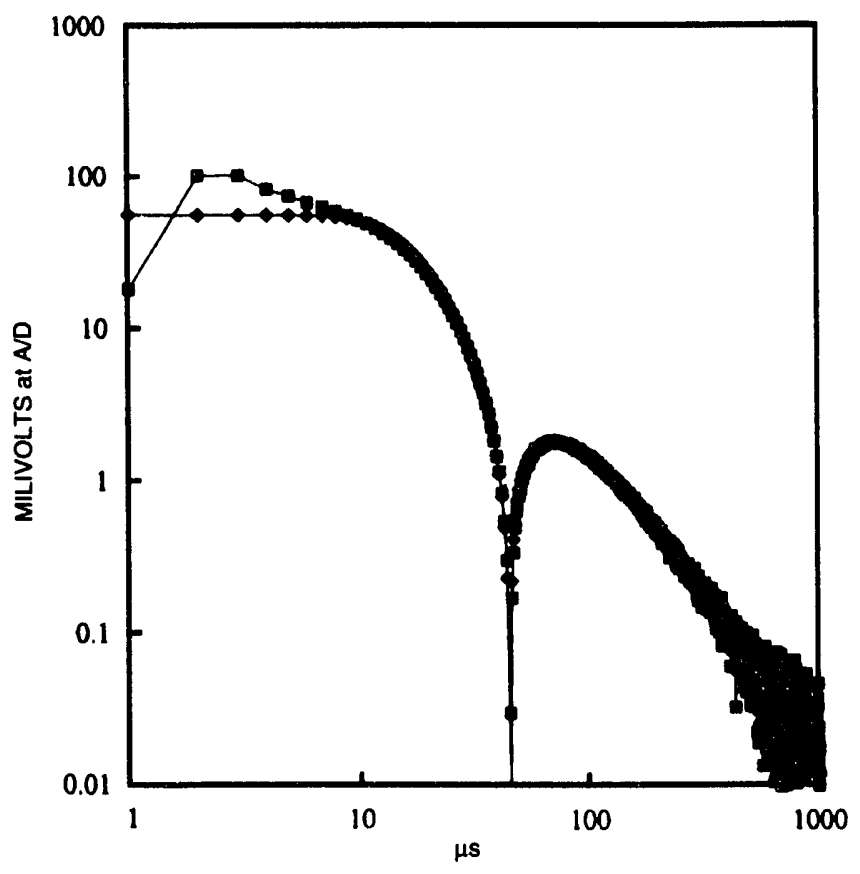

Fig. 7 Illustration showing comparison of theoretical solution and laboratory measurements (surface-to-surface time-domain electromagnetic model.) - - laboratory; $\rightarrow$-, theory.

\section{Reference}

1. M. J. Wilt, H. F. Morrison, A. Becker, and K. H. Lee, Cross-Borehole and Surface-1o-Borehole Electromagnetic Induction for Reservoir Characterization, Report DE91002253, Lawrence Livermore National Laboratory, 1991. 


\section{GEODIAGNOSTICS FOR RESERVOIR HETEROGENEITIES AND PROCESS MAPPING}

\author{
Sandia National Laboratories \\ Albuquerque, N. Mex. \\ Contract Date: Oct. 1, 1987 \\ Anticipated Completion: Sept. 30, 1993 \\ Funding for FY 1992: $\$ 200,000$ \\ Principal Investigator: \\ David A. Northrop \\ Project Manager: \\ Robert Lemmon \\ Bartlesville Project Office
}

Reporting Period: Apr. 1-June 30, 1992

\section{Objective}

The objective of this project is to increase the producibility of existing oil resources by better definition of reservoir heterogeneities and monitoring of oil recovery processes through the application of advanced geodiagnostics systems. This project provides a geologic and reservoir engineering perspective for the integrated Electromagnetic Geophysical Method research and develupment program being coordinated by the Department of Energy at Sandia National Laboratories, Lawrence Livermore National Laboratory, Lawrence Berkeley Laboratory, and the University of California at Berkeley. FY92 tasks include (1) develop and apply an oil recovery/resistivity simulator system, (2) apply reservoir characterization concepts to bulk resistivity and electrical/electromagnetic (E/EM) field data interpretation, (3) acquire and characterize an industry field site, and (4) field test reservoir characterization data collection.

\section{Summary of Technical Progress}

\section{Application of Reservoir Characterization to Electromagnetic Field Data Interpretation}

The geology of an oil reservoir is not homogeneous at the scale of resolution of an EM measurement or at the grid scale of an oil reservoir simulator. It is therefore necessary to understand how the petrophysical laws governing resistivity of homogeneous rocks average to give bulk or gridscale resistivity.

A concern in past work has been that resistivity variations on a scale finer than resolved by EM techniques may cause the bulk rock resistivity to be frequency dependent. To investigate this issue, a system was developed to evaluate the equations governing the propagation of plane waves through a layered media. This approach will be used to compare the amplitude of a signal passing through a layered media with that passing through a homogeneous media to determine if the effective conductivity is frequency dependent. The same program may also be useful in examining surface-to-borehole data taken at the Lawrence Field.

\section{Acquire and Characterize an Industry Field Site}

Controlled field experiments are essential to test EM instrumentation, measurement techniques, and interpretation methods. A petroleum reservoir field site and industry partner are needed to provide a realistic and demanding environment for field tests.

Marathon's Lawrence Field, Illinois, was chosen for this year's Sandia field work testing equipment and demonstrating the EM method. The history of development of the polymer-waterflood in the Lawrence Field appears to be a classic example of how EM monitoring of the flood could have been integrated into reservoir management with the oil-field recovery/resistivity simulator system (ORRSim) being developed at Sandia. Before the flood, with the best available characterization information, Marathon simulated the performance of the flood to determine when the fronts should arrive and how to confine the pattern. When oil prices dropped in 1986, the economics of the project was not encouraging. The fronts had not arrived at the producers, and Marathon wanted to know if the polymer chemistry was working properly and if the project should be abandoned. Fiberglass wells were included in the project for early identification of the progress of the flood. These were induction logged, which demonstrated that the chemistry of the polymer was adequately characterized in the original simulation and oil was banking properly. Thus the project was continued. The logs also showed that the flood was progressing more slowly than predicted, which indicated that fluid was being lost off pilot. Eventually, the fronts reached the producers, and polymer lost off pilot was produced in off-pilot wells, which confirmed what had been inferred from the induction logs.

EM monitoring and ORRSim would provide a better way than induction logging fiberglass-cased wells to provide early information on the performance of an oil recovery process. In fact, an EM survey very early in the project could have indicated the direction in which fluid was going off pilot in time to resimulate and adjust the field pattern to maximize the chance of economic success. In doing so, the success or failure of a pilot study would be based on the success or failure of the process itself and not adversely affected by the adequacy of the reservoir hydrodynamic characterization.

\section{Develop the Oil Recovery/Resistivity Simulator System}

For an electrical resistivity structure obtained from field EM measurements to aid in increasing the productivity of 
an oil reservoir, the effect of the process on the electrical properties of the reservoir must be understood and characterized. An ORRSim that includes a standard oil field simulator (such as BOAST-II) and the petrophysics to calculate electrical resistivity was developed to provide design and validation information for the EM measurement systems, provide conditioning information for EM inversions, and simulate oil recovery processes conditioned to the inverted EM measurements.

During May, AMOCO approached Sandia to inquire about ORRSim. AMOCO is considering the start-up of a program to investigate the use of EM methods to monitor oil recovery processes. Their concept is to begin by investigating the utility of EM monitoring methods rather than begin with an instrumentation project. They consider the ability to do the calculations incorporated into ORRSim as critical for integrating EM monitoring and reservoir management.

During June, IROC, an independent producer, approached Sandia to inquire about ORRSim. IROC is in the business of electrically stimulating wells and was interested in learning how ORRSim predicts formation resistivity during an oil recovery process. IROC's request for information suggests that, in addition to being needed for interpretation of EM monitoring of oil recovery processes, ORRSim may be useful in managing electrical stimulation of wells and reservoirs.

\section{SIMULATION STUDIES TO EVALUATE THE EFFECT OF FRACTURE CLOSURE ON THE PERFORMANCE OF NATURALLY FRACTURED RESERVOIRS}

\section{Contract No. DE-AC22-90BC14654}

K\&A Energy Consultants, Inc. Tulsa, Okla.

Contract Date: Sept. 18, 1990

Anticipated Completion: Sept. 30, 1993

Government Award: \$582,269

\section{Principal Investigator: Dwight L. Dauben}

\section{Project Manager:}

Rhonda Lindsey

Bartlesville Project Office

Reporting Period: Apr. 1-June 30, 1992

\section{Objective}

The objective of the study is to evaluate both the effects of fracture closure on the recovery of oil and gas reserves from naturally fractured petroleum or natural gas reservoirs and the procedures for improving the recovery of these reserves using innovative fluid injection techniques to maintain reservoir pressure and mitigate the impact of fracture closure.

\section{Summary of Technical Progress}

\section{Literature Review}

No search activity was performed during the reporting period. The search of the technical literature will be resumed as soon as the 1991 Index to the Petroleum Ab. stracts is published in August.

\section{Pressure-Sensitive Fractures}

The Albuskjell Field data' reported by Sandia National Laboratories were adapted to typical Pearsall Field Austin Chalk conditions to develop stress-dependent fracture-flow properties. Figures 1 and 2 illustrate the properties derived for two assumed overburden stress conditions. For the data in Fig. 1, the rock was assumed to be lithostatically loaded (i.e., all three principal stress components are equal to the depth of burial, $6592 \mathrm{ft}$ times the lithostatic gradient, which was assumed to be $1 \mathrm{psi} / \mathrm{ft}$ ). Figure 2 data were derived by reducing the net overburden stress, $\sigma$, as follows:

$$
\sigma=\frac{\sigma_{z z}+\sigma_{y y}+\sigma_{x x}}{3}
$$

$$
\text { where } \begin{aligned}
\sigma_{z z} & =\text { vertical component of principal stress } \\
& =0.9 \times 6592 \mathrm{psi} \\
\sigma_{\mathrm{yy}} & =\mathrm{y} \text {-direction principal stress component } \\
& =0.75 \times \sigma_{z z} \\
\sigma_{\mathrm{xx}} & =\mathrm{x} \text {-direction principal stress component } \\
& =1.1 \times \mathrm{p}_{\mathrm{i}} \\
\mathrm{p}_{\mathrm{i}} & =\text { initial reservoir pressure } \\
& =3000 \mathrm{psi}
\end{aligned}
$$

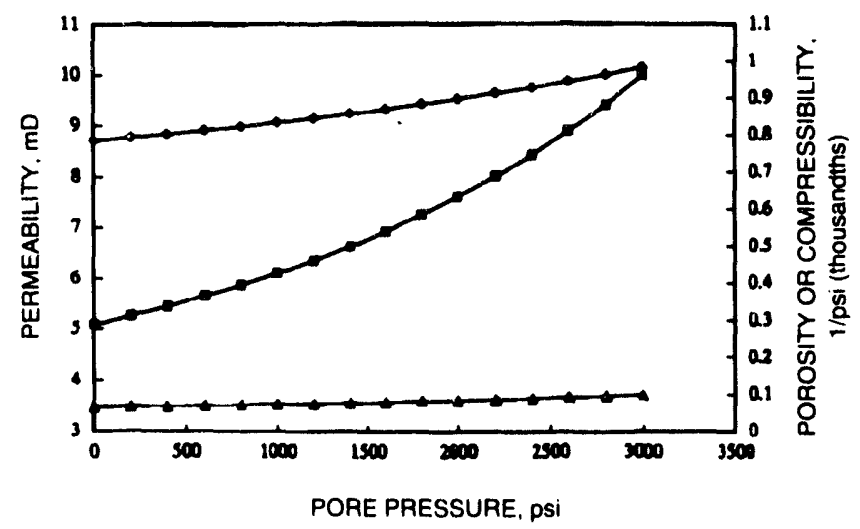

Fig. 1 Fracture properties vs. pore pressure for $\sigma=6592$ psi. Basis: SPE 22666 data and cubic equation. $-\bullet-$, permeability; $-\infty$, porosity; $-\wedge-$, compressibility. 


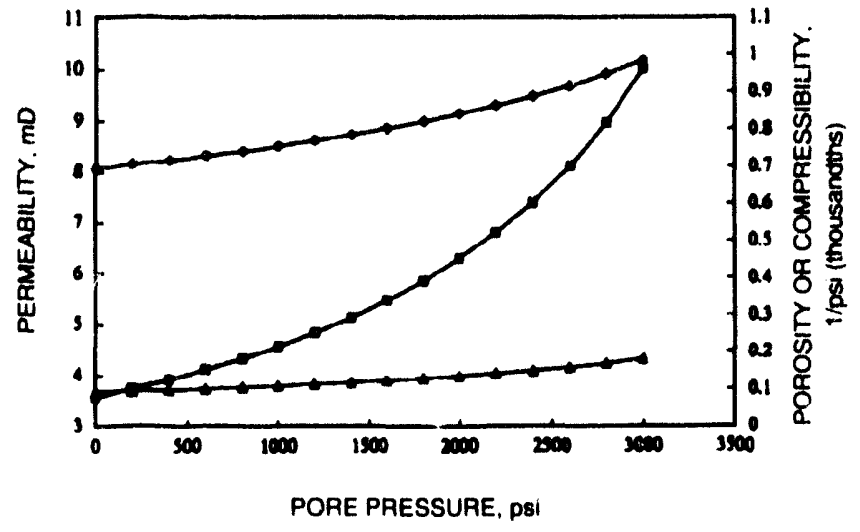

Fig. 2 Fracture properties vs. pore pressure for $\sigma=\mathbf{4 5 6 0 . 8}$ psi. Basts: SPF 22666 data and cubic equation. $\rightarrow-$, permeability: $\downarrow$, porosity; $-\Delta-$, compressibility.

The foregoing discussion is repeated from the last quarterly report and is repeated here for convenient reference. The series of simulation runs, which hegan last quarter, continued and was expanded during the current quarter.

The work performed during the current reporting period was devoted entirely to the running of a large number of simulation cases to ascertain how various reservoir parameters affect the simulated reservoir performance when the fracture permeability is assumed to be stress sensitive. This has involved multiple runs with both models, the vetical well model and the horizontal well model, and two depletion methods, natural depletion and water injection. The number of cases is doubled by the need to run each alternative for each of the two fracture permeability vs. stress functions presented in Progress Report 6. The number of cases simulated is summarized by category in Table 1 .

\section{TABLE 1}

\section{Cases Simulated by Category}

\begin{tabular}{lcc}
\hline $\begin{array}{c}\text { Depletion method } \\
\text { and parameter }\end{array}$ & $\begin{array}{c}\text { Horizontal } \\
\text { model cases }\end{array}$ & $\begin{array}{c}\text { Vertical } \\
\text { model cases }\end{array}$ \\
\hline $\begin{array}{l}\text { Natural depletion } \\
\text { Base cases }\end{array}$ & 2 & 3 \\
$\begin{array}{l}\text { Relative conductivity } \\
\text { Relative storativity }\end{array}$ & 8 & 8 \\
Capillary pressure & 8 & 8 \\
Relative permeability & 8 & 8 \\
\multicolumn{1}{c}{ Total } & 8 & 8 \\
Water injection & 34 & 35 \\
Base cases & 2 & 2 \\
Relative conductivity & 10 & 12 \\
Relative storativity & 10 & 12 \\
Capillary pressure & 6 & 6 \\
\multicolumn{1}{c}{ Total } & 28 & 32 \\
\hline \multicolumn{1}{c}{ Grand total } & 62 & 67 \\
\hline
\end{tabular}

Four sensitivity runs with the horizontal well water injection model remain to complete the current set. Additional runs will likely be required to round out the sensitivity testing in the next and final quarter of the current fiscal year.

\section{Reference}

I. N. R. Warpinski, L. W. Teufel, and D. C. Graf, Effect of Stress and Pressure on Gas Flow Through Natural Fractures, paper SPE 22666.

\section{RESEARCH ON IMPROVED AND ENHANCED OIL RECOVERY IN ILLINOIS THROUGH RESERVOIR CHARACTERIZATION}

Contract No. DE-FG22-89BC14250

\author{
IIIInois Department of Energy \\ and Natural Resources \\ Springfield, III.
}

Contract Date: June 28, 1989

Anticipated Completion: June 27, 1993

Funding for FY92: $\$ \mathbf{6 6 0 , 0 0 0}$

\section{Principal Investigator:}
D. F. Oltz

Project Manager:

R. Michael Ray

Bartlesville Project Office

Reporting Period: Apr. 1-June 30, 1992

\section{Objective}

This project will provide information that can be used to maximize hydrocarbon production, minimize formation damage, and stimulate new production in Illinois. Such information includes definition of hydrocarbon resources, characterization of hydrocarbon reservoirs, and the implementation of methods that will improve hydrocarbon extractive technology. The increased understanding of reservoir heterogeneities that affect oil recovery can aid in identifying producible resources. The transfer of technology to industry and the general public is a significant component of the program. The project is designed to examine selected subsurface oil reservoirs in Illinois. Scientists use advanced scientific techniques to gain a better understanding of reservoir components and behavior and to address ways of potentially increasing the amount of recoverable 
oil. Initial production rates for wells in the Illinois Basin commonly decline quite rapidly, and as much as $60 \%$ of the oil in place cannot be recovered with standard operating procedures. Heterogeneities (geological differences in reservoir makeup) affect the capability of a reservoir to release fluids. Bypassed mobile and immobile oil remains in the reservoir. To learn how to get more of the oil out of reservoirs, the Illinois State Geological Survey (ISGS) is studying the nature of reservoir rock heterogeneities and their control on the distribution and production of bypassed mobile oil.

\section{Summary of Technical Progress}

\section{Bartelso Field}

The Bartelso field study, "Reservoir Heterogeneity and Potential for Improved Oil Recovery Within the Cypress Formation at Bartelso Field, Clinton County, Illinois," is being printed.

\section{Boyd Field}

The repor for Boyd field was rewritten after peer review.

\section{Dale Consolidated Field}

Sandstone bars in the Aux Vases Formation at southwest Dale Consolidated field constitute structurally modified stratigraphic traps. Sandstone bars are "shingled" and separated by shale beds that are less than $3 \mathrm{ft}$ thick. Petrographic analyses reveal a distinct upper zone of higher permeability within the reservoir interval. An investigation of the nature of hydraulically induced fractures and their adverse effects on the oil production in the McCreery Waterflood Unit (McCreery/McCullum bar) is under way. The Osburn Waterflood Unit (currently inactive) in the Cantrell bar was also hydraulically fractured, and oil production may be adversely affected as well. Similarities between the two units are being investigated.

\section{Energy Field}

The Energy field manuscript has gone through peer review and is currently being revised before going to publication.

The simulation modeling of the Energy field is near completion. A two-dimensional model and a single-well radial model were used to study the effects of early water injection for pressure maintenance and wellbore formation damage on productivity of Energy field, respectively. The effectiveness of the historical water injection programs was also studied using a three-dimensional full-field reservoir model. Finally, an optimal incremental oil recovery strategy based on the simulated results is suggested.

\section{Xenia East Field}

Well logs were used to reevaluate oil reserves by reinterpreting Xenia East field pay zone thickness. A Monte Carlo method and planimeter measurement were used to calculate original oil in place (OOIP) by volumetric meth ods. Calculated results match the actual production data. Probability distribution graphs are complete.

\section{Lawrence Field}

Lawrence field is in the mapping and petrographic analysis phase. Engineering analysis and simulation were initiated.

\section{Mattoon Field}

Intraformational analysis (Fhase 2) of the Cypress Formation is in progress. Recent corrections to the regional well database required necessary changes to the Mattoon field base map, subsequent existing cross sections, interformational structure maps (Phase 1), and intra-Cypress structure and isopach and facies maps (Phase 2). The database was expanded from 440 to 663 well logs to map four complex intervals within the Cypress Formation. From lower to upper Cypres;, these intervals have been arbitrarily named the purple, $z$. brown, and yellow zones. Structure, 50 and $25 \%$ net isopach and lithofacies maps are either complete or nearly complete for each of the four Cypress intervals.

\section{Oakdale and Markham N. Fields}

Mapping is in progress.

\section{Richview Field}

Richview field is in the final stages, and volumetric calculations, final map interpretations, and initial manuscript preparations are in progress.

Richview field has produced over 3.2 million bbl of $\mathrm{Cy}$ press oil from 86 wells on 800 acres. Although some production is attributed to an upper stray sandstone that immediately underlies the Barlow limestone, a majority of the oil has been produced from the upper $20 \mathrm{ft}$ or less of a sandstone, the top of which is 10 to $30 \mathrm{ft}$ below the base of the stray sand horizon. This sandstone varies in thickness from 20 to $50 \mathrm{ft}$ and displays a very clean, blocky, spontaneous potential (SP) log character. Increases in thickness occur as incremental, blocky sands, 10 to $20 \mathrm{ft}$ thick, which indicates a stacking of genetic depositional units. Log indicaions show that thin, laterally traceable shales separate these sand units.

The northeast-southwest trending field appears to be largely stratigraphically controlled. The sandstones change facies to shale rapidly away from the field. Structurally the field lies in a saddle between Irvington field to the north and Ashley field to the south. Richview field lies immediately west of and on the uplifted limb of the Du Quoin monocline.

\section{Stewardson Field}

Reservoir characterization of the Mississippian Aux Vases Formation at Stewardson field in southeastern Shelby County, Illinois, is in press. 


\section{Storms Field}

Samples from the Cypress and Aux Vases were submitted for thin-section and clay analysis. Preliminary cross sections and structure and isopach maps were constructed.

\section{Tamaroa Field}

The Tamaroa field study is at the editing and drafting stage. Reservoir compartmentalization and pressure maintenance control cumulative production and ultimate recovery efficiency. Maximum production is obtained by draining and pressure maintaining separate, correlative sandstones from a vertically stacked, multilateral marine bar setting. Both marginal and very successful production programs are apparent within the multiple oil reservoirs of Tamaroa and Tamaroa South fields. Recovery of 40 to 60 thousand bbl of oil per well from 10-acre spacing and less than $10 \mathrm{ft}$ of reservoir thickness is typical where pressure is maintained within distinct, correlative sandstone bodies. Recovery efficiency for the more effectively managed reservoirs is $43 \%$.

\section{Zeigler Field}

An integrated geological modeling and reservoir engineering simulation study on Zeigler field, Franklin County, is near completion. A reservoir model capable of simulating the oil, water production, and pressure history of the 30 productive wells over a $30-y r$ production period was constructed.

This model estimates the OOIP of the Plumfield lease to be 4.5 MMSTB and the overall after waterflood recovery to be $43 \%$. Simulation results showed that oil recovery of the eastern portion of Plumfield could have been better if pressure maintenance had been started earlier. Unrecovered mobile oil distributions were identified for possible future implementation of improved oil recovery technology.

The first draft of the field study is in review.

\section{Outcrop Studies}

The regional Cypress outcrop work was completed in April and a manuscript is in preparation. Nearly 50 different outcrops were visited and described in detail.

The data collection for the Interstate 57 project, which entailed a total of 60 measured sections, was also completed in Apr l. Two core samples were taken at each section, and each section was logged with a hand-held gammaray spectrometer along with field minipermeameter readings every 6 in. vertically. Photomosaics were taken of each of the four road cuts, and depositional facies were drawn on a Mylar overlay. Paleocurrent measurements were also taken at selected sites on each of the four road cuts, and rose diagrams were constructed. These diagrams were also placed on the overlay. The main goal of this project is to develop outcrop analogs for reservoir facies, and this work continues.

\section{Oil and Gas Development Maps}

Development of a computer-generated series of maps to replace the older ISGS series of hand-drawn oil and gas development maps continues.

\begin{tabular}{ll}
\hline \multicolumn{2}{c}{ Maps completed to date } \\
Alto Pass & McLeansboro \\
Benton & Mt. Vernon \\
Carbondale & Murphysboro \\
Carlyle & Nashville \\
Cave-In-Rock & New Burnside \\
Centralia & Noble \\
Clay City & Pinckneyville \\
Du Quoin & Roaches \\
Effingham & Rosiclare \\
Fairfield & Shelbyville \\
Goreville & Thompsonville \\
Mattoon & Xenia \\
\multicolumn{1}{c}{ Maps in progress } \\
Carmi & \\
Kinmundy & \\
Louisville & \\
Patoka & \\
\hline
\end{tabular}

\section{Engineering Work}

A report on experimental investigations of formation damage in the Aux Vases Formation is near completion and will show experimental results obtained when Aux Vases Formation rock samples are flooded with mud clean-out acid $(15 \% \mathrm{HCl}$ with additives) and injection water of various salinities. Data presented in this work include thin sections, scanning electron microscope (SEM), energy dispersive X-ray (EDX), and X-ray diffraction (XRD) analyses of Aux Vases sandstones from various oil fields. Permeability changes resulting from the injection of fluids are explained with regard to rock mineralogical changes and can be used to establish the least damaging fluids for reservoir treatment in the Aux Vases Formation.

\section{Scanning Electron Microscopy and Energy Dispersive X-Ray Spectroscopy}

Data have been cataloged and readied for entry into the project database. Samples from mud clean-out acid static and dynamic experiments were analyzed to determine the reaction of minerals, in particular, diagenetic clay minerals, to commonly used well treatment fluids. Emphasis was placed on analysis of minerals most commonly found in pore systems of Aux Vases sandstone reservoirs.

\section{Petrographic Synthesis}

Synthesis of petrographic data generated during the project is ongoing. XRD data have been combined with 
porosity and permeability data (where available) to facilitate graphing, comparisons, correlations, and statistical analyses of data. A draft paper entitled "The Role of Diagenesis on Reservoir-Fluid Interactions in the Aux Vases and Cypress Sandstones" was prepared for peer review.

\section{Seismic Study, King Field, Jefferson County, Illinois}

Ten and one-half miles of very high-resolution, highfold, conventional reflection seismic data were acquired from King Field in Jefferson County, Illinois. These data were obtained to demonstrate a seismic technique that would detect subtle reservoir heterogeneity. Because of the lack of empirical data, an interactive approach was taken throughout the entire operation. Field tests, data acquisition, and data processing were all regulated by staff members to fit with existing geological data. Preliminary interpretation of the records was integrated with well logs and vertical seismic profile (VSP) data.

\section{Regional Mapping}

Three work cross sections through Jefferson County are being completed.

\section{Clay Minerals}

The program for analysis of clay and other minerals was refined to allow calculation of the total mineral content of a sample at accuracies and precisions that are adequate for a large number of applications. The analyses include a characterization of the clay minerals, which are often important to geological framework studies and to completion and production problems. The basic costs of the analyses are quite low, although more costly methods were developed that determine the location of the clay minerals with respect to open pores, within carbonate framework grains and cement, and beneath quartz overgrowths. Figure 1 illustrates the precision with which mineral content can be determined.

\section{Geochemistry of Formation Fluids for Reservoir Characterization and Enhanced Oil Recovery}

The Morgari Coal No. 3 well in Energy field was treated with mud-cleaning acid (MCA) containing about $15 \% \mathrm{HCl}$. Production declined significantly after the treatment. The treatment of other wells with $\mathrm{MCA}$ containing $7.5 \% \mathrm{HCl}$ helped production. Reactions between the acid and the minerals and the water of the formation were modeled to predict likely cause(s) of the formation damage.
In response to treatment with $15 \% \mathrm{HCl}-\mathrm{MCA}$, the geochemical model predicted a drastic increase in pore volume in the zone immediately adjacent to wellbore. A little farther away from the wellbore, a slight decrease in porosity was predicted. On the other hand, the model predicted a relatively less, but consistent, increase in porosity in response to treatment with $7.5 \% \mathrm{HCl}-\mathrm{MCA}$ for all the zones modeled. Excess acidity and dissolved iron species were generated in the model when the well was treated with $15 \%$ $\mathrm{HCl}-\mathrm{MCA}$ and increased the chance of asphaltene precipitation which would reduce the permeability. The amount of acidity and dissolved iron species generated in response to treatment with $7.5 \% \mathrm{HCl}-\mathrm{MCA}$ was predicted to be relatively small. Thus the treatment of the well with $7.5 \% \mathrm{HCl}-$ MCA appears to be preferable to that with $15 \% \mathrm{HCl}-\mathrm{MCA}$. This modeling is based on a number of assumptions that have not yet been verified. Furthermore, the model evaluates only chemical reactions. Physical changes, such as clay swelling, fines migration, and fracturing, can also affect the porosity and permeability.

\section{Technology Transfer}

Two team members presented a talk on "Optimizing Reservoir Management" to the local Society of Petroleum Engineers chapter on Feb. 20, 1992.

An application of 3-D modeling of the sandstone reservoir at King Field, Jefferson County, Illinois, was presented at the 2nd Annual Reservoir Characterization Symposium on May 10-13, 1992, in Houston, Tex.

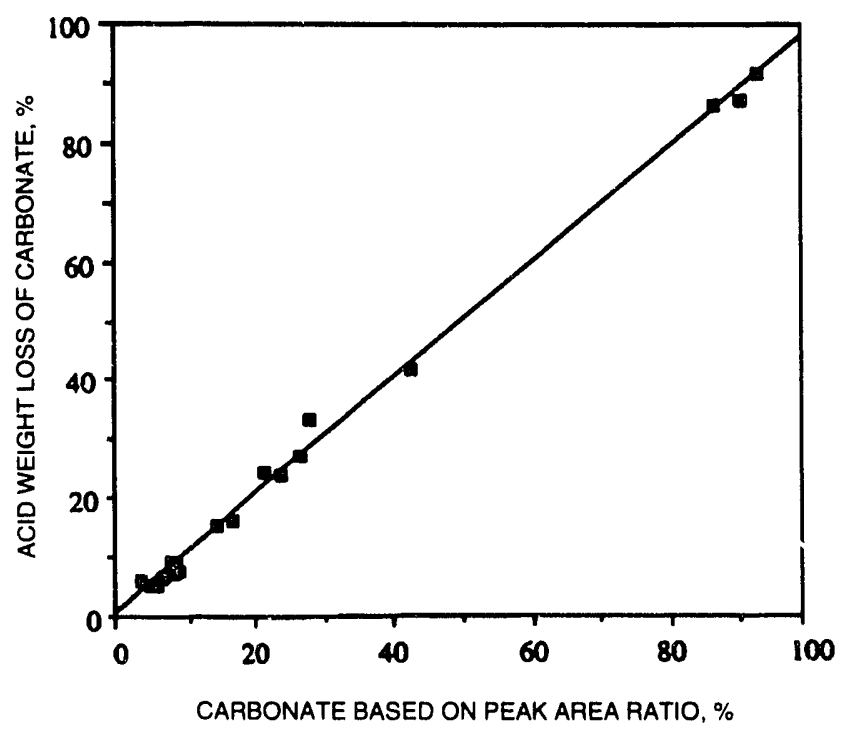

Fig. 1 Analysis of the carbonate in two Aux Vases fields. $y=1.0080+0.95776 x ; R^{\wedge} 2=0.997$. 


\section{MEASURING AND PREDICTING RESERVOIR HETEROGENEITY IN COMPLEX DEPOSYSTEMS}

\section{Contract No. DE-AC22-90BC14657}

\author{
West Virginia University \\ Appalachian Oil and Natural Gas \\ Research Consortium \\ Morgantown, W. Va.
}

Contract Date: Sept. 20, 1990

Anticipated Completion: Sept. 20, 1993

Government Award: $\$ 1,915,000$

\author{
Principal Investigators: \\ Alan C. Donaldson \\ Robert Shumaker \\ Christopher Laughrey \\ Kashy Aminian \\ Michael Ed. Hohn

\section{Project Manager: \\ Edith Allison} \\ Bartlesville Project Office
}

Reporting Period: Apr. 1-June 30, 1992

\section{Objectives}

The recovery of additional oil from existing fields in the Appalachian basin is hampered by poorly known permeability barriers within the reservoirs. Vertical barriers, caused by stacking of sandstones separated by shale breaks, are relatively easy to recognize in a given well but difficult to project laterally. Lateral barriers caused by facies changes are more difficult to predict, and subtle changes within the reservoir caused by diagenetic changes are the most difficult of all. Thus several scales of heterogeneity exist, from those imposed by shifts in depositional environments down to the pore throat barriers developed during diagenesis. The result is that the oil reservoirs consist of a complex series of flow systems dependent on lithology, sandstone genesis, and structural and thermal history.

The proposed research is designed to use a multidisciplinary approach to measure and map heterogeneity at various scales and ultimately to develop tools and techniques to predict heterogeneity both in existing fields and in undrilled areas. Two stratigraphic units were chosen for this research: the Big Injun sandstone (Mississippian) in West Virginia and the Rose Run sandstone (Ordovician) in Ohio and Pennsylvania. The main objectives of this research are to

1. Map the geometry of sandstone bodies within a regional depositional system and classify these bodies in a scheme of relative heterogeneity; this will determine the heterogeneity across the depositional systems.
2. Map facies changes within the given reservoirs, interpret environments responsible for each facies, predict the inherent relative heterogeneity of each facies, and share these results with petrologists and petroleum engineers.

3. Correlate structural variations with hydrocarbon production and variations in geologic and engineering parameters that affect production in the Big Injun reservoirs in West Virginia.

4. Develop a reliable seismic model of the reservoir expressed in terms of impedance variation such that physical heterogeneity within the reservoir can be interpreted.

5. Describe the pore types and relate them to permeability, fluid flow, and diagenesis and, by integrating petrographic studies with facies and depositional environments derived from stratigraphic work, develop a technique to use diagenesis as a predictive tool in future reservoir development.

6. Study effects of heterogeneities on fluid flow and efficient hydrocarbon recovery to improve reservoir management and future development.

7. Apply graphical methods to production data and develop new geostatistical methods to detect regional trends in heterogeneity.

8. Use the geologic and engineering data on the Big Injun reservoirs in West Virginia to construct facies maps and compute the local probability that new, in-fill wells will intersect rock with favorable reservoir characteristics.

The main goal of this research project is to understand reservoir heterogeneity sufficiently to predict optimum drilling locations vs. high-risk locations in a given field so that the most cost-effective infill-drilling programs can be recommended.

\section{Summary of Technical Progress}

\section{Stratigraphy}

Regional stratigraphic relationships for the Big Injun reservoir sandstones were completed and reported in the previous quarterly report. During the past three months, attention shifted to analyzing stratigraphy at the field scale (Granny Creek and Rock Creek fields), but investigators also scrutinized the four-county subregional area where Granny Creek, Rock Creek, Tariff, and Blue Creek fields are located. The results of the stratigraphic analyses were presented to representatives from industry and government at two different meetings in June. The stratigraphic computer data file for Granny Creek field is complete.

A revised initial oil production map (Fig. 1) shows a northwest trend of high initial potential that also parallels the "pinch out" of the coarse-grained Big Injun (members $A$ and $B$ ) in the Pennzoil part of the field (northern part). This relationship indicates the influence of the preGreenbrier unconformity on the accumulation of oil in Granny Creek field. 


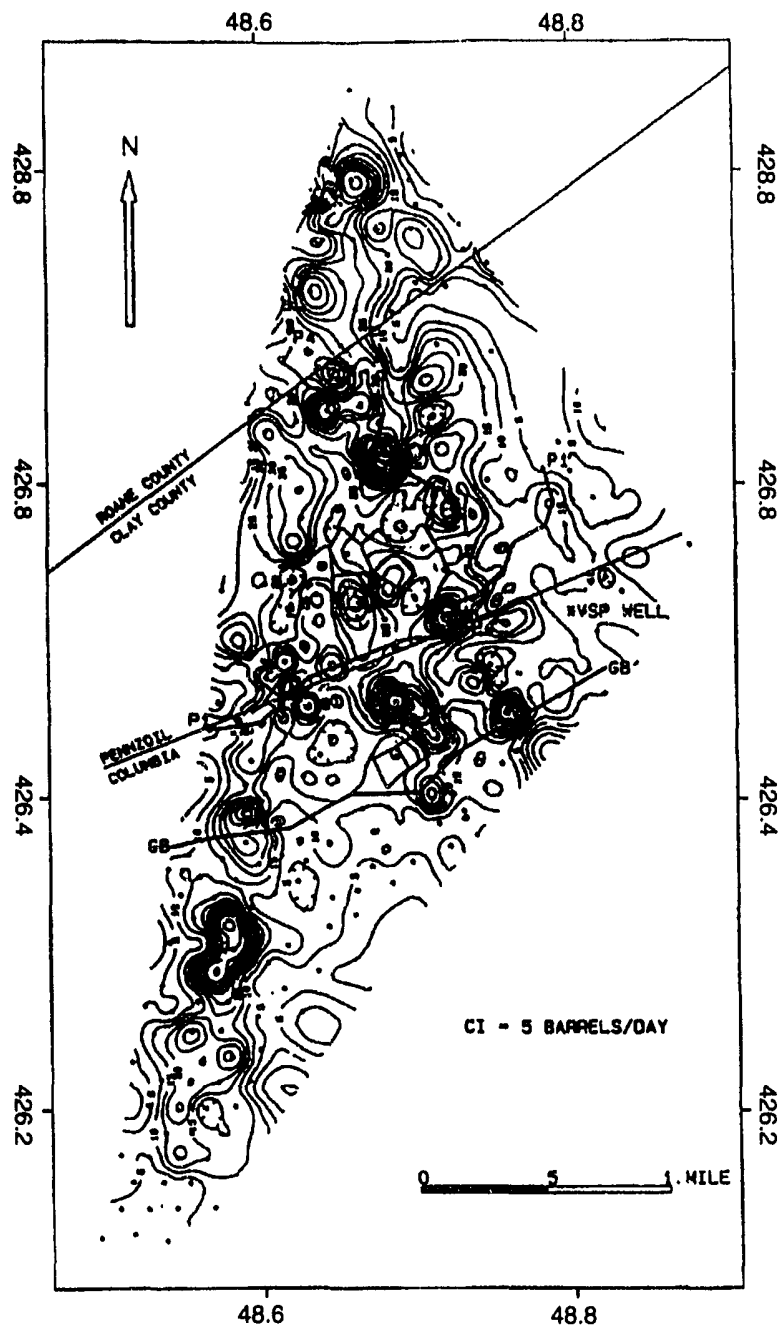

Fig. 1 Initial oil production map (bbl/d) for Granny Creek field. The locations of two waterflood projects also are shown by the five-spot pattern.

A stratigraphic cross section showing porosity information superposed on lithofacies interpreted from core and log analyses along section GB-GB' was constructed (Fig. 2). The marine-dominated proximal mouth-bar and upper distal mouth-bar subfacies generally exhibit the best laterally persistent permeability, sandwiched between the relatively impermeable lower distal mouth-bar and overlying coarsegrained fluvial channel facies. A petrographic study of these facies using thin sections indicates a dependency between the diagenetic and depositional facies.

The stratigraphic study of Rock Creek field was initiated with the digitizing of 297 well logs representing about 150 wells. Four stratigraphic cross sections were constructed on the basis of logs from 50 wells. Preliminary interpretations indicate a belt of thicker Big Injun sandstone within the field and progradation eastward (the mirror image of Granny Creek field) of the fine-grained sandstone facies (ancient river-mouth bar depositional environment). A core from Rock Creek field also was described.
Reservoir heterogeneity of the Rose Run and Beekmantown was examined at three levels: megascopic, mesoscopic, and microscopic. Megascopic heterogeneity is the result of stratigraphic changes taking place within the Knox dolomite on a regional scale controlled in part by paleogeography and tectonic history. Mesoscopic heterogeneity is apparent in field-scale studies and further at an individual well level. Finally, interwell reservoir heterogeneity is present at a microscopic level as a result of local diagenetic changes.

Cuttings from wells in south-central Ohio were examined to better delineate the western limit of the Rose Run An updated Rose Run subcrop map based on wireline logs and well cuttings is being constructed. This map illustrates regional-scale heterogeneity of the Rose Run and shows areas in southern Ohio where the Rose Run section is dominated by a less-porous carbonate lithology.

Megascopic descriptions were completed for all Rose Run sandstone and Beekmantown dolomite cores within the project area (Fig. 3). A tidal flat environment was interpreted for the Rose Run in Ohio with five predominant facies recognized in cores: cross-bedded sandstone, bioturbated dolomite, algal laminated stromatolitic dolomite, oolitic chert intraclasts, and oncolitic dolomite. Gammaray and density curves were digitized for five of these cores, and core descriptions were related to wireline logs.

\section{Structural Geology}

Work continued to refine and integrate regional and local structural data for the Big Injun study. Field work and subsurface studies suggest greater importance of detached deformation in the region of Granny Creek field than was indicated by previous geologic studies. Attempts are being made to define trends and the influence of detached and basement deformation in and around Granny Creek field.

Isopach and structure contour maps were compiled for the Squaw, Big Injun, Little Lime, Big Lime, and the Little Lime to Big Lime intervals.

Although productive zones may be slightly compartmentalized by local and lateral changes in porosity, the primary control of reservoir heterogeneity is thought to be fractures and small offset faults resulting from recurrent movement along basement faults.

Detailed geologic and seismic mapping indicate a major basement fault trending west-northwest beneath the producing area (Fig. 4). The fault appears to correlate to the Akron-Suffield fault ${ }^{1}$ and will be called the Suffield fault system for this discussion. Figure 4 is a structure map on the top of the Knox unconformity based on 73 wells penetrating the Knox. The position of faulting was interpreted by the offsets in the Precambrian basement reflectors observed on seismic data and along the inflection points of the monoclinal flexure on the Mississippian Berea structure map. 


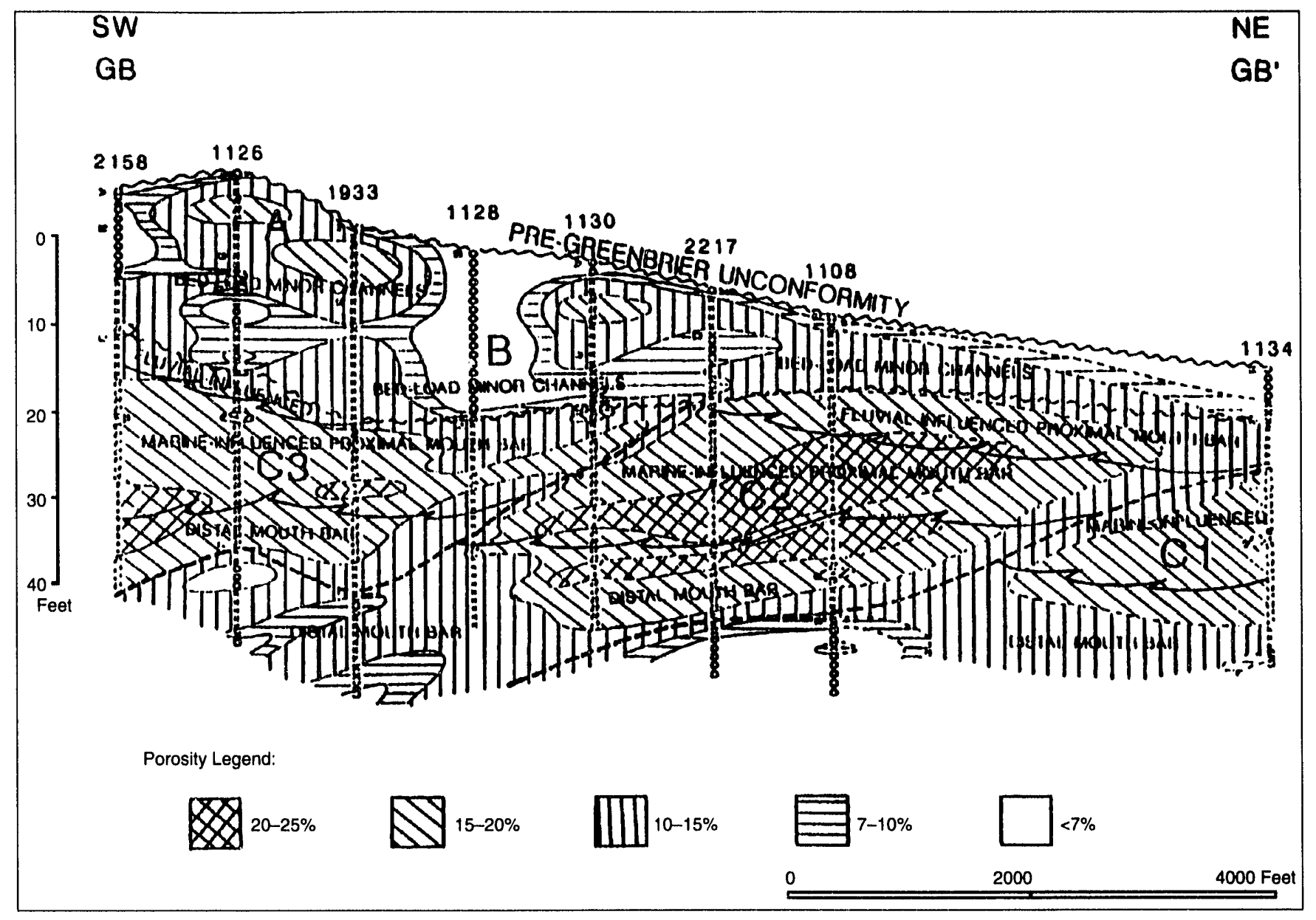

Fig. 2 Overlay of porosity facies on stratigraphic cross section GB-GB' showing the preference of high porosity for the marine-influenced proximal bar and the upper part of the distal river-mouth bar. Lower porosity commonly occurs at boundaries between prograding tongues of the $\mathrm{C}$ member of the Big Injun sandstone.

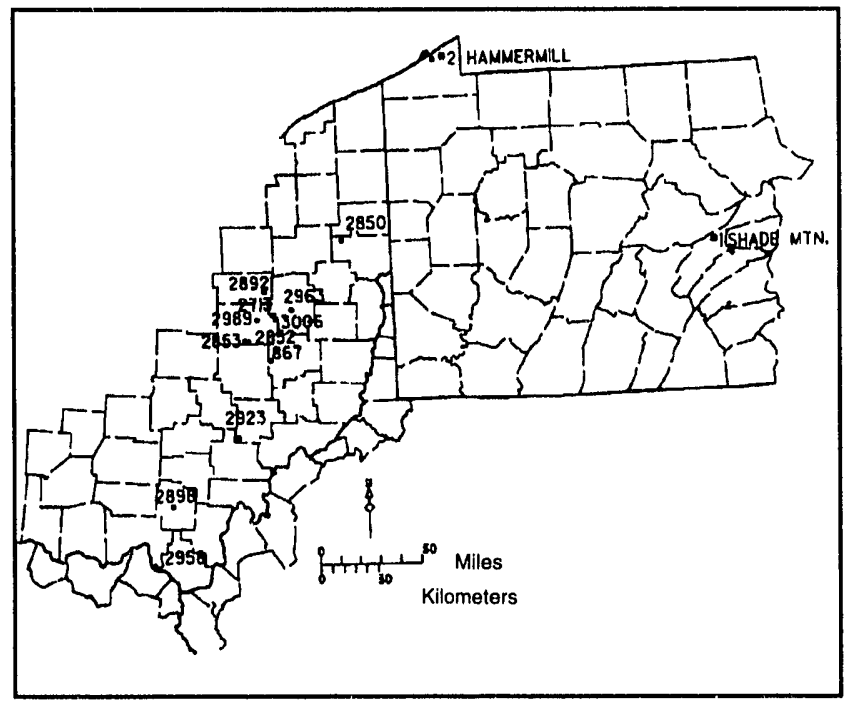

Fig. 3 Core location map of Upper Cambrian and Lower Ordovician cores examined in this project.

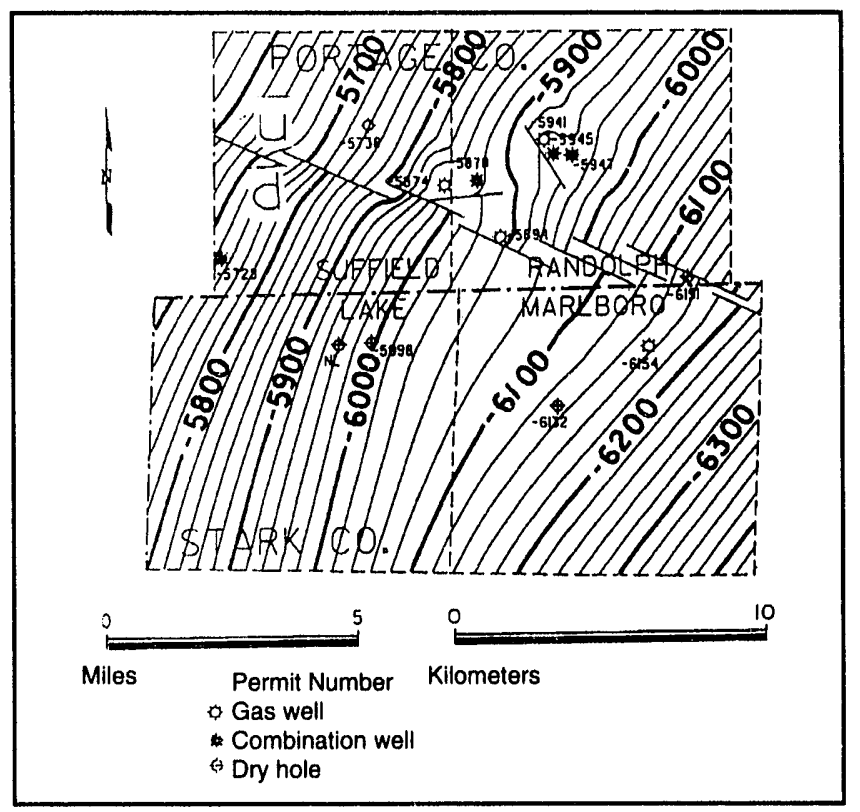

Fig. 4 Structure map in portions of Portage and Stark counties, Ohio, on the top of the Knox unconformity showing interpreted Suffield Fault System and deep well control; contour interval equals $20 \mathrm{ft}$. 


\section{Petrology}

Detailed point counting of Big Injun thin sections continued in West Virginia. Analytical efforts before this quarter had focused on sandstone composition, but attention turned to textural aspects in April. Work to date demonstrates a relationship between the original sedimentary process acting in the depositional environment, as expressed by lithofacies, and the path of subsequent diagenetic modifications to the original porosity and permeability.

Clay minerals in the Rose Run sandstones of Ohio, determined by X-ray analyses of the less than 2- or $1-\mu \mathrm{m}$ clays collected from the rocks, include illite, chlorite, and randomly interstratified smectite-illite. Glauconite occurs in the sandy dolomites.

In Pennsylvania, point counts of all Rose Run sandstone thin sections were completed. Table 1 contains selected re- sults of thin-section analyses as well as a comparison of these with the results of analyses in Ohio. Pore textures are currently being related to geophysical log characteristics.

\section{Reservoir Engineering}

\section{Oil Recovery and Reservoir Management}

During the last quarter efforts were focused on two main aspects of the production profile of the first five-spot pattern in Columbia's lease (southern portion of Granny Creek).

As shown in Fig. 5, daily oil production in this waterflood pattern experienced a short decreasing period followed by a longer increasing period before starting to stabilize. Numerical studies show that such behavior in a production well can be simulated by using constant water injection rate specifications at four injection wells and constant pressure specifications at the production well.

TABLE 1

Petrographic Analysis of the Rose Run Sandstone, Beekmantown Dolomite, and Wells Creek Formation from Three Cores in Coshocton County, Ohio

\begin{tabular}{|c|c|c|c|c|c|c|c|c|c|c|c|c|c|c|}
\hline \multirow[b]{2}{*}{ Formation } & \multirow[b]{2}{*}{$\begin{array}{c}\text { Core } \\
\text { No. }\end{array}$} & \multirow[b]{2}{*}{$\begin{array}{c}\text { Depth, } \\
\text { ft }\end{array}$} & \multirow{2}{*}{$\begin{array}{c}\text { Total } \\
\text { framework, } \\
\%\end{array}$} & \multirow{2}{*}{$\begin{array}{c}\text { Total } \\
\text { matrix, } \\
\%\end{array}$} & \multirow{2}{*}{$\begin{array}{c}\text { Total } \\
\text { cement, } \\
\%\end{array}$} & \multicolumn{3}{|c|}{ Framework grains, \% } & \multicolumn{5}{|c|}{ Cement diagenetic minerals,\% } & \multirow{2}{*}{$\begin{array}{c}\text { Total } \\
\text { porosity, } \\
\%\end{array}$} \\
\hline & & & & & & Quartz & Feldspar & Other & Dolomite & Clay & $\begin{array}{c}\text { Quartz } \\
\text { overgrowths }\end{array}$ & $\begin{array}{c}\text { Feldspar } \\
\text { overgrowths }\end{array}$ & Other & \\
\hline Beekmantown & 2608 & 6715.0 & 0.0 & 0.0 & 100.0 & 0.0 & 0.0 & 0.0 & 100.0 & TR* & 0.0 & 0.0 & 0.0 & 2.0 \\
\hline Beekmantown & 2608 & 6722.0 & 0.0 & 0.0 & 100.0 & 0.0 & 0.0 & 0.0 & 97.9 & 2.1 & 0.0 & 0.0 & 0.0 & 4.0 \\
\hline Rose Run & 2608 & 6811.5 & 90.0 & 0.0 & 10.0 & 89.0 & 1.0 & 0.0 & 0.0 & 3.0 & 7.0 & 0.0 & 0.0 & 10.0 \\
\hline Rose Run & 2608 & 6819.5 & 92.0 & 0.0 & 7.0 & 90.0 & 2.0 & 0.0 & 0.0 & 6.0 & 1.0 & 0.0 & 0.0 & 19.0 \\
\hline Rose Run & 2608 & 6828.0 & 87.0 & 0.0 & 14.0 & 77.0 & 10.0 & 0.0 & 0.0 & 1.0 & 13.0 & 0.0 & 0.0 & 6.0 \\
\hline Rose Run & 2608 & 6865.0 & 92.0 & 0.0 & 7.0 & 80.0 & 12.0 & 0.0 & 0.0 & 0.0 & 7.0 & 0.0 & 0.0 & 13.0 \\
\hline Rose Run & 2608 & 6905.0 & 64.0 & 0.0 & 36.0 & 55.0 & 9.0 & 0.0 & 32.0 & 0.0 & 4.0 & 0.0 & 0.0 & 6.0 \\
\hline Copper Ridge & 2608 & 7000.0 & 89.0 & 0.0 & 11.0 & 71.0 & 18.0 & 0.0 & 8.0 & 1.0 & 2.0 & 0.0 & 0.0 & 10.0 \\
\hline Rose Run & 2852 & 5986.0 & 51.7 & 0.0 & 48.4 & 49.3 & 2.4 & 0.0 & 40.9 & 0.0 & 6.8 & 0.0 & 0.7 & 3.3 \\
\hline Rose Run & 2852 & 5988.0 & 65.8 & 0.0 & 34.2 & 60.6 & 4.9 & 0.3 & 26.4 & 0.0 & 7.5 & 0.0 & 0.3 & 7.3 \\
\hline Rose Run & 2852 & 5989.5 & 59.4 & 0.0 & 40.5 & 55.6 & 3.5 & 0.3 & 28.0 & 0.0 & 12.2 & 0.3 & 0.0 & 1.0 \\
\hline Rose Run & 2852 & 5991.0 & 67.4 & 0.0 & 32.5 & 54.1 & 0.6 & 12.7 & 27.4 & 0.3 & 4.5 & 0.0 & 0.3 & 3.1 \\
\hline Rose Run & 2852 & 5991.5 & 0.0 & 0.0 & 100.0 & 0.0 & 0.0 & 0.0 & 100.0 & 0.0 & 0.0 & 0.0 & 0.0 & 0.0 \\
\hline Rose Run & 2852 & 5992.0 & 0.0 & 0.0 & 100.0 & 0.0 & 0.0 & 0.0 & 100.0 & 0.0 & 0.0 & 0.0 & 0.0 & 1.0 \\
\hline Rose Run & 2852 & 5992.5 & 74.8 & 0.0 & 25.1 & 70.1 & 4.4 & 0.3 & 15.1 & 4.0 & 5.7 & 0.0 & 0.3 & 2.3 \\
\hline Rose Run & 2852 & 5994.0 & 87.1 & 0.0 & 13.0 & 69.3 & 16.7 & 1.1 & 0.0 & 11.1 & 1.5 & 0.4 & 0.0 & 12.6 \\
\hline Rose Run & 2852 & 5997.0 & $\dagger$ & $\dagger$ & $t$ & + & + & $t$ & $t$ & + & + & + & $t$ & 0.4 \\
\hline Rose Run & 2852 & 5998.0 & $\dagger$ & $\dagger$ & $\dagger$ & $t$ & + & + & $t$ & + & $t$ & + & + & 1.0 \\
\hline Wells Creek & 2853 & 5967.0 & 24.3 & 0.0 & 75.7 & 20.3 & 4.0 & 0.0 & 75.7 & 0.0 & 0.0 & 0.0 & 0.0 & 0.0 \\
\hline Wells Creek & 2853 & 5968.0 & 24.3 & 0.0 & 75.8 & 20.1 & 3.2 & 1.0 & 72.9 & 0.0 & 0.0 & 0.0 & 2.9 & 0.3 \\
\hline Wells Creek & 2853 & 5969.0 & 99.9 & 0.0 & 0.0 & 80.1 & 5.1 & 14.7 & 0.0 & 0.0 & 0.0 & 0.0 & 0.0 & 2.5 \\
\hline Wells Creek & 2853 & 5970.0 & 30.5 & 0.0 & 69.6 & 25.6 & 4.9 & 0.0 & 69.3 & 0.0 & 0.0 & 0.0 & 0.3 & 1.0 \\
\hline Wells Creek & 2853 & 5971.0 & 43.9 & 0.0 & 56.1 & $t$ & $t$ & + & + & + & + & $t$ & $t$ & 1.3 \\
\hline Wells Creek & 2853 & 5972.0 & 74.4 & 0.0 & 25.5 & 69.9 & 4.2 & 0.3 & 20.3 & 0.0 & 4.9 & 0.3 & 0.0 & 9.5 \\
\hline Rose Run & 2853 & 5973.0 & $\dagger$ & $\dagger$ & $\dagger$ & $t$ & + & $t$ & + & + & + & + & + & 10.0 \\
\hline Rose Run & 2853 & 5974.0 & 83.1 & 0.0 & 16.9 & $\dagger$ & $t$ & + & 8.2 & 0.0 & 7.5 & 0.7 & 0.4 & 11.0 \\
\hline Rose Run & 2853 & 5975.0 & 73.4 & 0.0 & 26.7 & 59.3 & 14.1 & 0.0 & 24.1 & 0.0 & 2.2 & 0.4 & 0.0 & 15.4 \\
\hline Rose Run & 2853 & 5976.0 & 61.8 & 0.0 & 38.1 & 44.3 & 17.5 & 0.0 & 36.8 & 0.3 & 0.0 & 0.7 & 0.3 & 4.6 \\
\hline Rose Run & 2853 & 5977.0 & 96.9 & 0.0 & 3.0 & + & $t$ & $t$ & 0.4 & 0.0 & 1.3 & 1.3 & 0.0 & 25.4 \\
\hline Rose Run & 2853 & 5979.0 & 74.2 & 0.0 & 25.8 & + & $t$ & $t$ & 19.0 & 0.8 & 4.8 & 0.8 & 0.4 & 16.0 \\
\hline Rose Run & 2853 & 5981.5 & 69.4 & 0.0 & 30.6 & 41.8 & 19.2 & 8.4 & 30.0 & 0.0 & 0.3 & 0.3 & 0.0 & 3.3 \\
\hline Rose Run & 2853 & 5982.5 & $\dagger$ & $\dagger$ & $\dagger$ & + & + & + & + & + & + & + & + & + \\
\hline Rose Run & 2853 & 5983.0 & 39.9 & 0.0 & 60.0 & 33.1 & 6.8 & 0.0 & 56.5 & 2.3 & 0.6 & 0.0 & 0.6 & 1.3 \\
\hline Rose Run & 2853 & 5983.5 & 28.1 & 0.0 & 71.8 & 19.9 & 1.6 & 6.6 & 70.9 & 0.0 & 0.0 & 0.0 & 0.9 & 0.3 \\
\hline Rose Run & 2853 & 5984.0 & $t$ & + & + & $t$ & + & + & $\dagger$ & + & $t$ & + & + & + \\
\hline Rose Run & 2853 & 5985.0 & 89.8 & 0.0 & 10.2 & 74.0 & 15.9 & 0.0 & 4.1 & 0.3 & 4.1 & 1.3 & 0.3 & 8.7 \\
\hline Rose Run & 2853 & 5986.0 & 39.9 & 0.0 & 60.0 & 33.1 & 6.8 & 0.0 & 56.5 & 2.3 & 0.6 & 0.0 & 0.6 & 1.3 \\
\hline
\end{tabular}

*TR, trace.

†Not determined 
Figure 5 exhibits some irregularities, mainly after $1000 \mathrm{~d}$, when a sharp increase takes place, and at $1600 \mathrm{~d}$, when a sharp decrease appears. These irregularities are not characteristic of waterflood projects. A series of numerical tests was designed and implemented to ensure that changes in rock and fluid properties are not responsible for this behavior. The results showed that changes in rock and fluid properties, such as porosity, absolute permeability, directional permeability, layer thickness, initial oil and water saturations, initial formation pressure, and relative permeability as well as pressure-volume-temperature characteristics of the reservoir fluids do not alter the production profile qualitatively.

There are two possible explanations for these irregularities. First is the presence of "unconventional heterogeneity," such as open fractures or small faults (channels) or well-cemented fractures (obstacles). The second explanation is based on man-made influences, such as workovers or stimulations, that cannot be confirmed by any recorded data.

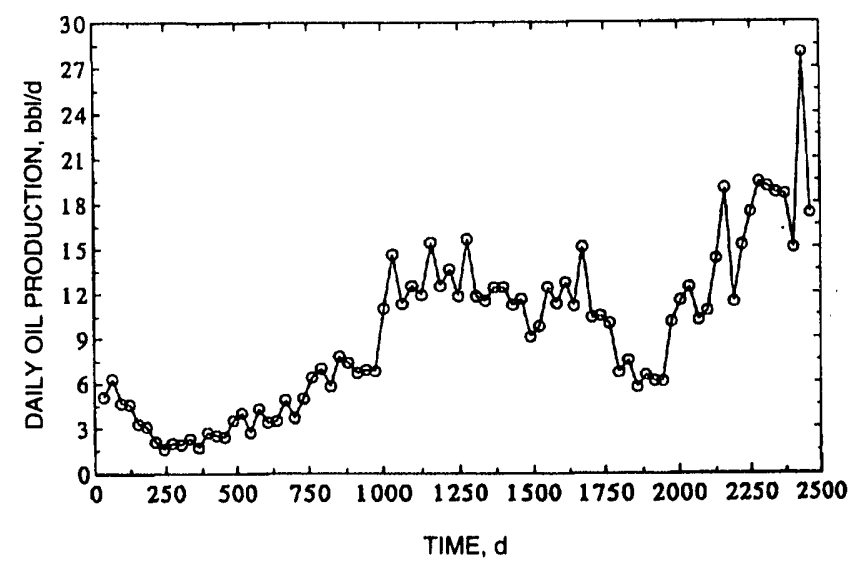

Fig. 5 Field data (P-1) of five-spot waterflood for Columbia lease, Granny Creek, West Virginia.

\section{Geostatistics and Modeling}

Analysis of the producing intervals for Big Injun wells in Granny Creek and comparison to stratigraphic intervals determined from geophysical logs indicate that approximately $90 \%$ of the Big Injun oil production for Granny Creek comes from the fine-grained ("C") interval and approximately $2 \%$ from the coarse-grained (" $A$ " and " $\mathrm{B}$ ") interval. The remainder of the wells produce from both the coarse- and fine-grained intervals.

Examination of cumulative production, initial production probability, structure, and lithologic maps for Granny Creek field shows a well-developed, north-south trend in high cumulative production paralleling structural contours in the northern half of the field. This high appears to be situated on the western flank of the syncline containing Granny Creek. Production is observed to decrease downdip with progressive thinning of the Big Injun and an associated decrease in porosity and permeability. Within this northsouth trending, high-production region, a series of small, localized, production highs and lows are arranged obliquely to the major, north-south trend and may correspond to smallscale structural features postulated by structural geology researchers.

\section{Reference}

1. J. D. Gray et al., An Integrated Study of the Devonian-Age Black Shales in Eastern Ohio, Ohio Division of Geological Survey, Final Report for U.S. Department of Energy Eastern Gas Shales Project, DOE Report DOE/ET/12131-1399, 1982.

\section{IMAGING TECHNIQUES APPLIED TO THE STUDY OF FLUIDS IN POROUS MEDIA} Cooperative Agreement DE-FC22-83FE60149,
Project BE12

\author{
National Institute for Petroleum \\ and Energy Research \\ Bartlesville, Okla.
}

Contract Date: Oct. 1, 1987

Anticipated Completion: Sept. 30, 1992

Principal Investigator:

Liviu Tomutsa

Project Manager:
Robert Lemmon
Bartlesville Project Orfice

Reporting Period: Apr. 1-June 30, 1992

\section{Objectives}

The objectives of this project are to (1) develop and correlate reservoir engineering parameters from petrographic image analysis, computerized tomography (CT) scanning, and nuclear magnetic resonance imaging (NMRI); (2) characterize the recovery efficiency and measure the saturation distributions in cores for enhanced oil recovery (EOR) processes applicable to specific reservoirs, including Class I, using stateof-the-art imaging technology; (3) investigate the applicability of imaging technologies for the development of scale-up procedures from core plug to whole core to interwell scale; (4) develop an industry consortium or industrial advisory panel organized to help plan, review, and participate in the research 
through the work-for-others program and provide for effective technology transfer; and (5) strongly encourage collaborative research by industrial participants.

\section{Summary of Technical Progress}

Tracer tests were performed before and after polymer injection in a rectangular Berea core with laminations parallel to the fluid-flow direction. Several preliminary tracer tests were performed on the parallel Berea to optimize the CT scanning parameters: tracer injection rate, tracer slug size, and tag concentration. The tests were performed by injecting a brine slug tagged with $10 \%$ sodium iodide $(\mathrm{NaI})$ into the rock sample saturated with untagged brine. The shape of the brine slug, monitored throughout its advance through the rock sample by both conventional CT and topogram scanning, showed that the permiability contrast between the sample layers had a strong effect on the fluid advancement. The comparison between the change in the slug shape during the tracer tests before and after polymer injection showed that the polymer treatment caused an increased contrast between the permeability of the various rock layers. Subsequent tracer tests were performed by injecting a $20-\mathrm{cm}^{3}$ slug of a $10 \% \mathrm{Nal}$ brine through the sample saturated with untagged brine to study the effect of tracer injection rate on fluid advancement through the various permeability layers before and after polymer injection. Threedimensional (3-D) porosity and permeability distributions were generated with $\mathrm{CT}$ and computer-aided petrographic image analysis of the parallel laminated Berea sample. These data were used as input in two-dimensional (tracer) test simulations with the BEST-VHS simulator available at the National Institute for Petroleum and Energy Research (NIPER) and modified for tracer test core simulations. Further work needs to be done to correct problems related to excessive gas production at the low pressures used in the tracer test simulations. Simulations using $27 \times 114$ grid blocks were performed for the parallel laminated Berea core for the porosity-permeability case previous to polymer injection. Front advancement profiles generated by the simulations and those observed by X-ray CT scanning showed good agreement. Similar tracer experiments are currently under way on a rectangular Berea core sample with laminations at $30^{\circ}$ and $90^{\circ}$ to the direction of fluid flow.

Preparation of a $7.8 \times 5.2 \times 2.1 \mathrm{~cm}$ sandstone core was completed. The core will be used to study the effect of saturation distribution during two-phase oil-brine unsteadystate relative permeability experiments. Resistivity electrodes were placed at each end of the sample, and a third electrode was placed midway between the ends. The sample was encased in a polyester resin for fluid-flow confinement. Pressure taps were built into the flow distribution end pieces for monitoring pressure differentials during the flow tests. The volumetric porosity was $17.96 \%$. The CT porosity was $17.66 \%$. The absolute brine permeability of the sample was $5.3 \mathrm{mD}$. Calibrations for determining in situ brine satura- tion using the linear X-ray, CT X-ray, and resistivity are currently under way.

Because of the significant experimental difficulties related to CT imaging of steamfloods by using the 4 -ft titanium coreholder, the use of 2-D X-ray radiography equipment has been considered. Preliminary evaluations indicate that $\mathrm{X}$-ray radiography could have significant advantages over the CT both because of significantly lower cost and higher flexibility in experimental design. Further quantitative evaluations of the hardware and building requirements for installing a radiography system are needed. A preliminary survey of the costs for $\mathrm{X}$-ray radiography equipment indicates a price range of $\$ 5,000$ to $\$ 15,000$ for used medical equipment that would satisfy the imaging requirements for this project.

\section{Study of Scale-Up Procedures}

Minipermeameter measurements were completed on a rectangular sample $(2 \times 3 \times 10 \mathrm{in}$.) cut from a ripple bedded rock sample collected from a road-cut exposure of the Bluejacket sandstone. These data will be used together with the CT-derived porosities and thin-section image analysis to construct an accurate 3-D permeability distribution. Preliminary processing of data indicates permeabilities ranging from $50 \mathrm{mD}$ for the better sand to $1 \mathrm{mD}$ for the shaly regions. Minipermeameter measurements were completed on another rectangular sample $(2 \times 2 \times 10$ in.) cut from a ripple bedded fluvial deposit sandstone from the Tallant formation. High-permeability contrasts exist between the clay-rich laminae (30 to $60 \mathrm{mD}$ ) and the rest of the sandstone (200 to $1000 \mathrm{mD}$ ). The net gas permeability of the resin-encapsulated sample was measured to be $350 \mathrm{mD}$. Thin-section petrographic analyses, routine porosity and permeability calculations, and X-ray-diffraction mineral analysis were performed on the two samples.

A 1.5-in.-diameter Bentheim sandstone was CT scanned, and fluid saturations at residual brine were measured by CT. Two techniques were used for determining end-point oil and brine distributions measured by NMRI at pore level on microplugs (5-mm-diameter) drilled in selected locations. The first technique, which involves the NMRI of the microplug immediately after being drilled, has the advantage of speed, but errors in saturation can be introduced because of fluid interchanges during coring. The second technique involves extracting and drying the microplug; placing it in a newly designed microcoreholder, which allows flooding of the microcores while placed in the NMRI probe; and repeating the same flooding steps as performed on the 1.5 -in. plug. Although the original saturations seem to be reproduced better, this procedure is considerably slower and more complex. It was used to generate high-resolution images by NMRI microscopy for total fluid, oil, and brine distributions for the Bentheim microplugs at the residual oil and residual brine end points. Figure 1 shows 3-D images of a selected rectangular volume from the microcore plug 
data files. Part a shows the oil content of the pore system at residual brine conditions, and part $\mathrm{b}$ shows the brine content of the pore system at residual brine conditions for the same volume in the plug. The measured brine saturation by CT for this sample was $30 \%$. Also, the newly designed microcoreholder was used to generate high-resolution images by NMR microscopy for brine in Berea samples used in the polymer injection tests and in the Tallant sandstone samples. The NMRI images of the brine-saturated Tallant sandstone microcore plugs show the marked decrease in pore size and porosity in the clay-rich laminae compared with the rest of the sandstone. Figure 2 shows a 3-D image of a selected rectangular volume where the bottom half extends into one of the laminae and thus reveals this contrast in porosity and pore size.

(A)

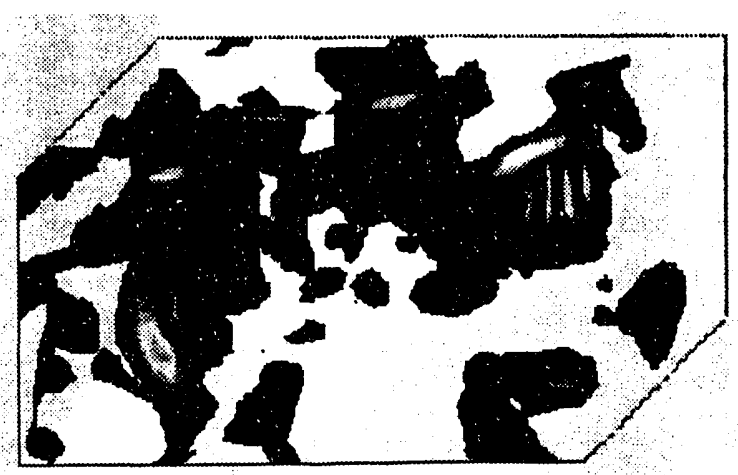

(B)

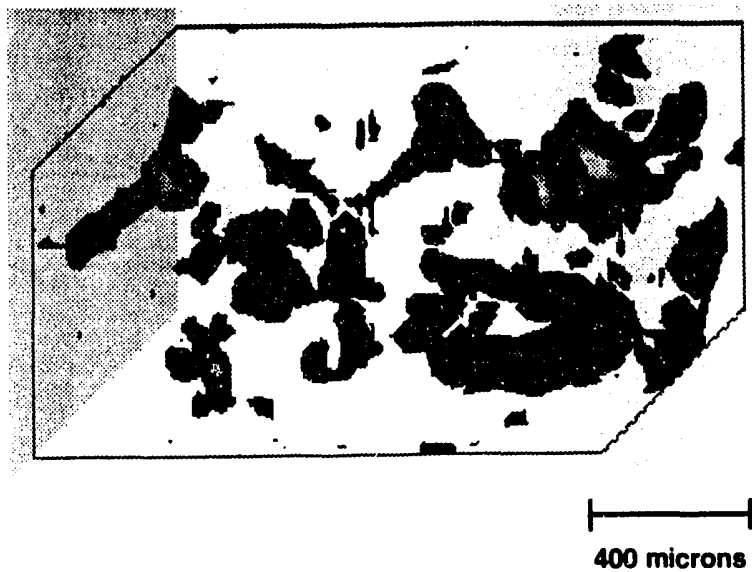

Fig. 1 Three-dimensional nuclear magnetic resonance image of Bentheim sandstone microcore plug saturated with two-phase oil-brine nuid system. (A) Oil phase at residual brine. (B) Brine phase at residual brine.

\section{Industry Consortium Development}

Two-way interaction with industry in relation to areas of imaging technology of interest to industry during the Society of Petroleum Engineers (SPE)/Department of Energy

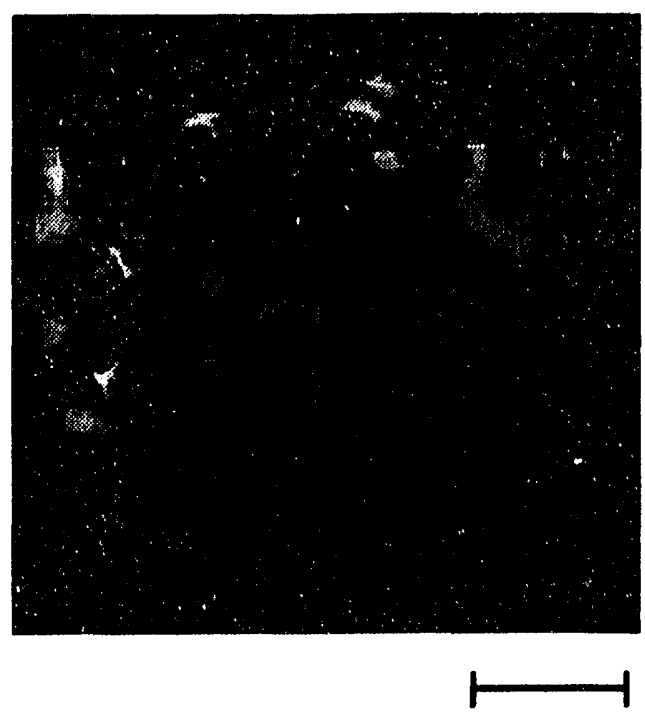

400 microns

Fig. 2 Three-dimensional nuclear magnetic resonance image of Tallant sandstone microcore plug saturated with brine. Shown is the contrast in porosity and pore size between the clay-rich laminae (below) and the rest of the sand (above).

(DOE) symposium through direct professional contacts and presentation of imaging work at the NIPER booth and during a field trip continued. X-ray images, generated from projection planes parallel to the axis of the core, were used to identify sedimentary, diagenetic, and structural features and to select the preferential slabbing plane for cores drilled behind an outcrop of Class I reservoir. The results were presented at a field trip held in conjunction with the Tulsa SPE/DOE EOR conference. Presentations containing CT imaging contributions were made by other projects (microbial and surfactant flooding) at the SPE/DOE EOR symposium and at the Tulsa chapter of Society of Core Analysts. Industry contacts established at these meetings continued by sending consortium materials.

Continued effort was directed this quarter in addressing the recent DOE directives regarding emphasis on environment, safety, and health.

\section{Technology Transfer}

A paper was presented at the joint meeting of the Society of Professional Well Log Analysts and the Society of Core Analysts. ${ }^{1}$ Copies of this paper and other rock-fluid imaging papers and reports were distributed.

\section{Reference}

1. D. Doughty and L. Tomutsa, NMR Microscopy for Fluid Imaging at Pore Scale in Reservoir Rock, paper presented at the joint meeting of the Society of Professional Well Log Analysts and the Society of Core Analysts, Oklahoma City, Okla., June 15-17, 1992. 


\section{DEVELOPMENT OF METHODS FOR MAPPING DISTRIBUTION OF CLAYS IN PETROLEUM RESERVOIRS}

\section{Cooperative Agreement DE-FC22-83FE60149, Project SGP42}

\author{
National Institute for Petroleum \\ and Energy Research \\ Bartlesville, Okla.
}

\section{Contract Date: July 1990}

Anticlpated Completion: June 30, 1992

Funding for FY 1992: $\$ 210,000$

\section{Principal Investigator: \\ Bljon Sharma}

\section{Project Manager: \\ Chandra Nautlyal \\ Bartlesville Project Office}

Reporting Period: Apr. 1-June 30, 1992

\section{Objective}

The objective of this project is to develop techniques for mapping the types and volumes of clays in clastic reservoirs from signature analysis of log responses in clayey formations. The scope of work in this project includes identification of a few clastic reservoirs where oil production has been affected by the presence of different types and volumes of clays and mathematical processing of wireline logs from the clayey formations to identify certain mathematical properties that may be correlated with the clay characteristics. The characteristics of clays under investigation are evaluated from detailed thinsection petrography, computerized tomography (CT) scans, and geological investigations.

\section{Summary of Technical Progress}

The vertical variability in the distribution of the type and volume of clays in a sandstone reservoir has a corresponding effect on the distribution of petrophysical properties like permeability and porosity. An effective measure to estimate the vertical variability of reservoir rock or petrophysical properties obtained from core or log data was developed from the decay of power spectra of the frequency-transformed reservoir property distributions in a well. Analyses of both corederived permeability distributions and digitized wireline log cata were performed. Results of vertical variability measures obtained by the new method were compared with other variability measures like the Dykstra-Parsons coefficient. The effect of vertical permeability variations estimated by the new method on primary and waterflood productions was studied on seven wells from Bell Creek (Montana) field.

\section{Vertical Variability of \\ Reservoir Rock Property}

Information about the vertical variability of reservoir rock properties, such as permeability, which in many reservoirs is controlled by the distribution of the types and volumes of clay, is of critical importance for exploitation of hydrocarbon resources and effective planning of enhanced recovery projects. The vertical sweep efficiency of a waterflood depends primarily upon the distribution of permeability within the reservoir and also upon the mobility ratio. ${ }^{1}$ In a miscible slug process, effective design of a slug required to maintain miscibility throughout the displacement process requires knowledge about the degree of stratification of the reservoir. ${ }^{2}$ Froning and Treiber $^{3}$ reported how the distribution of clays in reservoir pore surfaces may affect micellar design in several ways but primarily by higher adsorption of surfactants in high surface area clays compared with that on silica.

A realistic measure of variability of rock properties that is easy to compute and at the same time contains the essential information required for different applications is not readily available. Statistical parameters, such as mean, standard deviation, or kurtosis, although easy to compute, are generally poor measures of variability that do not always bring out the character of a distribution. Miller and Lents, ${ }^{4}$ Elkins and Skov, ${ }^{5}$ and others have extensively used simple measures of permeability stratification by relating the portion of the cumulative flow capacity (product of permeability and thickness) to the portion of the total reservoir thickness. Although these extensively used permeability measures could explain fluid production in certain projects, the complex heterogeneity character of certain permeability distributions cannot be incorporated in such heterogeneity measures.

A common measure of reservoir heterogeneity often used in reservoir engineering is the Lorenz coefficient in which, for different layers, the cumulative fraction of total flow capacity is plotted against the cumulative storage capacity (product of porosity and thickness). The area between the derived curve and a $45^{\circ}$ line is defined as the Lorenz coefficient. $^{\text {' }}$

A second, perhaps most popular measure of permeability variation, V, was introduced by Dykstra and Parsons. ${ }^{1}$ They calculated the spread of a set of permeabilities with log-normal distributions as follows:

$$
\mathrm{V}=\frac{\overline{\mathbf{k}}-\mathrm{k}_{\mathrm{o}}}{\overline{\mathbf{k}}}
$$

where $\overline{\mathrm{k}}$ is the mean permeability and $\mathrm{k}_{\sigma}$ is the permeability at $84.1 \%$ of the cumulative sample.

Although both the Lorenz and Dykstra-Parsons coefficients have been shown to be useful indicators of the level of heterogeneity in a variety of fluid recovery projects ${ }^{1}$ and modeling studies have demonstrated the strong correlation 
of these measures with performance ${ }^{6}$ in at least the highheterogeneity reservoirs, Jensen and Lake ${ }^{6}$ and others have shown that, for non-log-normal distributions, the two coefficients are not unique. The two coefficients are also influenced by the number of data points in the sample. Since reservoir permeabilities are known to exhibit different distributions, the two coefficients may not yield good variability measures.

The new measure of reservoir variability proposed is based on the analysis of the frequency content of a series of equi-distant observations of a reservoir rock property along the depth of a well that are typically obtained from logs or from laboratory measurements of core samples. It has been demonstrated ${ }^{7-9}$ that such a series consisting of equidistant readings of reservoir properties may be considered as a statistical sample from an infinity of other realizations of the data series, and techniques of time series analysis may be applied to such a series to extract useful information about the distribution.

In this investigation certain statistical parameters, such as "power spectrum" and "coherence," were estimated from the distributions of reservoir properties obtained from log or core data, and the decay of statistical parameters with frequency was correlated with known heterogeneities of the original distribution and available production data. Certain diagnostic features of the statistical parameters that can effectively quantify certain types of heterogeneities in the original distribution were identified.

\section{Estimation of Statistical Parameters of Reservoir Property Distributions}

\section{Computation Theory}

Statistical parameters of various reservoir property distributions were estimated in the frequency domain and compared with other measures of vertical variability. The reservoir properties studied were those obtained from digitized wireline logs, petrophysical or fluid-flow property estimated from the log data, laboratory-measured permeability, porosity, water saturations, etc. Essentially, the computation of the statistical parameters is initiated by calculation of the covariances between the $n$ observations, $x_{t}$ (where $t=1,2, \ldots n)$, making up a stationary time series. The covariances give a measure of the correlation between the contiguous values. Whenever only one series is considered, the covariance becomes the autocovariance function of the series $x_{t}$. The normalized value of autocovariance function, $\gamma(\tau)$, where $\tau$ is the lag, is called the autocorrelation function, $\rho(\tau)$. As demonstrated, ${ }^{7-9}$ the autocorrelation function and the power spectrum, $f(\omega)$, are Fourier transforms of one another. Knowledge of one therefore implies knowledge of the other. The Fourier transformation that yields $f(\omega)$ from $\rho(\tau)$ may be stated as follows:

$$
f(\omega)=\int_{-\infty}^{\infty} \rho(\tau) \cos \omega \tau d \tau
$$

and

$$
\rho(\tau)=\int_{-\infty}^{\infty} f(\omega) \cos \omega \tau d \omega
$$

The preceding equation shows that, at lag, $\tau=0$

$$
\rho(0)=v=\int_{-\infty}^{\infty} f(\omega) d \omega
$$

where $v$ is the variance of the series. Mathematical manipulation of the data is much simpler in the frequency domain than in the depth domain.

\section{Computation of Statistical Parameters from Field Data}

The statistical parameters of reservoir rock property distributions were computed for data from Bell Creek (Montana) and Patrick Draw (Wyoming) fields. These two fields were selected because of the availability of log, core, and production data from all the wells and thin-section, X-ray diffraction, scanning electron microscope, and CT scan data from selected wells for detailed analysis of vertical distribution of reservoir rock properties. A number of geological, petrophysical, and petrographical investigations were carried out on the reservoirs from these two fields with detailed examination of cores for identification of facies, sedimentary structures, grain, and pore-size distributions, thin-section analysis for clay types, etc.

\section{Analysis of Data from Bell Creek Field}

\section{Background Information}

The productive interval at Bell Creek field, located in the northeastern flank of Powder River Basin, Montana, is the Lower Cretaceous Muddy formation, which is composed of two genetically different major reservoir sandstone units interpreted as ${ }^{10-12}$ (1) barrier islands (littoral marine bars) and (2) valley fills. The upper, clay-rich, valley-fill sandstones generally have much poorer reservoir properties compared with the lower, high-productive foreshore and shoreface facies of the barrier island sandstones.

This analysis was carried out in a few selected wells from four sections located in Unit " $A$ " (the largest and the most productive of the six units) of the field. The locations of wells studied (which includes wells drilled for primary production, waterflood, and chemical injection) and the Tertiary Incentive Project (TIP) area where a chemical flood was initiated in 1980 are shown in Fig. 1.

The Dykstra-Parsons coefficients (Fig. 2), computed from core measurements of air permeability data, have low values in the central part of the study area, moderately high values in the eastern part and the western part, and significantly higher values in the southwestern part. The generally 


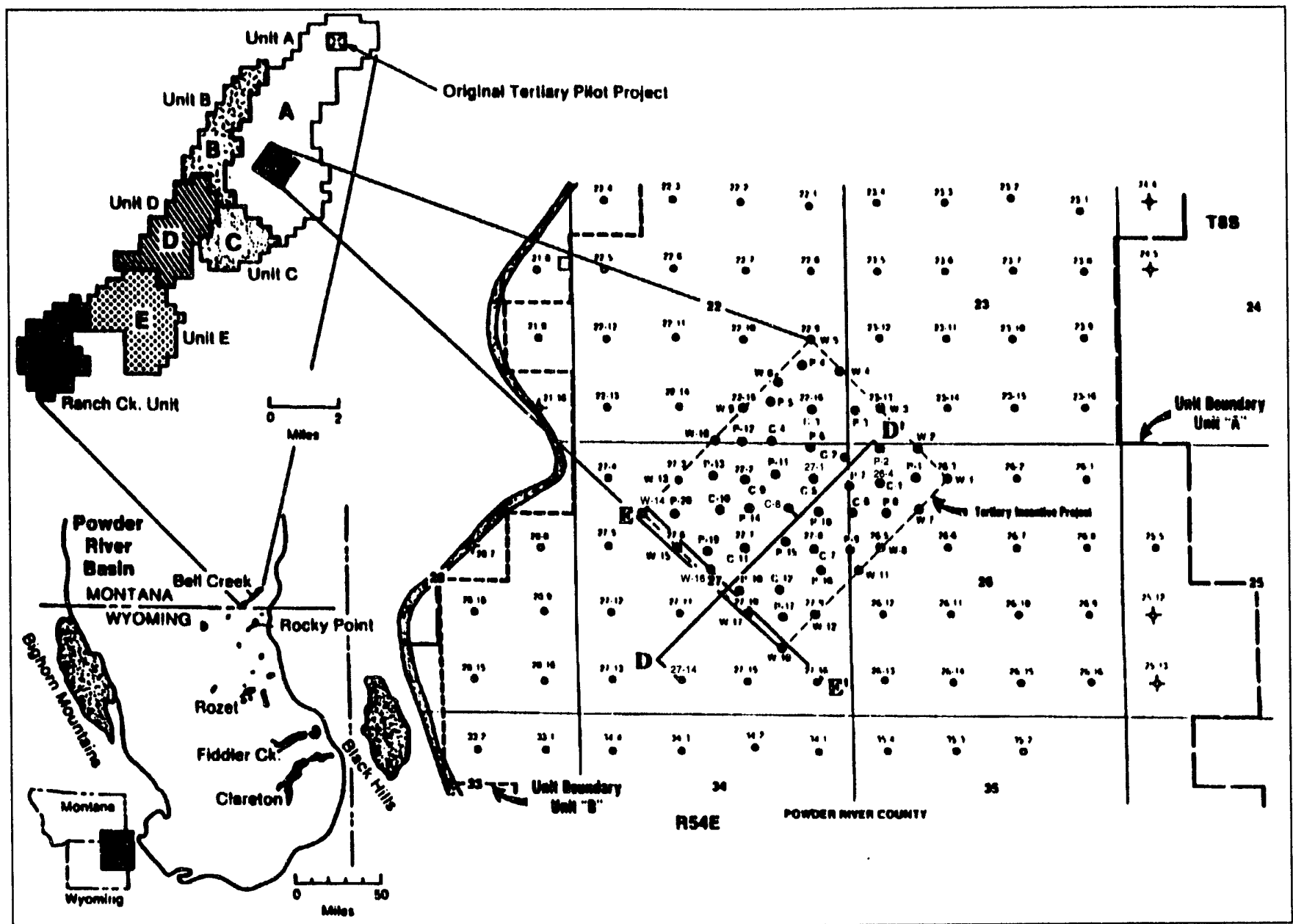

Fig. 1 Index map showing units comprising Bell Creek field and well control. P, production wells; W, water injection wells; and C, chemical injection wells.

uniform permeability distribution in the central part of the study area (low Dykstra-Parsons coefficients) is caused by the deposition of clean, high-permeability sandstones with low clay content, whereas the southwestern area with high Dykstra-Parsons coefficients has a large vertical variation of permeability mainly caused by a significant amount of diagenetic clays in the sandstone pore spaces. ${ }^{10-12}$

In the computation of the Dykstra-Parsons coefficients in the highly heterogeneous part of the field, certain approximations were necessary because the permeability distributions were not always log normal. This implies that, in these highly heterogeneous areas, the Dykstra-Parsons coefficients may not give a realistic measure of vertical variability of reservoir permeability.

\section{Statistical Parameters of Permeability Data}

The statistical parameters were computed for air permeability data for seven wells (wells 26-4, P-2, 27-1, C-8, W-14, W-16, and 27-14; see Fig. 1 for locations) and a hypothetical, ideal profile with practically zero variability. These wells were selected for analysis for their wide varia- tions in the vertical distribution of permeability and oil production performances. For easy appreciation of the variations in the computed parameters, the permeability data and the ideal series were arbitrarily divided into two sets for plotting. The natural logarithms of permeability of the two data sets are plotted in Figs. 3 and 4 and their power spectra for the eight permeability series in Figs. 5 and 6.

The mean, variance, and calculated Dykstra-Parsons coefficients of permeability variations in the seven wells are listed in Table 1. The initial primary production rates and cumulative waterflood production for all the wells studied and tertiary oil production rates in the vicinity of the four wells located within the Tertiary Incentive Project area where a polymer chemical flood was conducted are listed in Table 2. For those wells which were drilled subsequent to the initial primary production phase, extrapolated values from closely spaced production contours were used. For the tabulation of pay thicknesses for the upper, valley-fill, and barrier island sandstones, a cutoff of $69 \mathrm{mD}$ for pay was assumed.

Wells in the central part of the field (wells 27-1, 26-4, and P-2) have the best petrophysical properties and 


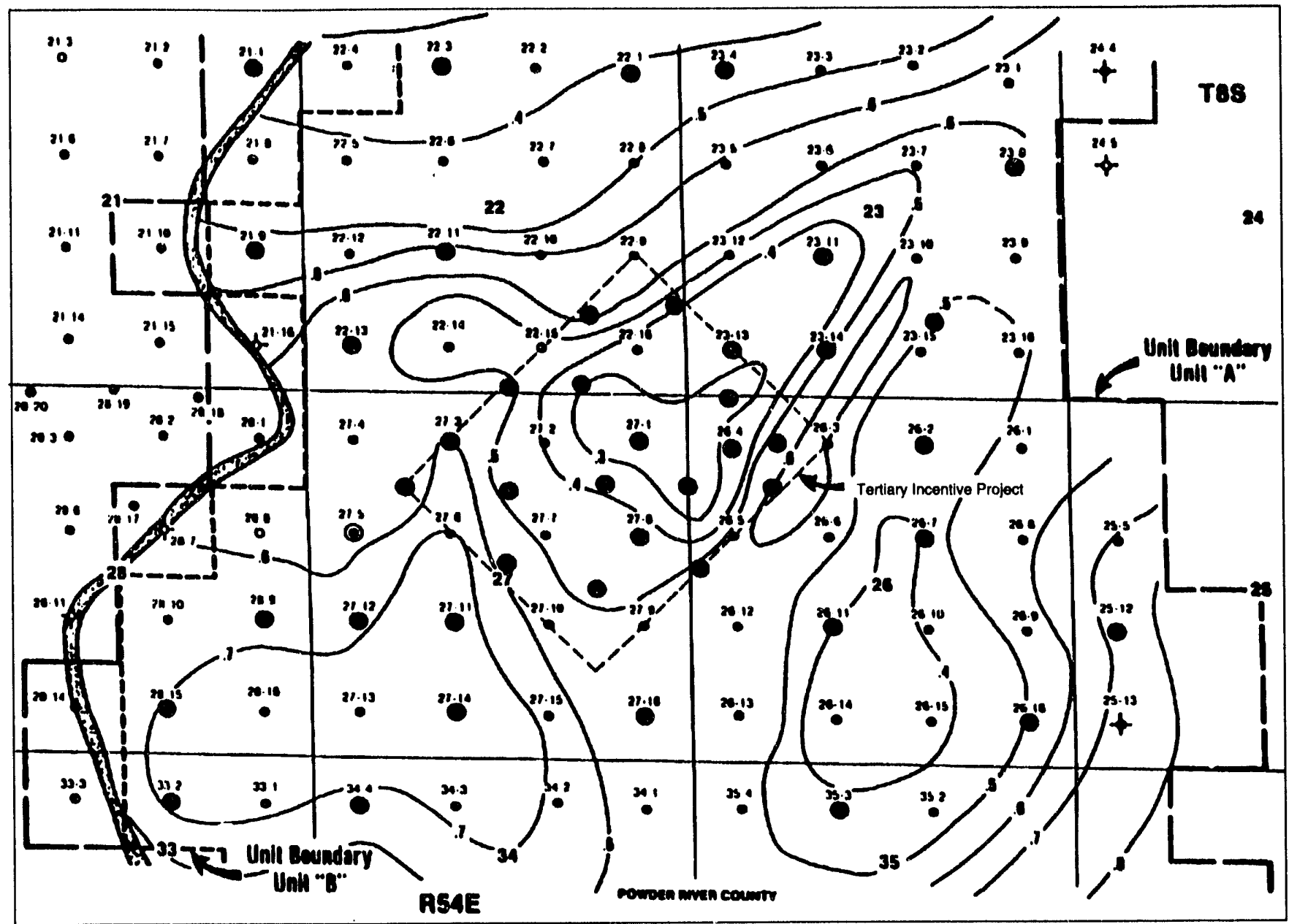

Fig. 2 Distribution of Dykstra-Parsons coefficients obtained from air permeability data in the study area. Wells with permeability data are indicated by large circles.

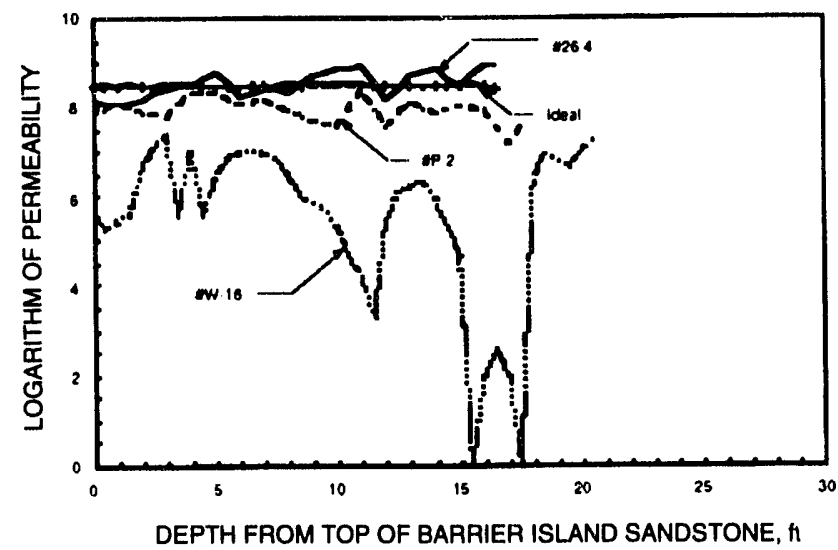

Fig. 3 Distribution of logarithms of permeability across the brarrier island sandstones in three wells from Bell Creek field (Montara) and an ideal profile.

production histories (Table 2). Petrophysical properties gradually deteriorate toward the southwestern part of the study area primarily because of significant amounts of detrital and diagenetic clays.

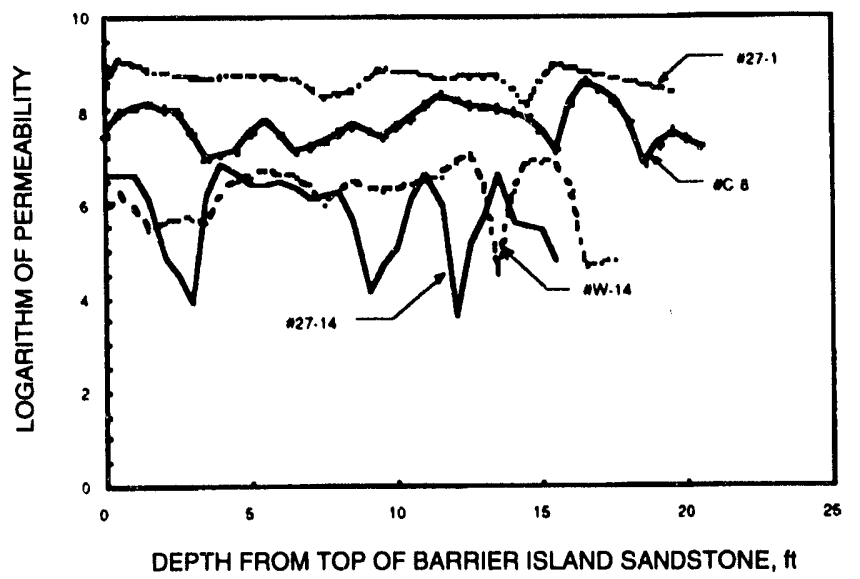

Fig. 4 Distribution of logarithms of permeability across the barrier island sandstones in four wells from the Bell Creek field, Montana.

\section{Analysis of Power Spectra}

Figures 5 and 6 show considerable variations of power with frequency for the eight permeability distributions analyzed. From Eq. 1, the total variance, v, of the 


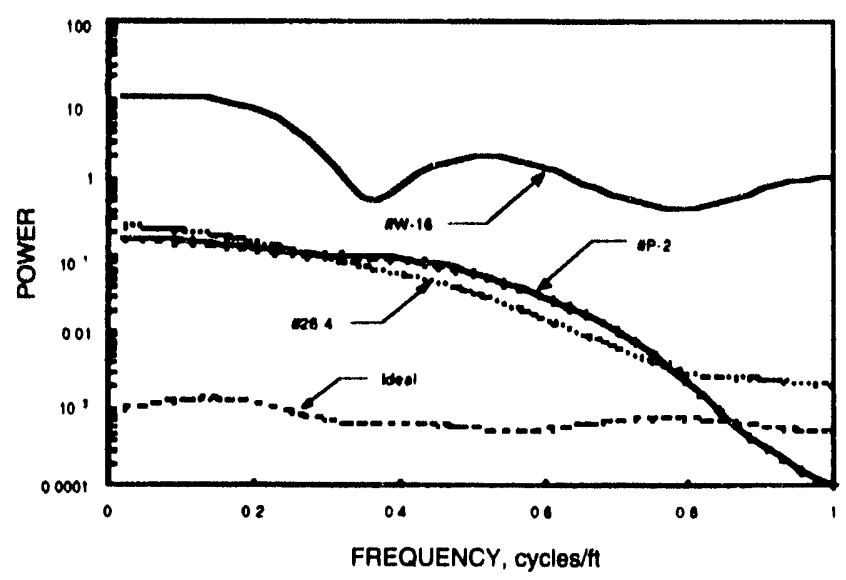

Fig. 5 Power spectra of $\log$ permeability data from three wells and an ideal profile shown in Fig. 3.

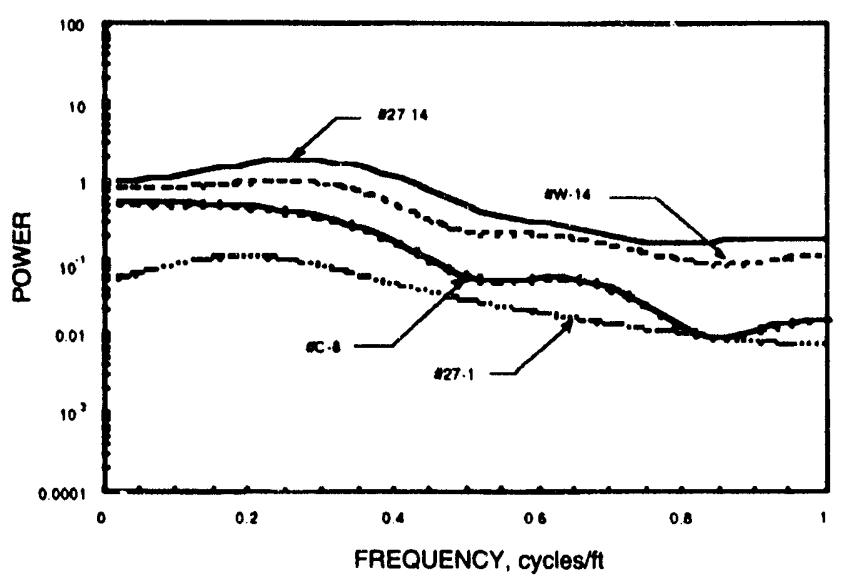

Fig. 6 Power spectra of log permeability data of four wells from the Bell Creek field shown in Fig. 4.

permeability distribution is expressible as follows:

$$
v=\int_{-\infty}^{+\infty} f(\omega) d \omega
$$

where $f(\omega)$ is the power spectrum at frequency $\omega$.

Numerical integration of the area within each power distribution was carried out for the entire frequency range for which computations vere performed, and the results are shown in Table 1 . The close agreement between the variances of the log permeability data and the area under the power curve for each profile underscores the accuracy that may be obtained from calculations in the frequency domain. For a quantitative estimate of the contributions to the total variance in the different frequency ranges, the area under the power curve for each of the four quadrants into which the frequency scale was divided was tabulated (Table 3). The area within each quadrant represents the contribution to the total variance by frequencies within that quadrant. Below the area for each quadrant is also shown
TABLE 1

Measures of Vertical Variability of Permeability Distributions in Wells from Bell Creek Field, Montana

\begin{tabular}{lcccc}
\hline $\begin{array}{l}\text { Well } \\
\text { No. }\end{array}$ & $\begin{array}{c}\text { Dykstra-Parsons } \\
\text { coemeients }\end{array}$ & $\begin{array}{c}\text { Mean of log } \\
\text { permeability } \\
\text { series }\end{array}$ & $\begin{array}{c}\text { Variance of } \\
\text { permeabillty } \\
\text { series }\end{array}$ & $\begin{array}{c}\text { Area } \\
\text { under } \\
\text { power } \\
\text { curve }\end{array}$ \\
\hline Ideal profile & & & 0.0008 & 0.0008 \\
$26-4$ & 0.33 & 8.518 & 0.0682 & 0.0656 \\
P-2 & 0.28 & 7.914 & 0.0643 & 0.0624 \\
W-16 & 0.60 & 5.498 & 3.2642 & 3.1719 \\
W-14 & 0.58 & 6.120 & 0.4247 & 0.4170 \\
$27-1$ & 0.20 & 8.659 & 0.0410 & 0.0405 \\
C-8 & 0.40 & 7.677 & 0.1835 & 0.1781 \\
$27-14$ & 0.75 & 5.718 & 0.7405 & 0.7317 \\
\hline
\end{tabular}

the normalized area for that quadrant obtained by dividing the computed area by the variance of each series. The normalized values are useful for comparison of variance distributions in different quadrants for normalized total variance of unity for the different series.

The power spectra for the different distributions are discussed in increasing order of vertical variability of permeability as given by their variances (Table 1). The spectrum for the ideal profile has very low powers for the entire frequency range because of very low permeability variations for this profile. The sandstone in well 27-1 has one of the best petrophysical properties and primary oil production rates per foot of pay in the entire field. The spectrum for this well also has low values for the entire frequency range and this, coupled with the fact that power does not drastically change for the entire frequency range, suggests that the sandstone in this well is probably massive with more or less uniform permeability distribution. Compared with this well, which has an average clay content of about $1 \%$ and average permeability of $5760 \mathrm{mD}$ for the barrier island facies, the average clay contents and permeabilities in wells $26-4$ and P-2 are around $2.5 \%$ and $5000 \mathrm{mD}$ and $4 \%$ and $2730 \mathrm{mD}$, respectively. In these three wells, the higher clay content is probably reflected in the higher variances in the power spectra in the mid-frequency range (quadrants 2 and 3, Table 3).

The vertical variability of permeability increases significantly in well C-8, which is located only $800 \mathrm{ft}$ southwest of well 27-1, primarily because of higher average clay content (around 5\%) that has reduced the average permeability of the sandstone to $2160 \mathrm{mD}$ (Ref. 11). The higher variability in this sandstone is reflected on the higher variances throughout the frequency range compared with the three wells discussed earlier. The power curve also displays some periodicity with comparatively lower power and hence low variances for certain frequency bands, such as at frequencies 0.5 and 0.8 cycle/ft. The variability in the well W-14 sandstone, with an average permeability of $455 \mathrm{mD}$, 

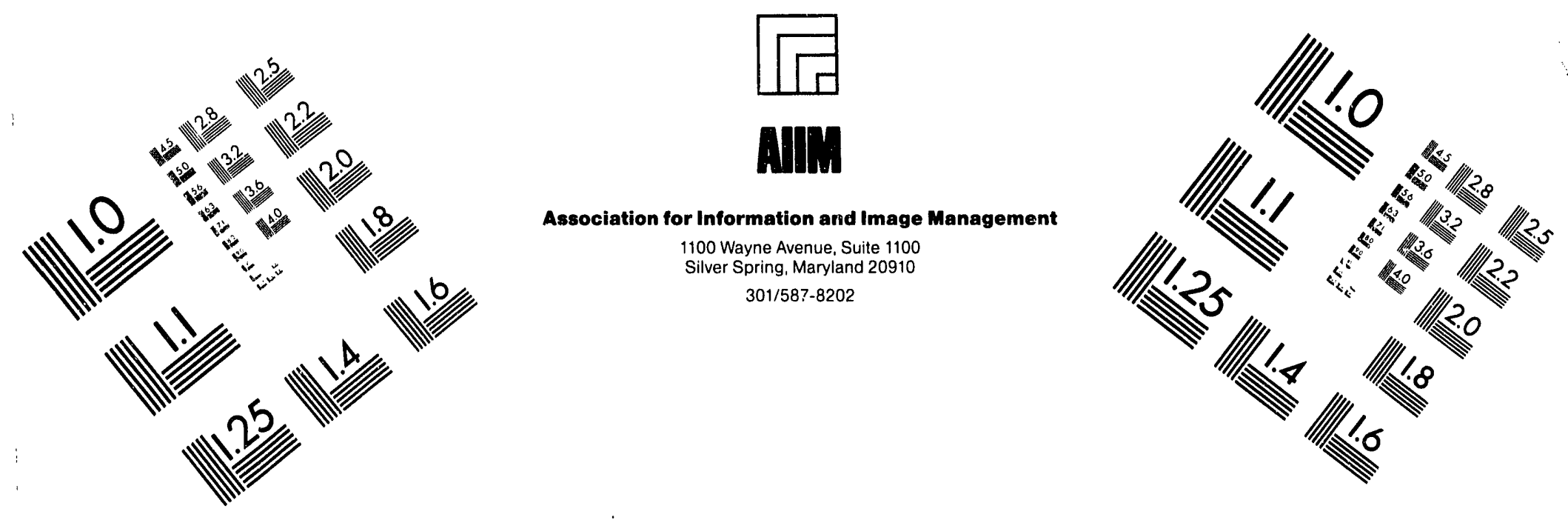

\section{Centimeter}

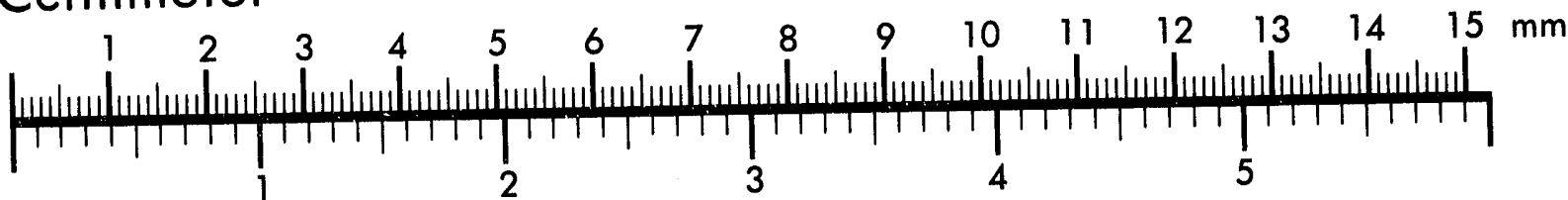
Inches
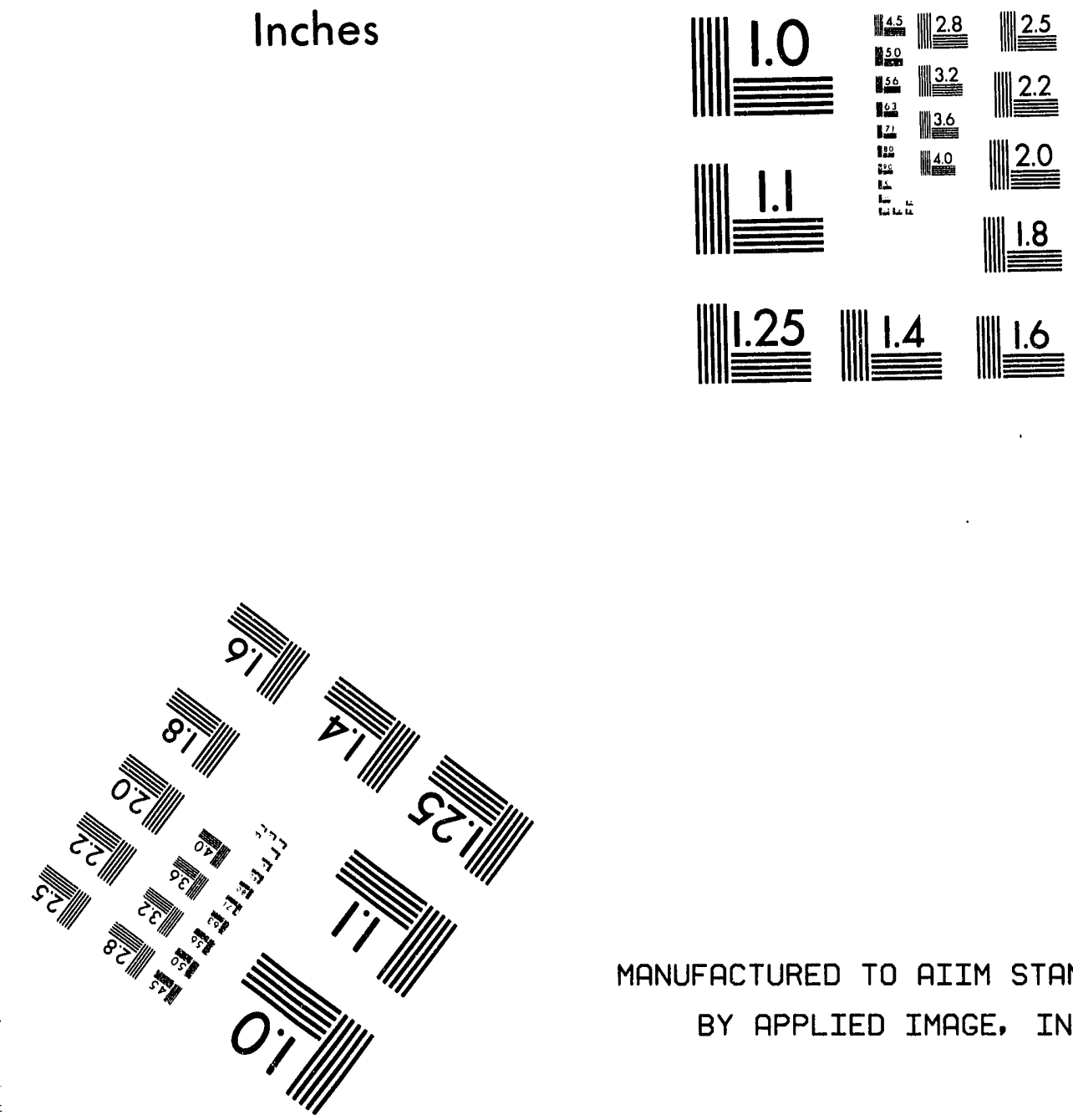

MANUFACTURED TO AIIM STANDARDS

BY APPLIED IMAGE, INC.

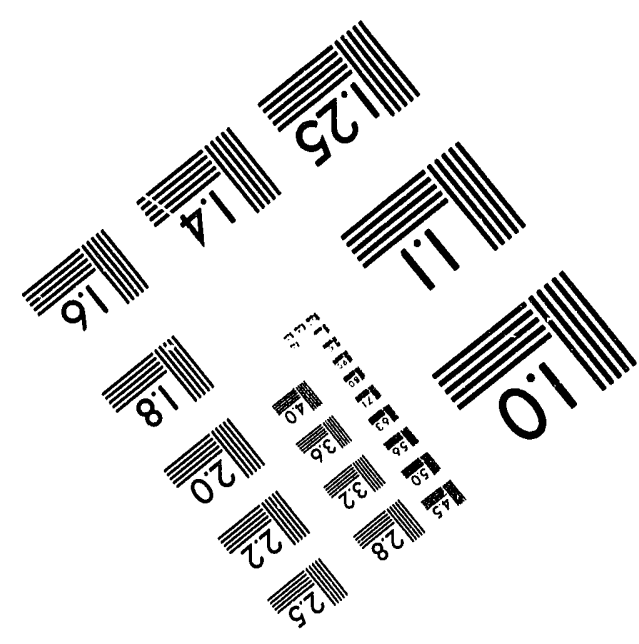



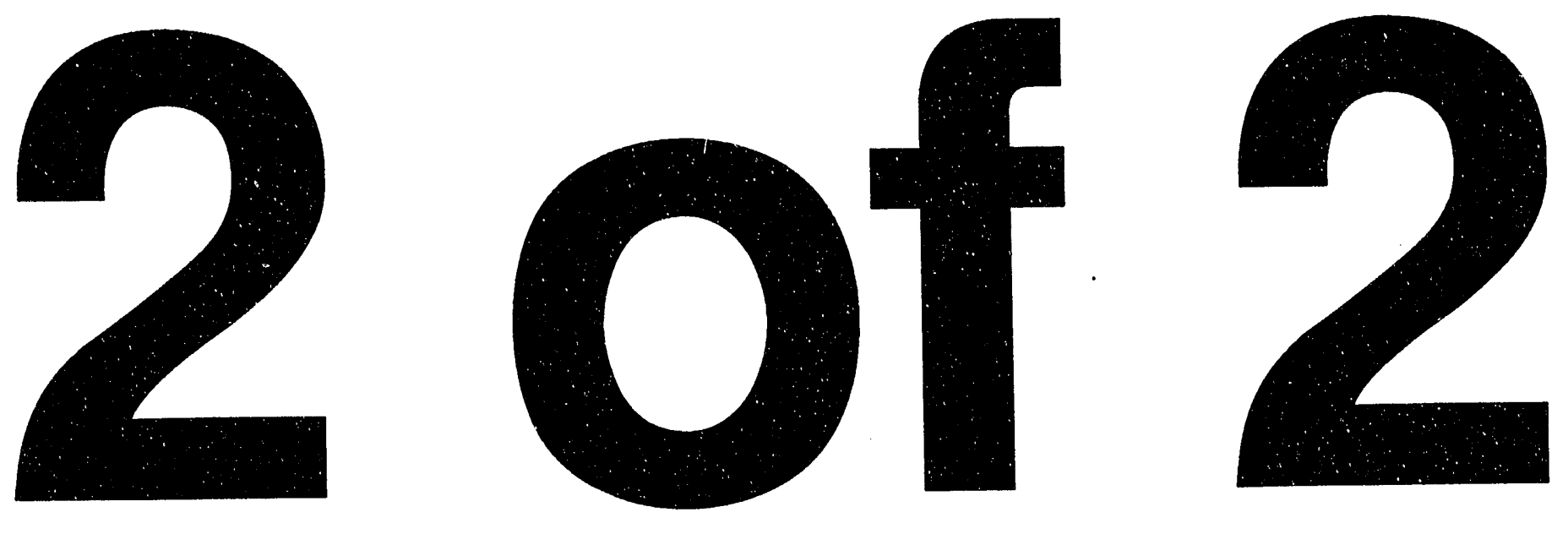


\section{TABLE 2}

Initial Primary, Cumulative Waterflood, Polymer Oil

Production, and Pay Thicknesses of Muddy Sandstone Ress:rvoir in the Study Area of Bell Creek Field

\begin{tabular}{cccccc}
\hline & $\begin{array}{c}\text { Initial } \\
\text { primary } \\
\text { oil } \\
\text { production } \\
\text { rate,* } \\
\text { BOPD }\end{array}$ & $\begin{array}{c}\text { Pay } \\
\text { thickness, } \dagger \\
\text { No. }\end{array}$ & $\begin{array}{c}\text { Initial } \\
\text { primary } \\
\text { production } \\
\text { rate per font } \\
\text { of pay, } \\
\text { BOPD }\end{array}$ & $\begin{array}{c}\text { Cumulative } \\
\text { waterflood } \\
\text { oil } \\
\text { production, } \\
\text { million bbl }\end{array}$ & $\begin{array}{c}\text { Approximate } \\
\text { tertiary oil } \\
\text { production } \\
\text { at well } \\
\text { locations, } \\
\text { million bbl }\end{array}$ \\
\hline $27-1$ & 936 & $\begin{array}{c}20 \\
(0+20) \\
21\end{array}$ & 46.8 & 910 & 160 \\
$26-4$ & 800 & $\begin{array}{c}21+17) \\
21\end{array}$ & 48.2 & 1050 & 80 \\
P-2 & 850 & $\begin{array}{c}(1+20) \\
25\end{array}$ & 38.1 & 980 & 65 \\
C-8 & 950 & $\begin{array}{c}(4+21) \\
19\end{array}$ & 30.0 & 580 & 75 \\
W-14 & 570 & $\begin{array}{c}(1+18) \\
25\end{array}$ & 27.2 & 350 & - \\
W-16 & 680 & $\begin{array}{c}18+17) \\
18\end{array}$ & 31.9 & 410 & - \\
$27-14$ & 574 & $(4+14)$ & & & \\
\hline
\end{tabular}

*In wells that did not have initial primary or tertiary production, data extrapolated from detailed production contours in neighboring areas. BOPD, bbl of oil per day.

$\dagger$ The first figure refers to thickness of upper valley-fill sandstone and the second figure the thickness of barrier island sandstones.

$\ddagger$ A chemical polymer flood was conducted in a limited area enclosing the first four wells on this table.

TABLE 3

Distributions of Areas Under the Power Curve in the Different Quadrants of the Frequency Scale of Power Distributions of Log Permeability Data*

\begin{tabular}{|c|c|c|c|c|c|}
\hline \multirow[b]{2}{*}{$\begin{array}{l}\text { Well } \\
\text { No. }\end{array}$} & \multicolumn{5}{|c|}{ Area under power curve } \\
\hline & In quadrant & $\begin{array}{c}\text { In quadrant } \\
2\end{array}$ & $\begin{array}{c}\text { In quadrant } \\
\mathbf{3}\end{array}$ & $\begin{array}{c}\text { In quadrant } \\
4\end{array}$ & Total \\
\hline $26-4$ & $\begin{array}{c}4.585 \times 10^{-2} \\
(0.6989)\end{array}$ & $\begin{array}{c}1.577 \times 10^{-2} \\
(0.2484)\end{array}$ & $\begin{array}{c}0.326 \times 10^{-2} \\
(0.0498)\end{array}$ & $\begin{array}{l}0.064 \times 10^{-2} \\
\left(9.72 \times 10^{-3}\right)\end{array}$ & $\begin{array}{c}6.56 \times 10^{-2} \\
\text { (1) }\end{array}$ \\
\hline P-2 & $\begin{array}{c}3.457 \times 10^{-2} \\
(0.5538)\end{array}$ & $\begin{array}{c}2.153 \times 10^{-2} \\
(0.3449)\end{array}$ & $\begin{array}{c}0.6007 \times 10^{-2} \\
(0.0962)\end{array}$ & $\begin{array}{r}0.0243 \times 10^{-2} \\
\left(3.90 \times 10^{-3}\right)\end{array}$ & $\begin{array}{c}6.243 \times 10^{-2} \\
\text { (1) }\end{array}$ \\
\hline W-16 & $\begin{array}{c}2.3683 \\
(0.7479)\end{array}$ & $\begin{array}{c}0.3470 \\
(0.1096)\end{array}$ & $\begin{array}{c}0.2802 \\
(0.0885)\end{array}$ & $\begin{array}{l}0.17133 \\
(0.0541)\end{array}$ & $\begin{array}{c}3.1668 \\
(1)\end{array}$ \\
\hline W-14 & $\begin{array}{l}0.20971 \\
(0.5036)\end{array}$ & $\begin{array}{l}0.14161 \\
(0.3401)\end{array}$ & $\begin{array}{c}0.0425 \\
(0.1021)\end{array}$ & $\begin{array}{c}0.0226 \\
(0.0543)\end{array}$ & $\begin{array}{l}0.4164 \\
(1)\end{array}$ \\
\hline $27-1$ & $\begin{array}{l}0.02103 \\
(0.5195)\end{array}$ & $\begin{array}{c}0.013 \\
(0.3211)\end{array}$ & $\begin{array}{l}0.004321 \\
(0.1067)\end{array}$ & $\begin{array}{c}0.0021284 \\
(0.0526)\end{array}$ & $\begin{array}{c}0.0405 \\
(1)\end{array}$ \\
\hline $\mathrm{C}-8$ & $\begin{array}{l}0.11521 \\
(0.6477)\end{array}$ & $\begin{array}{c}0.04832 \\
(0.27164)\end{array}$ & $\begin{array}{c}0.01128 \\
(0.06341)\end{array}$ & $\begin{array}{r}0.0030654 \\
(0.017233)\end{array}$ & $\begin{array}{c}0.1779 \\
(1)\end{array}$ \\
\hline $27-14$ & $\begin{array}{l}0.3304 \\
(0.452)\end{array}$ & $\begin{array}{l}0.294225 \\
(0.4026)\end{array}$ & $\begin{array}{c}0.065 \\
(0.0889)\end{array}$ & $\begin{array}{c}0.04125 \\
(0.05643)\end{array}$ & $\begin{array}{l}0.7309 \\
(1)\end{array}$ \\
\hline
\end{tabular}

*Values obtained by dividing the area under the curve by the variances of the series are shown in parentheses. 
follows the same general pattern as that in well C-8 except that, for all frequencies, the variances are an order of magnitude higher in this well. Note the cunsiderably higher thin-bed stratification in this well, which is indicated by higher variances at the high-frequency end, compared with the wells discussed earlier.

With a total clay content averaging $16 \%$ (3\% matrix and $13 \%$ authigenic clay), the barrier island sandstone in well 27-14 contains the highest percentage of clay ${ }^{10-12}$ among all the wells studied in the field. The average permeability of the sandstone is $304 \mathrm{mD}$, and it fluctuates between 36 and $948 \mathrm{mD}$ across the producing zone. The power spectrum for this well has very high power throughout the frequency range, which indicates high variability in clay content throughout the sandstone. Although the average,total clay content in well $\mathrm{W}-16$ is slightly lower (around 10\%) than in well $27-14$, the average cement content in this sandstone is much higher (around $9 \%$ ). ${ }^{10-12}$ This has not only lowered the average permeability of this sandstone to $244 \mathrm{mD}$ but also has caused highly fluctuating permeability distribution that raised the power very significantly for beds of all thicknesses, and the sharp rise in power at the high-frequency end is indicative of a high degree of thin-bed stratification.

\section{Correlation of Power Spectra with Production}

When correlating the statistical properties with production, it should be mentioned that the Muddy sandstone reservoir at the Bell Creek field produces from the nonbarrier valley fill as well as from the barrier island sandstones, although in this analysis only the higher productive barrier island sandstones were discussed. Compared with the barrier island sandstones, the average production from the valley-fill sandstones is much lower, only about an eighth of the production from the high productive facies. The pay thickness of both the barrier and the nonbarrier sandstones for the wells analyzed is shown in Table 2.

The initial primary oil production rates per foot of pay (Table 2) generally follow the heterogeneity character of the sandstones discussed previously. The slightly lower values in wells $26-4$ and W-14 from the general trend may be partly due to the valley-fill sandstones in these wells, which have lower productivity compared with the barrier sandstones. The more massive sandstones with less permeability variation (wells 27-1 and P-2) show higher productivity, and productivity decreases in wells with high-permeability swings (wells 27-14 and W-16).

The vertical variability has affected cumulative waterflood production much more than the primary production because of poor sweep efficiency in stratified reservoirs, and the greater the stratification, the lower the production. Again the waterflood production in well $\mathrm{W}-14$ is below the trend observed in the other wells.

The approximate tertiary chemical flood production in the four wells analyzed (Table 2) seems to have been strongly affected by the distributions of clays in the sandstone pore spaces, ${ }^{10-12}$ which, in turn, have introduced variability in permeability distributions in the sandstones. The highest production is in well 27-1 because the sandstone in this well is very clean and there is very little permeability variation throughout the pay thickness.

\section{Vertical Variability Estimation of Wireline Log Data}

Similar computations were performed on wireline log data from the Bell Creek field, Montana, and the Patrick Draw field, Wyoming. The results of computations indicate good correlatiois of spectral decay with vertical variability of reservoir rock properties.

\section{Discussion of Results}

The frequency domain analysis of vertical variability of rock properties can separate the total variability of a distribution into a continuous function of frequency. The main advantage of such an analysis is an overall assessment of the quality of reservoir rocks for varion's applications. Such studies will only provide information about the vertical variability of the rock property under investigation and not directly about the quality of reservoir rocks, although information on reservoir rock variability, in conjunction with other reservoir information, is a good indicator of reservoir rock quality.

\section{References}

1. F. F. Craig, Jr, The Reservoir Engineering Aspects of Waterflooding, Monograph Sirries, Vol. 3, pp. 62-68, 78-96, Society of Petroleum Engineers, Richardson, Tex., 1971.

2. J. B. Agan and R. J. Fernandes, Performance Prediction of a Miscible-Slug Process in a Highly Stratified Reservoir, J. Pet. Technol., 81-86 (January 1962).

3. H. F. Froning and L. D. Treiber, Development and Selection of Chemical Systems for Miscible Waterflooding, paper SPE 5816 presented at the 5lst Annual Fall Technical Conference and Exhibition, New Orleans, La., 1976.

4. M. G. Miller and M. R Lents, Performance of Bodcaw Reservoir, Cotton Valley Field Cycling Project: New Methods of Predicting GasCondensate Reservoir Performance Under Cycling Operations Compared to Field Data, Drill. Prod. Pract., 128-149 (1947).

5. Lincoln F. Elkins and Arlie M. Skov, Some Field Observations of Heterogeneity of Reservoir Rocks and Its Effects on Oil Displacement Efficiency, paper SPE 282 presented at the SPE Production Research Symposium, Tulsa, Okla., 1962.

6. J. L. Jensen and L. W. Lake, The Influence of Sample Size and Permeability Distribution of Heterogeneity Measure, SPE Reserv. Eng., 629-637 (1988).

7. G. M. Jenkins and Donald G. Watts, Spectral Analysis and Its Applications, pp. 141-257, Holden-Day, San Francisco, 1968.

8. S. Bendat and A. G. Piersol, Random Data: Analysis and Measurement Procedure, pp. 286-341, Wiley-Interscience, a Division of John Wiley and Sons, Inc., New York, 1971.

9. Y. W. Lee, Statistical Theory of Communication, John Wiley and Sons, Inc., New York, 1963.

10. Final Report for October 1, 1985-September 30, 1988, Energy Production Research No. NIPER-390, Contract No. DE-FC22-83FE60149, Bartlesville, Okla., February 1989. 
11. B. Sharma et al., Critical Heterogeneities in a Barrier Island Deposit and Their Influence on Various Recovery Processes, SPE Format. Eval., 103-112 (March 1990).

12. B. Sharma et al., Determining the Productivity of a Barrier Island Sandstone Deposit from Integrated Facies Analysis, SPE Format. Eval., 413-420 (December 1990).

\section{ANALYSIS OF RESERVOIR HETEROGENEITIES DUE TO SHALLOWING-UPWARD CYCLES IN CARBONATE ROCKS OF THE PENNSYLVANIAN WAHOO LIMESTONE OF NORTHEASTERN ALASKA}

Contract No. DE-AC22-89BC14471

\author{
University of Alaska \\ Fairbanks, Alaska
}

Contract Date: Sept. 29, 1989

Anticipated Completion: Dec. 31, 1992

Government Award: \$149,935

\section{Principal Investigator:}

Keith F. Watts

\section{Project Manager: \\ Robert Lemmon \\ Bartlesville Project Office}

Reporting Period: Apr. 1-June 30, 1992

\section{Objectives}

The primary objective of this project is to develop an integrated database to characterize reservoir heterogeneities resulting from numerous small-scale shallowing-upward cycles composing the Pennsylvanian Wahoo Limestone of northeastern Alaska. The Wahoo Limestone is the upper part of an extensive carbonate platform sequence of the Carboniferous Lisburne Group, which is widely exposed in the Brooks Range and is a widespread potential reservoir unit in the subsurface of the North Slope of Alaska.

The project involves a number of carbonate researchers from four institutions. Carbonate sedimentologists at the University of Alaska Fairbanks are developing a correlation scheme using cyclic stratigraphy. This will allow interpretation of the depositional history and paleogeographic evolution of the region and development of predictive models and paleogeographic maps. Biostratigraphic data (Univer- sity of Montreal, algae and foraminifera; U.S. Geological Survey, conodonts) will serve as independent means of correlation. Exposure surfaces and associated variations in cement stratigraphy analyzed by University of Kansas staff will figure importantly in refining correlations. A computerized database system is being developed to accommodate information on carbonate petrology, diagenesis, and biostratigraphy derived from analyses of thousands of samples systematically collected from over 25 stratigraphic sections in the Arctic National Wildlife Refuge (ANWR). The objective is to determine lateral and vertical variations in the complex mosaic of carbonate facies composing the Wahoo Limestone.

The ultimate goal is to construct sea-level curves modeling the carbonate cycles and to determine the ability to use cyclic stratigraphy as a means of correlation. In the later stages of the project, the relationship between cyclic stratigraphy and reservoir properties in correlative rocks at the Lisburne oil field will be examined, and the use of cyclic stratigraphy for regional correlations will be tested. This detailed analysis of the Wahoo Limestone will provide a basis for interpreting correlative rocks in the adjacent subsurface of the coastal plain of ANWR, a potential hydrocarbon lease/sale area. In a broader sense, this work will serve as an excellent study of carbonate shallowing-upward cycles, which typify carbonate sediments. In addition, if the cyclicity resulted from global (eustatic) sea-level fluctuations, the sea-level curves may be applicable to Pennsylvanian rocks elsewhere.

\section{Summary of Technical Progress}

This report presents the results of research accomplished during the third quarter of the fiscal year. Much of the work involved initiating research on the Lisburne oil field, processing samples collected during the 1991 field season, and preparing for the 1992 field season. Ongoing petrographic studies, biostratigraphic work, analyses of diagenesis, and computer database development and entry continued.

\section{Regional Stratigraphic Framework}

Preliminary petrographic analyses were completed on thin sections from three stratigraphic sections slated for additional field studies in 1992. These analyses provide information on the composition and texture of carbonates of the Lisburne Group which will aid in additional description and sampling of these measured sections. The ultimate goal is to determine the depositional history, paleogeography, and tectonic setting of the Lisburne Group with detailed analyses of cyclicity in the Wahoo Limestone.

\section{Wahoo Limestone-Type Section}

The type locality of the Wahoo Limestone (locality 13 in Fig. 1) $)^{1}$ is located on the outer portion of a southwarddipping carbonate ramp. Petrographic analyses of samples 
systematically collected from the Wahoo-type section indicate the following:

- The boundary between the Wahoo Limestone and Alapah Limestone is gradational. Dark muddy limestones (wackestone and mudstone) typifying the Alapah are interbedded with fossiliferous bryozoan-pelmatozoan packstone and grainstone characteristic of the Wahoo in an approximately 100 - $\mathrm{m}$-thick transitional interval. This transitional interval can be mapped as a separate lithologic unit between light-weathering cliff-forming limestone of the Wahoo Limestone and dark, talus-forming lime mudstone and dolomite of the upper Alapah Limestone.

- Although bioclastic grainstone and packstone are common in the Wahoo Limestone, oolitic grainstone is rare, occurring in only a few thin intervals. This supports the notion that the Wahoo-type section was located on the outer part of the Wahoo carbonate ramp near the distal fringe of an ooid shoal complex. With the lack of oolitic grainstone and subtle variations in composition and texture in these bioclastic limestones, carbonate cycles are difficult to define compared with cyclical strata farther to the north, which are punctuated by distinctive oolitic grainstones.

- The upper 40 to $50 \mathrm{~m}$ of the Wahoo is primarily composed of dark mudstone, argillaceous limestone, and spiculitic mudstone, which were apparently deposited in relatively deep water (below wave-base). Rare thin laminae of oolitic grainstone were redeposited from adjacent ooid shoals. Localized beds of bioclastic grainstone containing intraclasts of spiculite were also redeposited into this deeper water setting from shallower parts of the ramp.

\section{Paleogeography of the Lisburne Group}

Along the Aichilik Transect-Lateral

Facies Changes and Palinspastic

\section{Reconstructions}

Previous reconnaissance studies of the Lisburne Group along the Aichilik River transect recognized significant facies and thickness changes between "the wall" and the northern flank of the Bathtub Ridge syncline (localities 15, 16, and 22 in Fig. 1). Preliminary petrographic analyses of thin sections from these reconnaissance stratigraphic sections were completed in preparation for additional field studies at these localities in 1992. Of special interest are algal limestones and cross-stratified bioclastic grainstone in the lower part of the Alapah at "the wall" (locality 16 in Fig. 1) that represent restricted platform ("lagoonal") and shoal deposits.

\section{Biostratigraphic Studies}

Studies of conodont biostratigraphy provide new interpretations of ages for stratigraphic sections at Clarence River in ANWR and for the type section of the Alapah in the central Brooks Range.

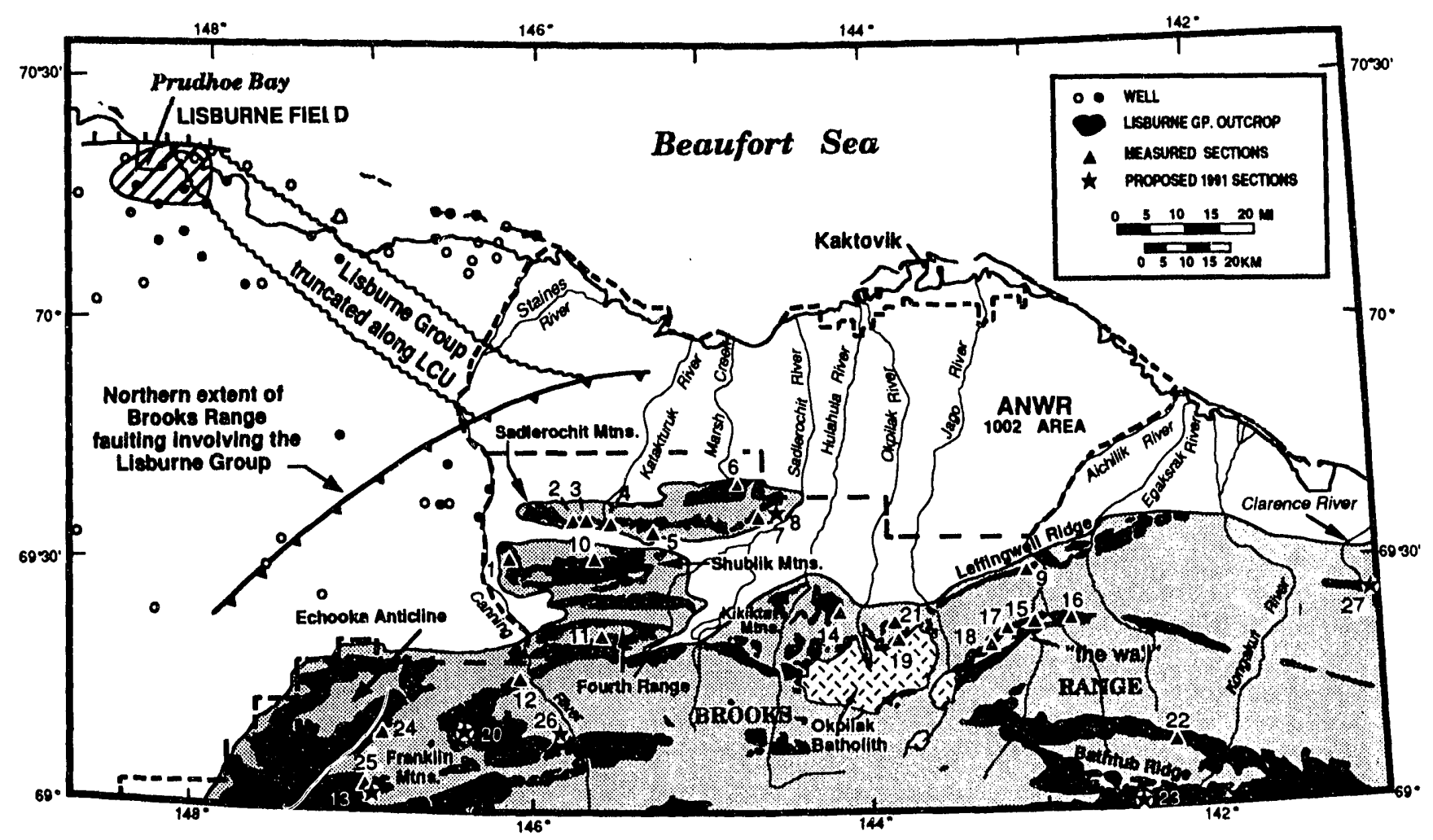

Fig. 1 Map of northeastern Alaska showing the distribution of Lisburne Group exposures and focations of stratigraphic sections. 
At Clarence River near the Canadian border the uppermost Wahoo Limestone is Late Morrowan to Atokan in age with an Idiognathodus fauna similar to that in the Sunset Pass section (localities 8 and 27 in Fig. 1). Because of poor conodont recovery from several samples, the position of the Pennsylvanian-Mississippian boundary is imprecisely located within the Wahoo Limestone, between 132.5 and $276 \mathrm{~m}$ above the base of section 91Y (see Fig. 19b in Ref. 2). Additional sampling during the 1992 field season should provide more precise age determinations. The upper Alapah Limestone is within Upper muricatus Subzone, which indicates a latest Chesterian age (latest Mississippian). The lower Alapah contains badly abraded conodont elements and well-sorted phosphatized grains, which supports the interpretation of a highenergy shoal environment for the cross-stratified oolitic and bioclastic grainstones dominating this interval. Although most of the conodonts recovered from the lower Alapah are nondiagnostic, a sample from $94 \mathrm{~m}$ above the base of the section indicates a Late Meramecian to Chesterian age.

At its type locality near Shainin Lake, the Alapah Formation ranges in age from Late Meramecian/Early Chesterian to Early Chesterian. Unfortunately, the top of the Alapah is not exposed at its type locality, so its entire age range and relationship to overlying strata are unknown.

Conodont samples from the Wahoo-type section, Marsh Fork of the Canning River, and south Bathtub Ridge, are being processed (localities 13, 23, and 26 in Fig. 1).

\section{Diagenetic Studies}

In diagenetic studies during this quarter, 100 samples of different calcite cement phases were taken for carbon and oxygen isotope analyses. A dentist drill was used to obtain discrete samples of the separate cement phases that were previously identified with cathodoluminescence petrography. The purpose of these analyses is to determine the isotopic signature of each of the various phases of calcite cement and to compare lateral variations in selected cement phases down depositional dip.

\section{Analysis of the Lisburne Oil Field}

A representative well from the Lisburne oil field was selected for detailed study. Core plugs from the Wahoo Limestone (at 1-ft intervals) were examined at the Alaska Geologic Materials Storage Facility, and rock chips were cut and sent for thin-section preparation. Negotiations with the owners of the Lisburne oil field progressed, and plans were made to describe cores at ARCO Alaska core warehouse in Anchorage in August 1992. The well-log analysis with the use of the
LOGCALC program was begun with subsurface data obtained from the Alaska Oil and Gas Commission.

\section{Computer Database Development}

A new file containing basic sample information was developed and serves as a hub for comparing sample information contained in separate files on petrography, conodont biostratigraphy, and locality information. In addition, a graphing module was modified to allow plotting of data vs. depth (or other linear variable) on a linear scale. The standard Fourth Dimension graphing allowed data to be plotted with each sample given an equal amount of space regardless of actual sample spacing. This caused data to be portrayed inaccurately where sample spacing was irregular and would not allow large arrays of data (i.e., thick stratigraphic intervals) to be plotted. By plotting data against a linear depth plot, both of these problems can now be avoided, and relatively thick intervals of strata with numerous data points can be plotted without distortions in the depth scale (e.g., Fig. 2).

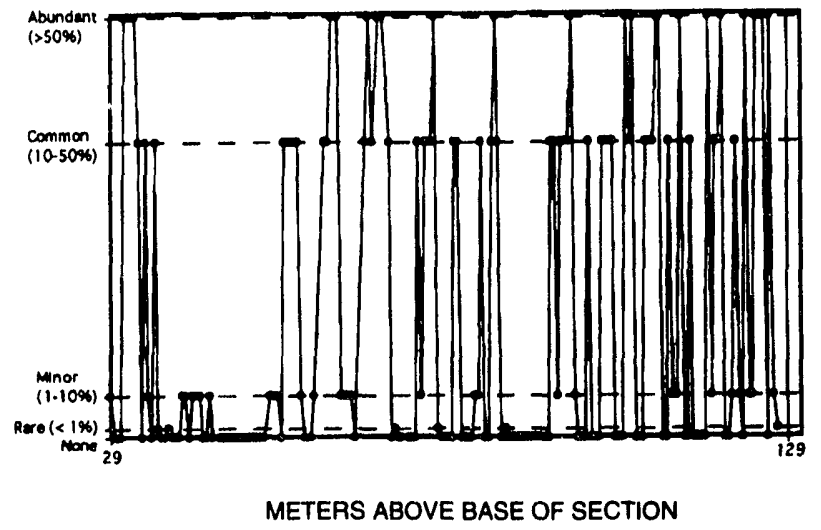

Fig. 2 Plot showing ooid abundance vs. depth for the skeletal-oolitic and shale-based parasequences of the upper Wahoo Limestone at the Shublik Mountains section (locality 10 in Fig. 1 ). Variation in ooid abundance is one of the major factors used to define parasequentes in the upper Wahoo Limestone.

\section{References}

1. W. P. Brosgé, J. T. Dutro, Jr., M. D. Mangus, and H. N. Reiser, Paleozoic Sequence in Eastern Brooks Range, Alaska, Am. Assoc. Pet. Geol., Bull., 46(12): 2174-2198 (1962).

2. K. F. Watts, Analysis of Reservoir Heterogeneities Due to ShallowingUpward Cycles in Carbonate Rocks of the Pennsylvanian Wahoo Limestone of Northeastern Alaska, Second Annual Progress Report for the 1990-1991 Fiscal Year, DOE annual reports, Bartlesville Project Office, 1992. 


\section{USE OF ROCK-TYPING TO CHARACTERIZE CARBONATE RESERVOIR HETEROGENEITY}

\author{
Contract No. DE-AC22-91BC14655
}

Ikwuakolam Energy Company Inc.
Donver, Colo.

Contract Date: Dec. 7, 1990

Anticipated Completion: Oct. 31, 1992

Government Award: $\$ 30,000$

(Current year)

\section{Principal Investigator: Killian C. Ikwuakor \\ Project Manager: \\ Rhonda Lindsey \\ Bartlesville Project Office}

Reporting Period: Apr. 1-June 30, 1992

\section{Objective}

The overall project objective is to apply techniques of "rock-typing" and quantitative formation evaluation to borehole measurements to identify reservoir and nonreservoir rock types and their properties within the " $\mathrm{C}$ " zone of the Ordovician Red River carbonates in the northeast Montana and northwest North Dakota areas of the Williston Basin. Rock-typing discriminates and grades rock units according to their pore-size distribution.

The area of study is T32N-T34N, R56E-R59E, Sheridan County, Montana, and T158N-T160N, R102W-R103W, Williams and Divide counties, North Dakota.

Tasks undertaken during the reporting period include the following:

- Conclusions and recommendations.

- Final report preparation.

\section{Summary of Technical Progress}

\section{Conclusions and Recommendations}

The Ordovician Red River "C" zone carbonates are extremely heterogeneous. The heterogeneity occurs in the following elements: multiple lithologic types, porosity, permeability, pore fluid composition/distribution, lithologic (rock-type) distribution, and depositional environment.

Seven different lithologic types and sixty-four different rock types were identified. Forty-six of the rock types either produce or have the potential to produce oil in different wells. Many rock types that were not reservoir quality in some wells developed reservoir quality in others. Because of this, pore fluid composition was not an important factor in discriminating rock types.
The lithologic types were identified by the first element in the three-element code system of distinguishing rock types. The lithologic types and their associated heterogereities are summarized as follows:

\section{Lithologic code \\ 6 Anhydrites: 1 rock type, tight, widespread. \\ 6 Anhydritic dolomite: tight; low and high porosities; 7 different rock types; 5 rock types calculate favorable water satura- tion in one or more wells. \\ 5 Anhydritic dolomite: tight; low, medium, and high porosities; 13 different rock types; 10 calculate favorable water satu- ration in one or more wells. \\ 4 Dolomite: tight; low, medium, and high porosities; 14 different rock types; 11 calculate favorable water saturation in one or more wells. \\ 3 Dolomitic limestone or calcitic dolomite: tight; low and medium porosities; 12 dif- ferent rock types; 9 calculate favorable water saturation in one or more wells. \\ 2 Limestone: tight; low porosities; 13 dif- ferent rock types; 9 calculate favorable water saturation in one or more wells. \\ 1 Kerogenite, sandstone, or arenaceous lime- stone: tight; very low porosities; 4 dif- ferent rock types, 2 calculate favorable water saturation in one or more wells.}

Detailed interpretation of heterogeneities in the second and third elements of the rock-type code system is beyond the scope of this study. The integration of more rock-typing criteria and petrographic data would be required. It is safe, however, to assume that the heterogeneities observed in porosities, permeabilities, and, possibly, pore fluid composition-distribution are also embedded in those two elements.

The only source of permeability was the one measured in the key well by the well operator, Chevron USA, Inc. Generally, lower permeabilities were associated with lower porosities and higher permeabilities with higher porosities. There were few cases where high-porosity zones had corresponding low permeabilities and vice versa.

In several wells widely separated $z$ nes produce or have the potential to produce oil. This implies the occurrence of multiple oil-water contacts.

Rock typing is an important process for discriminating and quantifying lithologic heterogeneities. Its greatest advantage is that it is economical because it uses routine well logs. Rock typing can be expanded beyond the three rock-typing criteria used in this study. It can include the other rock-typing criteria identified early in the study. Its 
usefulness can be enhanced by integrating the techniques with other disciplines and reservoir characterization techniques. By so doing, a more definitive identification of the most favorable reservoir rock types can be made for enhanced oil recovery $(E O R)$ projects.

For example, by involving quantitative formation evaluation, it was possible to extract more information than if only the results from rock typing were considered in isolation. The techniques applied in the characterization of the Red River "C" zone carbonates can be applied to other carbonate sequences, with perhaps slight modifications in the construction of the Iso-Rock-Property (IRP) lines.

This study is considered regional in scope. Other similar studies should incorporate as much data and as many wells as possible in order to better predict interwell heterogeneities and relationships. Even though the number of wells studied was limited, the positive results from the regional study should lead to more successful field scale studies for EOR modeling and EOR pilot projects.

\section{Final Report Preparation}

Preparation of the first draft of the final report is in progres's.

\section{CHARACTERIZATION AND MODIFICATION OF FLUID CONDUCTIVITY IN HETEROGENEOUS RESERVOIRS TO IMPROVE SWEEP EFFICIENCY}

\section{Contract No. AC22-89BC14474}

\author{
University of Michigan \\ Ann Arbor, Mich.
}

Contract Date: Sept. 26, 1989

Anticipated Completion: Sept. 25, 1992

Government Award: \$112,000

(Current year)

\section{Principal Investigator: \\ H. Scott Fogler}

Project Manager:

Robert Lemmon

Bartlesville Project Office

Reporting Period: Apr. 1-June 30, 1992

\section{Objective}

The objective of this work is to develop effective flowdiverting techniques through experimentation with the use of neutron imaging for flow characterization before and after treatment. Theoretical modeling will be used to identify the important parameters that govern the process of diverting fluids.

\section{Summary of Technical Progress}

In the second quarterly report the three-dimensional (3-D) network model for the simulation of flow, precipitation, and dissolution in a porous medium was described. Some of the features of this model were demonstrated by studying the acidization of limestone with $\mathrm{HCl}$. The results of these simulations indicated that this 3-D network model was capable of describing the flow and reaction of various species in a porous medium. Furthermore, the change of the pore space structure resulting from the dissolutionprecipitation procisses could be represented graphically.

The goal of this project is to quantitatively, as well as graphically, describe the changing reservoir characteristics (i.e., permeability an:i porosity) that occur during diagenesis. The network model will have advantages over continuum models because it will be able to describe the diagenetic processes on a pore level where many important phenomena are occurring. The formation of precipitation waves in a $\mathrm{BaSO}_{4}-\mathrm{CaSO}_{4}$ system is being studied in an effort to verify the model by comparing these results with those obtained by other simulators. ${ }^{1.2}$ Once these simulations are complete, the focus will be on the precipitation and dissolution of minerals more closely associated with the diagenesis process.

The model system planned for these simulations will be simplistic in an effort to more clearly understand some of the important processes that affect the properties of a reservoir. In the initial simulations a uniform matrix that is composed of sandstone in contact with a characteristic formation water will be assumed. No other minerals will be initially present in the matrix, and the reservoir conditions (temperature and pressure) will be uniform. Later runs may begin with a sandstone matrix that has varying amounts of calcite or dolomite. Appropriate solutions will then flow into the sandstone matrix to ensure calcite precipitation in the pores and pore throats. Calcite will be examined because of its prominence as an authigenic material in many types of sandstones (Frio, Plio, and Stevens sandstones). ${ }^{3}$ During successive time steps the amount of calcite that precipitates in the media will be calculated, and then a determination of how this calcite deposition affects the permeability and porosity of the medium will be made. This calcite precipitation will be an accurate representation of the calcite cementing that plays such an integral role in dictating a reservoir's characteristics in many diagenetic systems. Because pore bodies are accounted for in this network model, the porosity determination will be greatly enhanced, which is a significant advantage over other models. Because this network model functions on the pore level, such phenomena as porosity occlusion can also be studied. The inclusion 
of calcite precipitation kinetics will provide another decided advantage over other models given the fact that kinetics can play such an important role in diagenetic reactions such as this. ${ }^{3}$ Once an examination of how calcite deposition affects the permeability and porosity of a simulated porous medium is complete, another solution of different composition will be added into the matrix to ensure the dissolution of the calcite. Again, the features of this model (pore body inclusion and kinetic rate expressions) will aid in providing an accurate description of how the dissolution of calcite from pores and pore throats affects the permeability and secondary porosity (enhanced porosity) of a reservoir. All simulations will graphically show, in three dimensions, the pore and pore throat evolution during the course of diagenesis.

After these initial simulations are complete, systems that contain more than one mineral can be examined. As stated previously, other authigenic minerals, such as dolomite or siderite, can be included in the initial matrix, or the formation water and invading fluid compositions can be set to induce deposition of these minerals in the matrix. With the inclusion of these minerals, precipitation waves may be attained with representative diagenetic materials. Dolomite dissolution, which is reaction-rate limited below $323 \mathrm{~K}$, whereas calcite dissolution is often mass-transfer limited, can provide these characteristic precipitation waves by varying the invading fluid flow rates. ${ }^{4}$ Another important parameter that will be examined is the temperature of the matrix under study. The temperature effects will be incorporated by changing the appropriate kinetic parameters of precipitation and dissolution. In the case of calcite, different temperatures will affect the resulting deposition regime. ${ }^{5}$ By comparing simulations at different temperatures, an examination of how reservoir temperatures affect the resulting permeability and porosity changes can be made. In addition, an attempt will be made to incorporate a dual-zone matrix with each zone having a different temperature. With these experiments the effect that upward flow in a formation caused by compaction (accompanied by a temperature gradient) has on the permeability and porosity of a formation will be examined.

\section{References}

1. D. A. Aliaga, G. Wu, L. W. Lake, and M. M. Sharma, Barium and Calcium Sulfate Precipitation, Dissolution, and Migration Inside Sandpacks, paper SPE 19765 presented in San Antonio, Tex., 1989.

2. M. P. Walsh, S. L. Bryant, R. S. Schechter, and L. W. Lake, Precipitation and Dissolution of Solids Attending Flow Through Porous Media, A.I.Ch.E., 30(2): 317-328 (1984).

3. R. C. Surdan, L. J. Crossey, E. S. Hagen, and H. P. Heasler, OrganicInorganic Interactions and Sandstone Diagenesis, Am. Assoc. Pet. Geol., Bull., 73(1): 1-23 (1989).

4. M. L. Hoefner, Matrix Acidizing in Carbonates Using Microemulsions: The Study of Flow, Dissolution, and Channeling in Porous Media, Ph.D. Thesis, University of Michigan, 1987.

5. G. L. Yoder, The Deposition of Calcium-Carbonate in Geothermal Systems, Ph.D. Thesis, Princeton University, 1985. 


\section{RESOURCE ASSESSMENT TECHNOLOGY}

\section{CHARACTERIZATION OF THE \\ GRAVITY DRAINAGE PHENOMENA \\ THROUGH NUMERICAL AND \\ PHYSICAL SIMULATION}

Contract No. DIE-AC22-908C14472

Western Résearch Institute

Laramie, Wyo.

Contract Date: Jan. 1, 1990

Anticipated Completion: Oct. 30, 1992

Government Award: \$299,986

Principal Investigator:

Lyle A. Johnson

Project Manager:

Jerry Ham

Metairie Site Office

Reporting Period: Apr. 1-June 30, 199:

\section{Objective}

The objective of this project is to provide a predictive model for the gravity drainage mechanism and to verify the model by performing one-dimensional (1-D) and three- dimensional (3-D) physical simulations. The model will be used to evaluate well pattern geometries on gravity drainage flow patterns and the effects of natural fracture orientations of these systems. The predicted production rates from these models will aid in the evaluation of infill drilling and the use of horizontal, slant, or vertical wells and in oil mining.

\section{Summary of Technical Progress}

An extensive review of the gravity drainage and associated moving boundary problem literature was conducted. The gravity drainage phenomena is characterized by the fact that part of the boundary defining the fluid system is a free surface. A conceptual model based on previous experience and the literature review was developed for the gravity drainage mechanism. The gravity drainage is best described by consideration of two-phase flow (oil and water or gas). On the basis of the model review, the model development was approached in three phases. First, an implicitly solved 1-D fixed- $\varepsilon$-id two-phase transient model was developed with validation by the 1-D tube test data. Sesond, the model was extended to three dimensions and three phases. Finally, the model wis validated by the results of the physical simulations and was also compared with the results of a proprietary commercial model. The final product will be a fully documented numerical model to predict the gravity drainage phenomena. All modeling tasks are complete, and 
documentation of the model is under way. The simulator was modified to produce the 3-D numerical simulator.

All eight 1-D tubes and the five 3-D simulations are complete. The tests were analyzed and the results were used for the validation of the numerical simulator.

A no-cost time extension for this contract was requested and approved for a total of three extensions. The time extensions were requested to permit completion of the model validation caused by the extended length of the production period in the physical simulations and problems with the operational proficiency of the numerical simulator. The contractor desires to provide a quality numerical simulator to the Department of Energy. The last time extension changed the completion date to October 30; 1992.

During the last quarter problems with the operation speed of the simulator were corrected, and history matching of gravity drainage data in the published literature has shown excellent results.

\section{NATURAL. RESOURCES INFORMATION SYSTEM FOR THE STATE OF OKLAHOMA}

Contract No. DE-FG22-89BC14483

\author{
Oklahoma Geological Survey \\ University of Oklahoma \\ Norman, Okla.
}

Contract Date: June 22, 1989

Anticipated Completion: June 21, 1992

Government Award: $\mathbf{\$ 2 5 8 , 9 5 1}$

(Current year)

\section{Principal Investigator: \\ Charles J. Mankin}

Project Manager:
R. Michael Ray
Bartlesville Project Office

Reporting Period: Apr. 1-June 30, 1992

\section{Objective}

The objective of this research program is to continue developing, editing, maintaining, using, and making publicly available the Natural Resources Information System (NRIS) for the state of Oklahoma. This contract funds the ongoing development work that began with contract No. DE-FG19-88BC14233. The Oklahoma Geological Survey (OGS), working with Geological Information Systems at the University of (Oklahoma Sarkeys Energy Center, has undertaken to construct this information system in response to the need for a computerized, centrally located library containing accurate, detailed information on the state's natural resources. Particular emphasis during this phase of development is being placed on computerizing information related to the energy needs of the nation, specifically oil and gas.

\section{Summary of Technical Progress}

\section{The Oil and Gas Production Subsystem}

The Oil and Gas Production (OGP) subsystem is composed of three major files: a Lease File, a Field File, and a County File. The Lease File contains production and formation records based on data obtained from the Oklahoma Tax Commission (OTC); data elements include lease name and number, location information, formations data, and monthly production totals. The Field File contains historical and current records for all 5130 active and inactive Oklahoma oil and gas fields, as identified by the Oklahoma Nomenclature Committee (ONC); data elements include field identification data, consolidation histories when relevant, discovery data, location information, and monthly production aggregated (by location) from the records maintained on the Lease File. The County File has monthly oil and gas production data aggregated by county.

Processing for the OGP subsystem primarily consists of processing monthly computer tapes received from the OTC to update production totals for all three files and to add new records to the Lease Master File. At the beginning of the quarter, monthly production was on file for the period January 1979 to December 1991. New records for the Field Master File are added by manually coding and keying the results of ONC meetings. The Lease and Field Master Files are reconciled through combined computerized and manual efforts.

A primary thrust for the OGP subsystem must be the enhancement of the files through ongoing quality assurance (QA) efforts. Although the estimated error rate in the production input tapes received from the Tax Commission is low, the sheer volume of data processed from these tapes creates many errors on the Lease File. One result of the errors in the OTC source tapes is the significant number of production records that are added to the file with invalid "Producing Unit Numbers" (PUNs), commonly called "nomaster" records. A series of computerized and manual processes was developed to research company reporting patterns as part of the effort to allocate the no-master production to the appropriate leases. Significant efforts also are required to detect and resolve cases in which a monthly production total is unreasonably large for a lease; these usually are caused by decimal problems in the production reports or by the allocation of production to the wrong lease.

The January to February 1992 source data received frotn the OTC were added to the OGP subsystem files. The 
January 1979 to December 1982 production data are now available to the public. Although there are still data problems in those years, most of the significant ones have heen resolved; this allows the July 1992 data release to include production histories back to 1979.

Approximately $1.435,000$ records, which represent over 144.000) unique PUNs, are on the Lease File. About 105,000 of these PUNs have had production reported sometime from 1979 to 1992, and about 70,000 of them report 1990, 1991, and/or 1992 production.

Table 1 is an overview of the progress and current status of production data QA efforts by region and county. Production QA was emphasized during this quarter, including efforts on the 1979 to 1982 data. At the end of June, a total of 9,148 no-master records from 1983-1991 had been resolved since the beginning of the grant; 9,072 had been added from OTC tapes and 8,385 remained on file. Since production QA efforts hegan in October 1988 , over 88,000 transactions have been generated to correct 1983-1991 nomaster and other types of production data problems. With the addition of the 1979-1982 data to the file, 4,383 additional no-master records also have been identified; of these, only the very large data problems are under review, and 4,333 remain at the end of this quarter. The bar chart in Fig. 1 provides more perspective on the no-master resolution rates. For the data years 1983 to 1989 , progress has been made on reducing the number of no-master records. For 1990 and 1991, there continues to be a large number of no-master records, and new problems are added by each monthly OTC tape. Current efforts include an emphasis to correct the remaining problems in the 1983 to 1986 data. Very few changes come through from the OTC for these years, but the problems that do remain tend to be difficult, and their resolution rate is fairly slow.

\section{TABLE 1}

Progress and Current Status of Production Quality Assurance Efforts Progress Summary (May 1989-June 1992)

\begin{tabular}{|c|c|c|c|c|c|c|c|c|c|c|c|c|c|}
\hline & \multicolumn{4}{|c|}{ Counts of "no-master" records 1983-1991 } & \multirow{2}{*}{$\begin{array}{l}\text { Cumulative } \\
\text { quality } \\
\text { assurance } \\
\text { transactions } \\
\text { since } \\
\text { October } 1988\end{array}$} & \multirow[b]{2}{*}{$\begin{array}{c}\text { Number of } \\
\text { no-master } \\
\text { records } \\
1979 \text { to } 1982\end{array}$} & & \multicolumn{4}{|c|}{ Counts of "no-master" records 1983-1991 } & \multirow{2}{*}{$\begin{array}{c}\text { Cumulative } \\
\text { quality } \\
\text { assurance } \\
\text { transactions } \\
\text { since } \\
\text { October } 1988\end{array}$} & \multirow[b]{2}{*}{$\begin{array}{c}\text { Number of } \\
\text { no-master } \\
\text { records } \\
1979 \text { to } 1982\end{array}$} \\
\hline & $\begin{array}{c}\text { Starting } \\
\text { total, } \\
\text { May } 1989\end{array}$ & $\begin{array}{l}\text { Number added } \\
\text { from OTC tapes, } \\
\text { February } 1989- \\
\text { February } 1992\end{array}$ & $\begin{array}{l}\text { Number } \\
\text { resolved }\end{array}$ & $\begin{array}{l}\text { Ending } \\
\text { total } \\
\text { June } \\
1992\end{array}$ & & & & $\begin{array}{c}\text { Starting } \\
\text { total, } \\
\text { May 1989 }\end{array}$ & $\begin{array}{l}\text { Number added } \\
\text { from OTC tapes, } \\
\text { February } 1989- \\
\text { February } 1992\end{array}$ & $\begin{array}{l}\text { Number } \\
\text { resolved }\end{array}$ & $\begin{array}{c}\text { Ending } \\
\text { total } \\
\text { June } \\
1992\end{array}$ & & \\
\hline $\begin{array}{l}\text { North central } \\
(4)^{4} \text { Garfield }\end{array}$ & 292 & 160 & 207 & 245 & 5,6018 & 170 & $\begin{array}{l}\text { Southeast } \\
\text { 005 Atoka }\end{array}$ & 4 & 14 & 13 & 5 & 40 & 2 \\
\hline 053 Grant & 154 & 67 & 84 & 1.37 & 2,530 & 39 & 013 Bryan & 14 & $\begin{array}{r}14 \\
4\end{array}$ & $\begin{array}{r}1,1 \\
9\end{array}$ & 9 & $\begin{array}{l}40 \\
76\end{array}$ & $\begin{array}{r}2 \\
17\end{array}$ \\
\hline 07! Kay & 114 & 195 & 18.3 & 126 & 1.351 & 53 & 023 Choctaw & 0 & 0 & 0 & 0 & 0 & 2 \\
\hline 073 Kingfisher & 331 & 226 & 262 & 295 & 3.769 & 298 & (027 Cleveland & 52 & 42 & 56 & 38 & 309 & 20 \\
\hline (88) Lincoln & 123 & 133 & 89 & 167 & 384 & 86 & 029 Coal & 17 & 27 & 26 & 18 & 260 & 8 \\
\hline 083 Logan & $|4|$ & 135 & 103 & 173 & 691 & 140 & 049 Garvin & 246 & 148 & 199 & 195 & 1.917 & 120 \\
\hline 10,3 Noble & 145 & 6.3 & 95 & 113 & 640 & 52 & ()6I Haskell & 108 & 131 & 137 & 102 & 1.800 & 8 \\
\hline 109 Oklahoma & 302 & 140 & 203 & 239 & 1,894 & 61 & O6.3 Hughes & 160 & 168 & 186 & 142 & 916 & 75 \\
\hline 119 Payne & 106 & 100 & 95 & 111 & 491 & 8.3 & O69 Johnston & 1 & 1 & 2 & 0 & 5 & 2 \\
\hline & & & & & & & 077 Latimer & 148 & 26.3 & 222 & 189 & 1,991 & 13 \\
\hline Region subtotal & 1,708 & 1,219 & 1,321 & 1,606 & 17,358 & 982 & 079 Le Flore & 84 & 179 & 91 & 172 & 1.475 & 5 \\
\hline Northeast & & & & & & & 087 McClain & 133 & 77 & 93 & 117 & 467 & 51 \\
\hline Dol Adair & 2 & 16 & 10 & 8 & 26 & 6 & .089 McCurtain & 0 & 1 & 1 & 0 & 5 & 3 \\
\hline 021 Cherokee & 0 & 4 & 3 & $i$ & 16 & 0 & 091 McIntosh & 45 & 15 & 44 & 16 & 456 & 7 \\
\hline 035 Craig & 3 & 4 & 4 & 3 & 9 & 6 & ()95 Marshall & 25 & 18 & 29 & 14 & 378 & 40 \\
\hline 0.37 Creek & 264 & 165 & 327 & 102 & 1,912 & 105 & (499 Murray & 28 & 17 & 28 & 17 & 126 & 8 \\
\hline (4) Delaware & 0 & 1 & 1 & 0 & $\begin{array}{r}1,912 \\
8\end{array}$ & 0 & 121 Pittsburg & 197 & 400 & 264 & 333 & 2,462 & 20 \\
\hline 097 Mayes & 1 & 2 & 1 & 2 & 6 & 0 & 123 Pontotoc & 61 & 71 & 68 & 64 & 1,558 & 40 \\
\hline 101 Muskugee & 64 & 26 & 77 & 13 & 440 & 30 & 125 Pottawatomic & 105 & 108 & 116 & 97 & 700 & 61 \\
\hline IUS Nowata & 60 & 25 & 76 & 9 & 334 & 40 & 127 Pushmataha & 1 & 0 & 1 & 0 & 2 & 7 \\
\hline 107 Okfuskec & 120 & 64 & 152 & 32 & $\begin{array}{r}., 34 \\
1.082\end{array}$ & 64 & 133 Seminole & 106 & 66 & 76 & 96 & 560 & 80 \\
\hline III Okmulgee & 170 & 90 & 198 & 62 & 2,872 & 124 & Region subtotal & 1.535 & $\overline{1.750}$ & 1,661 & 1.624 & $\overline{15.503}$ & $\overline{589}$ \\
\hline $1130 \mathrm{Oage}$ & 115 & 85 & 148 & 52 & 1.542 & 127 & & & & & & & \\
\hline 115 Ottawa & I & 2 & 2 & 1 & 2 & 1 & Southwest & & & & & & \\
\hline 117 Pawnec & 160 & 158 & 294 & 24 & 1.521 & 41 & (x)9 Beckham & 139 & 206 & 156 & 189 & 1.156 & 81 \\
\hline 1.31 Rogers & 50) & 30 & 73 & 7 & 264 & 12 & OII Blaine & 133 & 1.59 & 93 & 199 & 1.641 & 45 \\
\hline 135 Sequoyah & 12 & 17 & 22 & 7 & 155 & 6 & ols Caddo & 268 & 3.54 & 264 & 338 & 2,499 & 79 \\
\hline 143 Tulsa & 72 & .39 & 97 & 14 & 686 & 51 & 017 Canadian & 264 & 219 & 309 & 174 & 4,122 & 212 \\
\hline 145 Wagoner & 47 & 27 & 57 & 17 & 291 & 3 & 019 Carter & 215 & 26.3 & 2.39 & 239 & 1.550 & 224 \\
\hline 147 Washington & 76 & 51 & 82 & 45 & 486 & 29 & 0.31 Comanche & 38 & 30 & 47 & 21 & 559 & 15 \\
\hline & & & & & & & 033 Cotton & 21 & 29 & 37 & 13 & 148 & 37 \\
\hline Region subtotal & 1.217 & 806 & 1.624 & 399 & 11,646 & 645 & 039 Custer & 234 & 34.3 & 327 & 250 & 2,493 & 66 \\
\hline Nothwest & & & & & & & 051 Grady & 284 & 417 & 301 & $4(x)$ & 2,530 & 71 \\
\hline (x), Alfalfa & 162 & 88 & 192 & 58 & 2,689 & 99 & 055 Greer & 57 & 59 & 96 & 20 & 383 & 22 \\
\hline o07 Beaver & 319 & 382 & 268 & 433 & 2.782 & 175 & 057 Harmon & 0 & 2 & 1 & 1 & 2 & 0 \\
\hline 025 Cimarron & 37 & 49 & 41 & 45 & 318 & 23 & 065 Jackson & 2 & $i$ & 2 & $i$ & 8 & 0 \\
\hline (4.3 Dewey & 157 & $(9)$ & 176 & 171 & 1,360 & 99 & 067 Jefferson & 34 & 14 & 4.3 & 5 & 179 & 6 \\
\hline (4.5 lillis & 144 & 181 & 142 & 183 & 851 & 37 & 075 Kiowa & 17 & 19 & 6 & 30 & 36 & 4 \\
\hline 0554 Harper & 254 & 369 & 278 & 345 & 2,486 & 58 & 085 Love & 82 & 37 & 95 & 24 & 682 & 51 \\
\hline (火) 3 Мајor & 334 & 317 & 329 & 312 & 5,346 & 193 & 129 Roger Mills & 184 & 498 & 350 & .332 & $2,8.34$ & 52 \\
\hline 139 Texas & 185 & 388 & 291 & 282 & 2,647 & 8.3 & 137 Stcphens & 181 & 279 & 147 & 313 & 2,028 & 158 \\
\hline 151 Werkls & 72 & 1.58 & $8 k$ & 142 & 861 & 143 & 141 Tillman & 3 & 1 & 2 & 2 & 7 & 0 \\
\hline 153 Wockward & 95 & 14.3 & 105 & 133 & 656 & 41 & 149 Washita & 86 & 112 & 97 & 101 & 98.5 & 43 \\
\hline \multirow[t]{2}{*}{ Region subtotal } & 1.759 & 2.255 & 1.910 & 2,104 & 19,496 & 951 & Region subtotal & 2.242 & 3.042 & 2.6 .32 & $2,6.52$ & 23,842 & 1.166 \\
\hline & & & & & & & Grand total & 8,461 & 9,072 & 9.148 & 8,385 & 88,345 & 4,333 \\
\hline
\end{tabular}




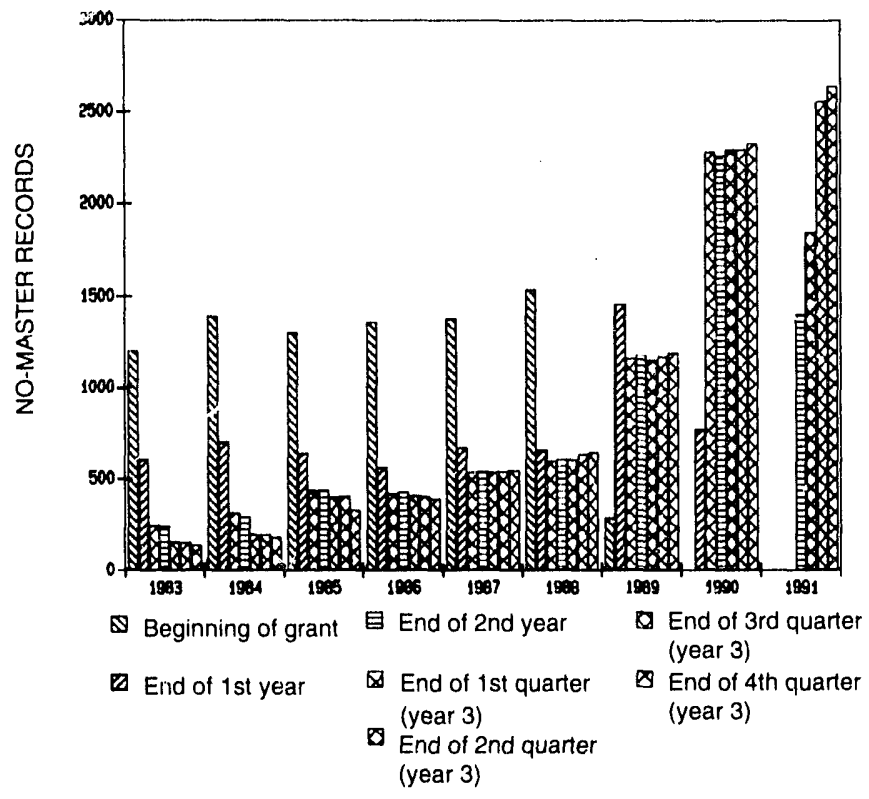

Fig. 1 Change in the no-master record totals.

A second goal of the OGP subsystem work involves efforts to "assign" leases and wells to fields and derive field production totals from these lease assignments. (Lease and well assignments are based on the official field outlines as designared by the Midcontinent Oil and Gas Association's ONC and documented in the "Blue Sheets" released by that committee.) Some areas exist in which significant field extension drilling has taken place, but the ONC has had insufficient resources to update the field boundaries accordingly; therefore, at the beginning of 1990, almost $25 \%$ of the state's production was not allocated to any field(s) in the OGP subsystem.

Information packages for selected areas are produced from the NRIS data to assist the ONC in updating their field outlines. On the basis of this input, the Committee set a goal of first updating all gas-field boundaries and then emphasizing the oil-field boundaries. Considerable progress has been made in this area, and the efforts are continuing. Table 2 provides more detailed information about the current status of unassigned production by region and county. During this quarter the Committee has continued to focus on Texas County. A package was also prepared on adjoining Beaver County, and Committee review efforts have begun for that county. As previously reported, this is a particularly difficult area because of the large number of overlapping field areas (e.g., oil fields, the Guymon Hugoton and Mocane-Laverne gas areas, and other gas fields and areas). Overall, during this quarter unassigned gas production remains at $14 \%$ of the annual average production.

Quality assurance efforts regarding the producing formativins data comprise a third area of emphasis. During this quarter further applications were developed to test a system of Producing Interval Codes for analyses of production by formation. The goal is to have production by producing interval in selected areas available to the public in the very near future.

Progress was also made on a fourth goal (mapping applications development). The OGS's Gas Atlas project is still providing a major impetus for the generation of a variety of mapping applications. Several applications were developed with the NRIS data with GeoGraphix mapping software, and arrangements were finalized with Radian Corporation to obtain a donated copy of their CPS/PC contour mapping software.

\section{The Well History File}

The Well History File contains historical and current completion records for oil and gas wells reported to the Oklahoma Corporation Commission on Form 1002-A. At the start of the quarter, the Well History File contained 232,022 records for the southern and western halves of Oklahoma. Data elements on this file include demographic items (e.g., API well number, lease name and well number, location information, elevations, and dates of significant activities for the well), formation items (e.g., formation names, completion and test data, depths, and perforations), and reference :nformation (e.g., for drilling samples, core samples, and well logs).

In addition to the standard Well History File processing, special projects are being undertaken to add supplemental data to the file from well logs, scout tickets, and core and sample documentation. Work continued on a parallel track within the NRIS Project to organize and computerize information from the OGS Core and Sample Library and from the Ardmore Sample Cut Library. Through computer and manual reconciliation processes, relevant data are being added to the Well History File. As other data sources become available, they will be reviewed as a cost-effective means to add supplemental information to the well records.

A large portion of the Well History File work involves photocopying the completion reports for use in coding before data entry. All new completion reports are copied as soon as they are received from the Oklahoma Corporation Commission; the originals are filed in the OGS's Well Log Library. Completion reports for areas of the state that have already been (or are being) "worked" are entered into the processing stream immediately. All others are filed for processing at the appropriate times. The historical completion reports are checked out of the Well Log Library and copied at a rate determined by priorities; over 290,000 completion reports have now been copied.

Processing of the Oklahoma Corporation Commission's oil and gas well completion reports (Form 1002-A) is proceeding smoothly. Some student workload interruptions were experienced in May following the Spring semester because new students had to be hired and trained. As previously reported, however, the streamlining of procedures and the general stabilization of staffing have minimized the disruptions from these turnovers. 
TABLE 2

Unassigned Production* by Region and County

\begin{tabular}{|c|c|c|c|c|c|c|c|c|c|c|c|c|c|}
\hline & \multicolumn{3}{|c|}{$\begin{array}{l}\text { Gas production (annual } \\
\text { average), } \uparrow \mathrm{MmcI}\end{array}$} & \multicolumn{3}{|c|}{$\begin{array}{l}\text { Liquids production (annual } \\
\text { average), } \uparrow \text { Mbbls }\end{array}$} & & \multicolumn{3}{|c|}{$\begin{array}{l}\text { Gas production (annual } \\
\text { average), } t \text { Mmef }\end{array}$} & \multicolumn{3}{|c|}{$\begin{array}{l}\text { Liquids production (annual } \\
\text { average), } \uparrow \text { Mbbls }\end{array}$} \\
\hline & Total & Unassigned & Percent & Total & Unassigned & Percent & & Total & Unassigned & Percent & Total & Unassigned & Percent \\
\hline North central & & & & & & & Southeast & & & & & & \\
\hline 047 Garfield & 47.240 & 6.864 & 15 & 2,464 & 407 & 17 & 005 Aloka & 1.182 & 4 & 0 & 2 & 0 & 0 \\
\hline 05.3 Granı & 14,350 & 9,578 & 67 & 2,516 & 1.510 & 60 & 013 Bryan & 1.741 & 3 & 0 & 98 & 0 & 0 \\
\hline 071 Kay & 3,011 & 254 & 8 & 1,381 & 98 & 7 & 023 Choctaw & (2) & (2) & 0 & 0 & 0 & 0 \\
\hline 073 Kingfisher & 59,907 & 19,669 & 33 & 4,050 & 1.015 & 25 & 027 Cleveland & 5,863 & 2.604 & 44 & 2,072 & 732 & 35 \\
\hline 081 Lincoln & 10,230 & 5,860 & 57 & 1.444 & 507 & 35 & 029 Coal & 4,771 & 89 & 2 & 186 & 1 & 0 \\
\hline 083 Logan & 18,701 & 6.694 & 36 & 1,901 & 676 & 36 & 049 Garvin & 45,600 & 6,203 & 14 & 6,585 & 1,084 & 16 \\
\hline 10.3 Noble & 8,708 & 3,029 & 35 & 2,994 & 968 & 32 & 061 Haskell & 38,064 & 188 & 0 & 0 & 0 & 0 \\
\hline 109 Oklahoma & 25,368 & 12,925 & 51 & 3.407 & 1,188 & 35 & 063 Hughes & 13,135 & $5,32.3$ & 41 & 1,140 & 467 & $4 i$ \\
\hline 119 Payne & 4.643 & 1,076 & 23 & 1,908 & 420 & 22 & O69 Johnston & 7 & 0 & 0 & 0 & 0 & 100 \\
\hline & & & & & & & 077 Latimer & 105,280 & 2,295 & 2 & 0 & 0 & 0 \\
\hline Region subtotal & 192.158 & 65,950 & 34 & 22.066 & 6,788 & 31 & 079 Le Flore & 23,479 & 546 & 2 & 0 & 0 & $\mathbf{0}$ \\
\hline Northeast & & & & & & & 087 McClain & 23,474 & 4,984 & 21 & 3.401 & 1.123 & 33 \\
\hline (O)I Adair & 0 & ) & 0 & 0 & 0 & 0 & 089 McCurtain & 0 & 0 & 0 & 0 & 0 & 0 \\
\hline 021 Cherokee & 0 & 0 & 0 & 0 & 0 & 0 & 091 McIntosh & 7,388 & 2.616 & 35 & 5 & 4 & 85 \\
\hline 03.5 Craig & 26 & is & 59 & 7 & 5 & 74 & 095 Marshall & 5,964 & 87 & 1 & 370 & 3 & 1 \\
\hline 0.37 Creek & 7.355 & 2,620 & 36 & 5.426 & 729 & 13 & 099 Murray & 475 & 40 & 8 & 1,542 & 499 & 32 \\
\hline (097 Mayes & 2 & 2 & 100 & 30 & 30 & 100 & 121 Pittsburg & 72,183 & 1,719 & 2 & 0 & 0 & 50 \\
\hline 101 Muskogee & 1.241 & 722 & 58 & 272 & 42 & 15 & 123 Pontotoc & 1,152 & 79 & 7 & 4,329 & 48 & 1 \\
\hline 105 Nowata & 658 & 335 & 51 & 491 & 119 & 24 & 125 Pottawatomie & 6,232 & 558 & 9 & 4,088 & 603 & 15 \\
\hline 107 Okfuskee & 5,913 & 2.850 & 48 & 1.010 & 407 & 40 & 127 Pushmataha & 0 & 0 & $\mathbf{0}$ & 0 & 0 & 0 \\
\hline III Okmulgee & 6.078 & 1.579 & 26 & 1.263 & 273 & 22 & 133 Seminole & 3.459 & 1.156 & 33 & 4,062 & 606 & 15 \\
\hline 113 Osage & 7.458 & 2.842 & 38 & 7.579 & 1,142 & 15 & & & & - & & & \\
\hline 115 Oltawa & 0 & 0 & 0 & 1 & 1 & 100 & Region subtotal & 359.446 & 28,492 & 8 & 27.883 & 5,169 & 19 \\
\hline 117 Pawnee & 6.489 & 5.167 & 80 & 2,337 & 1,513 & 65 & Snuthwest & & & & & & \\
\hline 131 Rogers & 335 & 311 & 93 & 138 & 73 & 53 & 009 Beckham & 82.160 & 3.204 & 4 & 1,051 & 70 & 7 \\
\hline 135 Sequoyah & 3.962 & 964 & 24 & 0 & 0 & 0 & & 89,740 & 13.888 & 15 & 1,171 & 421 & 36 \\
\hline 14.3 Tulsa & 1.249 & 381 & 31 & 797 & 67 & 8 & 015 Caddo & 100,387 & 1,458 & 1 & 3,862 & 173 & 4 \\
\hline 145 Wagoner & 654 & 389 & 60 & 265 & 109 & 41 & 017 Canadian & 104.263 & 41,240 & 40 & 2,650 & 1.707 & 64 \\
\hline 147 Washington & 1,009 & 523 & 52 & 770 & 59 & 8 & 019 Canter & 18,711 & 4,867 & 26 & 13,973 & 1,178 & 8 \\
\hline Region subıntal & 42.429 & 18.699 & 44 & $\approx 1,386$ & 4,568 & 22 & 031 Comanche & 8,898 & 3,203 & 36 & 286 & 184 & 64 \\
\hline & 42,429 & 10,093 & 4 & -10.500 & $4, .600$ & 22 & 033 Cotton & 211 & 53 & 25 & 373 & 50 & 14 \\
\hline Northwest & & & & & & & 039 Custer & 124.358 & 950 & 1 & 2,181 & 14 & 1 \\
\hline (10)3 Alfalfa & 14.147 & 920 & 7 & 951 & 119 & 12 & 05/ Grady & 109,663 & 5,052 & 5 & 6,803 & 221 & 3 \\
\hline 007 Beaver & 85,438 & 26.939 & 32 & 2,769 & 1,240 & 45 & oss Greer & 260 & 53 & 21 & 14 & 2 & 15 \\
\hline 025 Cimarron & 11.457 & 3,614 & 32 & 572 & 319 & 56 & 057 Harmon & 0 & 0 & 0 & 62 & 0 & 0 \\
\hline (44.3 Dewey & 62.509 & 9.527 & 15 & 2,299 & 812 & 35 & 065 Jackson & 0 & 0 & 0 & 91 & 20 & 22 \\
\hline 045 Ellis & 35.151 & 2.363 & 7 & 1.055 & 162 & 15 & 067 Jefferson & 321 & 273 & 85 & 952 & 633 & 66 \\
\hline 059 Harper & 52.415 & 7,079 & 14 & 399 & 165 & 41 & 075 Kiowa & 240 & 33 & 14 & 100 & 38 & 38 \\
\hline 093 Major & 84.362 & 15.185 & 18 & 3,972 & 99.3 & 25 & 085 Love & 4,062 & 1,232 & 30 & 1.510 & 1,005 & 67 \\
\hline 139 Texas & 103,865 & 5.690 & 5 & 3.666 & 185 & 5 & 129 Roger Mills & 151.354 & 3.582 & 2 & 1.111 & 95 & 9 \\
\hline 151 Woods & 28,514 & 627 & 2 & 543 & 7 & 1 & 13) Stephens & 42,722 & 7,692 & 18 & 10,869 & 769 & 7 \\
\hline 153 Woodward & 31.188 & 753 & 2 & 438 & 22 & 5 & 141 Tillman & 0 & 0 & 0 & 124 & 73 & 59 \\
\hline \multirow{3}{*}{ Region subtotal } & 509.045 & 72.697 & 14 & 16,664 & 4,022 & 24 & 149 Washita & $61, i r$ & 487 & 1 & 723 & 3 & 0 \\
\hline & & & & & & & Region subtotal & 899.113 & 87,267 & 10 & 47,907 & 6,655 & 14 \\
\hline & & & & & & & Grand total & $2,002,192$ & 273,106 & 14 & 134,906 & 27,203 & 20 \\
\hline
\end{tabular}

*Production nol assigned to any field

† Annual averages based on January 1983-February 1992 production 'us of 06/30/92).

Well records are being prescanned, keyed, and edited for the following counties in north central and northeastern Oklahoma: Creek, Lincoln, Payne, Tulsa, and Wagoner. More than 18,000 well records were added to the file this quarter; thus 250,432 records were on file as of June 1992. The Well History File progress by NRIS Regional Division is shown in Table 3. The current status of county coverage and the total record counts by county are shown in Figs. 2 and 3 , respectively.

As proposed, the project staff has fully met the NRIS goal of adding 250,000 well records to the file by the end of this grart cycle (June 21, 1992). Revised estimates show that the total well record count expected for Oklahoma is 400,000 ; the steps taken to ensure that the project continues until complete state coverage is achieved resulted in another DOE contract to continue building the NRIS Well History File over the next 2 yr.
Both general and specialized edit procedures continued on the well data. Search strategies are used to research well records with incorrect township/range/section or county location data and well records that should be cross-referenced. OTC lease numbers are being assigned to well records through a combined machine and manual matching process between the Lease and Well Files. This process is complete for the following counties: Latimer, LeFlore, Haskell, McCurtain, McIntosh, and Pushmataha. A statewide Lease/Well File match was used to identify sections with significant discrepancies in the lease and well counts. Efforts to locate the missing 1002-A forms for the identified areas resulted in the addition of approximately 800 missing records. The search was facilitated by cooperation from NRIS users and from Sooner Well Log Service, located in Oklahoma City, which has an extensive, well-organized hard-copy collection of completion reports available for research at reasonable cost. 
TABLE 3

Well History File Progress by NRIS Regional Division

\begin{tabular}{|c|c|c|c|}
\hline Area of coverage & Start of contract & Start of quarter & Current \\
\hline Southeast region & 27,385 & 65,712 & 65,820 \\
\hline Southwest region & 9,284 & 69,453 & 69,785 \\
\hline Northeast region & 6,768 & 23,467 & 37,228 \\
\hline Northwest region & 4,735 & 32,507 & 32,543 \\
\hline North central region & 138 & 40,883 & 45,056 \\
\hline Total & 48,310 & 232,022 & 250,432 \\
\hline
\end{tabular}

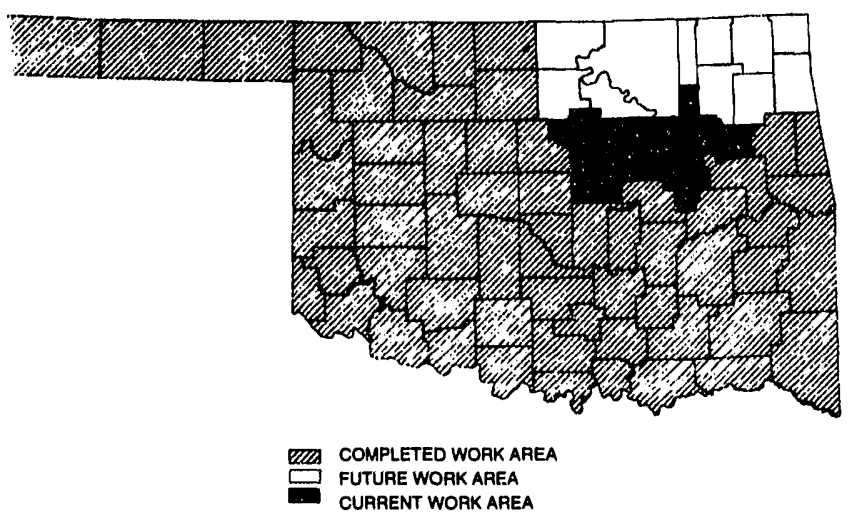

Fig. 2 Status of well history database project county coverage.

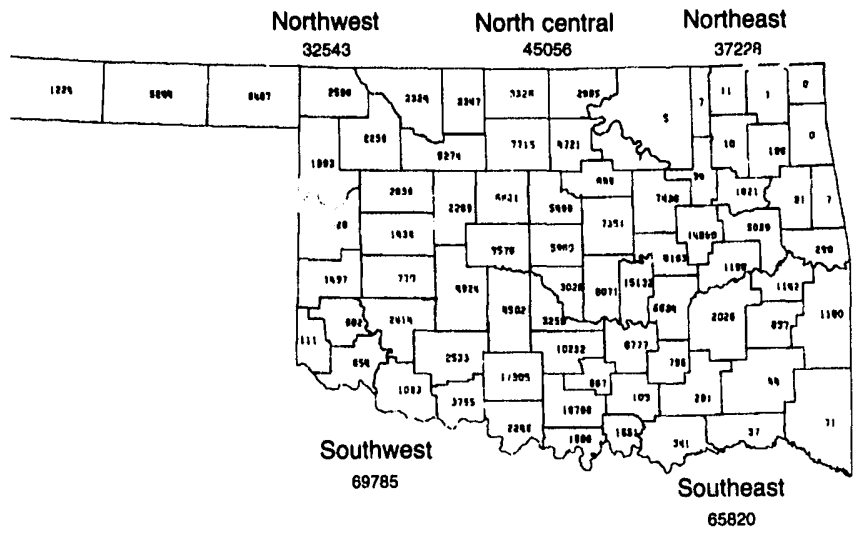

Fig. 3 Status of well history database project. Total well records, 250,432 .

Further efforts continued this quarter on a system for standardizing the formation names on the Well History File. This PC-based program uses a conversion table to standardize spellings and allows the user to interactively build new entries for the conversion table as new spelling variations are encountered. Over 28,500 entries are now in this table. In the southeast and southwest regions, over $98 \%$ of the 609,848 reported names have been standardized in this effort. Efforts in the coming quarter will result in similar rates for northern areas. This formations-editing process is further enhanced by the addition of a table to determine the standard "Franklinized" abbreviation for each reported name following the convention with which industry users are familiar.

Special efforts were also undertaken this quarter to prepare for the July data release of the file. The basic wellidentification data records and all remaining record types (with supporting documentation) as well as data updates were processed in preparation for next quarter's data release to Well History File subscribers.

\section{Public Data Release}

Since early 1991 efforts have been made to disseminate NRIS information through meetings, workshops, OGS annual reports, and mass mailings to numerous individuals, companies, and organizations. As a result, a dramatic response to the release of NRIS data began last summer and has continued. Feedback from the public reflects a great deal of excitement about this new resource for the oil and gas industry in Oklahoma. Data and analyses have been provided that would not have been feasible before construction of the NRIS system.

The NRIS well data have been made available through the Oklahoma City Geological Society Library with very positive results. The high level of interest by library members has led to their acquisition of nearly 125,000 records as well as to constructive feedback on data anomalies they have detected.

Three companies subscribe to the Well History File, and large data orders received from two other companies will likeiy result in additional subscriptions. Typically, small companiss and independents are acquiring NRIS subsets to evaluate $w^{\prime}$ ithin their specific computer systems before committing to large data acquisitions.

The OGS is in the process of establishing a user lab to facilitate user access to the NRIS data initially by Survey staff and eventually by the public. A PC-level relational database management system called Advanced Revelations will be used to develop a menu-driven retrieval system customized to NRIS data. A large digitizer and large plotter will enhance capabilities available through GeoGraphix software. Radian, a company that markets a contour mapping package, has donated a $\mathrm{cC}_{1} \mathrm{y}$ of their CPS/PC software for use in the user lab; Van Tech, Inc., the regional Radian distributor, incorporated the NRIS Well History File formats within the menu system of their Master Well Manager software (much like GeoGraphix has done). Similarly, Energy Software Co., located in Midland, Tex., is incorporating the NRIS file formats within their Paragon database management software.

For the OGS, NRIS data continue to play a major role in the development of the Oklahoma section of a Midcontinent Gas Atlas. Field and reservoir maps, well lists, and reservoir production summaries are being generated for the project. For the School of Petroleum and Geological Engineering, NRIS data are being provided to a graduate student and faculty member for use in their study of fractured reservoirs. 


\section{RESERVOIR ASSESSMENT \\ AND CHARACTERIZATION}

\section{Cooperative Agreement DE-FC22-83FE60149, Project BE1}

\author{
National Institute for Petroleum \\ and Energy Research \\ Bartlesville, Okla.
}

Contract Date: Oct. 1, 1985

Anticipated Completion: Sept. 30, 1992

Funding for FY 1992: $\$ 785,000$

\section{Principal Investigator: \\ Susan R. Jackson}

\section{Project Manager: \\ Edith Allison \\ Bartlesville Project Office}

Reporting Period: Apr. 1-June 30, 1992

\section{Objective}

The objective of this project is to develop an improved methodology for effective characterization of barrier island reservoirs to predict oil saturations at interwell scales and flow patterns of injected and produced fluids.

\section{Summary of Technical Progress}

\section{Tectonic Framework at Patrick Draw Field}

Patrick Draw oil field is located in the Greater Green River Basin, east of the Rock Springs Uplift within the Washakie sub-basin and on the southern limb of the eastwest-trending Wamsutter Arch.

Numerous east-to-northeast-trending normal faults have been documented in the outcrop belt of the Almond formation on the Rock Springs Uplift, ${ }^{1,2}$ however, few have been shown to cut through Patrick Draw field. Although not emphasized in most reports, subsurface evidence since 1961 indicates that faults traverse the producing sandstone within the northern part of Patrick Draw field. ${ }^{3}$

Seven N-S oriented and $16 \mathrm{E}-\mathrm{W}$ oriented structural log cross sections were constructed in Arch and Monell Units to investigate the relationship between structure and reservoir behavior. This field-wide intersecting network of structural cross sections was designed to provide a large-scale view of the dominant fault zones or other structural complications within the upper Almond intervals UA-5, UA-6, UA-7, and the top of UA-8. Faults were suspected in the E-W cross sections in Arch Unit when the dip between adjacent segments of the cross sections exceeded $4^{\circ}$ or deviated to a great extent from the overall dip in that portion of the cross section.
In the N-S oriented cross sections, faults were more often indicated at inflections of otherwise straight profile segments. The slope of the profiles increases considerably in the suthernmost portion of Monell Unit, and possibly more fault: are in this area than are currently identified.

Because the ideritified faults could lie anywhere between two wells on a given log cross-section segment, they were plotted at the midpoint between adjacent wells. Once all the structural cross sections were evaluated and the fault locations plotted, the resulting map was analyzed to determine the most probable location of major faulted zones.

The structure map for the top of the Almond formation at Patrick Draw field was then updated honoring the fault zones (Fig. 1). Contouring required small adjustments of the fault positions from those in the original fault map and indicated the presence of additional faults, particularly in the southern Monell Unit. The updated structure map (Fig. 1) may be compared to the previous structure map (Fig. 12 in reference 4) used in most earlier publications about Patrick Draw ${ }^{1,5}$ which did not take into account faults within Patrick Draw field. Great potential for tectonic compartmentalization of the field can be readily seen in Fig. 1, whereas the older structure map indicates a gradual, uninterrupted eastward-dipping monoclinal surface.

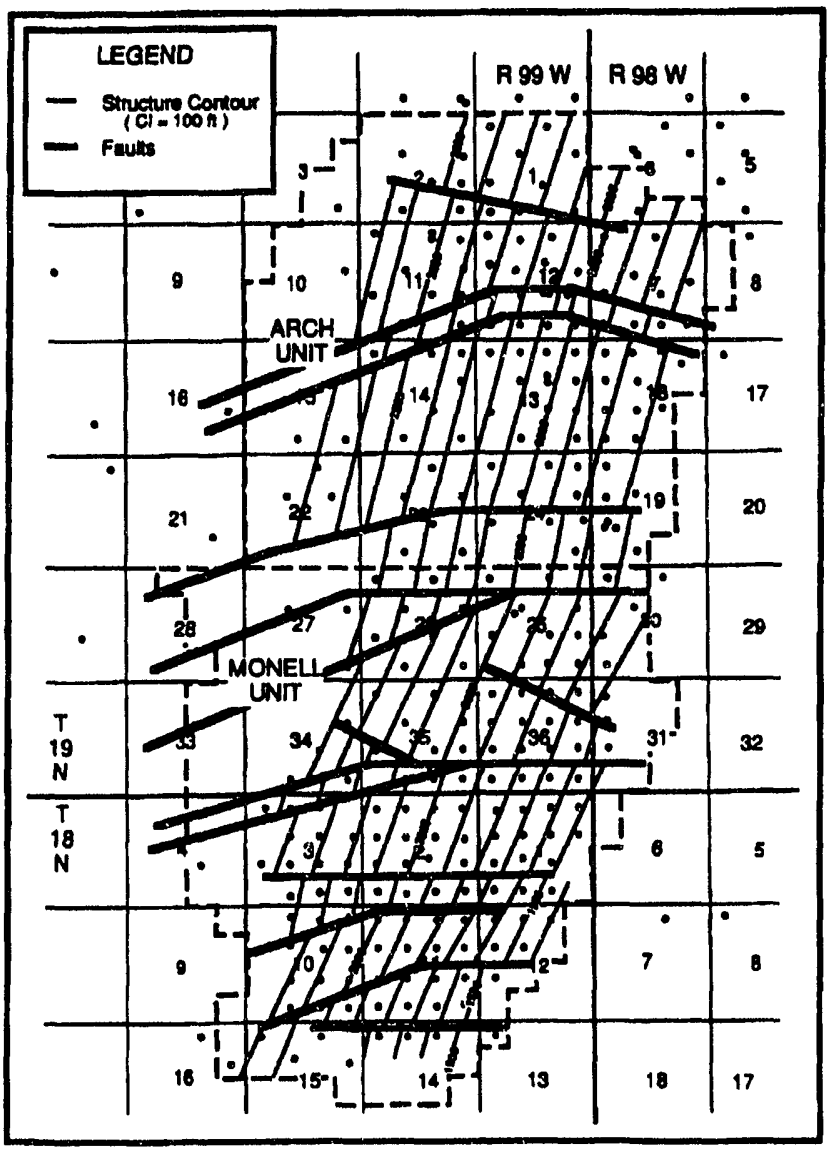

Fig. 1 Faults identified in Patrick Draw field from wireline log structural sections. 
Comparison of the fault directions identified within Patrick Draw with surface incaments (linear features) from the same area shows a decided lack of agreement with respect to locations and directions. The data, however, fall into several distinct directional groups. Average lineament directions $^{6}$ were plotted for each group and can be compared with the directions of faults identified in this report. The results show an approximate $30^{\circ}$ offset between the major fault direction (determined by log correlations) and the two major lineament directions. Lineament groups can also be identified at approximately $30^{\circ}$ and $60^{\circ}$ to the second major fault direction. Lang et al. ${ }^{6}$ indicated that lineaments are generally regarded as some manifestation of topographic and vegetative enhancement of linear fracture traces. These observations suggest that, because of the consistent offset of fault and lineament directions, the surface lineaments are genetically related to the direction of subsurface faults. As suggested, although the faults at Patrick Draw field may not be well represented at the surface, their related fracture system is, and many of the surface lineaments represent these fractures. A statistical summary of 1860 topographic lineaments identified within the Rock Springs Quadrangle was also presented by Lang et al. The cumulative diagram indicates that the dominant direction for lineaments is $67^{\circ}$, which is $8^{\circ}$ less than the average direction of faults identified at Patrick Draw by $\log$ analysis. Given the amount of error inherent in plotting directions of faults within the field by $\log _{5}$ correlations alone, the similarity to the dominant lineament direction is most striking.

No obvious correlation is observed between fault zone locations and primary and cumulative waterflood production for the Arch and Monell Units. As reported, however, the pattern of production for Patrick Draw field generally agrees with the sand thicks for UA-5B sandstone. ${ }^{7}$ The southern margin of the permeable sand thick $(>25 \mathrm{ft})$ in the Monell Unit is subparallel with one of the fault zones shown in Fig. 1. In addition, a second fault zone, which comprises the southern boundary of a small graben in the southern Arch Unit, lies close to the northern extent of the thick sandstone deposit that extends into the Monell Unit. The coincidence of laults bounding the highly productive sand thick that straddles the Arch-Monell Unit boundary reinforces an earlier suggestion 7 that there may have been some synsedimentary structural control of sand accumulation. Therefore, although it is not obvious in the production maps, some linkage between tectonics and patterns of production within the Arch and Monell Units is suspected.

A second source of structural information was from analysis of three seismic lines. Analysis of the seismic lines began with accurately identifying and mapping the reflector at the top of the Almond formation. Faults identified on the seismic lines were mapped by constructing log cross sections close to the seismic line. Along seismic line AA-6 there are clear indications of four faults that were identified in nearby $\log$ cross section No. 5 (Fig. 2a). The location of each fault was then traced with $\log$ data away from the seismic line (Fig. 2b). Where possible, faults were traced and iuentified on a second seismic line to provide further contirmation for the existence of the fault being traced.

The faults identified were of two types: thrust or reverse faults and normal faults. The thrust or reverse faults result from the general compressional forces that give rise to a number of thrust and anticlinal structures in the area, such as the Table Rock anticline east of Patrick Draw field. An important identifying feature of the reverse fault in the seismic section was tighter folds, which are generally associated with a thrust or a reverse fault caused by the effect of compressional forces. A smaller number of gravity or normal faults was also identified on the seismic section. Fault throws generally range from 10 to $30 \mathrm{ft}$.

The interpretation of the orientation of the faults from the seismic analysis was slightly different from those identified on the $\log$ cross sections shown in Fig. 1. The fault locations interpreted from the seismic lines were oriented northeast-southwest, whereas those in Fig. 1 are oriented nearly east-west. The different interpretations are currently being reconciled and illustrate the difficulty in interpreting and mapping fault locations from point data.

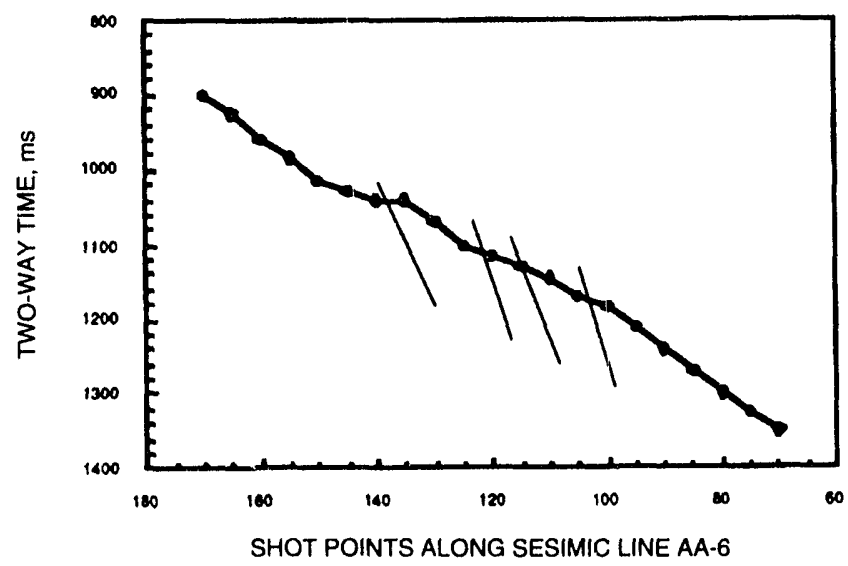

Fig. 2a Two-way reflection times from the top of the Almond formation showing fault locations.

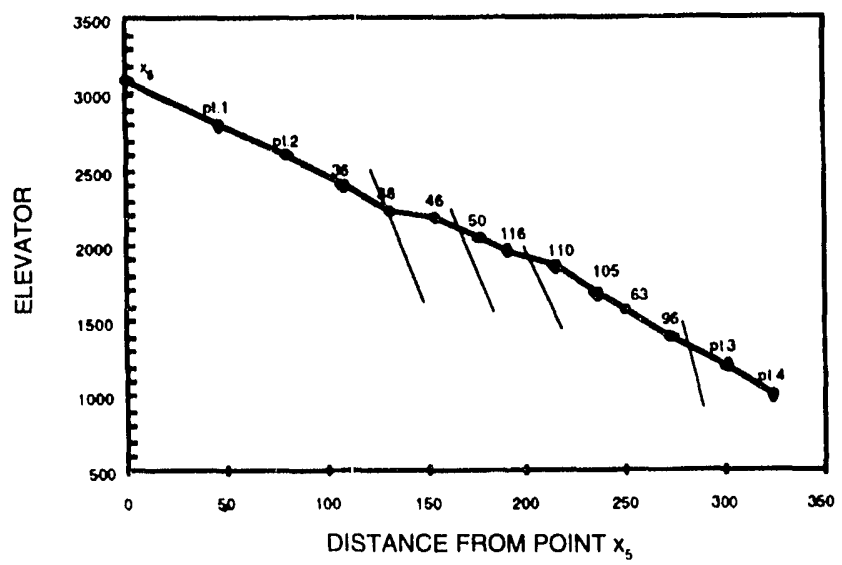

Fig. 2b Elevation of the topi of UA-5B sandstone from core and $\log$ data. Locations of wells and other points along the section are marked on the graph. Distances along this profile are measured from an arbitrary point $\left(x_{5}\right)$ located at the western end of this profile. 
Studies of Patrick Draw and Bell Creek fields indicate that structural features influence sand distribution, reservoir compartment size and number, and primary and waterflood production. Upgrading the structure map of a production unit should be an ongoing process as new wells are added to the pattern to provide successively more realistic appraisals of reservoir compartment size and connectivity.

\section{Reservoir Compartmentalization Determined from Hydrogeochemical Analysis}

Hydrogeochemical analysis of oil-associated formation waters in Patrick Draw field provides a dynamic aspect of reservoir characterization to the sedimentological, diagenetic, and structural "static" analysis of reservoir rocks. The analysis indicates a complicated hydrodynamic system in Patrick Draw field where both barriers to lateral flow and open vertical conduits for fluids may exist.

There is a strong indication of lateral fluid compartmentalization in the oil productive units. The barriers to lateral flow and mixing of fluids within the updip and downdip portions of the upper Almond formation are most probably created by a combination of depositional, diagenetic, and structural features documented in this report, such as facies changes (impermeable coquina "mounds" in particular), zones of intensive calcite cementation provided by migrating fluids oversaturated with respect to carbonates of probable outside origin, and the previously unidentified faults indicated on log cross sections and seismic lines.

The high salinity (two times that of sea water) and composition of some oil-associated brines in the system cannot be explained by the water-rock interaction processes acting within the Almond formation and indicate upward migration of deep-seated formation waters (together with hydrocarbons from thermally mature source rock?) through a locally conductive system of deep-cutting faults. Vertical migration of hot fluids from deeper horizons is further indicated by enhanced heat flow and the resulting high thermal maturity of organics in the Almond formation. ${ }^{8,9}$ Limited geochemical data preclude dating of fluid exchange and the identification of the conductive fault zones that provide pathways for fluid flow. Regional hydrodynamic and isotopic analyses, however, may provide conclusive information regarding the general fluid flow pattern and the distribution of specific fluids in the system.

An isosalinity map for the Almond formation in the entire Patrick Draw field was constructed using the Petroleum Data System (PDS-BRIN) data. The map illustrates a highly heterogeneous distribution of total dissolved solid (TDS) content in the oil-associated formation waters trapped in the shoreline barrier sandstones. Hydrogeochemical inversion within the Almond formation is clearly expressed by the presence of high-salinity waters (more than $70 \mathrm{~g} / \mathrm{L}$ of TDS brines) in the updip portions of the Almond formation in the Arch and Monell productive units, whereas the brackish and saline waters (less than 20 to $40 \mathrm{~g} / \mathrm{L}$ of TDS, respec- tively) occur downdip in the area above the oil-water contact. In general, the zone of high water salinity drop runs across the Monell Unit in an SW-NE direction and across the Arch Unit in a perpendicular SE-NW direction. The highest hydrochemical gradients $(40 \mathrm{~g} / \mathrm{L}$ of TDS drop at a lateral distance of half a mile or less) can be observed on the isosalinity map in the southeastern part of Arch Unit (T19R98 Secs. 18 and 19) and in the central part of the Arch Unit (T19R99 Secs. 11, 13, and 14) as well as in the south-central part of the Monell Unit (T18R99 Secs. 2, 10, and 11). Location of the highest TDS gradients indicates the position of effective barriers to flow that prevented lateral equilibration of fluid chemistry by mixing processes. The same barriers may negatively affect the oil drainage to producing wells and also may impose strong limitations on the effectiveness of waterflood processes. The variations in the isosalinity map correspond with the location of reservoir pressure drops and shifts of the oil-water and gas-oil contacts (in Ref. 7) and indicate reservoir compartmentalization.

Compartmentalization of fluids in the Monell Unit has been confirmed by detailed analysis of production history in the area of well Nos. 60,61, and 66, where hydrochemical anomalies were earlier identified. The highly saline waters (TDS from 52 to $72 \mathrm{~g} / \mathrm{L}$ ) produced with oil from these wells $r$ esent in situ formation water separated from the rest of the dominantly oil-producing Almond formation in the area. The water samples were taken during primary oil production from the UA-5 horizon in March and April 1964, long before the waterflood front from the first injection well in the area (No. 171) could reach these wells. Analysis of breakthrough time within the five-spot pattern formed by production well Nos. 56, 60,61, 66, and 171, where injection started in January 1964, indicates that hydraulic communication between these wells may be strongly impaired. The unique salinity and composition of the formation waters from well Nos. 60, 61, and 66 also indicate that the updip reservoir section is hydraulically disconnected from the major aquifer located about 2 miles eastward in the downdip direction.

In addition to the formation water anomalies identified in the Monell Unit, a distinct compositional heterogeneity of pre-waterflood formation waters also has been documented in the UA-8 horizon of the East Arch Unit. Hydrochemical data from well Nos. 80 and 84 in the East Arch Unit clearly demonstrate an effective vertical and horizontal compartmentalization of formation fluids. The geologic profile of well No. 80 core, described by the National Institute for Petroleum and Energy Research geologists, reveals a few feet of impermeable swamp and marsh facies separating two prominent hydrocarbon productive UA-8A and UA-8B sandstone units interpreted as tidal delta facies. On the basis of documented differences in water salinity, as well as bicarbonate, chloride, and sulfate ionic composition above and below the marsh and swamp facies, the conclusion can be made that in well No. 80 the facies act as an 
effective hydraulic barrier between the two (UA-8A and UA-8B) tidal delta sandstones. The UA-8 sandstones in well No. 84, located less than 1 mile northwest of well No. 80 , produced water of much higher salinity and somewhat different chemical composition. The hydrochemical differences clearly indicate a disruption of lateral communication between the stratigraphically equivalent hydrocarbon productive sandstones in the East Arch Unit of Patrick Draw field.

\section{Relationship of Waterflood Recovery to Rock Permeability}

The efficiency of waterflood recovery increased with the average permeability of reservoir rock among 12 five-spot patterns in the Monell Unit (Fig. 3). The reason for this correlation may be a relatively high ratio of oil relative permeability to water relative permeability $\left(k_{\mathrm{ro}} / \mathrm{k}_{\mathrm{rw}}\right)$ for the rock of higher permeability values in this strongly water-wet system.

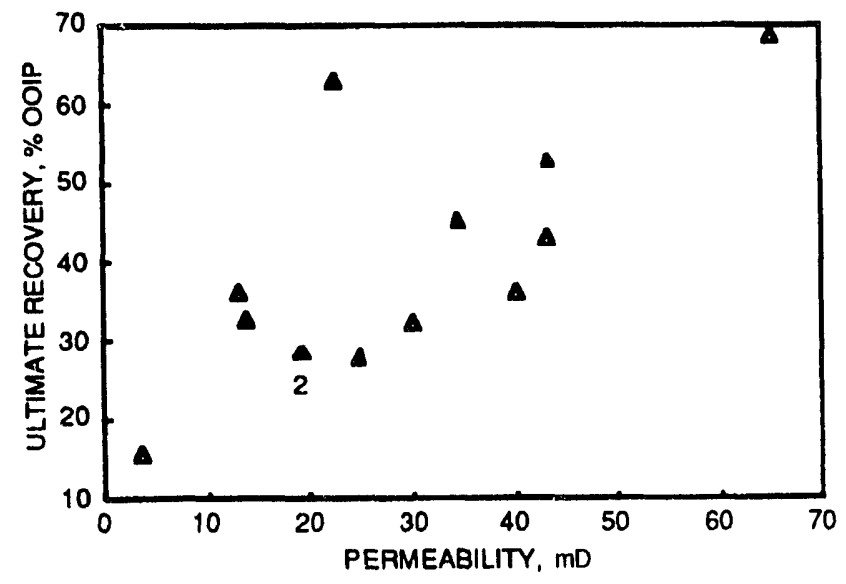

Fig. 3 Ultimate recovery vs. permeability in 12 five-spot patterns in the Monell Unit, Patrick Draw field.

The relationship between $k_{r o} / k_{r w}$ and the rock permeability can be explained as follows. In a porous media, the nonwetting phase occurs in isolated globules several pore diameters in length that occupy the center of the pores. The wetting phase, on the other hand, occupies the crevices between rock grains and coats the rock surfaces. In the high-permeability rock, the pore throats are large and the nonwetting phase is the mobile phase in the pore center. In the low-permeability rock, the pore throats are small and the nonwetting phase becomes isolated islands and the wetting phase becomes the mobile phase. As a result, $\mathrm{k}_{\mathrm{ro}} / \mathrm{k}_{\mathrm{rw}}$ values are high for water-wet rock with high-permeability values. As reported in the drainage process, $\mathrm{k}_{\mathrm{ro}} / \mathrm{k}_{\mathrm{rw}}$ values are high for rocks with low values of initial water saturation, which usually occur in highpermeability rock. The good waterflood recovery from highpermeability rocks in the Monell Unit suggests that the same relationship of $\mathrm{k}_{\mathrm{rr}} / \mathrm{k}_{\mathrm{rw}}$ with permeability also holds for the imbibition process.
Dykstra-Parsons coefficients $\left(\mathrm{V}_{\mathrm{DP}}\right)$ were calculated for 70 wells in the Arch Unit and 38 wells in the Monell Unit. No correlations were found between primary or waterflood oil recovery efficiencies and Dykstra-Parsons coefficients in either the Arch Unit or the Monell Unit (Figs. 4a and $4 b$ ), which suggests that the Dykstra-Parsons coefficient is not a good predictor of production performance in the Patrick Draw field.

Typically, low oil recoveries are associated with high values of $\mathrm{V}_{\mathrm{DP}}$; however, this assumption is based on the injection of high fluid volumes (more than 1 pore volume), and relative permeability values are not considered. The results of this study indicate that the relative permeability values of oil and water phases are much more important than $V_{D P}$ for the waterflood recovery in the Patrick Draw field. The rock of $100-\mathrm{mD}$ permeability has a larger value of $\mathrm{k}_{\mathrm{ro}} / \mathrm{k}_{\mathrm{rw}}$ than the rock of $10 \mathrm{mD}$ in the Patrick Draw field. In contrast, a correlation was found between $V_{D P}$ and the waterflood recovery in the Bell Creek field. This indicates that values of $k_{r o} / k_{r w}$ to not vary much for rocks of high

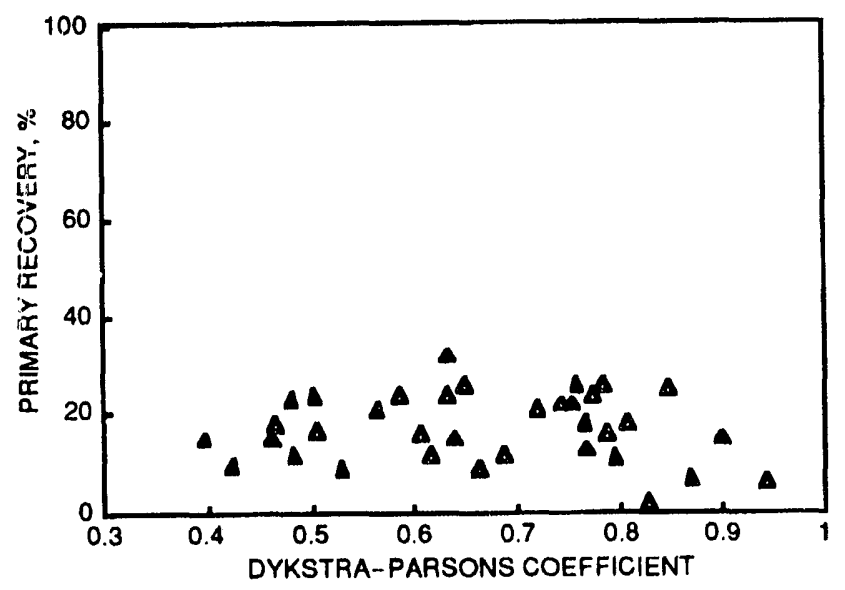

Fig. 4a Primary recovery efficiency vs. Dykstra-Parsons coefficient in the Monell Unit, Patrick Draw field.

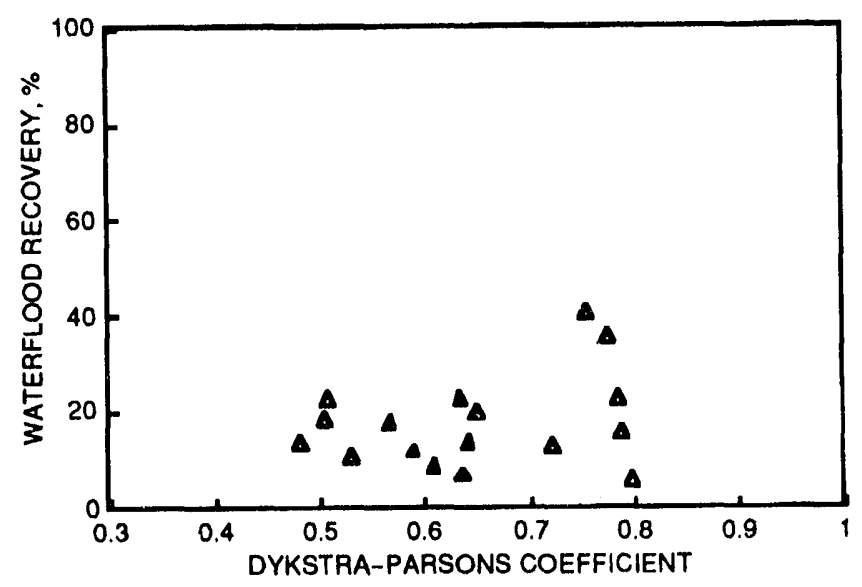

Fig. 4b Waterflood recovery efficiency vs. Dykstra-Parsons coefficient in the Monell Unit, Patrick Draw field. 
permeability (approximately 1D); therefore the less variable permeability profile in the vertical direction becomes the controlling factor in waterflooding recovery.

\section{Effect of Salinity on Saturation Calculations}

The highly heterogeneous distribution of formation water salinities in the Patrick Draw field results in a wide range of water resistivities. The water resistivity values measured at $68^{\circ} \mathrm{F}$ vary from $0.12 \Omega-\mathrm{m}$ (for $72.8 \mathrm{~g} / \mathrm{L}$ TDS in the Monell Unit well 60) to $1.02 \Omega-m$ (for $7.6 \mathrm{~g} / \mathrm{L}$ TDS in the East Arch well 80). The relationship between water salinities and resistivities presents a smiooth curve with the exponential drop of resistivities between 5 and $15 \mathrm{~g} / \mathrm{L}$ TDS (Fig 5). The isosalinity map for the Patrick Draw field and the quantified relationship between salinity and resistivity provide opportunity for more accurate estimation of the initial oil saturations in different sections of the field.

The initial water saturation profiles were calculated for all wells in the Patrick Draw field on the basis of resistivity logs and the recently developed salinity map. The salinity map shows a decrease of salinity (TDS) from 70,000 ppm at the western edge to $20,000 \mathrm{ppm}$ at the eastern part of Patrick Draw field. Simandoux and Schlumberger equations were used to account for the clay effect in the interpretation of resistivity logs. The calculations result in lower water saturations in the western part of Patrick Draw field in comparison with original calculations, which are based on an assumption of constant water resistivity of $0.2 \Omega-\mathrm{m}$ (corresponding to $21,000 \mathrm{ppm}$ at $110^{\circ} \mathrm{F}$ ).

The initial oil saturation $\left(\mathrm{S}_{\mathrm{oi}}\right)$ in the Monell Unit increases from less than $30 \%$ at the gas-oil contact in the western edge to more than $70 \%$ at the water-oil contact in the eastern edge. This trend matches well with the direction of the formation dip, which results in a smooth capillary transition of oil saturation. No major discontinuity was found in this saturation transition in the Monell Unit. This smooth saturation transition suggests no major compartments within

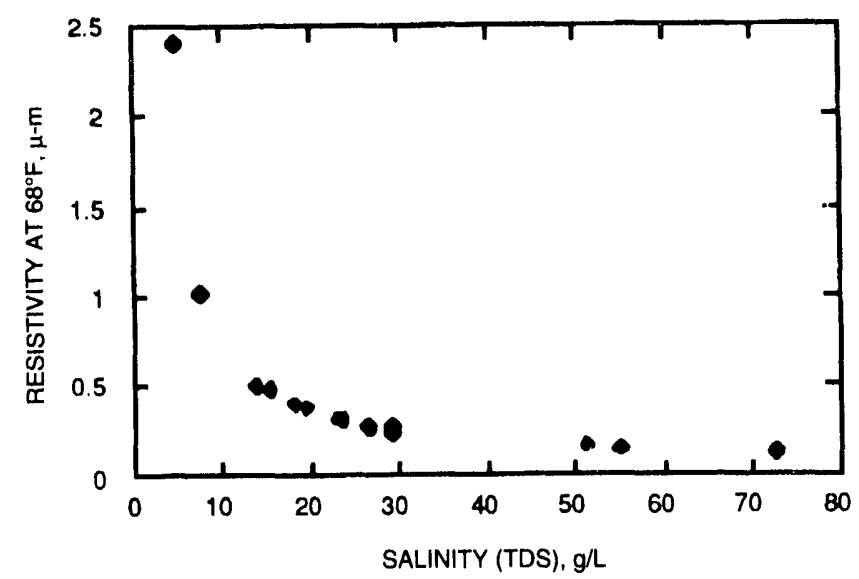

Fig. 5 Formation water salinity vs. resistivity measured at ambient temperature $\left(68^{\circ} \mathrm{F}\right)$ in water samples coproduced with oil and gas in different areas of Patrick Draw field, Wyoming. the Monell Unit in spite of faults found from logs and seismic data.

The initial oil saturation is low, as expected, in the western area close to the gas-oil contact in the Arch Unit. No clear trend, transition, or distribution pattern of $S_{o i}$ is found east of the low-permeability barrier despite a water-oil contact located at the eastern edge of this unit. This indicates a geological discontinuity, which destroys the capillary transition in this area. The geological discontinuity may be caused by faults, carbonate barriers, or change of facies in the lateral direction. The water saturation $(>70 \%)$ in Arch well 94 is much higher than that in neighboring wells. This is a good example and evidence of compartmentalization in the eastern part of the Arch Unit. This reservoir heterogeneity is responsible for its poor performance of waterflooding.

\section{Production Analyses}

Oil-recovery efficiency and remaining oil saturation after waterflood were calculated for each well pattern. Recovery efficiency in the Monell Unit varies from $20 \%$ to more than $50 \%$, which indicates good oil recovery. The Arch unit has a relatively poor recovery efficiency except for the area immediately west of the low-permeability flow barrier.

In the Monell Unit, approximately one-half of the wells recovered $20 \%$ of original oil in place (OOIP), and the majority of the infill wells produced 10 to $20 \%$ OOIP from waterflooding. The northwestern and central area showed a relatively higher remaining oil saturation than the southeastern area because of higher values of $S_{0 j}$. Seven wells (well Nos. 4, 6, 7, 17, 18, 27, and 38) produced more than 1 million bbl of oil in the northwestern part of the Monell Unit because of large oil reserves.

Arch wells showed a large contrast in primary recovery efficiency. The highest recovery was from wells located immediately west of the low-permeability barrier in the Arch Unit. These wells locate at the bottom of the oil column, which is caused by the formation dip and low-permeability barrier. The gas-cap expansion maintained the well pressure, which resulted in a recovery efficiency of more than $40 \%$ OOIP for Arch wells 21, 22, 30, 44, 45, and 46.

Poor waterflood recovery in the Arch Unit was indicated by the fact that 12 out of 22 infill wells produced less than 100 thousand bbl of oil from five-spot waterflooding. Arch well No. 94 produced only $7,000 \mathrm{bbl}$ of oil, whereas the surrounding wells produced from 26 to 270 thousand bbl of oil per well. The construction of a reservoir model in this heterogeneous area is a challenge to both geologists and engineers.

\section{References}

1. R. J. Weimer, Time-Stratigraphic Analysis and Petroleum Accumulations, Patrick Draw Field, Sweetwater County, Wyoming, Am. Assoc. Pet. Geol., Bull., 50: 2150-2175 (1966).

2. M. D. Van Horn, Stratigraphy of the Almond Formation, East-Central Flank of the Rock Springs Uplift, Sweetwater County, Wyoming: A 
Mesotidal Shoreline Model for the Lute Cretaceous, M.S. Thesis, Colorado School of Mines, 1979.

3. G. Burton, Patrick Draw Area, Sweetwater Co., Wyoming, in Wyoming Geological Association Symposium on Late Cretaceous Rocks, Wyoming and Adjacent Areas, Sixteenth Annual Field ConferenceGreen River. Washakie, Wind River and Powder River Basins, G. J. Wilath (Ed.), Wyoming Geological Association, pp. 276-279, 1961

4. M. Szpakiewicz, R. Schatzinger, S. R. Jackson, B. Sharma, A. Cheng, and M. Honarpour, Selection of a Second Barrier Island Reservoir System for Expanding the Shoreline Barrier Reservoir Model and Refining NIPER Reservoir Characterization Methodology, DOE Report NIPER-472, April 1990.

5. R. J. Weimer, K. W. Porter, and C. B. Land, Depositional Modelling of Detrital Rocks-Emphasis on Cored Sequence, Society of Economic Paleontologists and Mineralogists, Core Workshop, No. 8, 1985.

6. H. R. Lang, W. H. Alderman, and F. F. Sabins, Jr., Section IIPatrick Draw, Wyoming, Petroleum Test Case Report, in The Joint NASA/Geosat Test Case Project, Final Report, M. J. Abrams, J. E.
Conel, and H. R. Lang (Eds.), American Association of Petroleum Geologists, Tulsa, Okla.. p. 11-1-11-112, 1984.

7. R. A. Schatzinger, M. J. Szpakiewicz, S. R. Jackson, M. M. Chang, B. Sharma, and M. K. Tham, Integrated Geological-Engineering Model of Patrick Draw Field and Examples of Similarities and Differences Among Various Shoreline Barrier Systems, DOE Report NIPER-575, 1992.

8. B. E. Law, Relationship of Source-Rock. Thermal Maturity, and Overpressuring to Gas Generation and Occurrence in LowPermeability Upper Cretaceous and Lower Tertiary Rocks, Greater Green River Basin, Wyoming, Colorado, and Utah, in Hydrocarbon Source Rocks of the Greater Rocky Mountain Region. J. Woodward, F. Meissner, and J. Clayton (Eds.), Rocky Mountain Association of Geologists, Denver, Colo., 1984.

9. B. E. Law, Pateofluid Flow-Paths-Evidence from Thermal Maturity Mapping, Greater Green River Basin, Wyoming and Utah, paper presented at the American Association of Petroleum Geologists 1992 Annual Convention, Calgary, Alberta, June 21-24, 1992; abstract is available in the Convention Program.

\section{TORIS RESEARCH SUPPORT}

\section{Cooperative Agreement DE-FC22-83FE60149, Project BE2}

\author{
National Institute for Petroleum \\ and Energy Research \\ Bartlesville, Okla.
}

\section{Contract Date: Oct. 1, 1983 \\ Anticipated Completion: Sept. 30, 1992 \\ Funding for FY 1992: $\$ 340,000$}

\author{
Principal Investlgator: \\ James F. Pautz \\ Project Manager: \\ Chandra Nautiyal \\ Bartlesville Project Office
}

\section{Reporting Period: Apr. 1-June 30, 1992}

\section{Objective}

The objective of this project is to provide research support to the Department of Energy (DOE) Program Manager for the Tertiary Oil Recovery Information System (TORIS) in the areas of enhanced oil recovery (EOR) project and reservoir database management, EOR project technology and trends analysis, and computer simulation.

\section{Summary of Technical Progress}

\section{New Projects}

One important aspect of the BE2 effort is to find information on new EOR projects. Table 1 shows the lack of new EOR projects. Only four new projects have been identified in the past 9 months. All are in sandstones, each using a different process, and are being conducted by four different companies.

\section{Project Database Design}

This project is responsible for the maintenance of the DOE EOR project database. This database is located on a computer in Washington and also on a computer in the Bartlesville Project Office. The computer at Bartlesville is changing, and the database management system is changing from RELIANCE to INGRES. To help in the transfer of the database to this new system, the relational logic of the project database was analyzed.

The entity-relationship diagram as displayed in Fig. 1 graphically represents the tables that are connected by lines representing the relationships. A relationship is the connection (or connections) between two or more tables. Each line represents the degree of relationship between the tables (also referred to as entities). The solid line represents a one-toone relationship. The lines with the crow's foot notation at one end represents a one-to-many relationship.

The FIELD INFORMATION entity has a one-to-many relationship with the KEY INFORMATION entity and the PROJECT INFORMATION entity. The ability to form such a relationship implies that a piece of information is shared by both entities. Therefore all entities with relationships must have shared or common information. The PROJECT INFORMATION entity has the possibility of many occurrences of RESERVOIR INFORMATION, thus the one-to-many relationship. Proceeding to the right, the entity RESERVOIR REMARKS has a many-to-one relationship with RESERVOIR INFORMATION, as does CLAY. The GEOLOGIC HISTORY entity occurs once with the possibility of many RESERVOIR INFORMATION entities related to it. 
TABLE 1

New Enhanced Oil Recovery Projects

\begin{tabular}{|c|c|c|c|c|}
\hline \multirow[b]{2}{*}{ Field name } & \multicolumn{4}{|c|}{ Project name } \\
\hline & Mabee & DOE & House Creek & Ant Hill \\
\hline FIPS DOE field code & $48-438233$ & $56-012153$ & $56-334741$ & $06-019973$ \\
\hline State code & TX & WY & WY & $\mathrm{CA}$ \\
\hline Field county & Andrews & & Campbell & Kern \\
\hline Regulator conservation district & 80 & & & \\
\hline Reservoir name & San Andres & Minnelusa "A" & Sussex & Olcese \\
\hline Reservoir system & Permian & & & \\
\hline Oil gravity, ${ }^{\circ} \mathrm{API}$ & 32.2 & 35 & & 14 \\
\hline Present oil saturation, \% & 50 & & & \\
\hline Initial oil, Mbbl & 290,000 & 1182 & & \\
\hline Present oil, Mbbl & 199,000 & 1119 & & \\
\hline Oil viscosity, $\mathrm{cP}$ & 3 & & & \\
\hline Lithology & Sandstone & Sandstone & Sandstone & Sandstone \\
\hline Depth, ft & 4650 & 11325 & & 2650 \\
\hline Net pay thickness, ft & 40 & 14 & & 40 \\
\hline Av. porosity, $\%$ & 11 & & & \\
\hline Initial res, bottomhole pressure, psi & & 4400 & & \\
\hline Present res. bottomihole pressure, psi & & 550 & & \\
\hline Bottomhole pressure, year & & 1991 & & \\
\hline Permeability, mD & 3.8 & & & \\
\hline Initial gas/oil ratio & & 190 & & \\
\hline Present gas/oil ratio & 167 & & & \\
\hline Project number & NIP77I & NIP772 & NIP773 & NIP774 \\
\hline Discovery year & 1944 & 1988 & & 1944 \\
\hline Secondary year & 1949 & & & 1959 \\
\hline Tertiary year & 1992 & 1992 & 1992 & 1991 \\
\hline Producing wells & & 1 & 87 & 1 \\
\hline Injection wells & & 1 & 29 & 1 \\
\hline Method name & Carbon dioxide & Alkaline & Polymer & Conventional steam \\
\hline Method code & 314 & 215 & 230 & 120 \\
\hline Operator name & Texaco & LA Land and Exp. Co. & Kerr McGee & Stockdale Oil and Gas Inc. \\
\hline
\end{tabular}

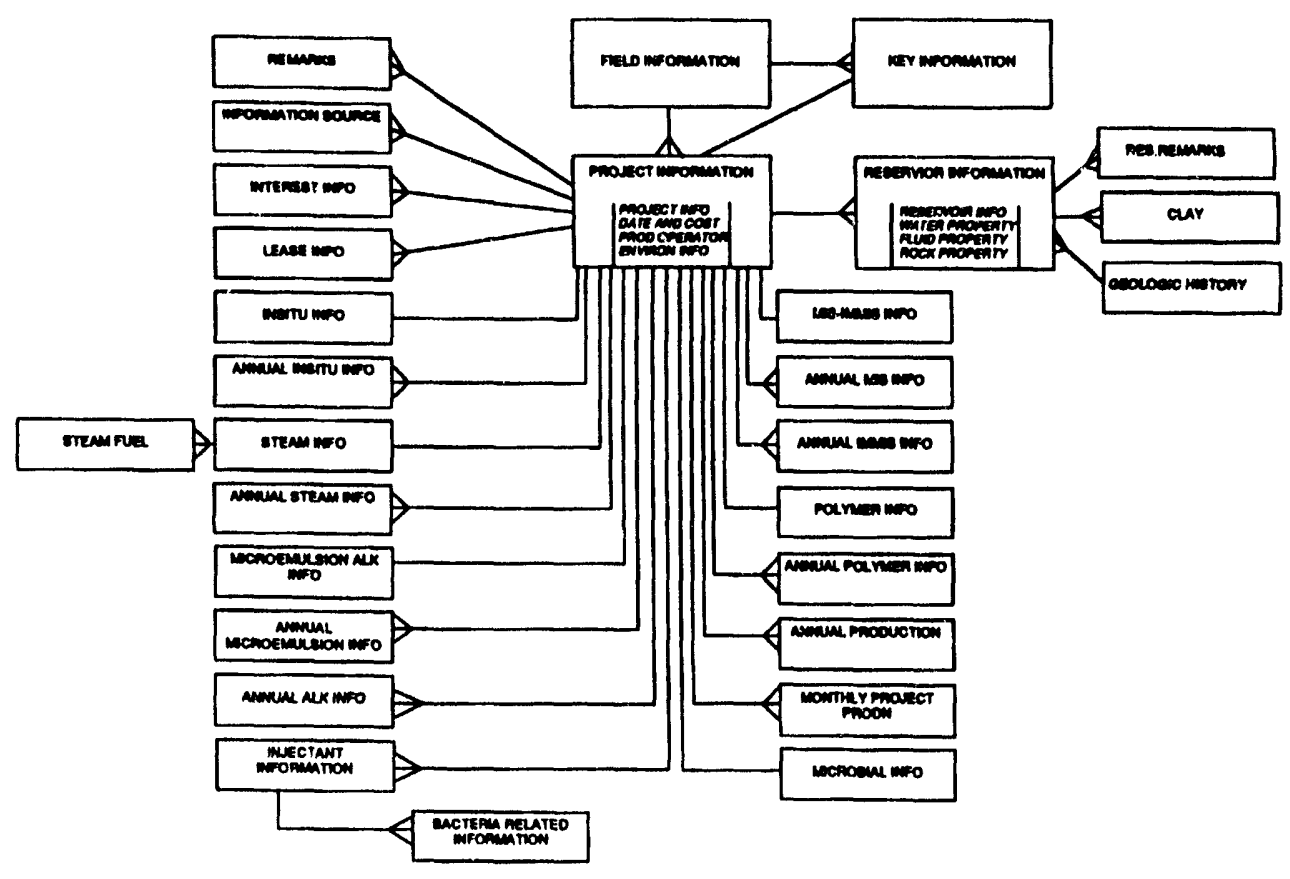

Fig. 1 Entity-relationship diagram for DOE enhanced oil recovery project data. 
Within the RESERVOIR INFORMATION entity are four separate entities (RESERVOIR INFO, WATER PROP. ERTY, FLUID PROPERTY, and ROCK PROPERTY). Each of these entities has a one-to-one relationship with each other and is logically related because all deal with reservoir information. Also, within the PROJECT INFORMATION entity are four separate tables with the same type of relationship that pertain to project data. The entities with a one-to-one relationship to PROJECT INFORMATION are INSITU INFO, STEAM INFO, MICROEMULSION ALK INFO, MIS-IMMIS INFO, POLYMER INFO, and MICROBIAL INFO. The entities that have a many-to-one relationship are REMARKS, INFORMATION SOURCE, INTEREST INFO, LEASE INFO, ANNUAL INSITU INFO, ANNUAL STEAM INFO, ANNUAL MICROEMULSION INFO, ANNUAL ALK INFO, INJECTANT INFORMATION, ANNUAL MIS INFO, ANNUAL IMMIS INFO, ANNUAL POLYMER INFO, ANNUAL PRODUCTION, and MONTHLY PROJECT PRODN. The STEAM FUEL is related to STEAM INFO on a many-to-one basis. The same is also true for the relationship between BACTERIA RELATED INFORMATION and INJECTANT INFORMATION.

\section{THREE-PHASE RELATIVE PERMEABILITY RESEARCH}

\section{Cooperative Agreement DE-FC22-83FE60149, Project BE9}

\author{
National Institute for Petroleum \\ and Energy Research \\ Bartlesville, Okla.
}

\section{Contract Date: Oct. 1, 1985}

Anticipated Completion: Sept. 30, 1992

Funding for FY 1992: $\$ 290,000$

\section{Principal Investigator: Dan Maloney}

\section{Project Manager: Rhonda Lindsey Bartlesv'ille Project Office}

Reporting Period: Apr. 1-June 30, 1992

\section{Objectives}

The objectives of this project are to (1) improve the reliability of laboratory measurements of three-phase relative permeability for steady- and unsteady-state conditions in core samples, (2) investigate the influence of rock, fluid, and rock-fluid properties on two- and three-phase relative permeabilities, and (3) expand the state of the art for measuring relative permeabilities at higher temperatures and pressures.

\section{Summary of Technical Progress}

\section{Milestone 2}

This milestone was completed during this reporting period. Thin sections of rock from the Arch Unit were microscopically evaluated. The thin sections were consistent for a flood tidal delta environment with respect to lithology and diagenesis. Pore structures were primarily affected by compaction and leaching. Feldspars in the rock were leached, causing microporosity. Visual examinations of samples $4,953,4,959$ and 4,961 indicate that they are all very similar texturally and lithologically. All three are classified as feldspathic litharenite. Macroscopic examinations reveal that 4,953 is massive in appearance in contrast to 4,959 and 4,961 , which have bedding accented by organic matter (coaly materials in thin, often discontinuous laminae). Microporosity is abundant in all three samples because of leaching of feldspars and other less stable grains. Microporosity composes 38 to $67 \%$ of total porosity. The micropores are expected to trap fluids. Most pores have fine networks of clay. The microporosity and clay networks indicate that fluid trapping and fines migration may be problems in laboratory experiments with this rock.

Textural features show that the rock has undergone grain compaction and pore size reduction. An estimated 30 to $40 \%$ of the original porosity was lost because of compaction, whereas cement reduction accounts for only 3 to $8 \%$ of the porosity loss. Because of similarity of mineralogy, texture, proportions of microporosity, and dominance of compactional processes over cementation, these three samples should behave in a similar manner to fluid flow, although differences in porosity and permeability suggest that 4,953 and 4,961 will behave more similarly than 4,959 , which has more obvious partitioning of the pore space by relatively greater amounts of impermeable organic laminae.

Grain size frequency data were plotted on log-normal probability paper. Figure 1 shows the plotted results. Median $\left(\mathrm{d}_{50}\right)$ diameters for samples 4,953 and 4,961 were $161 \mu \mathrm{m}$ and $102 \mu \mathrm{m}$, respectively.

Plug 4,953A was tested by mercury injection porosimetry. The mercury injection results indicated that the unconfined sample porosity was $19.7 \%$. The median pore diameter was $1.48 \mu \mathrm{m}$. Much of the porosity is contributed by microporosity as shown by Fig. 2. Further analyses are in progress. An air/brine porous plate capillary pressure test was started using plug 4,953B.

Several centrifuge wettability tests were conducted with plugs from depths in the 4,955 to $4,965 \mathrm{ft}$ range. The plugs were of 1 -in. diameter with 1 -in. lengths. The tests were conducted at $74^{\circ} \mathrm{F}$ and at $150^{\circ} \mathrm{F}$. Soltrol 100 and a $2 \%$ by 


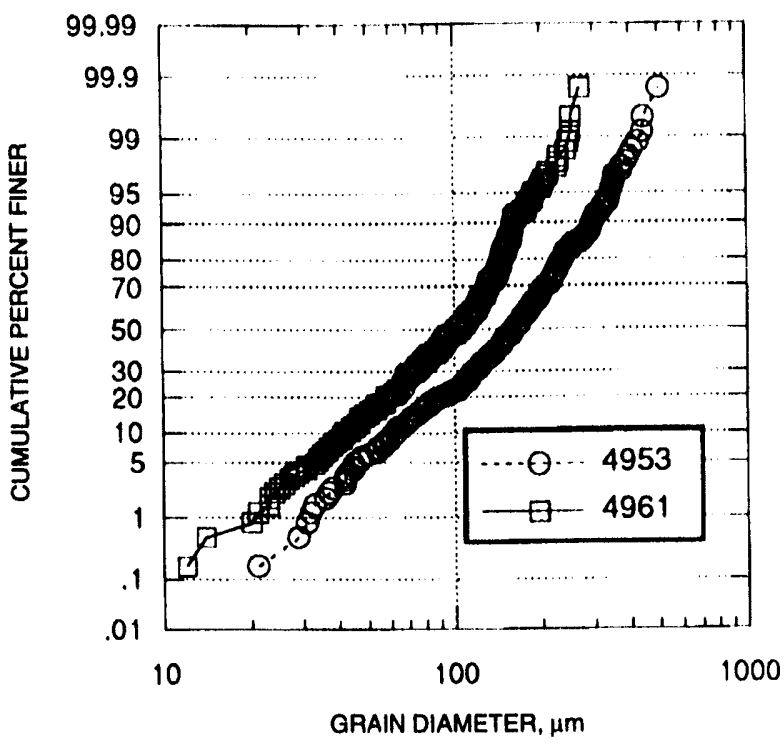

Fig. 1 Grain diameter distributions from samples 4,953 and 4,961 thin-section analyses.

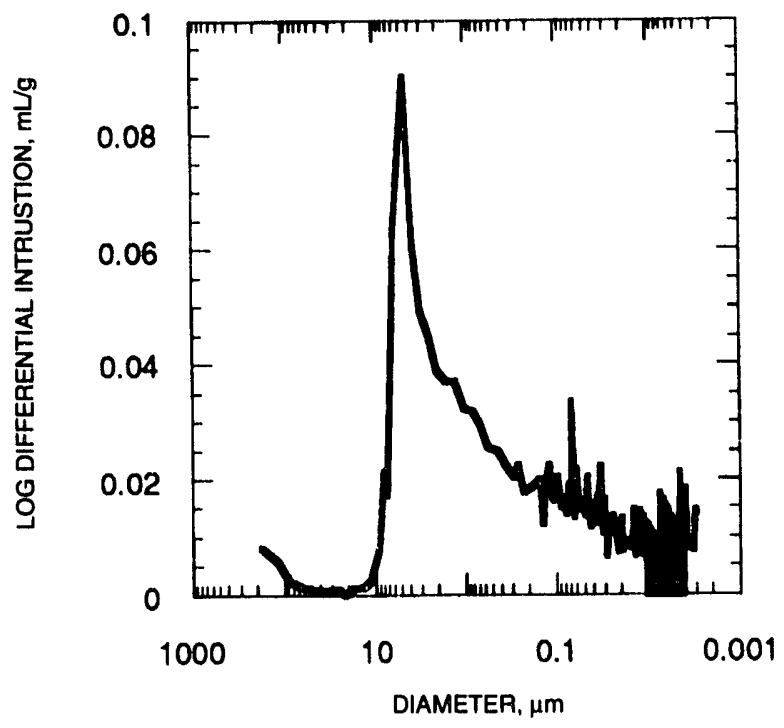

Fig. 2 Log differential intrusion vs. pore diameter from mercury injection tests on plug 4,953BA.

weight $\mathrm{KCl}$ brine were used as the test fluids. The samples were spun at five centrifuge speeds ranging from about 400 to $3,300 \mathrm{rpm}$, imposing positive (oil displacing brine) capillary pressures of 0.2 to $15 \mathrm{psi}$ and negative (brine displacing oil) capillary pressures of -0.4 to $-27 \mathrm{psi}$. The refined oil (Soltrol 100) reacted with the silicone rubber stoppers on the high temperature centrifuge tubes, causing errors in fluid measurements for three of the four tests that were performed. This problem was resolved by using a stopper of different chemical composition protected by a thin sheet of Teflon for the successful test on a plug from the 4,961-ft depth. The plug was centrifuged to provide capillary pres- sure vs. brine saturation results for brine-displacing-oil and oil-displacing-brine saturation cycles. Maximum capillary pressures of about $25 \mathrm{psi}$ for the brine-displacing-oil and $14 \mathrm{psi}$ for the oil-displacing-brine cycles were achieved. These maximum capillary pressures were a function of the maximum centrifuge speed, the fluid densities, and the radius of rotation. U.S. Bureau of Mines (USBM) wettability indices were calculated from the test data. Wettability indices ranging from 0.79 to 0.94 were obtained for the three samples tested at ambient temperature. The sample tested at $150^{\circ} \mathrm{F}$ had a calculated wettability index of 0.71 . These indices are indicative of water-wet rock.

Soltrol 100, an isoparaffinic oil marketed by Phillips Petroleum Company, is used as the oil phase in many tests. Another oil/brine USBM wettability experiment was conducted with two of the plugs in which Soltrol 100 was used as the oil phase with one plug while $n$-decane was used with the other plug. The drainage and imbibition capillary pressure vs. average saturation results for the two plugs were nearly identical, suggesting that both Soltrol 100 and $n$-decane are equally non-reactive with respect to this rock.

Low plug permeabilities $(\sim 30 \mathrm{mD})$, high microporosities (as evidenced by the thin section evaluations), and the limitations on the centrifuge spin radius and maximum rotational speed prevented residual brine saturations from being reduced to less than $60 \%$.

A porosimeter was constructed for measuring porosities of confined plugs. Tests were conducted using plugs 4,959A, $4,959 \mathrm{~B}$, and 4,961 . Sample porosities decreased by approximately one-half of a porosity percent unit when the unconfined samples were subjected to 2,000 psig confining pressure (for example, $19.5 \%$ pulosity at 2,000 psig compared to $20 \%$ unconfined). Plots of porosity vs. confining pressure were constructed. A capillary tube viscometer was assembled to measure brine and oil viscosities under elevated temperature and pressure conditions. The viscometer was calibrated using deionized water at temperatures to $350^{\circ} \mathrm{F}$.

\section{Milestone 3}

Discussions of testing procedures for high temperature relative permeability experiments were completed. The temperature cabinet designs were finished and work is in progress toward finishing the hot-air circulation temperature bath.

\section{Milestone 4}

The results from the unsteady-state tests that were conducted in February were evaluated. Whereas the end-point permeability and saturation data were useful and accurate, the unsteady-state results were not as good as expected. Apparently gas trapped within the syringe pump that was used for test measurements caused the brine injection rate to vary during each of the "constant rate" tests. Results from constant pressure tests are still under evaluation. Additional tests are planned. 
A steady-state gas-brine test for the 4,959 ft sample was completed. Permeability and saturation measurements were recorded for first-imbibition and second-drainage saturation cycles. Imbibition cycle results are shown in Fig. 3. The rock was cleaned and was resaturated for oil-water relative permeability tests. Imbibition and second-drainage oilwater relative permeability tests and gas-oil tests with a residual water saturation present were conducted next. Oilwater results are shown in Fig. 4. Gas-oil results are still under evaluation. Three-phase steady-state gas-oil-water measurements are in progress.

A computerized tomography (CT) unsteady-state oilbrine test was started on a sample of the reservoir rock. The sample length, height, and width dimensions are 7.8, 5.2, and $2.1 \mathrm{~cm}$, respectively. Electrodes were placed at the inlet and outlet sample faces and in the midway along the length of the sample. CT and linear X-ray scanner parameters were determined. Linear X-ray scans as well as CT scans were taken of the rock under dry, brine-saturated, and residual water-saturated conditions to provide a comparison of the saturation results calculated from the two scanners. The brine permeability of the sample when fully saturated with brine was $5.3 \mathrm{mD}$. The porosity was calculated as $17.96 \%$ from volumetric and gravimetric measurements. CTcomputed porosities ranged from 12.4 to $22.6 \%$ across the

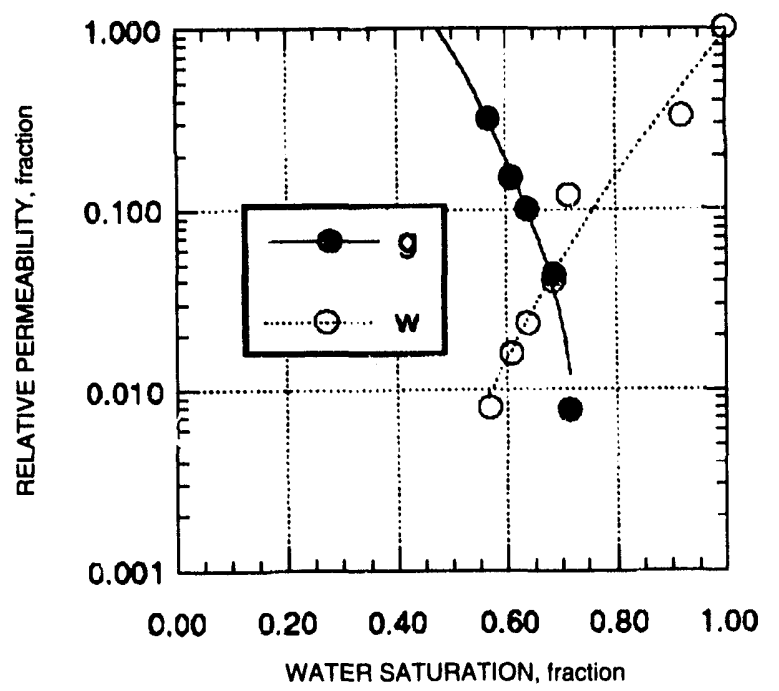

Fig. 3 Steady-state gas-water relative permeability results for plug 4,959. Results are normalized with respect to $k_{w}=5.78 \mathrm{mD}$ at $S_{w}=1.000 . g$, gas; $w$, water.

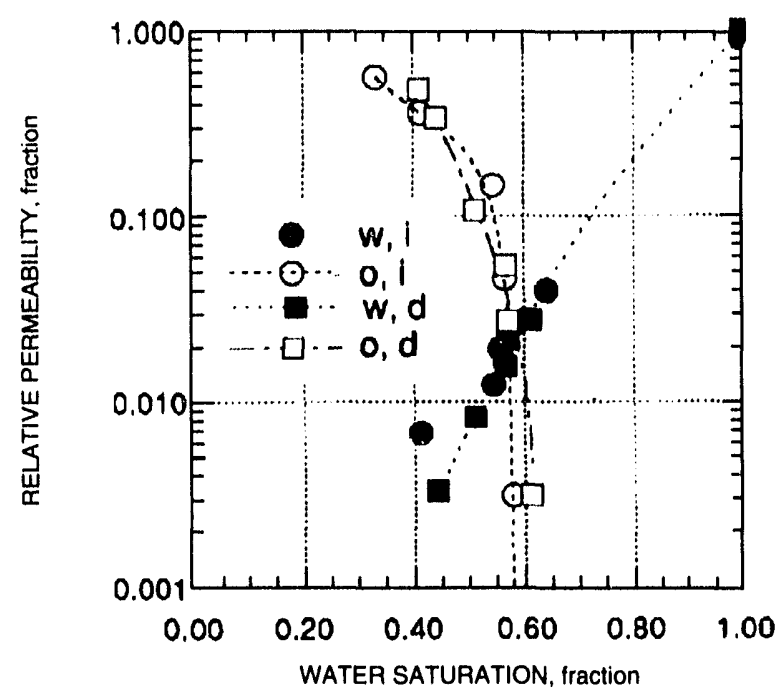

Fig. 4 Steady-state oil-water relative permeability results for plug 4,959. Results are normalized with respect to $k_{w}=5.78 \mathrm{mD}$ at $S_{w}=1.000$. w, water; o, oil; $i$, imbibition; $d$, drainage.

sample with an average of $17.66 \%$ for the sample. The $17.66 \%$ figure from the CT scan data compares favorably with the $17.9 \%$ volumetric/gravimetric result. Resistance measurements were recorded using the $1 \% \mathrm{NaCl}$ brine as the flowing medium, then again after injecting $5 \% \mathrm{KI}$, $2 \% \mathrm{CaCl}$ brine to replace the $\mathrm{NaCl}$ brine. Resistance measurements were recorded at a frequency of $1 \mathrm{kHz}$ using a series R-C approximation. The unsteady-state test will be conducted during the next reporting period.

\section{Technology Transfer}

The principal investigator gave talks on reservoir condition core analysis measurements for a major oil company during a special core analysis workshop in April.

Representatives attended the Society of Core Analysts/ Society of Professional Well Log Analysts (SCA/SPWLA) joint annual technical conference and exhibition in Oklahoma City on June 15-17. The National Institute for Petroleum and Energy Research (NIPER) had an exhibition booth at the SCA/SPWLA meeting. Many copies of topical reports for the BE9 project were given to SCA/SPWLA members who visited the NIPER booth during the meeting. The principal investigator attended an American Petroleum Institute (API) subcommittee meeting on routine core analysis on June 18. 


\section{THIRD INTERNATIONAL RESERVOIR CHARACTERIZATION TECHNICAL CONFERENCE}

\section{Cooperatlve Agreement DE-FC22-83FE60149, Project SGP47}

\author{
National Institute for Petroleum \\ and Energy Research \\ Bartlesville, Okla.
}

Contract Date: Dec. 1, 1990

Anticipated Coripletion: Sept. 30, 1992

Funding for FY 1992: $\$ 33,000$

Principal Investigator:

Bill Linville

Project Manager

Edith Allison

Bartlesville Project Office

Reporting Period: Apr. 1-June 30, 1992

\section{Objectives}

The objectives of the Third International Reservoir Characterization Technical Conference were to (1) explore meth- ods to integrate engineering and geological disciplines to improve the understanding of fluid flow in petroleum reservoirs; (2) review current practices, procedures, and technologies applied to reservoir characterization; (3) identify problems related to current practices and procedures for accurate reservoir descriptions and the information and technology required to solve the problems; (4) identify emerging technologies and promising directions for future research; and (5) provide a means for technology transfer.

\section{Summary of Technical Progress}

All authors who had not completed the revisions of their manuscripts were contacted and asked to send final copy to the National Institute for Petroleum and Energy Research (NIPER) by July 6, and most of those contacted agreed to the deadline.

Two authors were asked to submit manuscripts of their talks for publication in the Proceedings.

The address was returned for final revision. The author revised the manuscript and returned it to NIPER for final typing.

Because of delays in reviewing both oral and poster presentations, the anticipated date of publication of the Proceedings was extended 60 days to Dec. 1, 1992.

Several registrants have requested information about a Fourth Conference, indicating interest in continuing the biennial series. 


\section{MICROBIAL TECHNOLOGY}

\section{MICROBIAL. ENHANCED OIL RECOVERY AND WETTABILITY RESEARCH PROGRAM}

Contract No. DE-AC07-ID01570, Project 5AC3

Idaho Natlonal Engineering Laboratory EG\&G Idaho

Idaho Falls, Idaho

Contract Date: Oct. 1, 1988

Anticipated Completion: Sept. 30, 1995

Funding for FY 1992: $\$ 600,000$

\section{Principal Investigator:}

\section{P. Thomas}

Project Managers:

L. S. McCoy

idaho Operations Office

Rhonda Lindsey

Bartlesville Project Office

Reporting Period: Apr. 1-June 30, 1992

\section{Objectives}

The objectives of this research program are to develop microbial enhanced oil recovery (MEOR) systems for application to reservoirs containing medium to heavy oils and to evaluate reservoir wettability and its effects on oil recovery.

The MEOR research goals include

- Development of bacterial cultures that are effective for oil displacement under a broad range of reservoir conditions.

- Improved understanding of the mechanisms by which microbial systems displace oil under reservoir conditions.

- Determination of the feasibility of combining microbial systems with or following conventional enhanced oil recovery (EOR) processes, such as miscible and immiscible gas flooding, polymer and chemical flooding, and thermal methods.

- Development of an MEOR field process design and implementation of an industry cost-shared field demonstration project.

The goals of the reservoir wettability research are to develop

- Better methods for assessment of reservoir core wettability. 
- More certainty in relating laboratory core analysis procedures to field conditions.

- Better understanding of the effects of reservoir matrix properties and heterogeneity on wettability.

- An improved ability to predict and influence EOR response through control of wettability in reservoirs.

\section{Summary of Technical Progress}

\section{MEOR Research: Microbially Mediated Oil Displacement}

Experiments to define the potential of Bacillus licheniformis JF-2 MEOR systems and facilitate comparison to established EOR techniques have been initiated. A Berea sandstone core (Table 1, Fig. 1) was flooded with $15 \mathrm{PV}$ of $B$. licheniformis JF-2 cell-free supematant [recovery $=13,1 \%$ original oil in place (OOIP)], waterflooded with $15 \mathrm{PV}$ brine, and then flooded with $0.2 \mathrm{PV}$ of ethoxylated sulfate surfactant and $15 \mathrm{PV}$ brine (recovery $=37.8 \%$ OOIP). Entrainment of oil by the aqueous phase during the total supernatant flood and the shape of the oil recovery curve indicate that the supernatant does mobilize the oil that it contacts in the core. Results (the moderately sloped continual curve) strongly suggest the absence of an oil bank. The recovery mechanism of the supernatant appears to be either oil solubilization, interfacial ten- sion (IFT) reduction, or both. The supernatant was generated in conditions generally regarded as complete [trypticase soy broth (TSB) aerobically at $37^{\circ} \mathrm{C}$ ]. IFTs of the chemical surfactant were $\approx 10^{-2} \mathrm{mN} / \mathrm{m}$, and the $B$. licheniformis JF-2 cellfree supernatant was $\approx 3 \mathrm{mN} / \mathrm{m}$. A TSB control flood (no chemical or biological surfactants) produced $1.9 \%$ OOIP $[2.8 \%$ waterflood residual oil saturation $\left.\left(\mathbf{S}_{\text {orwf }}\right)\right]$.

Evaluation of microbial surfactant production using various carbon and energy sources continues. Constituents of various feedstocks (simple sugars, complex carbohydrates, organic acids, etc.) are being screened to aid in the identification of field amenable media constituents. Residuals from

TABLE 1

\section{Core 74 Flood Results*}

\begin{tabular}{lccc}
\hline \multicolumn{1}{c}{ Flood } & S or & $\begin{array}{c}\text { Er, \% } \\
\text { ROIP† }\end{array}$ & $\begin{array}{r}\text { Er, \% } \\
\text { OOIP† }\end{array}$ \\
\hline 1st waterflood & 56.0 & 32.9 & 32.9 \\
Straight supernatant & 45.1 & 19.5 & 13.1 \\
2nd waterflood & 42.5 & 5.8 & 3.1 \\
20\% PV slug of ethoxylated sulfate & & & \\
$\quad$ surfactant, followed by 15 PV brine & 11.0 & 74.1 & 37.8 \\
\hline
\end{tabular}

*Initial oil saturation $\left(\mathrm{S}_{\mathrm{oi}}\right), 83.4 \%$.

$\uparrow$ ROIP, residual oil in place; OOIP, original oil in place.

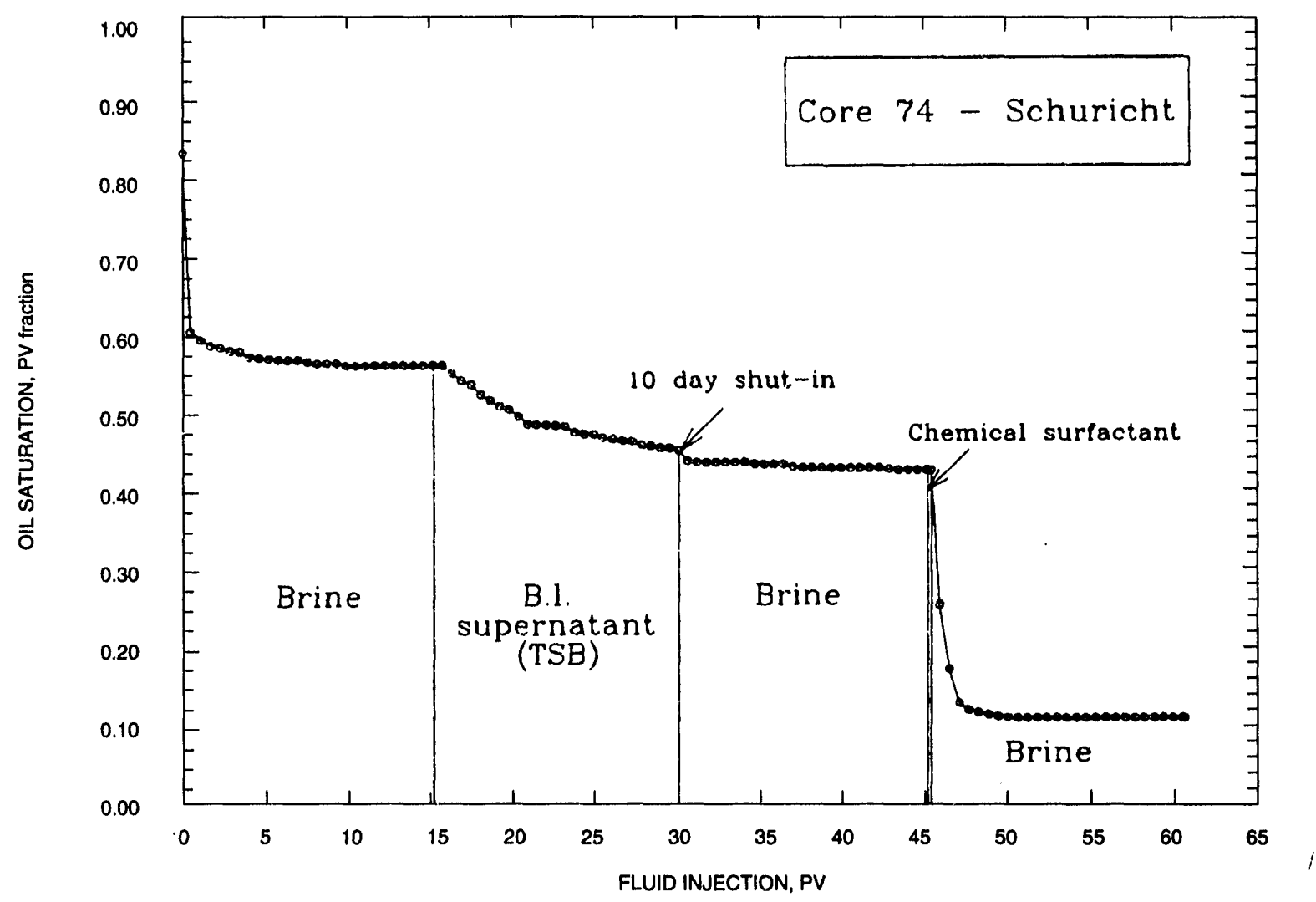

Fig. 1 Effect of $15 \mathrm{PV}$ of supernatant compared to $0.2 \mathrm{PV}$ of chemical surfactant. 
agricultural processing are often products that must be handled as waste unless a suitable market niche is identified. Utilization of these products for field trial application is being evaluated. Data indicate that surfactant production mediated by Bacillus subtilis (ATCC 21331) is greatest when grown on $0.5 \%$ starch. Starch is readily available as an agricultural processing residual. Further, $B$. subtilis outperformed $B$. licheniformis JF-2 with respect to surfactant production under all conditions tested. Surfactant production was evaluated by comparing the surface tension of abiotic media controls and cell-free supernatants. Cells were grown aerobically at $37^{\circ} \mathrm{C}$ for $72 \mathrm{~h}$. Data are presented in Fig. 2.

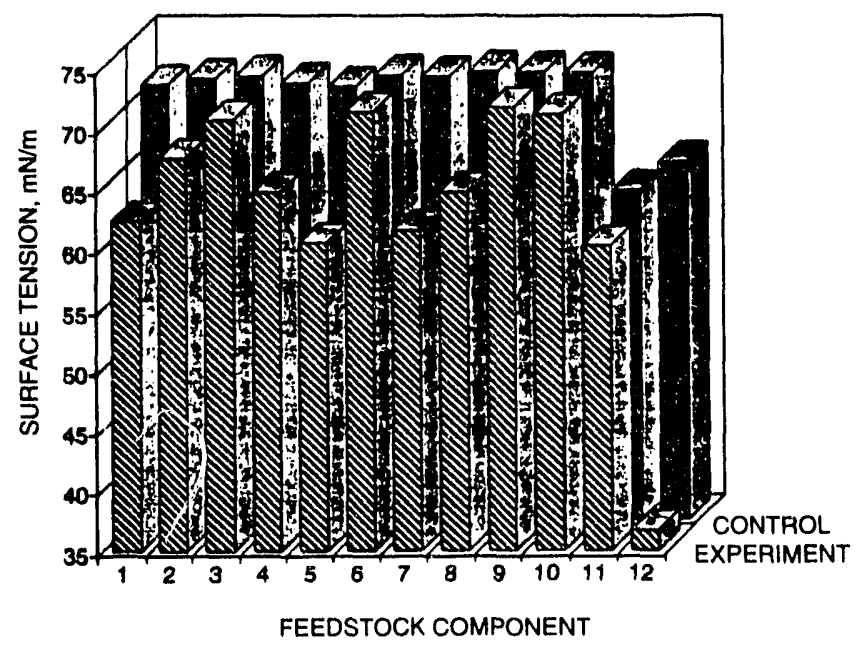

(a)

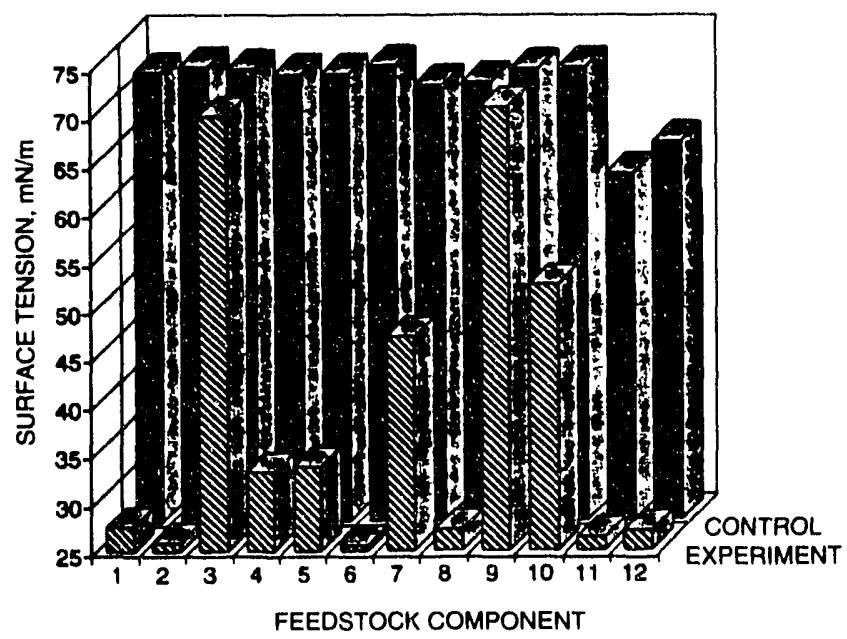

(b)

Fig. 2 Utilization of alternate feedstock components for production of surfactants by (a) Bacillus licheniformis JF-2 and (b) Bacillus subtilis (ATCC 21331). Components (1\% in Medium E unless noted) are (1) sucrose, (2) fructose, (3) galactose, (4) dextrose, (5) molasses, (6) starch $(0.5 \%),(7)$ glycerol, (8) pyruvate, (9) acetate, (10) citrate, (11) casitone, and (12) yeast extract.

\section{Evaluation of Reservoir Wettability and Its Effects on Oil Recovery}

\section{Effect of Flooding Rate on Oil Recovery}

It is widely accepted that most oil reservoirs have some form of mixed wettability condition. The effect of flooding rate on oil recovery is a crucial issue, both for reservoir performance and in the design of laboratory waterfloods. Previous studies indicated that oil recovery was essentially independent of rate for $I_{w-0}$ in the range of 0.3 to 0.6 and tended to increase slightly with rate (1 to $50 \mathrm{ft} / \mathrm{d}$ ) for $I_{w-1}$ in the range of 0.04 to 0.35 .

The effect of rate (or pressure drop) on oil recovery has been investigated for mixed wettability systems in the range of $\mathrm{I}_{w-1}=0.55$ to 0.83 . For systems with wettability in this range, oil recovery decreases systematically with reduction in flood rate over the interstitial velocity range 0.4 to $5.0 \mathrm{ft} / \mathrm{d}$. Experiments were conducted using Moutray crude oil (density $=0.868 \mathrm{~g} / \mathrm{cm}^{3}$, viscosity $=9.74 \mathrm{cP}$ ), a synthetic brine composed of $2 \% \mathrm{CaCl}_{2}$ in distilled water, and Berea sandstone cores $(3.8 \mathrm{~cm}$ in diameter and 4.0 to $7.2 \mathrm{~cm}$ in length). Further testing is planned to determine the extent to which observed trends are generally applicable.

\section{Rates of Displacement of Crude Oil by Spontaneous Imbibition}

An investigation has been made of short-term rates of imbibition of water and long-term recovery by spontaneous imbibition for crude oil-brine-rock (COBR) systems. The goal of this researr $h$ was to determine the effects of crude oil aging time and temperature on the rates of imbibition as a means of obtaining wettability control for the selected COBR system. Twenty-seven water imbibition tests were performed at ambient conditions. After establishing an initial water saturation, samples were aged in an Alaskan crude oil (Alaskan 5/90) for various time periods at either ambient temperature or $80^{\circ} \mathrm{C}$. For the system studied (Alaskan $5 / 90,2 \% \mathrm{CaCl}_{2}$ brine, and Berea sandstone) the rate of imbibition of water decreased with increasing aging time and increasing aging temperature. Long-term imbibition recovery was less affected by the aging, and recoveries were generally high. Moderately water-wet plugs gave the highest recovery by long-term imbibition. It is concluded that

- Measurement of short-term imbibition rates (STIR) of water provides a fast means of distinguishing between various wettability states, particularly for systems that exhibit a high Amott index to water.

- STIR decreases systematically with increase in aging time and temperature and provides a convenient means of investigating the effect of aging time and temperature on adsorption kinetics.

- After evaporation of light ends from the tested crude oil, the ability of the crude to change the wettability of initially water-wet sandstone increased. 
- Observations of how oil is expelled at the rock surface provide useful indications of the magnitude of capillary pressures acting within the rock when they are very close to zero.

- Continuity of the oil phase can be inferred when changes of expelled drop size with height are consistent with changes in buoyancy forces within the core.
- High oil recovery was observed for long-term spontaneous imbibition ( $\approx 55 \mathrm{~d}$ ) for cores that are weakly waterwet.

- Conditions of wettability induced by aging in crude oil, as measured by STIR, were almost unchanged after more than three months.

\section{EFFECTS OF SELECTED THERMOPHILIC MICROORGANISMS ON CRUDE: OILS AT ELEVATED TEMPERATURES AND PRESSURES}

\section{Contract No. DE-AC02-76CH00016}

\author{
Brookhaven National Laboratory \\ Upton, Long Island, N.Y.
}

\section{Contract Date: Mar. 1, 1989}

Anticipated Completion: Sept. 30, 1992

Government Award: $\mathbf{\$ 2 2 5 , 0 0 0}$

(Current year)

\section{Principal Investigators: \\ E. T. Premuzic \\ M. S. Lin}

Project Manager:

Rhonda Lindsey

Bartlesville Project Office

Reporting Period: Apr. 1-June 30, 1992

\section{Objective}

The objective of this program is to determine the chemical and physical effects of thermophilic organisms on crude oils and cores at elevated temperatures and pressures. Ultimately a database will be generated that will be used in technical and economic feasibility studies leading to field application.

\section{Summary of Technical Progress}

\section{Duration of Biotreatment and Media Effects}

The biochemical processes that occur during the biotreatment of crude oils are influenced not only by the type of microorganisms used, but also by the composition of the reaction mixture and duration of the treatment. ${ }^{1,2}$ These re- action mixture components include (a) oil as the sole carbon source; (b) oil plus an additional source of carbon; (c) oil plus detergent added before biotreatment; and (d) detergent produced from the oil by microorganisms during biotreatment. In addition, shorter periods of treatment appear to favor the chemical process. In order to further refine these observations, Monterey Crude Oil A836, an immature, off-shore Monterey California crude, was treated for $7 \mathrm{~d}$ and for $20 \mathrm{~d}$ in the presence and absence of tergitol in Medium 3. The medium is a modification of Medium 1, in which the sulfate was replaced by a chloride. The choice of tergitol, a C-21 carbon emulsifying agent containing ethylene oxide and hydroxide functional groups, was based on earlier experiments. ${ }^{3}$ In these experiments, after the biotreatment of a crude oil, the emulsion was extracted with an organic solvent and the extract was analyzed for hydrocarbon content. Chemical analysis showed that C-13 to C-26 hydrocarbons were dispersed in the emulsified phase. Although detailed chemical analyses of the contents of the aqueous and the emulsified phases after biotreatment have yet to be carried out, production of a long chain aliphatic, hydrocarbon alcohol from crude oil is a reasonable assumption. ${ }^{4}$ It is to be understood that this does not imply that the choice of tergitol is the best one, nor does it imply that only a single surface active agent is produced during the biotreatment of crude oils. Indeed, if the microbial production of detergents from crude oils is consistent with other observations, all of which indicate that after biotreatment the chemical composition of the end product depends on several factors including microbial species and type of crude oil, then one should expect to find several chemically distinct classes of detergents that can be biosynthesized from crude oils.

The results of biotreatment of A836 are given in Table 1 . The corresponding gas chromatography-mass spectrometry (GC-MS) results for A836 treated with BNL-4-22 and BNL-4-23 in absence of tergitol are given in Fig. 1. The GC-MS analyses have been carried out under identical experimental conditions, concentration, and instrument settings, allowing for direct comparison spectra. As expected, significant changes occur after a 20 -d treatment in the 
TABLE 1

Monterey Oil A836 Biotreatment

\begin{tabular}{|c|c|c|c|c|c|c|c|c|c|}
\hline Microorganism & Detergent & Medium & $\begin{array}{c}\text { Volume, } \\
\text { ml. }\end{array}$ & $\begin{array}{c}\text { Oll, } \\
\%\end{array}$ & $\begin{array}{c}\text { Incubation, } \\
\text { d }\end{array}$ & $\begin{array}{l}\text { Viscosity, } \\
\text { cP }\end{array}$ & $\begin{array}{l}\text { Optical } \\
\text { density, } \\
545 \mathrm{~nm}\end{array}$ & $\begin{array}{c}\text { Klett } \\
\text { units, } \\
\text { OD } \times 5(X)\end{array}$ & $\mathbf{p H}$ \\
\hline \multicolumn{10}{|c|}{ No Detergent Experiment II } \\
\hline BNL-4-22 & No & 3 & 125 & 0.484 & 7 & 2.5 & 0.0060 & 3.000 & 3.50 \\
\hline BNL-4-23 & No & 3 & 125 & 0.434 & 7 & 2.5 & 0.0050 & $2.5(x)$ & 3.50 \\
\hline Control oil & No & 3 & 125 & 0.518 & 7 & 2.6 & 0.0010 & $0.5(0)$ & 3.50 \\
\hline BNL-4-22 control & No & 3 & 125 & 0.000 & 7 & 2.4 & $0.01(0)$ & $5.0(X)$ & 3.50 \\
\hline BNL-4-23 control & No & 3 & 125 & 0.000 & 7 & 2.5 & 0.0010 & $0.5(0)$ & 3.50 \\
\hline Control/control & No & 3 & 125 & 0.000 & 7 & 2.5 & 0.00000 & $0.0(0)$ & 3.50 \\
\hline \multicolumn{10}{|c|}{ No Detergent Experiment III } \\
\hline BNL-4-22 & No & 3 & 125 & 0.491 & 20) & NA & 0.9570 & 28.490 & 4.00 \\
\hline BNL-4-23 & No & 3 & 125 & 0.510 & 20 & NA & 0.1935 & 96.725 & 4.25 \\
\hline Control oil & No & 3 & 125 & 0.518 & 20) & $N A$ & 0.0540 & 27.010 & 4.25 \\
\hline BNL-4-22 control & No & 3 & 125 & 0.000 & 20 & NA & 0.0292 & 14.595 & 4.25 \\
\hline BNL-4-23 control & No & 3 & 125 & 0.000 & 20 & NA & 0.0107 & 5.365 & 4.00 \\
\hline Control/control & No & 3 & 125 & 0.000 & 20) & NA & 0.0194 & 9.710 & 4.00 \\
\hline \multicolumn{10}{|c|}{ With Detergent Experiment II } \\
\hline BNL'-4-22 & Yes & 3 & 125 & 0.533 & 20) & 2.7 & 0.0240 & 12.000 & 3.50 \\
\hline BNL,-4-23 & Yes & 3 & 125 & 0.617 & 20 & 2.6 & 0.0140 & 7.000 & 3.50 \\
\hline Control oil & Yes & 3 & 125 & 0.528 & 20 & 2.6 & 0.0180 & 9.00() & 3.50 \\
\hline BNL-4-22 control & Yes & 3 & 125 & 0.000 & 20 & 2.5 & 0.0520 & 26.000 & 3.50 \\
\hline BNL-4-23 control & Yes & 3 & 125 & 0.000 & 20 & 2.4 & 0.0300 & 15.000 & 3.50 \\
\hline Control/control & Yes & 3 & 125 & 0.000 & 20 & 2.4 & 0.0390 & $19.50(x)$ & 3.50 \\
\hline \multicolumn{10}{|c|}{ With Detergent Experiment III } \\
\hline BNL-4-22 & Yes & 3 & 125 & 0.478 & 7 & 2.3 & 0.0268 & 13.400 & 4.00 \\
\hline BNL-4-23 & Yes & 3 & 125 & 0.512 & 7 & 2.5 & 0.0206 & 10.290 & 4.50 \\
\hline Control oil & Yes & 3 & 125 & 0.410 & 7 & 2.5 & 0.0592 & 29.580 & 4.50 \\
\hline BNL-4-22 control & Yes & 3 & 125 & 0.000 & 7 & 2.3 & 0.1036 & 51.800 & 4.25 \\
\hline BNL-4-23 control & Yes & 3 & 125 & $0.040)$ & 7 & 2.5 & 0.1239 & 61.950 & $4 .(0)$ \\
\hline Control/control & Yes & 3 & 125 & $0.000)$ & 7 & 2.3 & 0.0206 & 10.285 & 4.25 \\
\hline
\end{tabular}

presence or absence of the detergent $(0.0075 \%$ tergitol). However, comparable results are also obtained in the absence of the detergent, except in the BNL-4-23 case where an exceptionally high extent of emulsification (96 Klett units) relative to other samples was measured. These experiments are being repeated. The results given in Table 1 also show that a 7-d biotreatment is useful, and further studies with other oils will indicate whether the shorter (i.e., less than $20 \mathrm{~d})$ treatments should be considered for routine applications. GC-MS analyses shown in Fig. 1 clearly indicate a decrease in the higher molecular weight fractions (scans between 2000 and 3600). They also indicate fine changes in the 2400 region. Because the Monterey A836 crude oil is high in sulfur (4\%), a sulfur-specific detector has been used to carry out a GC analysis of untreated and biotreated samples. The results are shown in Fig. 2. The chromatographic analyses for organic sulfur compounds and the results have been recorded under identical experimental conditions (injected amount, retention, time and attenuation) allowing for direct comparison of the chromatographic scans. These results show a $50 \%$ or better conversion and/or removal from the oil phase of organic sulfur compounds.

\section{Comparative Studies with Domestic (USA) Crudes}

Experiments described in Section 1 are now being conducted with other Monterey California crudes as well as crude oils from Arkansas and Alabama.

\section{Microscopic and Chemical Comparison of Reaction Mixtures}

The work is continuing with additional samples subjected to different microbial species under otherwise identical experimental conditions.

A block of Berea Sandstone has been obtained and will be cut into cores for subsequent coreflooding experiments. 


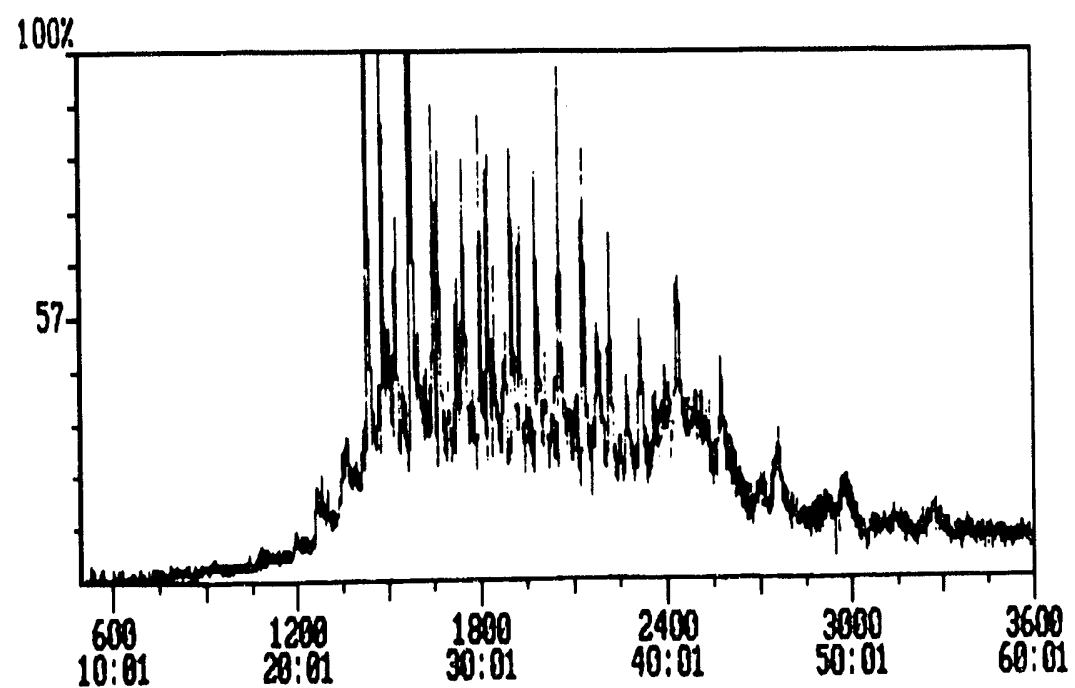

(a)

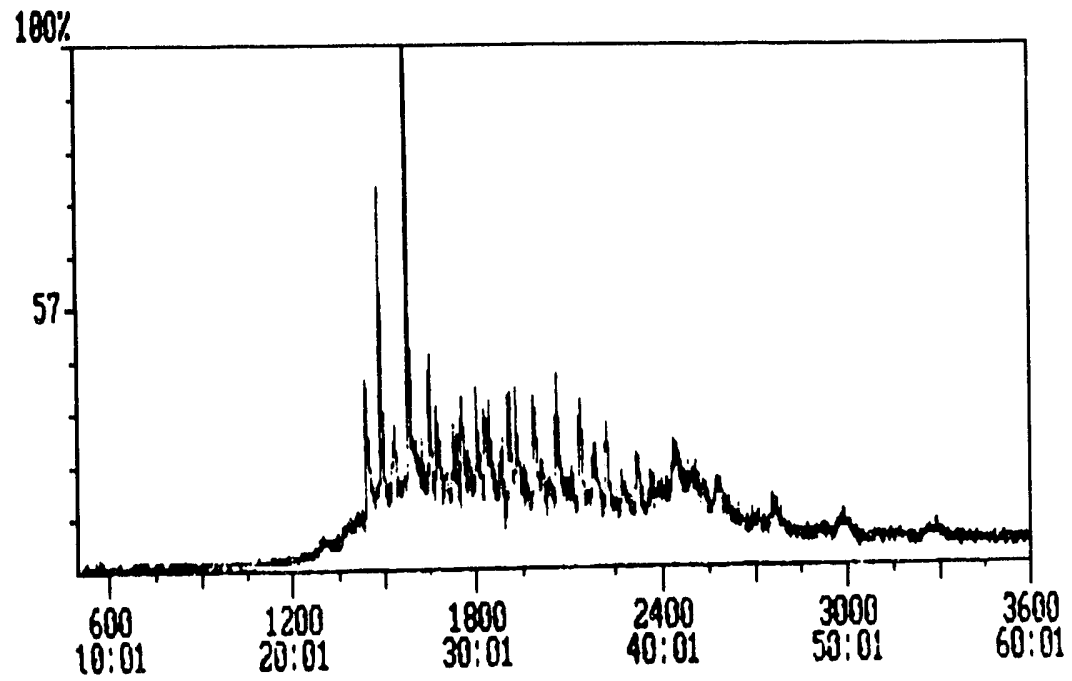

(b)

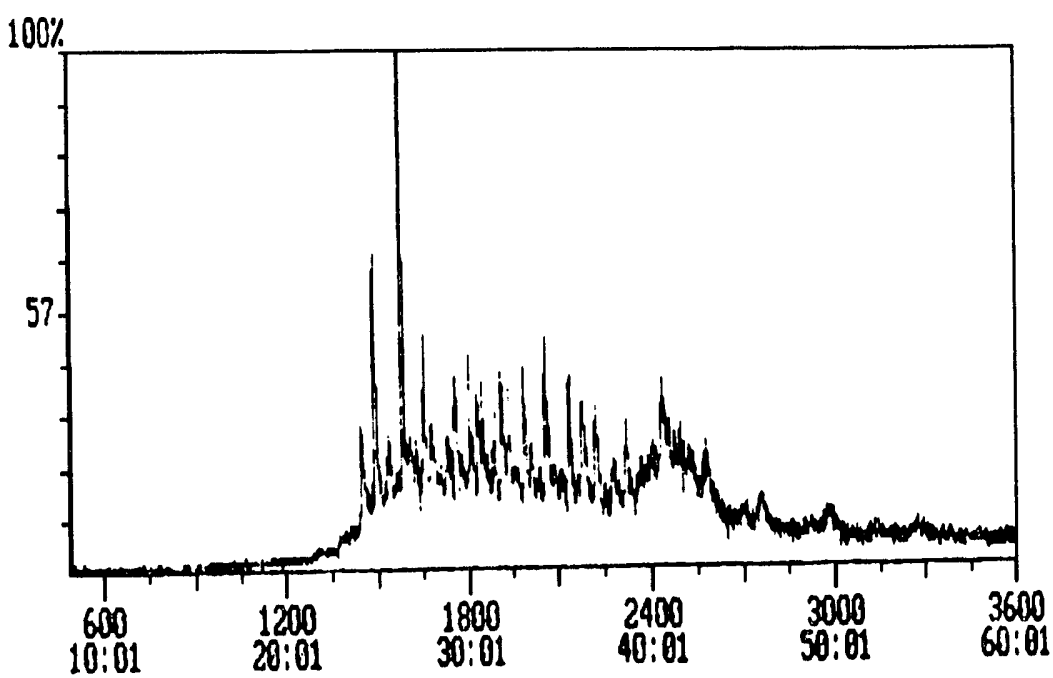

(c)

Fig. 1 Gas chromatography-mass spectrometry (GC-MS) scan of Monterey Crude Oil A836; (a) control; (b) treated with BNL-4-22; (c) treated with BNL-4-23. 


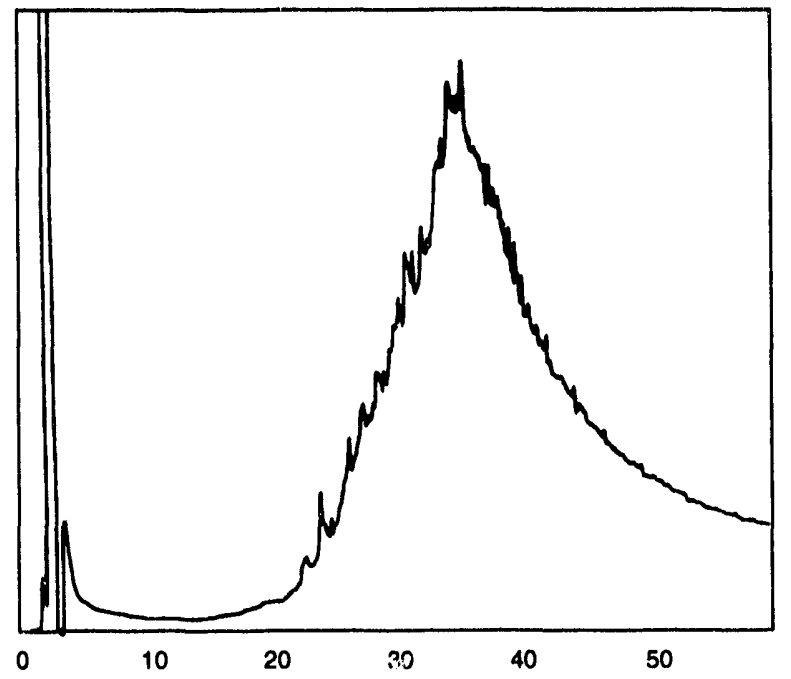

(a)

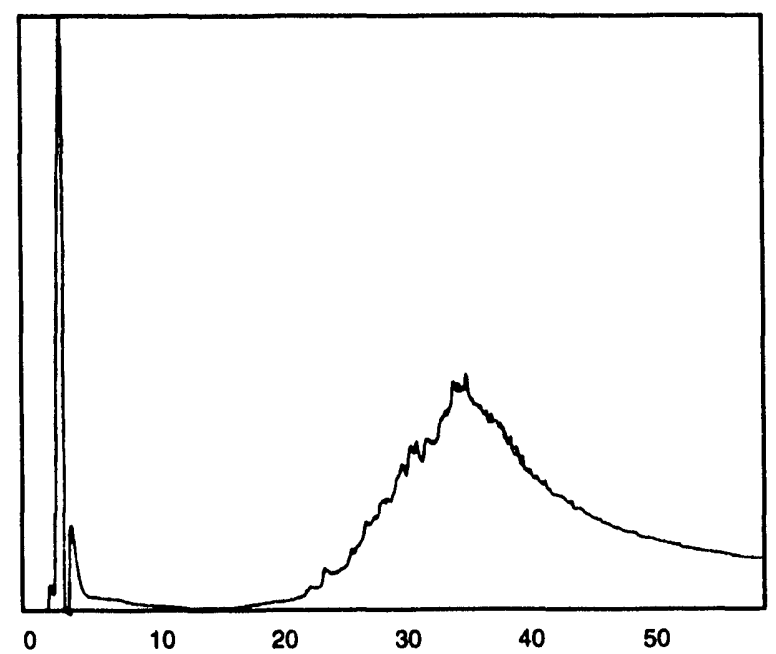

(b)

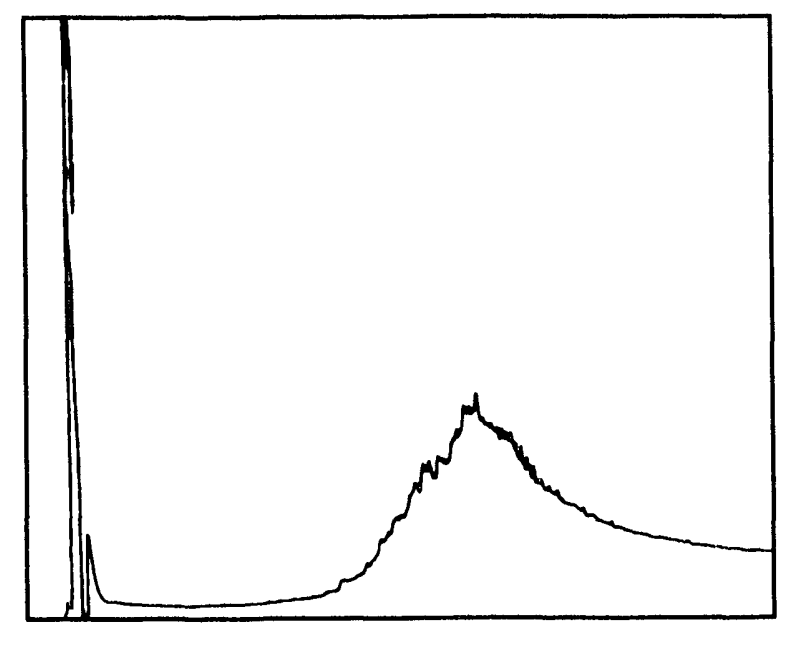

$0 \quad 10$

20

30

40

50

(c)

Fig. 2 Gas chromatographic analyses of Monterey A836 crude. Flame photometric detector (FPD) trace of (a) control A836; (b) treated with BNL-4-22; (c) treated with BNL-4-23.

\section{References}

1. E. T. Hremuzic and M. S. Lin, Effects of Selected Thermophilic Microorganisms on Crude Oils at Eleyated Temperatures and Pressures, Quarterly Report (Jan. I. 1992-Mar. 30, 1992), Report BNL 47555, May 1992.

2. E. T. Premuzic and M. S. Lin, Prospects for Thermophilic Microorganisms in Microbial Enhanced Oil Recovery (MEOR), in Proceedings of the 1990 International Conference on Microbial Enhancement of Oil Recovery-Recent Advances, Norman, Okla., May 1990; also in Developments in Petroleum Science, Vol. 31, E. C. Donaldson (Ed.), Report BNL 44984, Ch. R-18, pp. 277-296, Elsevier, Amsterdam, 1991.

3. E. T. Premuzic and M. S. Lin, Prospects for Thermophilic Microorganisms in Microbial Enhanced Oil Recovery (MEOR)-Part II, in Proceedings of the International Symposium on Oil Field Chemistry. February 1991, Anaheim, Calif., paper SPE 21015, Report BNL 45650. pp. 143-148, 1991.

4. J. E. Zajic and A. Y. Mahomedy, Biosynthesis of Surface Active Agents, in Petroleum Microbiology, R. M. Atlas (Ed.), Ch. 6, pp. 221-297, Macmillan, New York, 1984.

\section{DEVELOPMENT OF IMPROVED MICROBIAL FLOODING METHODS}

Cooperative Agreement DE-FC22-83FE60149, Project BE3

\section{National Institute for Petroleum and Energy Research Bartlesville, Okla.}

Contract Date: Oct. 1, 1983

Anticipated Completion: Sept. 30, 1992

Funding for FY 1992: $\$ 300,000$

Principal Investigator:

Rebecca S. Bryant

Project Manager:

Rhonda Lindsey

Bartlesville Project Office

Reporting Period: Apr. 1-June 30, 1992

\section{Objective}

The objective of this project is to develop an engineering methodology for designing and applying microbial methods to improve oil recovery. 


\section{Summary of Technical Progress}

Microbial mechanisms that have been shown by the National Institute for Petroleum and Energy Research (NIPER) to be important for oil mobilization include gas and surfactant production. It is important to determine the contribution of microbial gas production to oil mobilization. In this regard, experiments with computerized tomography/nuclear magnetic resonance (CT/NMR) imaging and an X-ray/ microwave relative permeability apparatus may provide information to assist in the determination of the effect of trapped gas saturation in porous media. To date, there are no reports in the literature where these types of experiments have been conducted with microbial formulations. The only reported relative permeability data for microbial formulations was obtained by NIPER's BE3 research program. This year, experiments with oil-wet rock will provide more information on the effects of wettability on microbial oil mobilization.

Work on this project has included the continuing development of a three-dimensional (3-D), three-phase, multiplecomponent numerical model to describe the microbial transport phenomena in porous media. Initial efforts have focused on incorporating the most important phenomena for which mathematical models or correlations are available or can be available in a reasonably brief period of time.

Work for FY92 will continue the development of laboratory experiments to refine the model, not only with the above parameters, but also for cbtaining data to incorporate microbial oil recovery mechapisms. Mechanisms considered to be important for oil recovery include changes in microscopic properties, such as interfacial tension, wettability, and adsorption, that govern oil mobilization and affect fractional flow and relative permeabilities. Other oil recovery mechanisms traditionally associated with fluid flow changes include polymer and biomass production by microorganisms.

Several microbial retention tests were completed this quarter. A Berea sandstone core with a permeability of 2.5 darcys was used to determine if the higher permeability had a different effect on microbial cell retention. Interestingly, it was found that a similar amount of microbial retention was obtained with this higher permeability core when compared with the $900-\mathrm{mD}$ cores. Another retention test using a $400-\mathrm{mD}$ core was then conducted and showed that 99\% of the cells were retained. The lower permeability of the Berea core is obviously causing a greater retention of the microbial cells. The pressure drop across the core during the microbial cell injection was measured and showed no significant increase in pressure. This may indicate that the greater cell retention is due to adsorption or cell destruction rather than to a high amount of plugging. Another experiment was conducted to evaluate what happens when a lower concentration of microbial cells $\left(1 \times 10^{5}\right.$ cells $\left./ \mathrm{mL}\right)$ is injected into a low-permeability core. The results here were interesting in that no cells were detected in the efflu- ent. Evidently all microbial cells injected were adsorbed or retained by some other mechanism.

Microbial adsorption studies with microbial formulations and crushed Berea sandstone were initiated. Sixteen grams of NIPER 6 bacterial cells was centrifuged, washed, and added to $8 \mathrm{~g}$ of crushed Berea. A corresponding flask containing no Berea was used as a control. All flasks were stirred for $24 \mathrm{~h}$. The microbial counts decreased from $3.4 \times 10^{8}$ to $2.9 \times 10^{5}$ and from $5.6 \times 10^{6}$ to less than $1 \times 10^{3}$ in the flasks containing Berea sandstone. An adsorption experiment was then conducted using the same concentration of cells from the retention test $\left(1 \times 10^{5}\right)$. The results corroborated those of the retention test. No cells were obtained in the effluent of the adsorption tests that used the lower concentration of cells.

A study was conducted to match the oil recovery and pressure drop results of two microbial corefloods that used the same microbial formulation and incubation conditions, but one core had 0.5 PV injected whereas the other had 1.0 PV injected. Figure 1 shows the results from the two corefloods. These data will be used in a simulation match.

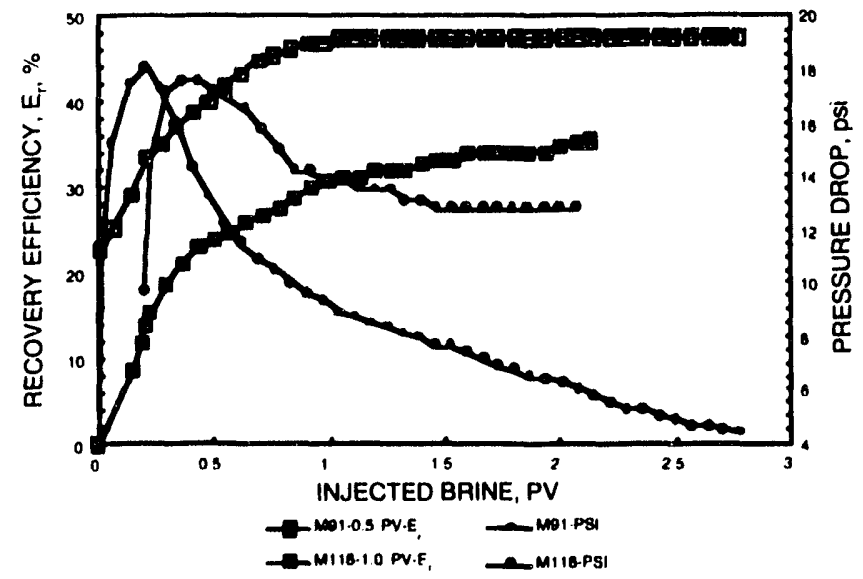

Fig. 1 Comparison of recovery efficiency and pressure drop of microbial corefloods.

A CT experiment was conducted this quarter with Chelsea-Alluwe crude oil tagged with $20 \%$ iododecane. The core was waterflooded to residual oil saturation and then injected with 0.1 PV of NIPER IA and 7 and 0.4 PV of $4 \%$ molasses. The core was then incubated for $48 \mathrm{~h}$, and the pressure was monitored. The core was then waterflooded at $1 \mathrm{ft} / \mathrm{d}$ while maintaining a pore pressure of $40 \mathrm{psi}$. The saturations of this core were as follows: (1) Initial oil saturation $\left(\mathrm{S}_{\mathrm{oj}}\right), 68 \%$; (2) Oil saturation after waterflood $\left(\mathrm{S}_{\mathrm{orwf}}\right), 34 \%$; (3) Oil saturation after incubation during the second waterflood $\left(\mathrm{S}_{\mathrm{ormf}}\right), 32 \%$; and (4) Oil saturation after release of pore pressure, $27 \%$. During microbial incubation the pressure rose to $40 \mathrm{psi}$. This particular microbial injection gave a recovery efficiency $\left(E_{\mathrm{f}}\right)$ of $5.8 \%$. The release of pore pressure obviously caused some additional oil production. 
Corefloods using various amounts of pore pressure will be conducted to further evaluate the oil recovery of these microbial systems.

Laboratory experiments were conducted, with the U.S. Bureau of Mines (USBM) centrifuge method, to determine the wettability of oil-wet field cores from North Burbank Unit, Oklahoma, and to compare the results with those from earlier tests where the method was used for determining the wettability of water-wet cores. The results obtained agreed with published wettability index values of the North Burbank rock. The results showed that NIPER 1A microbial system altered the wettability of the oil-wet rock $(-0.45)$ to a more intermediate state $(-0.22)$. Moreover, when the cells were filtered out of the NIPER 1A microbial system, the products alone did not alter the wettability from the control values with brine and oil. These results further substantiate earlier findings from this laboratory that the cells themselves are important for wettability alteration and thus oil mobilization. Table 1 and Figs. 2 and 3 show the results of the wettability data.

A paper entitled Laboratory Studies of Parameters Involved in Modeling Microbial Oil Mobilization was presented at the 8th SPE/DOE Enhanced Oil. Recovery Symposium in Tulsa, Okla., April 22-24, 1992 (Ref. 1).

\section{TABLE 1}

\section{Wettability Indices for Microbially Treated Cores}

\begin{tabular}{llc}
\hline Core & Microbes used & Wettability index \\
\hline Bu1 & Products* & -0.672 \\
Bu2 & Products* & -0.421 \\
Bu3 & NIPER 1A & -0.257 \\
Bu4 & NIPER 1A & -0.222 \\
Bu5 & Brine & -0.542 \\
Bu6 & Brine & -0.361 \\
Bu7 & Brine & -0.414 \\
\hline
\end{tabular}

*Products of NIPER IA in molasses.

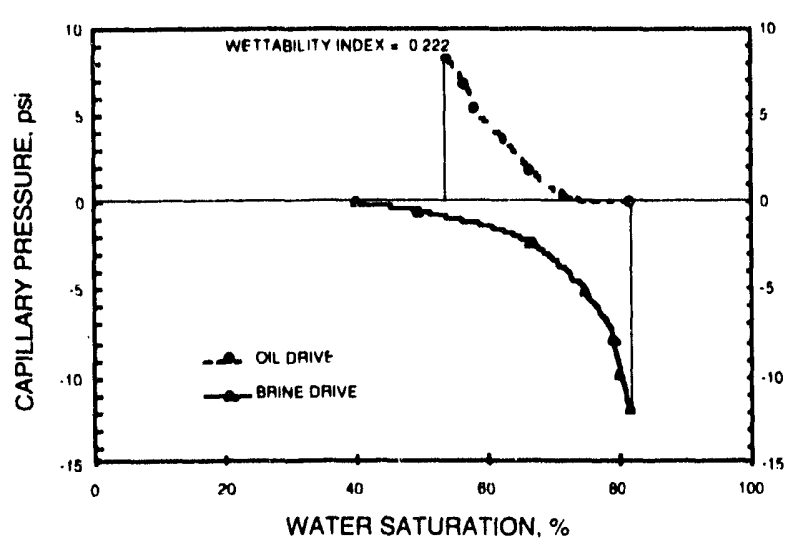

Fig. 2 Capillary pressure curve for core 5-NIPER 1A.

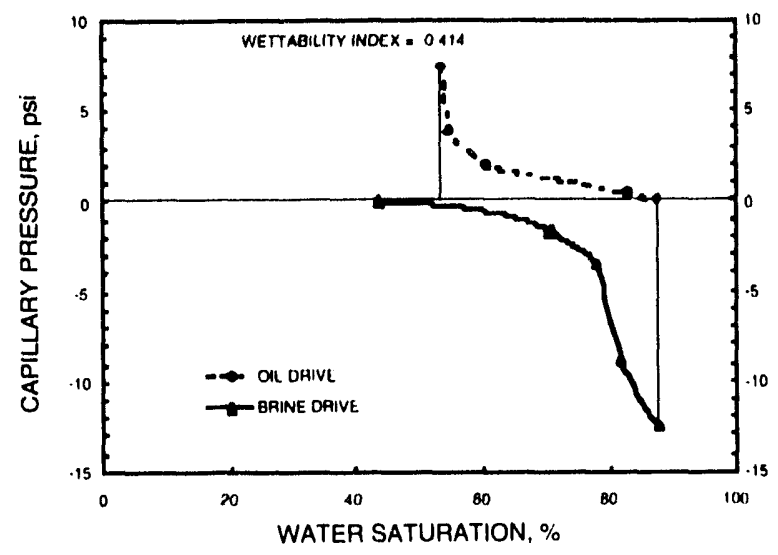

Fig. 3 Capillary pressure curve for core 7-brine.

\section{Reference}

I. R. S. Bryant, A. K. Stepp, K. M. Bertus, M.-M. Chang, and K. L. Chase, Laboratory Studies of Parameters Involved in Modeling Microbial Oil Mobilization, paper SPE 24205 presented at the 8th SPE/DOE Symposium on Enhanced Oil Recovery, Tulsa, Okla., April 22-24. 1992. 
MICROBIAL ENHANCED WATERFLOODING FIELD PROJECT

\section{Cooperative Agreement DE-FC22-83FE60149, Project SGP13}

\author{
Nationai Institute for Petroleum \\ and Energy Research \\ Bartlesville, Okla.
}

\section{Contract Date: Oct. 1, 1983}

Anticipated Completion: Sept. 30, 1992

Funding for FY 1992: $\$ 419,000$

\section{Principal Investigator:}

Rebecca S. Bryant

\section{Project Manager: \\ Rhonda Lindsey \\ Bartlesville Project Otfice}

Reporting Period: Apr. 1-June 30, 1992
Fluorescein was injected as a tracer on June 6, 1990. Samples were collected from all 19 injection wells at $2-\mathrm{h}$ intervals the first day. Twenty-one producers were sampled $24 \mathrm{~h}$ after injection of tracer, daily, weekly, once a month, and quarterly. Since the second day of sampling, the tracer response has never been higher than $0.30 \mathrm{ppm}$ for any of the wells. The pattern of the fluorescein response seems to follow the same trend as that observed during the monitoring of the Mink Unit. There was an initial quick response of tracer from some of the nearest production wells; the response then leveled out to very low values. Fluorescein values seemed to peak at $145 \mathrm{~d}$ and are still being monitored.

Wellhead injection pressures and volumes continue to be monitored and have shown no signs of plugging or any other problems. Molasses injection ceased at the end of December 1991. Figure 1 shows oil production values of the baseline and postmicrobial injection. As a result of inclement weather, oil production has declined slightly from January through March 1992. In April pulling units were able to be used, and oil production should increase the next quarter. Oil production data will continue to be obtained throughout this year.

\section{Objectives}

The objectives of this project are to determine the feasibility of improving oil recovery in an ongoing waterflood using microorganisms and to expand the initial pilot and determine the economics of microbial enhanced waterflooding. The scope of work includes continued monitoring of the Phoenix field site.

\section{Summary of Technical Progress}

The expanded microbial enhanced oil recovery (MEOR) project site is in Section 8, Township 24 North, Range 17E of Rogers County, Oklahoma. This site is part of ChelseaAlluwe field in the Bartlesville formation and was initially developed soon after Delaware-Childers field. The site owned by Phoenix Oil and Gas, Ltd., is being waterflooded. This field is in an isolated area with virtually no other oilproducing leases nearby.

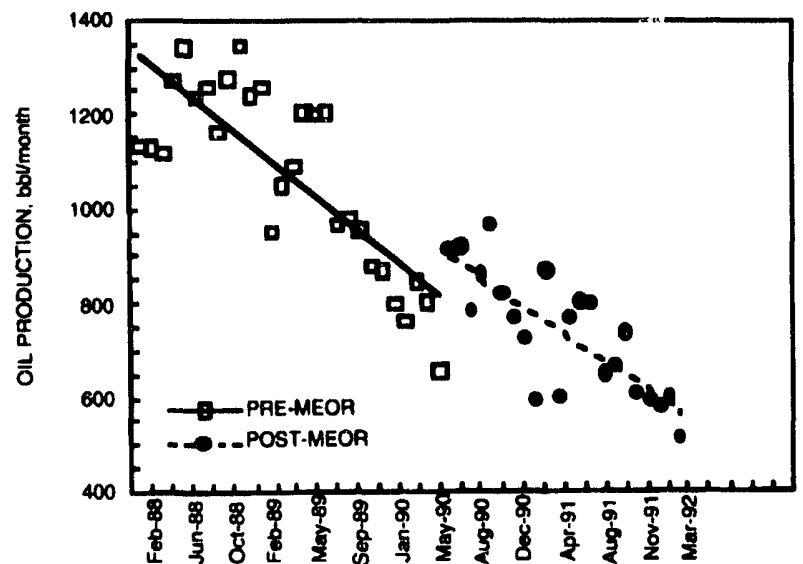

Fig. 1 Oil production from the Phoenix site through March, 1992. - $y=1345.5+-19.028 x \quad R=0.80655 .-\ldots-\ldots, y 54.5+$ $-15.823 \times R=0.79637$. 


\section{MICROBIAL ENHANCED OIL RECOVERY RESEARCH}

\section{Contract No. DE-FG07-89BC14445}

\author{
University of Texas at Austin \\ Austin, Tox.
}

Contract Date: Sept. 1, 1989

Antlcipated Completion: Aug. 31, 1992

Government Award: \$362,000

\section{Princlpal Investigators: \\ Mukul M. Sharma \\ George Georglou}

\section{Project Manager: \\ E. B. Nuckols \\ Metairle Site Office}

Reporting Perlod: Apr. 1-June 30, 1992

\section{Objective}

The objective of this project is to quantify and characterize microbial enhanced oil recovery (MEOR) processes through experimentation and computer simulation of bacterial metabolic processes, microbial transport through cores, and oil recovery processes resulting from the in situ production of biosurfactants. Computer simulation will be used to evaluate injection strategies and process optimization. The research will be conducted with Bacillus licheniformis JF-2.

\section{Summary of Technical Progress}

This quarterly report summarizes the progress made between April 1 and June 30, 1992. The mechanism of biosurfactant deactivation by $B$. licheniformis JF- 2 was elucidated. Approaches to optimize the production of biosurfactant and to attenuate the deactivation of biosurfactant were developed.

\section{Introduction}

Bacillus licheniformis strain JF-2 biosurfactant is of interest for a variety of applications, particularly for MEOR and the dispersion of oil spills. ${ }^{1,2}$ The chemical structure and surface properties of the surface-active agent from $B$. licheniformis JF-2 were characterized in a previous report. ${ }^{3}$ The commercial application of biosurfactants is determined by their cost and properties in relation to competing synthetic compounds. At present, however, the use of biosurfactants in the food and chemical industries is not generally competitive because if the relatively high production costs. In this work the effect of fermentation conditions on the growth and surfactant produc. tion by $B$. licheniformis JF-2 was investigated. Earlier effor/s to optimize the production of various biosurfactants were frustrated by the lack of reliable assays. Therefore a simple high-pressure liquid chromatography (HPLC) assay was developed for quantifying the concentration of the B. licheniformis JF-2 biosurfactant in the fermentation broth. By systematically varying the concentrations of different components in the growth medium, the maxinum concentration of biosurfactant was increased threefold from approximately $35 \mathrm{mg} / \mathrm{L}$ to about $110 \mathrm{mg} / \mathrm{L}$. The biosurfactant is produced in the mid-exponential phase but subsequently disappears as soon as the cells enter the stationary phase, thus resulting in a significant increase in interfacial tension. ${ }^{4}$ The mechanism of this phenomenon was investigated in some detail and was shown to bear some similarities to the adsorption of certain antibiotics such as polymyxin by Bacillus cells. 5

\section{Results}

An HPLC assay was developed to monitor the concentration of the lipopeptide in the fermentation broth and was used to determine the effect of the composition of the growth medium on biosurfactant production. A maximum concentration of $110 \mathrm{mg} / \mathrm{L}$ of lipopeptide was obtained in optimized minimal media with $1.0 \%$ glucose as the carbon source. The maximum concentration of surfactant was obtained in mid-exponential phase cultures but subsequently decreased rapidly and disappeared completely from the fermentation broth within $8 \mathrm{~h}$. The surfactant was shown to be chemically stable in the culture supernatant but became internalized or degraded by stationary phase cells. This phenomenon did not appear to be related to the surface hydrophobicity of the cells. Furthermore, it was not inhibited by carbonyl cyanide $m$-chlorophenylhydrazone, an uncoupler of oxidative phosphorylation, which suggests that it is not dependent on the availability of adenosinetriphosphate and/ or a charged membrane. A variety of physical and chemical treatments failed to release the surfactant from the cells. In minimal media the rate of surfactant internalization by the cells could be reduced by optimizing the concentration of phosphate and increasing the amount of magnesium, whereas the nitrogen source, calcium, and trace salts had no effect (Figs. 1 and 2). Because a related lipopeptide has been shown to be responsible for the development of deoxyribonucleic acid (DNA) transformation competence in certain Bacillus subtilis strains, it is possible that the internalization of the surfactant may be related to the ability of the cells to take up DNA. 


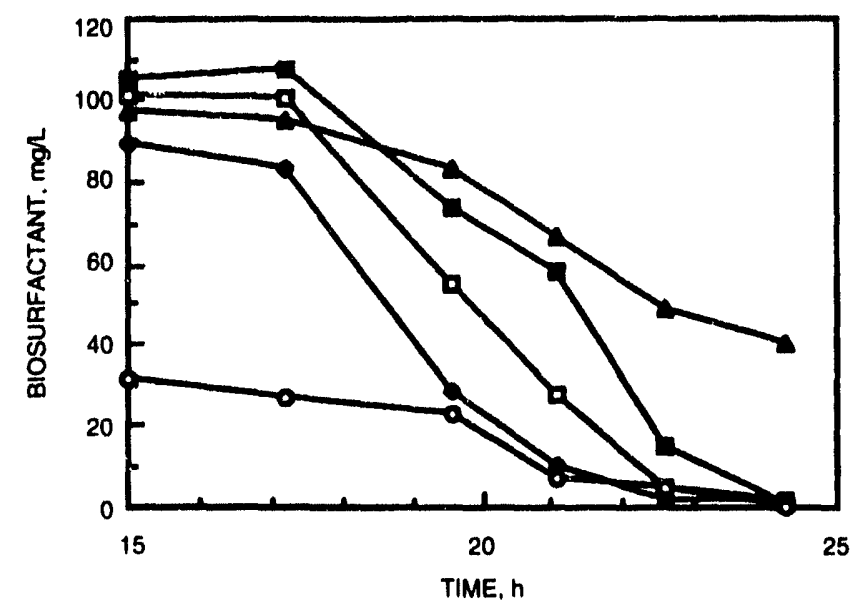

Fig. 1 Effect of sodium chloride and potassium phosphate on the production and deactivation of blosurfactant by Bacillus licheniformis JF-2. Cultures were grown in mineral salt media containing $\triangle, 25 \mathrm{mM}$ phosphate; $\rightarrow, 50 \mathrm{~m} M$ phosphate; $1,75 \mathrm{~m} M$ phosphate; $\bullet, 100 \mathrm{mM}$ phosphate; or, $0.5 \% \mathrm{NaCl}$ and $100 \mathrm{mM}$ phosphate. Biosurfactant concentrations were determined by high-pressure llquid chromatography analysis.

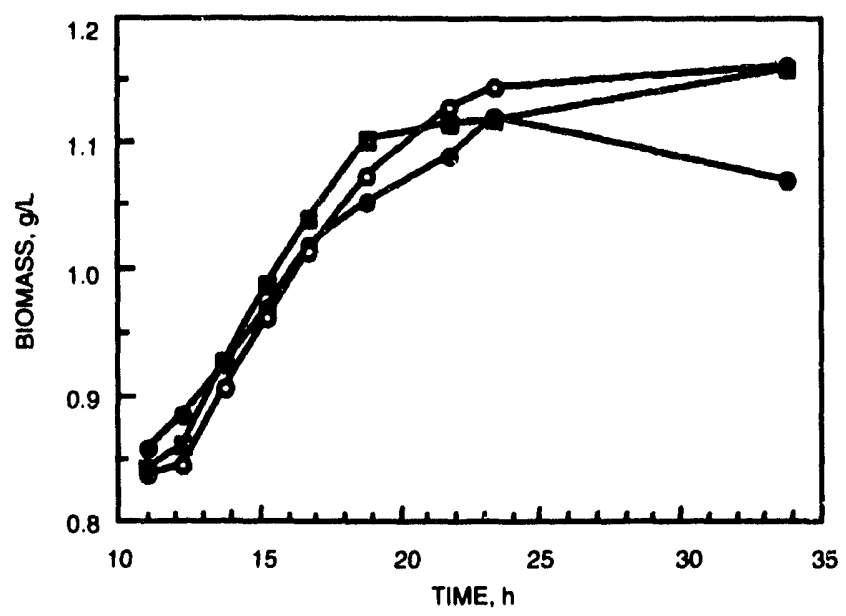

(a)

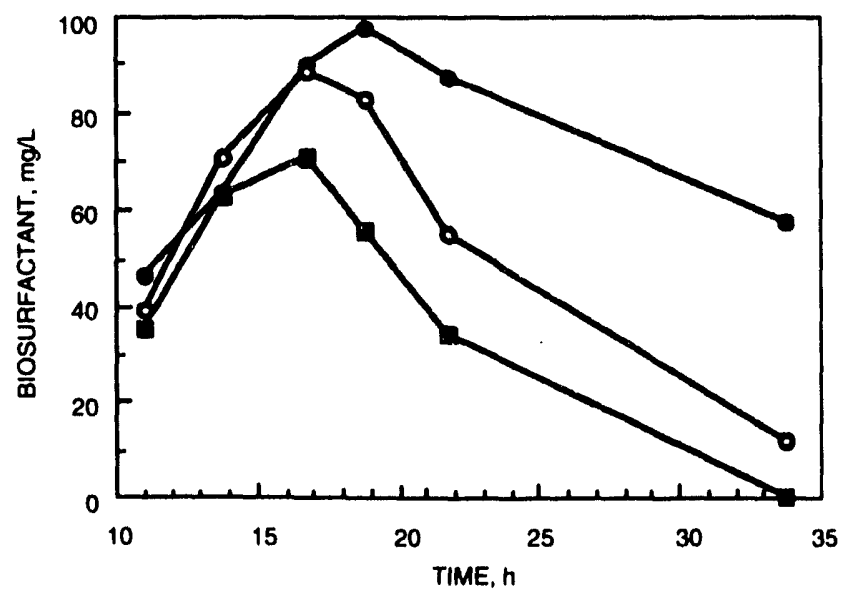

(b)

Fig. 2 Effect of magnesium sulfate on the growth (a) and biosurfactant production (b) of Bacillus licheniformis JF-2 grown in mineral salt media containing $50 \mathrm{mM}$ phosphate and $₫, 0.25 \mathrm{mM}$ magnesium sulfate, , $1 \mathrm{mM}$ magnesium sulfate; or $\bullet, 5 \mathrm{mM}$ magnesium sulfate.

\section{References}

1. G. Georgiou, S. C. Lin, and M. M. Sharma, Surface-Active Compounds from Microorganisms, Bio/Technology, 10:60-65 (1992).

2. M. 1. McInerney, M. Javaheri, and D. P. Nagle, Properties of the Biosurfactant Produced by Bacillus licheniformis Strain JF-2, J. Ind. Microbiol., 5: 95-102 (1990).

3. S. C. Lin, M. A. Minton, M. M. Sharma, and G. Georgiou, Purification and Characterization of Biosurfactant by Bacillus licheniformis JF-2, Appl. Environ. Microbiol. (1992) (submitted for publication).

4. S. C. Lin, J. C. Goursaud, P. J. Kramer, G. Georgiou, and M. M. Sharma, Production of a Biosurfactant by Bacillus licheniformis Strain JF-2, in Microbial Enhanced Oil Recovery-Recent Advances, E. C. Donaldson (Ed.), Elsevier Science Publishers, Amsterdam, 1990.

5. M. Teuber and I. R. Miller, Selective Binding of Polymyxin B to Negatively Charged Lipid Monolayers, Biochim. Biophys. Acta, 467: 280-289 (1977)

\section{POLYSACCHARIDES AND BACTERIAL PLUGGING}

\section{Contract No. DE-AC22-90BC14664}

\author{
University of Michigan \\ Ann Arbor, Mich.
}

Contract Date: July 1, 1990

Anticipated Completion: June 27, 1993

Total Project Cost: 160,000

\section{Principal Investigator: \\ H. Scott Fogler}

\section{Project Manager: \\ Chandra Nautlyal \\ Bartlesville Project Office}

Reporting Perlod: Apr. 1-June 30, 1992

\section{Objectives}

The objectives of this research are to elucidate and model bacterial transport in porous media, determine the importance of polysaccharides bridging as a retentive mechanism, and identify key parameters that influence porous media plugging.

This project has been subdivided into three tasks: (1) the determination of the growth kinetics of the Leuconostoc bacteria and how they are affected by the nutrient feed and surface effects, (2) the quantification of polysaccharide production as a cell retention mechanism, and (3) the elucidation of the rate of polysaccharide production and the combined effect that polysaccharide production and cell growth has upon plugging. 


\section{Summary of Technical Progress}

Batch growth experiments were conducted to determine the rate of cell growth, polymer production, and nutrient consumption. The data from these experiments are currently being reduced to aid the development of an overall growth model.

\section{Surface Effects on Cell Growth}

Two sets of experiments were performed in agitated batch reactors with cells of Leuconostoc $m$ using glucose or sucrose as substrates. All experimental conditions being identical, growth experiments were conducted in either the absence or the presence of clay particles (montmorillonite). Batch experiments were performed in' $0.1-\mathrm{L}$ sealed flasks, under a constant stirring, with an additional $0.1 \mathrm{~g}$ of montmorillonite clays in flasks used for the adsorption on clays. Whatever the sugar used, its concentration was $8.6 \mathrm{~g} / \mathrm{L}$ for each experiment, and other medium components were identical. Flasks were inoculated with $1 \mathrm{~mL}$ of a suspension of Leuconostoc $m$ grown on sucrose. Samples of the culture were taken every $2 \mathrm{~h}$ or after a significant increase in medium turbidity was observed. For samples taken from glucose medium and in the absence of clays, cell concentration was determined spectrophotometrically. Samples taken from sucrose medium (no clays) and from experiments performed in the presence of montmorillonite were centrifuged $(3000 \mathrm{~g}$, $10 \mathrm{~min}$ ) before further measurements. Centrifugates were dried until constant dry weight and their mass was measured. For batch cultures realized with sucrose, the measured mass of cells included the mass of insoluble dextran produced around the cells (the mass of clays was deducted from the total sample mass for cells grown in the presence of montmorillonite).

Figure 1 reports the cell densities growth for the two batch experiments performed in the absence and presence of clays with glucose as the main carbon source, whereas Fig. 2 illustrates the biomass increase obtained in the

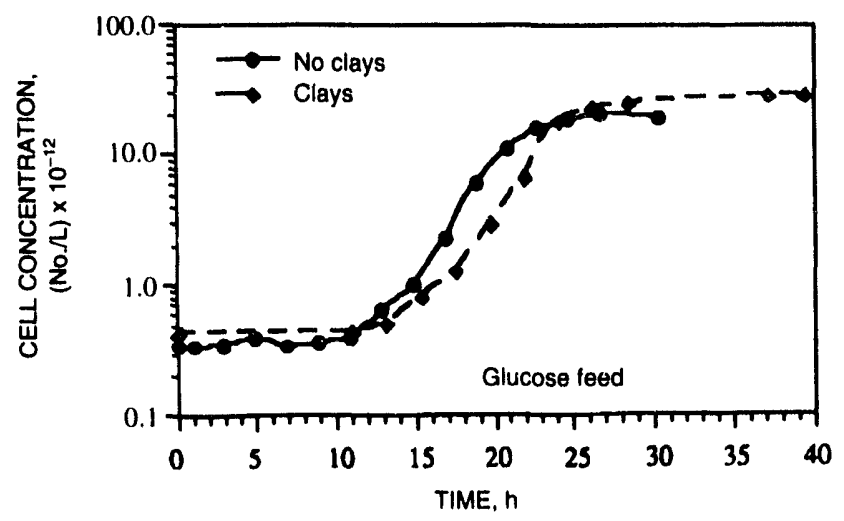

Fig. 1 Batch growth curves for Leuconostoc $m$ on glucose in the presence and absence of montmorillonite.

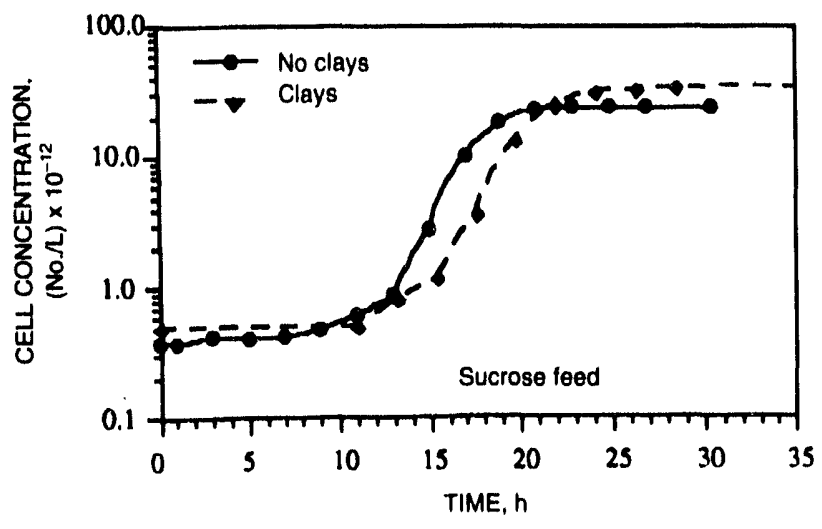

Fig. 2 Batch growth curves for Leuconostoc $m$ on sucrose in the presence and absence of montmorillonite.

absence and presence of clays with sucrose as the main nutrient component. A comparison of the specific growth rate constants for each growth curve (Table 1) illustrates the influence of the clay surface on the rate of cell growth. For both saccharides, the presence of the clays did not significantly enhance the specific growth rate of the cells. Thus it is concluded that the data obtained from the constantly stirred batch reactor in the absence of any supporting surfaces will suffice for the development of an in situ bacterial growth model.

TABLE 1

Specific Growth Rates for Leuconostoc $m$

Bacteria Growth in Batch Reactors

in the Presence or Absence of Montmorillonite

\begin{tabular}{lcc}
\hline & \multicolumn{2}{c}{ Specific growth rate constant, $\mu \mathbf{m} \mathbf{~ r}^{\mathbf{1}}$} \\
\cline { 2 - 3 } Saccharide & No clays & Clays \\
Glucose & 0.37 & 0.394 \\
Sucrose & 0.473 & 0.471 \\
\hline
\end{tabular}

\section{Surface Effects on Cell Growth}

From the literature, ${ }^{1.2}$ it is known that dextran is synthesized at the expense of sucrose according to Eq. 1.

$$
\begin{aligned}
& \text { Sucrose } \stackrel{E}{\longrightarrow} \text { Dextran + Fructose } \\
& \text { Sucrose } \stackrel{E}{\longrightarrow} \text { Glucose + Fructose }
\end{aligned}
$$

Hence the rate of dextran production can be correlated with the rate of fructose liberated by the enzymes. Fructose, however, is also liberated during glucose synthesis; thus a correlation between dextran synthesis and fructose liberation must exclude the production of fructose during glucose 
synthesis. The resulting correlation, taking into account fructose generation by dextran synthesis only, is written as

$$
\frac{d P}{d t}=Y_{p / x} \frac{d f_{d}}{d t}
$$

where $Y_{p / x}$ is the dextran-to-fructose production yield, $P$ is the product concentration, and $f_{d}$ is the concentration of fructose produced, according to $\mathrm{Eq} .1$.

From the batch experiments, $Y_{p} / f_{d}$ was estimated as $0.24 \mathrm{~g}$ of dextran/per gram of fructose. This value was calculated by using all the results from all the batch experiments and fitting them to the preceding model using the least squares procedure. The resulting dextran model was then used to simulate polymer production for experiments KE-33; this model and the experimental data are shown in Fig. 3.

According to the stoichiometry of the dextran to fructose liberated by Reaction 1 , the value of $Y_{p} / f_{d}$ would be expected to be equal to one. Dextran, however, is a biopolymer that initially grows from a monomer unit into a polymer containing over one hundred thousands monomer units. This change in polymer length changes the chemical properties of the polymer molecule from soluble to insoluble. Thus a $Y_{p} / f_{d}$ value of one is actually a maximum obtainable value; $Y_{p} / f_{d}$

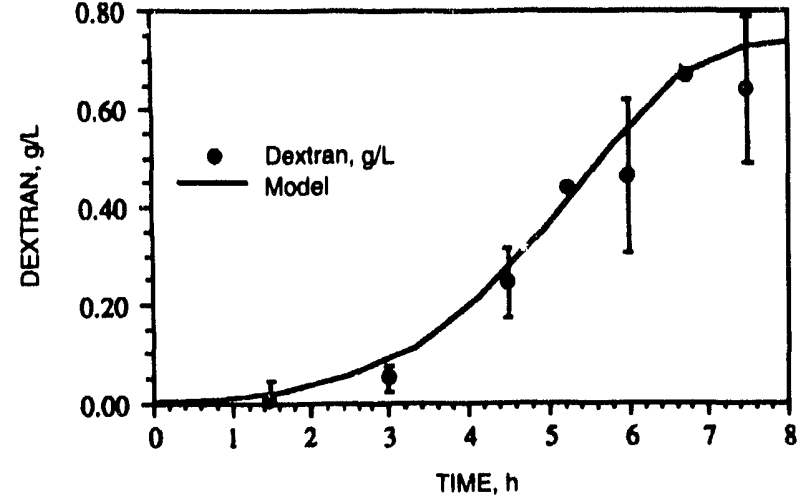

Fig. 3 Dextran production and model prediction from experiments KE-33.

less than one reflects the fact that not all the biopolymer is insoluble.

\section{References}

1. K. H. Ebert and G. Schenk, Advances in Enzymology and Related Areas of Molecular Biology, Vol. 30, E. F. Nord (Ed.), International Publishers, 1968.

2. G. R. Lawford, A. Klingerman, and T. Williams, Dextran Biosynthesis and Dextransucrase Production by Continuous Culture of Leuconostoc mesenteroides, Biotechnol. Bioeng., XXI: 1121-1131 (1979). 


\section{NOVEL TECHNOLOGY}

\section{A NOVEL APPROACH TO MODELING UNSTABLE ENHANCED OIL RECOVERY DISPLACEMENTS}

Contract No. DE-AC22-90BC14650

\author{
University of Texis at Austin \\ Austin, Tex.
}

Contract Date: Aug. 28, 1990

Anticipated Completion: Aug. 27, 1993

Government Award: \$407,118

(Current year)

\section{Principal Investigjator: \\ Ekwere J. Peters \\ Project Manager: \\ Jerry Ham \\ Metairie Site Office}

Reporting Period: Apr. 1-June 30, 1992

\section{Objective}

The objective of this research is to develop a methodology for predicting the performance of unstable displacements in heterogeneous reservoirs. A performance prediction approach that combines numerical modeling with laboratory imaging experiments is being developed. Flow visualization experiments will be performed on laboratory corefloods with X-ray computerized tomography (CT) and other imaging technologies to map the in situ fluid saturations in time and space. A systematic procedure will be developed to replicate the experimental image data with high-resolution numerical models of the displacements. The well-tuned numerical models will then be used to scale the results of the laboratory coreflood experiments to heterogeneous reservoirs in order to predict the performance of unstable displacements in such reservoirs.

\section{Summary of Technical Progress}

A new procedure has been derived to simplify the analysis, numerical modeling, and scaling of labora' ory coreflood experiments. The procedure consists of the following steps:

1. Image the coreflood by CT to obtain the temporal and spatial saturation profiles.

2. Transform the saturation profiles by means of a dimensionless self-similarity variable to obtain a unique, dimensionless response function that is characteristic of the coreflood.

3. History-match the characteristic response function for the coreflood with a numerical simulator.

4. After a satisfactory match, compare the experimental and computed saturation profiles and recovery curves for the coreflood.

5. With the well-tuned numerical model, scale the results of the laboratory coreflood experiment to other systems. 
Steps 1 and 2 of the above procedure were demonstrated previously. A dimensionless self-similarity variable $\left(\mathrm{x}_{\mathrm{D}} / \mathrm{t}_{\mathrm{D}}\right)$ was derived for two-phase immiscible displacement and then used to transform the saturation profiles of two laboratory corefloods to obtain their characteristic dimensionless response functions. In this report, steps 3 and 4 of the procedure will be demonstrated by numerically simulating the two corefloods. Step 5, the scaling of the laboratory corefloods to other systems, will be demonstrated in future reports.

\section{Procedure}

The objective of the numerical simulation was to history-match the dimensionless response functions of the unstable waterfloods described in the last report. The first waterflood was conducted in an oil-wet sandpack, whereas the second waterflood was conducted in a water-wet sandpack. Table 1 presents additional information about the two experiments.

Fine-grid simulations of the waterfloods were performed using UTCHEM, a numerical reservoir simulator developed at the University of Texas and widely available to the petroleum industry. ${ }^{2}$ The average properties of the numerical model were the same as in the experiments (see Table 1). The adjustable parameters in the numerical model were the degree of heterogeneity of the porous media and the wateroil relative permeability curves. Random permeability fields were used to simulate the sandpacks. The degree of heterogeneity of the porous media was characterized by the Dykstra-Parsons coefficient of the permeability field. ${ }^{3}$ The degree of heterogeneity and the relative permeability curves were adjusted systematically to match the dimensionless response functions of the waterfloods.

\section{Results and Discussion}

The relative permeability curves used in the simulations were based on the following analytical models:

$$
\begin{aligned}
& k_{r w}=k_{w r}\left(\frac{S_{w}-S_{w i}}{1-S_{w i}-S_{o r}}\right)^{n_{w}} \\
& k_{r o}=k_{o r}\left(\frac{S_{o}-S_{o r}}{1-S_{w i}-S_{o r}}\right)^{n_{o}}
\end{aligned}
$$

Table 2 shows the final relative permeability parameters used to simulate the two waterfloods. With these parameters, the shapes of the relative permeability curves were in agreement with those typically associated with oil-wet and water-wet media (Fig. 1). The final Dykstra-Parsons coefficients used to simulate the oil-wet and water-wet sandpacks were 0.576 and 0.050 , respectively.
TABLE 1

Summary of Waterflood Experiments

\begin{tabular}{lcc}
\hline & Experiment 1 & Experiment 2 \\
\hline Wettability & Oil-Wet & Water-Wet \\
Absolute permeability, darcy & 10.4 & 9.3 \\
Porosity, \% & 31.0 & 30.8 \\
Initial water saturation, \% & 0.0 & 15.0 \\
Darcy velocity, $\mathrm{m} / \mathrm{s}$ & $8.5 \times 10^{-5}$ & $8.5 \times 10^{-5}$ \\
Viscosity ratio & 91 & 91 \\
Stability number & 16.643 & 271 \\
Capillary number & $4.998 \times 10^{-4}$ & $4.623 \times 10^{-4}$ \\
Gravity number & $1.405 \times 10^{-3}$ & $1.257 \times 10^{-3}$ \\
Breakthrough recovery, \% & 17.5 & 32.9 \\
\hline
\end{tabular}

TABLE 2

Parameters Used in the Numerical Simulations

\begin{tabular}{llc}
\hline & Experiment 1 & Experiment 2 \\
\hline $\begin{array}{l}\text { Initial water saturation } \\
\text { Residual oil saturation }\end{array}$ & 0.0 & 0.15 \\
$\begin{array}{l}\text { End-point relative permeability to } \\
\quad \text { water }\end{array}$ & 0.38 & 0.20 \\
$\begin{array}{l}\text { End-point relative permeability } \\
\quad \text { to oil }\end{array}$ & 0.36 & 0.90 \\
$\begin{array}{l}\text { Relative permeability exponent } \\
\text { for oil }\end{array}$ & 1.00 & 0.90 \\
$\begin{array}{l}\text { Relative permeability exponent for } \\
\quad \text { water }\end{array}$ & 2.0 & 3.5 \\
Dykstra-Parsons coefficient & 2.0 & 0.49 \\
\hline
\end{tabular}

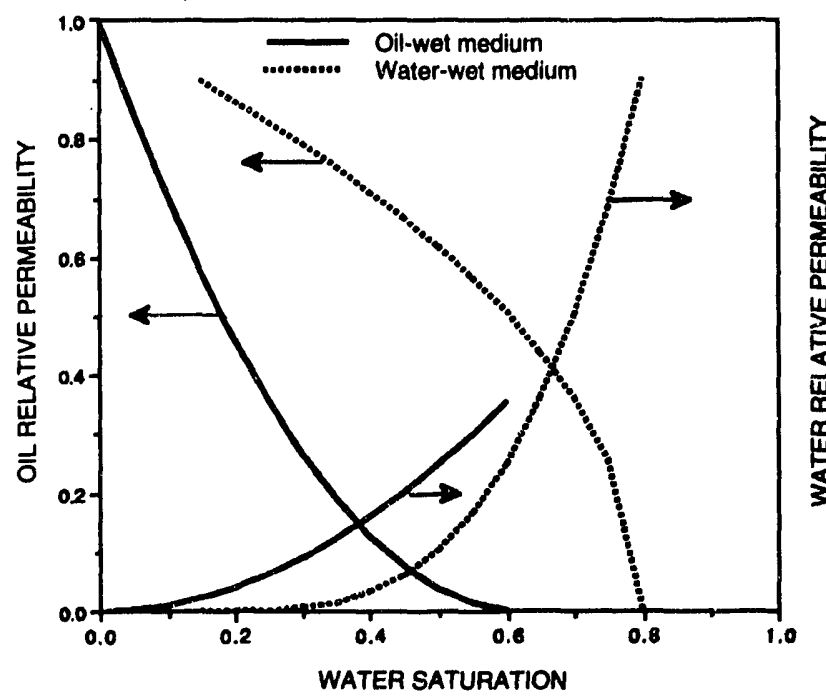

Fig. 1 Relative permeability curves used in the numerical simulations.

Figure 2 compares the experimental and simulated response functions for the waterflood in the oil-wet medium. The overall agreement between the experimental and simulated data is good. Figure 3 compares the experimental and 


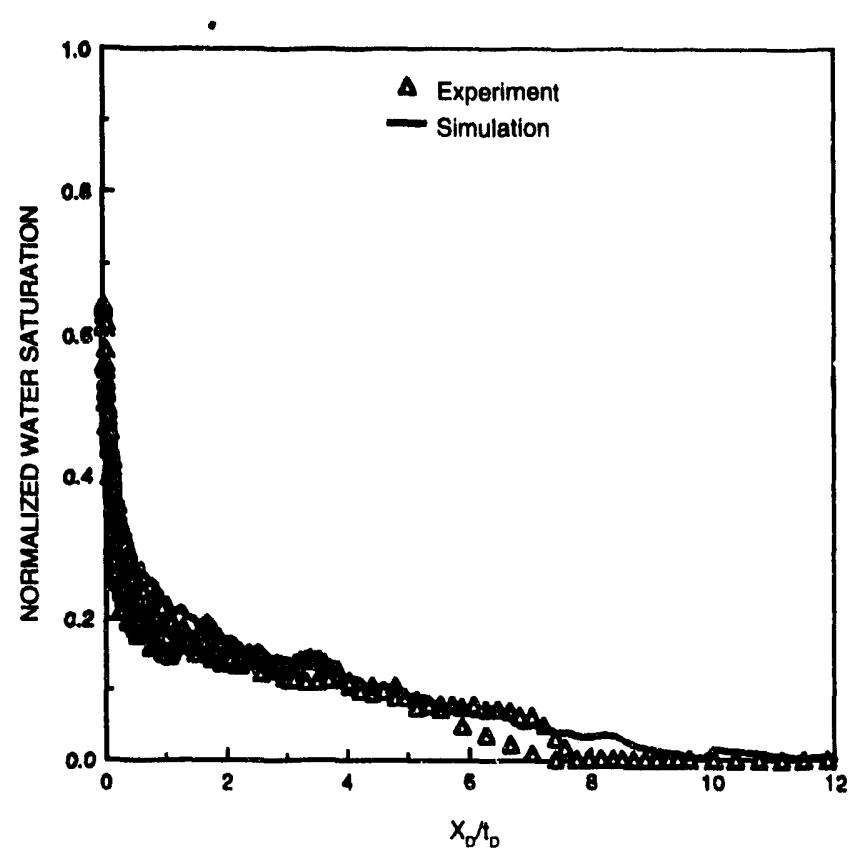

Fig. 2 A comparison of the experimental and simulated dimensionless response curves for unstable waterflood in an oll-wet sandpack. Viscosity ratio $=91$. No initial water saturation present.

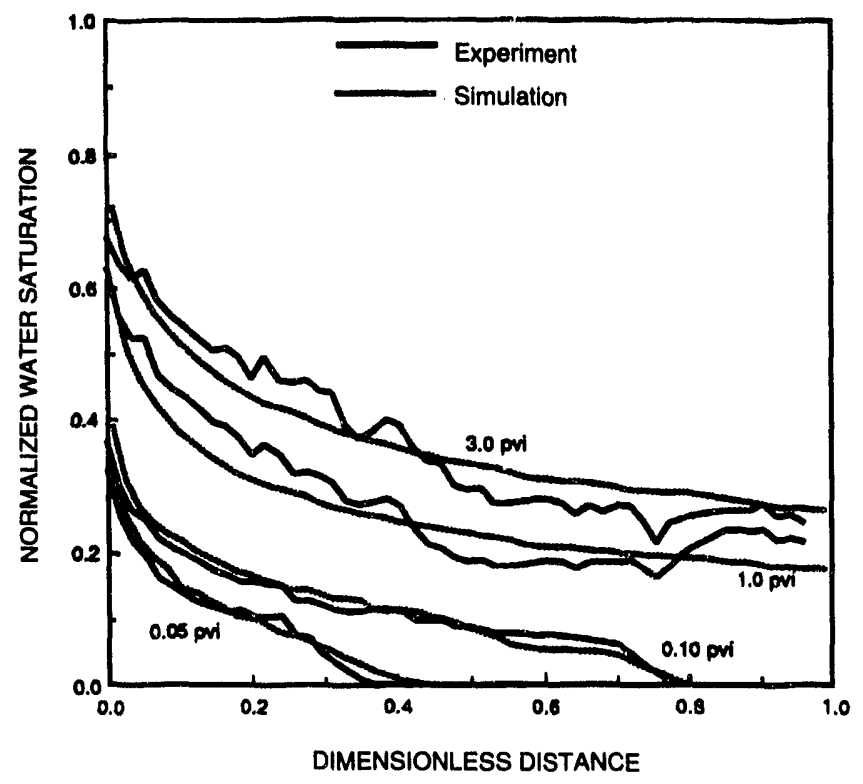

Fig. 3 A comparison of the experimental and simulated saturation proflies for unstable waterflood in an oil-wet sandpack. Viscosity ratio $=91$. No initial water saturation present. $p v i=$ pore volumes injected.

simulated saturation profiles at four time steps. Although the overall agreement is good, the results show better agreement in the early-time data (at 0.05 and 0.10 pore volume injected) than in the late-time data (at 1.0 and 3.0 pore volumes injected). It should be noted that although there was disagreement between the experimental and simulated profiles at late times, the simulated profiles passed evenly through the experimental profiles. This indicates that good material balance was maintained in the simulation at all times. Consequently, the experimental and simulated recovery curves will be in good agreement at all times. This is confirmed by Fig. 4, which shows excellent agreement in the recovery curves at all times. The fact that the recovery curves can be in excellent agreement even when the saturation profiles are not in agreement is a fundamental weakness of the recovery curve as a measure of the quality of the simulation. This is why our simulation strategy is focused on matching the saturation profiles rather than the recovery curves. If the saturation profiles are matched, the recovery curves are matched automatically as well. The converse is not true.

Figures 5, 6, and 7 show the corresponding results for the waterflood in the water-wet medium. in this case, the agreements between the experimental and simuiaied results are excellent and better than those obtained for the oil-wet medium.

This simulation approach constitutes a new and improved method for determining relative permeability curves from unsteady state displacements. Traditionally, the recovery curve alone is used to compute relative permeabilities by the Johnson-Bossler-Naumann (JBN) method regardless of the actual fluid distribution within the porous medium. ${ }^{4}$ History-matching of the saturation profiles obtained by CT imaging can be used to compute relative permeability curves that simultaneously satisfy the fluid distribution in the porous medium and the recovery curve from the unsteady state displacement. This is an improvement over the existing method that is based on the recovery curve alone.

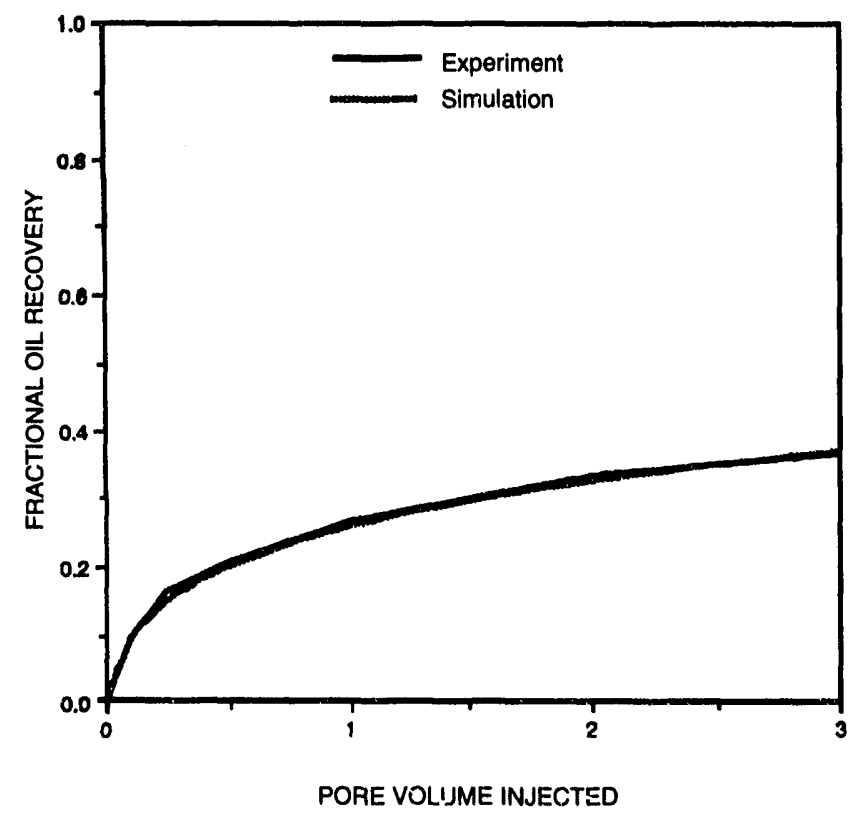

Fig. 4 A comparison of the experimental and simulated recovery curves for unstable waterflood in an oil-wet sandpack. Viscosity ratio $=91$. No initial water saturation present. 


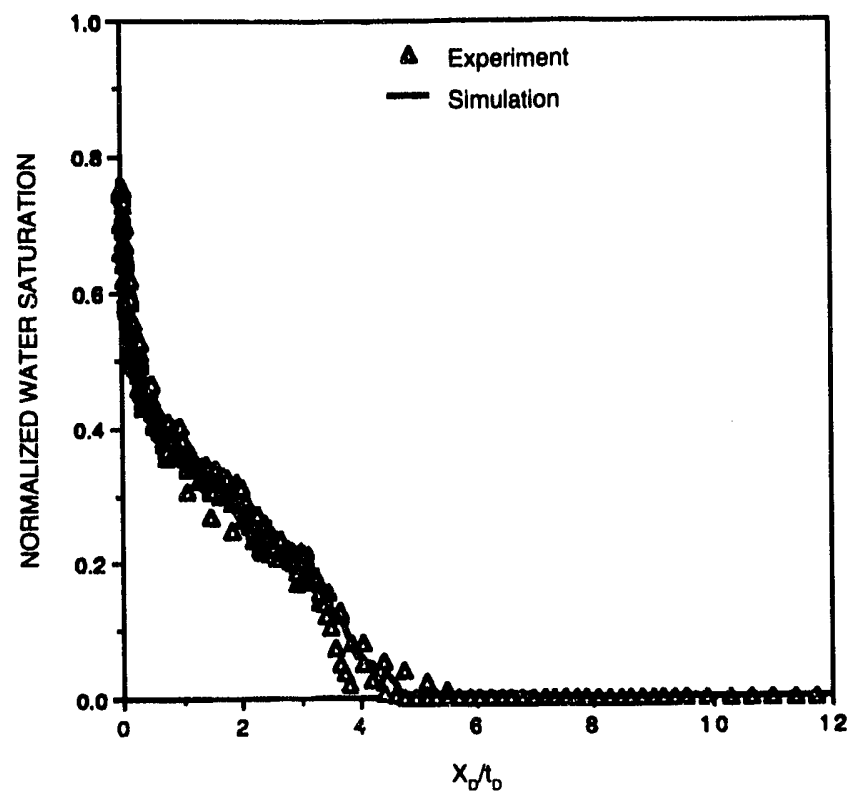

Fig. 5 A comparison of the experimental and simulated dimensionless response curves for unstable waterflood in a water-wet sandpack. Viscosity ratio $=91$. Initial water saturation present.

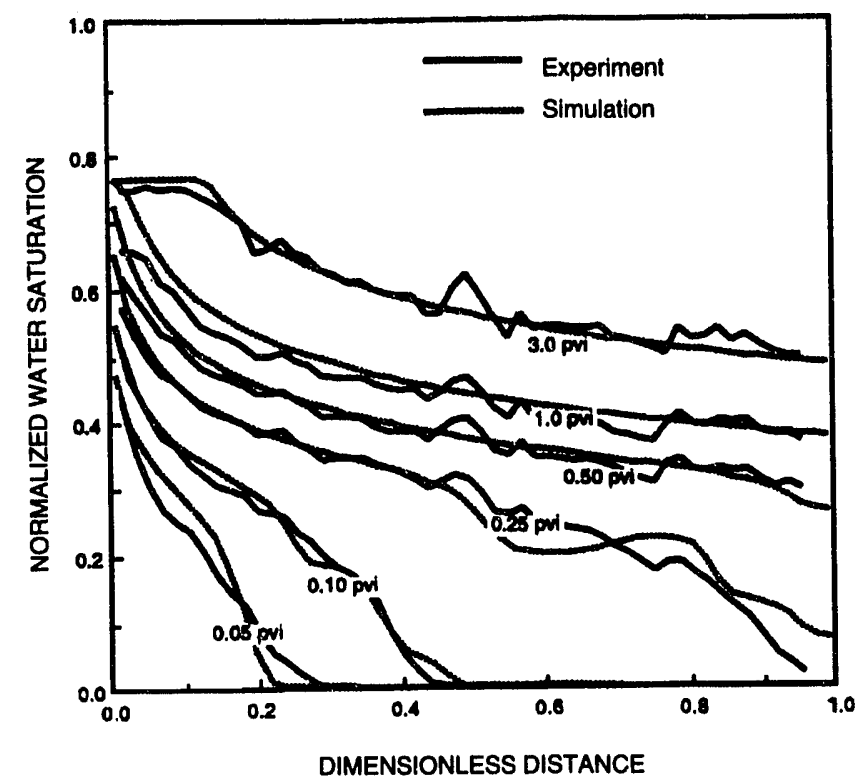

Fig. 6 A comparison of the experimental and simulated saturation profiles for unstable waterflood in a water-wet sandpack. Viscosity ratio $=91$. Initial water saturation present. pvi $=$ pore volumes injected.

\section{Concluding Remarks}

In this report, the third and fourth steps of a five-step procedure for modeling unstable displacements in permeable media have been presented. The dimensionless response functions of two unstable laboratory corefloods were successfully matched with a numerical simulator in order to model the corefloods. Results show that the dimensionless response function of a coreflood is a powerful tool for simu-

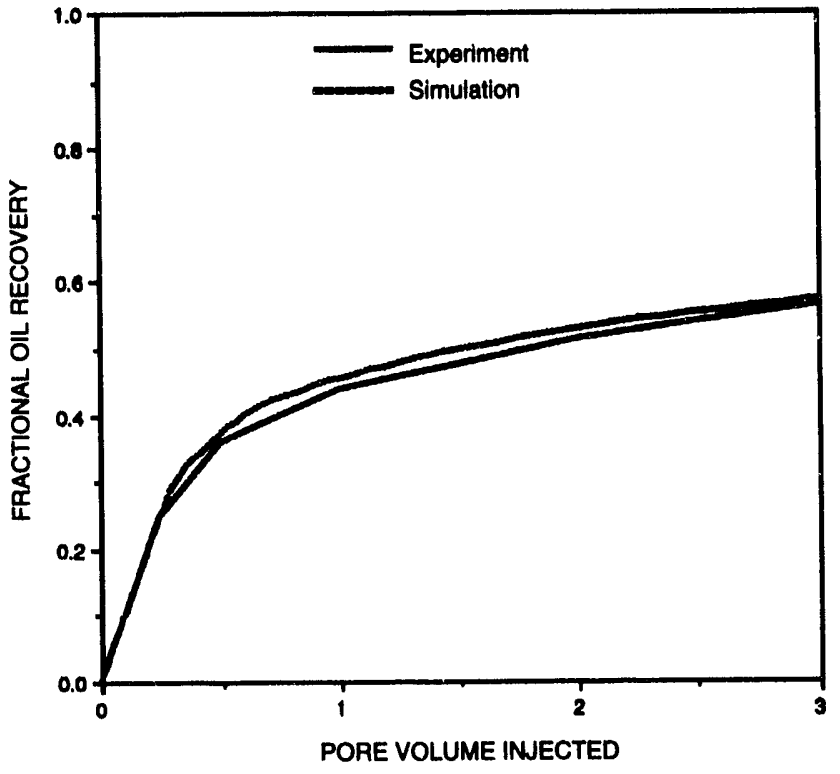

Fig. 7 A comparison of the experimental and simulated recovery curves for unstable waterflood in a water-wet sandpack. Viscosity ratio = 91 . Initial water saturation present.

lating the performance of the coreflood. This simulation approach which simultaneously matches the saturation profiles and the recovery curve offers a new and improved technique for determining relative permeability curves from unsteady state displacements.

\section{Nomenclature}

$\mathbf{k}_{\mathrm{ro}}=$ relative permeability to oil

$\mathrm{k}_{\mathrm{rw}}=$ relative permeability to water

$k_{\text {or }}=$ end-point relative permeability to oil

$k_{\mathrm{wr}}=$ end-point relative permeability to water

$\mathrm{n}_{\mathrm{o}}=$ relative permeability exponent for oil

$\mathrm{n}_{\mathrm{w}}=$ relative permeability exponent for water

$\mathrm{S}_{\mathrm{or}}$ " $=$ residual oil saturation

$\mathrm{S}_{\mathrm{wi}}=$ initial water saturation

$t_{D}=$ dimensionless time

$\mathrm{x}_{\mathrm{D}}=$ dimensionless distance along the core

\section{References}

1. E. J. Peters, A Novel Approach to Modeling Unstable EOR Displacements, DOE Quarterly Report, January-March 1992.

2. G. A. Pope, L. W. Lake, and K. Sepehrnoori, Modelling and Scale-Up of Chemical Flood: Third Annual and Final Report for the Period October 1987 to September 1988, prepared for the U.S. Department of Energy under Contract No. AC1985BC10846, Bartlesville, Okla., March 1990.

3. H. Dykstra and R. L. Parsons, The Prediction of ( $i l$ Recovery by Water Flood, in Secondary Recovery of Oil in the United States, 2nd ed., pp. 160-174, American Petroleum Institute, 1950.

4. E. F. Johnson, D. P. Bossler, and V. O. Naumann, Calculation of Relative Permeability from Displacement Experiments, Trans. Am. Inst. Min. Eng., 216: 370-372 (1959). 

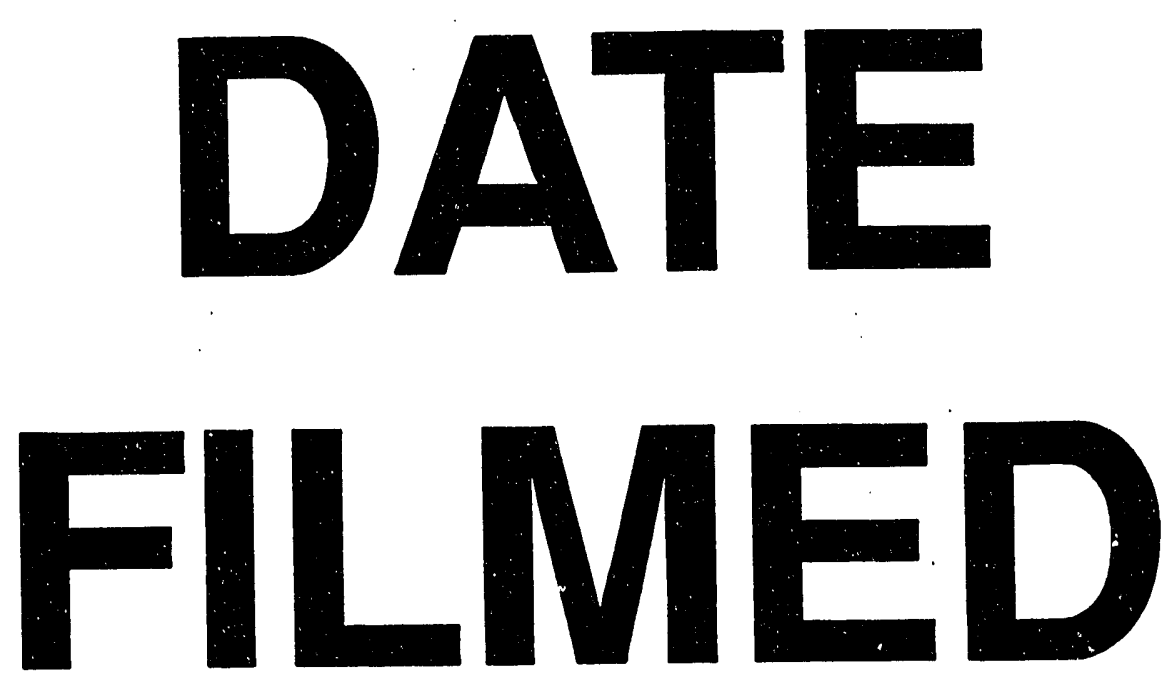

$8 / 17 / 93$
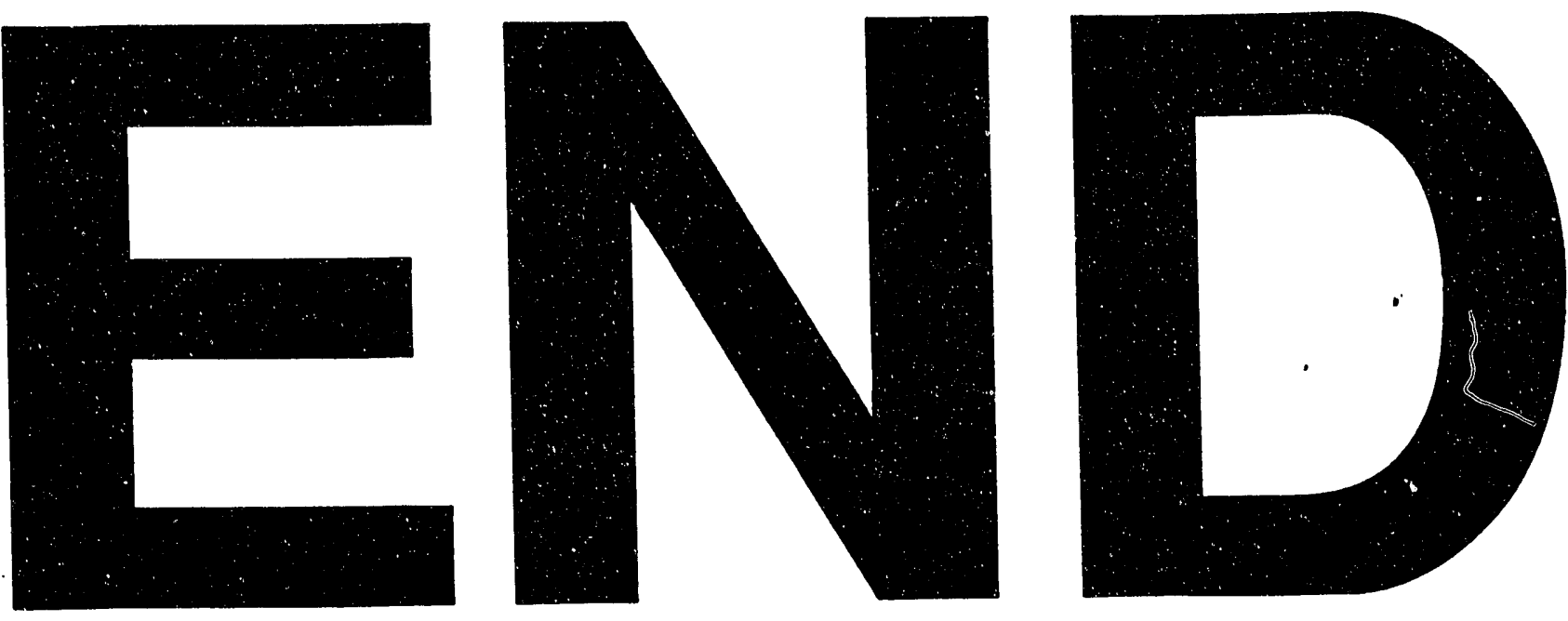
